
Q
NWU Education and Human Rights in Diversity Series Dio
Volume 2
AOSIS

\title{
A scholarly inquiry into disciplinary practices in educátional institutions
}

Edited by:

Connie B. Zulu, lzak J. Oosthuizen \& Charl C. Wolhuter 
NWU Education and Human Rights in Diversity Series Volume 2

\section{A scholarly inquiry into disciplinary practices in educational institutions}




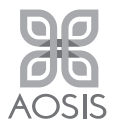

Published by AOSIS (Pty) Ltd, 15 Oxford Street, Durbanville 7550, Cape Town, South Africa Postnet Suite \#110, Private Bag X19, Durbanville 7551, South Africa

Tel: +27219752602

Fax: +27 219754635

Email: info@aosis.co.za

Website: https://www.aosis.co.za

Copyright (c) Connie B. Zulu, Izak J. Oosthuizen \& Charl C. Wolhuter (eds.). Licensee: AOSIS (Pty) Ltd.

The moral right of the author has been asserted.

Cover image: Original design created with the use of two images.The book https://pixabay. com/fr/photos/livre-lecture-litt\%C3\%A9rature-pages-1549589/ The mountains https:// pixabay.com/pt/photos/montanhas-c\%C3\%A9u-azul-natureza-4312789.

Published in 2019

Impression: 1

ISBN: 978-1-928523-13-0 (print)

ISBN: 978-1-928523-14-7 (epub)

ISBN: 978-1-928523-15-4 (pdf)

DOI: https://doi.org/10.4102/aosis.2019.BK157

How to cite this work: Zulu, C.B., Oosthuizen, I.J. \& Wolhuter, C.C. (eds.), 2019, 'A scholarly inquiry into disciplinary practices in educational institutions', in NWU Education and Human Rights in Diversity Series Volume 2, pp. i-326, AOSIS, Cape Town.

NWU Education and Human Rights in Diversity Series

ISSN: 2706-9125

Series Editor: Elda de Waal

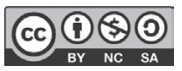

Printed and bound in South Africa.

Listed in OAPEN (http://www.oapen.org), DOAB (http://www.doabooks.org/) and indexed by Google Scholar. Some rights reserved.

This is an open access publication. Except where otherwise noted, this work is distributed under the terms of a Creative Commons Attribution-NonCommercial-ShareAlike 4.0 International license (CC BY-NC-SA 4.0), a copy of which is available at https:// creativecommons.org/licenses/by-nc-sa/4.0/. Enquiries outside the terms of the Creative Commons licence should be sent to the Rights Department, AOSIS, at the above address or to publishing@aosis.co.za

The publisher accepts no responsibility for any statement made or opinion expressed in this publication. Consequently, the publishers and copyright holder will not be liable for any loss or damage sustained by any reader as a result of his or her action upon any statement or opinion in this work. Links by third-party websites are provided by AOSIS in good faith and for information only. AOSIS disclaims any responsibility for the materials contained in any third-party website referenced in this work.

Every effort has been made to protect the interest of copyright holders. Should any infringement have occurred inadvertently, the publisher apologises and undertakes to amend the omission in the event of a reprint. 
NWU Education and Human Rights in Diversity Series

Volume 2

\section{A scholarly inquiry into disciplinary practices in educational institutions}

Editors

Connie B. Zulu

Izak J. Oosthuizen

Charl C. Wolhuter

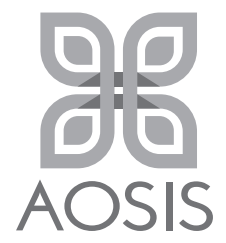




\section{Social Sciences, Humanities, Education \& Business Management Board domain editorial board at AOSIS}

\section{Commissioning Editor: Scholarly Books}

Andries van Aarde, Post-Retirement Professor in the Dean's Office, Faculty of Theology, University of Pretoria, South Africa

\section{Board Members}

Jan Botha, Professor in the Centre for Research on Evaluation, Science and Technology, University of Stellenbosch, South Africa

Joan Hambidge, Deputy Dean at the Faculty of Humanities for the University of Cape Town \& Professor for the School of Languages and Literatures, South Africa

Sakari Häkkinen, Dean of the Diocese of Kuopio, Finland

Glenna Jackson, Associate Editor, Professor Chair, Department of Religion and Philosophy, Otterbein University, Westerville, OH, United States of America

Gregory C. Jenkins, Dean-elect, St George's College, Jerusalem, Israel

Reina-Marie Loader, Director and Filmmaker, CinémaHumain, Vienna, Austria

Babita Marthur-Helm, Senior Lecturer, Organisational Transformation \& Development;

Managing Diversity Gender Empowerment, University of Stellenbosch Business School,

Stellenbosch, South Africa

Christopher Mbazira, Professor of Law \& Coordinator of the Public Interest Law Clinic, Makerere University, Kampala, Uganda

Piet Naudé, Professor, Ethics related to politics, economics and business \& Director, University of Stellenbosch Business School, Stellenbosch, South Africa

Charles Neill, Professor, Department of Business Administration, The British University in Egypt, El Sherouk, Cairo Governorate, Egypt

Cornelia Pop, Full professor at the Department of Business, Faculty of Business, Babes-Bolyai University, Cluj-Napoca, Romania

Michael Schratz, Professor, Institut für LehrerInnenbildung und Schulforschung, Dekan der School of Education, Leopold-Franzens-Universität Innsbruck, Innsbruck, Austria

Johann Tempelhoff, Professor, Research Niche for Cultural Dynamics of Water (CuDyWat), School of Basic Sciences, Vaal Triangle Campus of North-West University, Vanderbijlpark, South Africa

Anthony Turton, Professor, Centre for Environmental Management \& Director, TouchStone Resources, University of the Free State, South Africa

Willie L. van der Merwe, Professor \& Chair Philosophy of Religion, Apologetics and Encyclopaedia of Theology \& Professor Extraordinary, Stellenbosch University, South Africa, Vrije Universiteit Amsterdam, Amsterdam, the Netherlands

Christi van der Westhuizen, Associate Professor, Department of Sociology, Faculty of Humanities, University of Pretoria, South Africa

Joke van Saane, Professor, Amsterdam Center for the Study of Lived Religion, Vrije Universiteit, Amsterdam, the Netherlands

Paul van Tongeren, Professor, Department of Philosophy, Radboud University, Nijmegen, the Netherlands

Robert G. Varady, Deputy Director and Research Professor of Environmental Policy, Udall Center for Studies in Public Policy, University of Arizona, Tucson, AZ, United States of America Anné H. Verhoef, Associate Editor, Professor, Faculty of Arts: School of Philosophy, North-West University, Potchefstroom, South Africa

Xiao Yun Zheng, Professor \& Assistant President of Yunnan Academy of Social Sciences (YASS) and Director of International Center for Ecological Culture Studies (ICECS-YASS), Yunnan Academy of Social Sciences, Kunming City, China

\section{Peer review declaration}

The publisher (AOSIS) endorses the South African 'National Scholarly Book Publishers Forum Best Practice for Peer Review of Scholarly Books'. The manuscript was subjected to a rigorous twostep peer review process prior to publication, with the identities of the reviewers not revealed to the author(s). The reviewers were independent of the publisher and/or authors in question. The reviewers commented positively on the scholarly merits of the manuscript and recommended that the manuscript should be published. Where the reviewers recommended revision and/or improvements to the manuscript, the authors responded adequately to such recommendations. 


\section{Research Justification}

This book, A Scholarly Inquiry into Disciplinary Practices in Educational Institutions, is a collection of chapters based on original research dealing with issues of discipline and disciplinary practices in educational institutions. The aim of the book is to provide a scholarly and scientific perspective on the current state of discipline and disciplinary practices in schools and tertiary education settings. The issue of discipline is investigated from diverse paradigmatic and methodological perspectives presenting not only empirical but also philosophical research. The empirical perspective includes quantitative (positivistic), qualitative (interpretive) and mixed methods (pragmatic), designs and worldviews. This book offers a groundbreaking contribution to the field of learner or student discipline, as it offers insights into disciplinary practices and issues in educational institutions not hitherto researched, such as Technical Vocational Education and Training colleges and universities.

This book contains original research that has not been previously published, and it does not contain any content plagiarised from any other publication. Where a chapter is based on research from a dissertation or thesis, pertinent information is clearly indicated in the chapter. The target audience of the book are specialists and scholars in the field of education as well as policymakers, teachers and students at different levels of the education system. Following a widely circulated call for papers, several manuscripts were submitted. The manuscripts were screened and suitable ones were retained. Thereafter, where applicable, each author had to confirm that ethical clearance procedures had been followed prior to the study. All manuscripts were subjected to iThenticate plagiarism detection, and the authors were requested to double-check their manuscripts and address areas where the similarity index might have been an issue. iThenticate reports were securely filed. Subsequently, revised manuscripts were subjected to an external, double-blind peer review process by a panel of national and international reviewers. After the external peer review, chapters were again returned to the authors for a final revision in accordance with the reviewers' suggestions. The final revised chapters were submitted to the publisher along with change logs of amendments, and where applicable, iThenticate reports.

Connie B. Zulu, Faculty of Education, North-West University, Potchefstroom, South Africa

Izak J. Oosthuizen, Faculty of Education, North-West University, Potchefstroom, South Africa

Charl C. Wolhuter, Faculty of Education, North-West University, Potchefstroom, South Africa 



\section{Contents}

Abbreviations, Figures and Tables Appearing in the Text xix

List of Abbreviations xix

List of Figures $\quad x x$

List of Tables $\quad x x$

Notes on Contributors $\quad$ xxi

Foreword xxxi

Chapter 1: The future is upon us: Discipline in early 21st-century schools, with special reference to South Africa 1

Johannes (Hannes) L. van der Walt \& Charl C. Wolhuter

Abstract 1

Introduction and problem statement 2

Conceptual and theoretical framework $\quad 8$

The contribution of the prevailing sociopolitical conditions in South Africa in general, and in schools in particular, to the collapse or lack of discipline in schools

The contribution of global and local conditions and developments to the collapse or lack of discipline in schools

The exploitation of natural resources

The recent population explosion and changing

demographics

The rise of neoliberalism in education 16

Science and technology: The technological revolution 19

Political trends: Demise of the nation state and the

shifting of the locus of power in two opposite directions

Religious and life-conceptual trends: The persistent presence of religion, multicultural diversity, the values revolution and the rise of the Creed of Human Rights Internationalisation and globalisation 22

Discussion 23

Concluding remarks $\quad 25$ 
Chapter 2: Interactive relational dynamics as experienced by learners involved in bullying incidents in three

South African secondary schools

Ansie E. Kitching, Bianke van Rooyen \& Zahraa McDonald

Abstract

Introduction

Problem statement

Theoretical framework

Contextualising the research

Research design and methodology $\quad 34$

Presenting the findings $\quad 35$

Interactive patterns in the teacher-learner relationships 36

Interactive patterns in the learner-learner relationships $\quad 37$

Interactive patterns in the context of conflict 38

Discussion of the findings $\quad 40$

Conclusion $\quad 44$

Acknowledgements $\quad 44$

Chapter 3: Teachers' and learners' perceptions of alternatives to corporal punishment: A human rights perspective

Michael L. Marumo \& Connie B. Zulu

Abstract

Introduction and background

Discipline and the implementation of alternatives to corporal punishment

Problem statement

Aims of the study

Theoretical-conceptual framework

Research design and methodology

Research design

Methodology

Participant selection 
Data analysis

Issues of trustworthiness $\quad 58$

Ethical considerations $\quad 58$

Findings and discussion

Perceptions regarding the implementation of

alternatives to corporal punishment

Perceptions regarding the effectiveness of alternatives

to corporal punishment

Discussion

Conclusion and recommendations

\section{Chapter 4: Teachers' and learners' perceptions of} the effect and effectiveness of corporal punishment as learner discipline practice in Botswana public secondary schools

Amos T. Thebenyane \& Connie B. Zulu

Abstract

Introduction

Problem statement

Conceptual-theoretical framework

Corporal punishment

The effect of corporal punishment $\quad 75$

$\begin{array}{ll}\text { The effectiveness of corporal punishment } & 77\end{array}$

Research design and methodology $\quad 77$

$\begin{array}{ll}\text { Design } & 77\end{array}$

$\begin{array}{ll}\text { Methodology } & 78\end{array}$

Selection of participants $\quad 78$

Data collection $\quad 79$

Data analysis $\quad 79$

Ethical considerations $\quad 80$

Trustworthiness $\quad 80$

$\begin{array}{ll}\text { Findings and discussion } & 81\end{array}$

Teachers' perceptions on the effects of corporal punishment on learners 
Learners' perceptions on the effects of corporal punishment

Teachers' perceptions on the effectiveness of corporal punishment on learner conduct

Learners' perceptions on the effectiveness of corporal punishment on learner conduct

Alternative disciplinary methods that

might be effective in curbing learner indiscipline

Chapter 5: A normative analysis of student misconduct at a Technical and Vocational Education and Training college in the Western Cape

Louis J. Oosthuizen \& Izak J. Oosthuizen

Abstract 89 Introduction $\quad 90$

Background $\quad 90$

$\begin{array}{ll}\text { Student misconduct } & 91\end{array}$

Manifestation of misconduct in other countries 92

Student misconduct in South Africa 93

Conceptual-theoretical framework 94

Research design and methodology 96

Population, site selection and sampling 96

Data collection strategies $\quad 97$

Data analysis $\quad 97$

Quantitative reliability and validity $\quad 97$

Qualitative trustworthiness 98

Ethical considerations 98

Findings $\quad 99$

Gender of respondents $\quad 99$

Position of respondents $\quad 99$

Campus 100

The nature of student misconduct ranked 100

Absenteeism 102 
Use of mobile phones

Arriving late for class

Unsatisfactory work

Sleeping in class

104

Disruptive behaviour

Instigation

III-mannered behaviour

Narcotic substance abuse

Alcohol abuse

Illegal strikes

Dishonesty during tests and exams

Bullying

Possession of pornographic material

Harassment

Factor 1: Deliberateness

Factor 2: Negligence

Factor 3: Indifference

Summary of findings

Discussion

Chapter 6: Application of due process in ensuring fair learner disciplinary hearings

Nicholus T. Mollo \& Rika Joubert

Abstract

Introduction

Purpose of this chapter

Background

Methodology

Conceptualisation of learner disciplinary process

Human rights and the learner disciplinary process

Managing the disciplinary process

Stakeholders in the learner disciplinary process 
Due process

Procedural due process

Substantive due process

Practical application of due process

Preliminary investigation

Issuing notices that have sufficient information

Disciplinary committee

Conducting the hearing process

Process of adjourning and considering the facts

Reason must be given for the decision

Right to appeal

The model of the application of due process

Service providers

Capacity-building and training programmes

Capacity-building and training manuals

Theoretical and practical activities

\section{Chapter 7: Disciplinary hearings: Legal principles and procedures}

\section{Marius H. Smit}

Abstract

Introduction

Problem statement

Research design and methodology

The phenomenological design

Law research from an Education Law perspective

Findings of the phenomenological study

Investigation and pre-hearing phase

Preparation phase

Disciplinary hearing phase

Corrective measures and enforcement of discipline phase 
Uncertainties about the pre-hearing investigation and procedure

Legal technicalities and preliminary objections

Objections against charge sheets and notices of

disciplinary hearings

Substance and not form - The law does not require strict formalism in charge sheets

Objections about insufficient time to prepare a defence prior to the hearing

Strict proceduralism versus flexible procedural

fairness

Uncertainty about the roles and functions of persons involved in disciplinary hearings

Procedural fairness

Substantive fairness

Reasonable determination of the appropriate corrective measures

\section{Chapter 8: The application of positive discipline at} a Western Cape technical and vocational education and training college

Louis J. Oosthuizen, Izak J. Oosthuizen \& Andre van der Bijl

Abstract

Introduction

Problem statement

Conceptual and theoretical considerations

Learning and behaviour modification within the context of vocational education

Acceptance of positive discipline

Methods of applying positive discipline

Research design and methodology

Population, sampling and participant selection

Data analysis

Validity, reliability and trustworthiness 
Ethical considerations

The occurrence of the application of positive discipline at a Technical and Vocational Education and Training college in the Western Cape

Biographical detail

Attributes of Technical and Vocational Education and Training lecturers that contribute to a positive, disciplined teaching and learning environment ranked Measures that contribute towards a positive, disciplined teaching and learning environment ranked

The views and experiences of lecturers on positive student disciplinary measures

Conclusion and recommendations 194

Appendix A

Questionnaire

Section A: Biographical

Section B: Lecturer attributes

Section C: Application of disciplinary measures

\section{Chapter 9: The congeniality to sound learner discipline of the Finnish education system: Relevance for approaching learner discipline in South African schools}

Charl C. Wolhuter, Corene de Wet \& Johannes (Hannes) L. van der Walt

Abstract

Introduction

Learner discipline in schools: Correlates or determinants

Learner discipline in South African schools and the need

for a change in approach

Finland: The emergence of a noteworthy education system

The Programme for International Student Assessment studies

Finland: An unlikely achiever 
Form-giving social-contextual powers

The education system: Historic development and current structure

Reasons for the success of the Finnish education system

What insights could be gleaned from the Finnish experience for the purposes of addressing shortcomings regarding discipline in the South African education system?

What insights could be gleaned from the Finnish experience for the purposes of addressing shortcomings in school and classroom discipline in South Africa?

\section{Chapter 10: The neoliberal context and the demand for increased access as the Scylla and Charybdis for developing an agenda for the restoration of (student) discipline at South African universities}

Johannes (Hannes) L. van der Walt, Ferdinand J. Potgieter \&

Charl C. Wolhuter

Abstract

Introduction

Students' right to (higher) education in the context of the Creed of Human Rights

The rise of the Creed of Human Rights

Human rights and higher education

The historical roots of the elitist and exclusivist nature of the university

The historical roots of the university

The liberal-humanistic idea of a university

The Humboldtian idea of the university as part of the national project

The developmental university

The ethnic-oriented developmental university

The Africanist university

The revolutionary university

The current era 
The neoliberal economic societal context

The neoliberal economic revolution and the university

The stand-off between South African students' right to access to higher education and the current situation of South African universities

Towards an agenda for the restoration of student discipline in South African universities

What is meant by the term 'student discipline'?

What does this term mean in a South African university context?

Whose views regarding student discipline and good order should prevail in the attempt to restore student discipline?

Whose duty is it to inculcate these values and norms in students at universities?

Who should be held responsible and accountable for the enforcement of good discipline and order at universities?

What are the implications of neoliberalism and of (the call for) increased student access to universities for student discipline at South African universities?

\section{Chapter 11: The turn to positive discipline in education: Existentialist and other contributions}

\section{Johannes (Hannes) L. van der Walt, Izak J. Oosthuizen \&}

\section{Charl C. Wolhuter}

Abstract

Introduction and problem statement

Positive discipline and its adoption in pedagogical contexts in the 21st century

Codes of conduct

'Catch them doing good'

The remedial application of positive reintegration

Positive time-out

Building a positive relationship with the students 
A selection of existentialist psychological thinkers who might have had an influence on the turn towards positive discipline

Alfred Adler

Victor Frankl

Carl Rogers

Abraham Maslow

The possible contribution of 'pure' existentialists in this turn to positive discipline

Synopsis: Existentialist perspectives that arguably influenced the existentialist psychological thinking,

thereby giving impetus to the turn to positive discipline 276 A wider casting of the net: the Zeitgeistliche developments that might have promoted the chances of adopting positive discipline in pedagogical contexts

References 



\section{Abbreviations, Figures and Tables Appearing in the Text}

\section{List of Abbreviations}

ATCP Alternatives to Corporal Punishment

CELP Centre for Education Law and Policy

CPUT Cape Peninsula University of Technology

DHET Department of Higher Education and Training

ICT Information, Communication and Knowledge Technology

IEA International Association for the Evaluation of Educational Achievement

NATED National Accredited Technical Education Diploma

NCV

National Curriculum Vocational

NSFAS

National Student Financial Aid Scheme

NWU

North-West University

OECD

Organisation for Economic Cooperation and

Development

PD Positive Discipline

PISA Programme for International Student Assessment

QUAL Qualitative

QUAN Quantitative

SETA Sector Education and Training Authority

TIMSS Third International Mathematics and Science Study

TVET Technical and Vocational Education and Training

UNESCO United Nations Educational, Scientific and Cultural Organisation

UNICEF United Nations Children's Fund 


\section{List of Figures}

Figure 5.1: The nature of student misconduct ranked.

Figure 6.1: Conceptual framework of due process on learner discipline in South Africa.

Figure 6.2: A strategy for improving the application of due process during learner discipline.

\section{List of Tables}

Table 5.1: Gender.

Table 5.2: Position of respondents.

Table 5.3: Campus.

Table 5.4: Nature of student misconduct ranked.

Table 5.5: Factor analysis: The nature of student misconduct. 108

Table 5.6: Factor 1: Deliberate misconduct.

Table 5.7: Factor 2: Negligence.

Table 5.8: Factor 3: Indifference.

Table 8.1: Student programme.

Table 8.2: Lecturer attributes.

Table 8.3: Measures for maintaining PD. 


\section{Notes on Contributors}

\section{Corene de Wet}

Open Distance Learning, Faculty of Education,

University of the Free State,

Bloemfontein, South Africa

Email: dewetnc@ufs.ac.za

ORCID: https://orcid.org/0000-0002-5208-2963

Corene de Wet was a History and Afrikaans teacher for 16 years before she joined academe in 1992. She is an emeritus professor in Comparative Education, and a research associate at Open Distance Learning, South Campus, University of the Free State, Bloemfontein. She holds a DEd in Comparative Education (1991) and a PhD in History (1998). She has authored and co-authored more than 100 articles in national and international peer-reviewed journals, as well as eight book chapters. She presented numerous papers at South African and international conferences. Her research focusses, firstly, on violence, bullying and sexual harassment amongst learners and, secondly, on educators as victims and perpetrators of workplace bullying and violence. She is a C2 NRF-rated researcher.

\section{Rika Joubert}

Edutel Higher Education,

Roodepoort, South Africa

Email: hendrikajoubert@gmail.com

ORCID: https://orcid.org/0000-0002-8921-6670

Rika Joubert is an emeritus professor at the University of Pretoria. She was the director of the Interuniversity Centre for Education Law and Policy (CELP) from 2004 to 2016 and is a founding member of the South African Education Law Association. She specialises in school governance, school safety and school discipline and has presented papers at international conferences in the United States, Australia, New Zealand, Europe, England, China, Cyprus and Hong Kong. Her publications include books on law in education, school governance and discipline in schools. Currently, she is the academic head of Edutel Higher Education and is responsible for quality assurance and the management of academic affairs at this private higher education institution. 


\section{Ansie E. Kitching}

School of Psycho-Social Education, COMBER,

Faculty of Education, North-West University,

Vanderbijlpark, South Africa;

Department of Educational Psychology,

Faculty of Education, University of the Western Cape,

Cape Town, South Africa

Email: akitching@uwc.ac.za

ORCID: https://orcid.org/0000-0002-0290-3962

Ansie E. Kitching has a PhD in Psychology from North-West University that focussed on the development of a relationshipfocussed approach to the co-construction of enabling school communities. She is an educational psychologist and currently an associate professor in the Department of Educational Psychology, Faculty of Education, University of the Western Cape. Earlier, she was employed at the Faculty of Education, North-West University, for 15 years and involved in COMBER, a niche area that focusses on community-engaged research in education. The focus of her current research is on the implementation of the sustainable promotion of holistic well-being as a basis for transforming schools into enabling, inclusive communities. Her publications address the importance of relational dynamics in the facilitation of such a transformation process.

\section{Michael L. Marumo}

School of Commerce and Social Studies in Education,

Faculty of Education, North-West University,

Mafikeng, South Africa

Email: Michael.Marumo@nwu.ac.za

ORCID: https://orcid.org/0000-0003-0649-1640

Michael L. Marumo is a lecturer in the School of Commerce and Social Studies in Education at North-West University. He obtained his master's degree in Education Management from North-West University in 2016. He is currently a deputy subject group leader in the School of Commerce and Social Studies in Education. His research interests are in the area of school management, primarily focussing on school leadership and management of discipline. Michael is a PhD candidate at North-West University, focussing 
on the influence of curriculum leadership on learner performance in South African secondary schools.

\section{Zahraa McDonald}

Centre for International Teacher Education,

Cape Peninsula University of Technology,

Cape Town, South Africa

Email: zahraamcdonald@hotmail.com

ORCID: https://orcid.org/0000-0002-1411-8451

Zahraa McDonald is currently a research fellow at the Centre for International Teacher Education at Cape Peninsula University of Technology. She has a PhD from the University of Johannesburg that examines Islamic education and postsecular citizenship in South Africa. Currently, her research focusses on teacher education and development. Her publications have addressed religion and citizenship education as well as school safety.

\section{Nicholus T. Mollo}

Department of Education Law, Faculty of Education,

North-West University,

Potchefstroom, South Africa

Email: Mollo.Nicholus@nwu.ac.za

ORCID: https://orcid.org/0000-0003-0427-0836

Nicholus T. Mollo is lecturer in Education Law at the Faculty of Education at North-West University. He holds a PhD in Education Law. His research interests include discipline in schools and labour law in education. He is one of the founders of Besilindile Primary School and Sinqobile Abet Centre in Emalahleni (Mpumalanga). He was the centre manager of Sinqobile Abet Centre, the principal of Ukhwezi Primary School in Belfast and the principal of Emakhazeni Boarding School in Machadodorp. In 2014, he received the third position in the National Teacher Award at the district level (Nkangala) for Excellence in Primary School Leadership. He has been teaching Education Law in the distance programme (part-time) of the University of Pretoria for 7 years. He has also lectured and moderated on a part-time basis at Tshwane University of Technology. 


\section{Izak J. Oosthuizen}

Edu-HRight Research Focus Area,

Faculty of Education, North-West University,

Potchefstroom, South Africa

Email: 10055568@nwu.ac.za

ORCID: https://orcid.org/0000-0002-1193-4699

Izak J. Oosthuizen was appointed as an associate professor in 1989 in the Faculty of Education at the then Potchefstroom University for Christian Higher Education. In 1998, he became professor and in 2011 he was appointed as research professor at the Faculty of Education of North-West University, Mahikeng Campus. He taught Education Law, Education Management and Fundamentals of Research in Education. Currently, he is an extraordinary professor at North-West University. Earlier on in his career, he taught for 17 years at secondary schools in Pretoria and later on he lectured at the College for Further Education and the University of Pretoria (part-time).

He published widely in the field of Education Law and Learner Conduct. He has authored or co-authored, edited or co-edited more than 40 books and 70 articles in the field of education. He was rated as an established researcher in 2005 and 2010 and has received a senior research award from the Education Association of South Africa in 2004. He obtained the following qualifications: BA, BAHons, BEd, MEd (cum laude), PhD, Bluris, THED, FDE (Education Management) and Dip. Theol.

\section{Louis J. Oosthuizen}

Trimester Programme, NATED Programme,

West Coast College,

Vredenburg, South Africa

Email: loosthuizen8@gmail.com

ORCID: https://orcid.org/0000-0002-1760-4586

Louis J. Oosthuizen is a coordinator for NATED at the Vredenburg Campus of the West Coast TVET College.

Mr Oosthuizen is a qualified automotive technician (cum laude) and holds a Diploma in Mechanical Engineering from the West Coast College. Subsequently, he obtained a National Professional Diploma in Education (cum laude) from the Cape Peninsula 
University of Technology, an Advanced Certificate in Education (cum laude) as well as a BEd Hons from North-West University. At the end of 2018, he submitted his MEd dissertation at the Cape Peninsula University of Technology for examination.

\section{Ferdinand J. Potgieter}

Curriculum Studies,

Faculty of Education, North-West University,

Potchefstroom, South Africa

Email: Ferdinand.Potgieter@nwu.ac.za

ORCID: https://orcid.org/0000-0001-8963-3055

Ferdinand J. Potgieter studied at the University of Pretoria and the University of South Africa. Although he holds a Bachelor of Honours degree in African languages (cum laude), his doctorate was awarded in History of Education by the University of South Africa in 1992. He is currently a full professor in Philosophy of Education and Education Theory at North-West University, Potchefstroom Campus, South Africa. Earlier, he was a senior lecturer in Education Management, Law and Policy Studies in the Faculty of Education at the University of Pretoria. He has published widely in the field of spirituality and education, morality and education, children's spirituality, sources of inspiration for student teachers, religious tolerance education, hospitality education, anatheism and philosophy of education. Currently, he is a project leader of an international research project on religious (in)tolerance, hospitality and forgiveness in education together with colleagues in Bulgaria, Germany, the Netherlands and Cyprus.

\section{Bianke van Rooyen}

Provincial ASD Outreach Team,

Western Cape Education Department, Vera School for Learners with Autism,

Cape Town, South Africa

Email: biankebotha@gmail.com

ORCID: https://orcid.org/O000-0003-2951-9757

Bianke van Rooyen has a PhD in Educational Psychology from North-West University that focussed on the sustainable implementation of a holistic well-being process in school 
communities. She currently works as an educator on the Provincial ASD Outreach Team established by the Western Cape Department of Basic Education. She is interested in research on the application of mindfulness to enhance individual and relational well-being in schools.

\section{Marius H. Smit}

Department of Education Law,

Faculty of Education, North-West University,

Potchefstroom, South Africa

Email: Marius.Smit@nwu.ac.za

ORCID: https://orcid.org/0000-0002-5165-8799

Marius H. Smit (B.Com, LLM, PGCE, PhD) is an attorney, qualified educator and associate professor. He teaches Education Law modules to undergraduate, honours and master's students at the Faculty for Education Sciences, North-West University.

$\mathrm{He}$ is a C2 NRF-rated researcher and has published widely in academic journals (43 articles) and contributed chapters to 20 books in the field of Education Law. He has served as a member of four school governing bodies, the chair of the provincial council of the Federation of South African School Governing Bodies (FEDSAS) and is currently a member of the National Executive Council of the South African Education Law Association.

\section{Amos T. Thebenyane}

School of Professional Studies in Education, Education Management,

Faculty of Education, North-West University,

Mafikeng, South Africa

Email: tlhomamothebenyane@yahoo.com

ORCID: https://orcid.org/0000-0002-5004-2300

Amos T. Thebenyane is currently a doctoral candidate in Education Management at North-West University. He holds an MEd, a BEd Honours and an Advanced Certificate in Project Management awarded by North-West University (Mafikeng Campus) in 2015, 2012 and 2011, respectively. He obtained a Diploma in Primary Education from the Lobatse College of Education and has been employed by the Botswana Teaching Service Management under the Ministry of Education since 2000. He has worked as a 
permanent primary school teacher in a number of schools and was promoted to the post of senior teacher Guidance and Counselling in July 2010 (a post he still holds to date).

\section{Andre van der Bijl}

Teacher Professional Development,

Faculty of Education, Cape Peninsula University of Technology,

Cape Town, South Africa

Email: VanderBijIA@cput.ac.za

ORCID: https://orcid.org/0000-0002-0249-1902

Andre van der Bijl is a senior lecturer at the Faculty of Education of the Cape Peninsula University of Technology, where he has been employed in teacher education since 1994. Within the faculty, he is responsible for Technical and Vocational Education and Training (TVET) matters. He has served on numerous national and regional task teams and working groups. Of recent interest has been his involvement in Education Training and Development Practices Sector Education and Training Authority (SETA) Research Chair for Work Integrated Learning and Recognition of Prior Learning (WIL \& RPL) and the Department of Higher Education and Training European Union supported college lecturer development programme. He has published in peer-reviewed journals in business and education, mainly on topics related to educational management and TVET. He has presented many conference papers and published textbooks for the TVET National Accredited Technical Education Diploma (NATED) curriculum and chapters in teacher education programmes.

He has served on the governing body of two schools in the Western Cape and currently holds a ministerial appointment on the Council of the Western Cape Community Education and Training College.

He holds a PhD in higher education and a master's degree in Educational Administration from Stellenbosch University. He also has a Bachelor of Arts from the University of Cape Town and a Higher Diploma in Education (Commerce) Secondary from the University of Cape Town and Cape Technikon. 


\section{Johannes (Hannes) L. van der Walt}

Edu-HRight Research Focus Area,

Faculty of Education, North-West University,

Potchefstroom, South Africa

Email: Hannesv290@gmail.com

ORCID: https://orcid.org/0000-0001-9243-5973

Johannes (Hannes) van der Walt, an emeritus professor of Philosophy and History of Education, and past dean of the Faculty of Education at the former Potchefstroom University, is currently a specialist researcher at North-West University where he is involved in research and capacity-building programmes. These programmes, occasionally, also offered nation-wide scholarly article writing seminars, not only in Education but also in other scholarly disciplines. He has authored more than 200 articles in accredited journals on issues related to philosophy of education, history of education, Comparative Education and religion and morality in education.

\section{Charl C. Wolhuter}

School of Professional Studies in Education, Comparative and International Education,

Faculty of Education, North-West University,

Potchefstroom, South Africa

Email: Charl.Wolhuter@nwu.ac.za

ORCID: https://orcid.org/0000-0003-4602-7113

Charl C. Wolhuter studied at the University of Johannesburg, the University of Pretoria, the University of South Africa and the University of Stellenbosch, South Africa. He obtained a doctorate in Comparative Education from the University of Stellenbosch. He was a junior lecturer at the University of Pretoria and a senior lecturer at the University of Zululand, both in the History of Education and Comparative Education. Currently, he is a professor in Comparative and International Education at North-West University, Potchefstroom Campus, South Africa. He has held visiting professorships at i.a. Brock University, Canada; Driestar Pedagogical University, the Netherlands; the University of Crete, Greece; Canterbury Christ University, United Kingdom; the University of Joensuu, Finland; the University of Queensland, 
Australia; the University of Modena and Reggio Emilio, Italy; Mataj Bel University, Slovakia; Boris Grichenko University, Ukraine; the University of Zhengzhou, China; the University of Namibia, Namibia; the University of the Western Cape, South Africa; and The Education University of Hong Kong, Hong Kong. He is the author of various books and articles on History of Education and Comparative Education.

\section{Connie B. Zulu}

School of Professional Studies in Education, Educational Management,

Faculty of Education, North-West University,

Mafikeng, South Africa

Email: Connie.Zulu@nwu.ac.za

ORCID: https://orcid.org/0000-0002-9841-1670

Connie B. Zulu is a full professor in Educational Leadership at North-West University, Mahikeng Campus. She is a C3 NRFrated researcher who holds a DEd in Education Management from the University of South Africa. Earlier, she had received a master's degree in Educational Administration from the University of Michigan in the United States and later obtained a master's degree in General Linguistics from the University of Stellenbosch. She is a former high school teacher, school principal and English Subject Adviser. She is a member of Women in Higher Education Management Network, which is an international feminist research consortium spanning Australia, Austria, the Czech Republic, Germany, India, Ireland, New Zealand, Portugal, South Africa, Sweden, Turkey, the United Arab Emirates, the United Kingdom and the United States of America. Her research interests include leadership and management, and more specifically women in educational leadership. In addition to co-editing a DHET-accredited conference proceedings in 2013, she has co-edited a Special Edition on learner discipline problems in schools in the same year. She has published numerous articles and book chapters in scholarly journals and books. 



\section{Foreword}

Robert J. Balfour

Teaching-Learning, North-West University, Potchefstroom, South Africa

This book takes as its context international and national trends with regard to schooling and socialisation of learners into the wider society and considers the multiple relationships that are formed by, or regulated through, the learning interaction between teachers and learners and between learners themselves. The book considers research on discipline, misconduct and punishment across a range of countries and continents, exploring contexts where corporal punishment in schools, for example, is still legal. It takes as its problematic teacher ignorance concerning how to implement alternative forms of discipline and punishment, without resorting to corporal punishment, whether legal or not, and data emerging from schooling systems in developed and developing countries, which point to a deterioration of discipline in schools.

A number of studies are reported on, in which learners and teachers consider the challenges arising from social and ethical relationships between groups, within the institution of the school. The data describe approaches to, and perceptions of, discipline from learners and teachers alike, and consider the behavioural, procedural and social challenges associated with the need for, and regulation of, conduct. It points to a series of challenges experienced by teachers and learners in relation to each other as groups and within such groups themselves where approaches to

How to cite: Balfour, R.J., 2019, 'Foreword', in C.B. Zulu, I.J. Oosthuizen \& C.C. Wolhuter (eds.), A scholarly inquiry into disciplinary practices in educational institutions (NWU Education and Human Rights in Diversity Series Volume 2), pp. xxxi-xxxiii, AOSIS, Cape Town. https:// doi.org/10.4102/aosis.2019.BK157.00 
behaviour, in general, and the role of discipline, in particular, are considered. Even in contexts where corporal punishment is practised, the ambivalence towards it, how it might be prescribed with accepted legal procedures, the links between the practice and other behaviours (such as bullying and truancy) are drawn. Applying different philosophical and methodological frames to the challenge of regulation of behaviour, such as ethicality and followership, scholars featured in the book probe the social challenges that give rise to misconduct, such as peer pressure, globalisation, technology, population growth and changing approaches to human rights and parenting.

A range of perspectives to the nature of relationships between learners in social situations engendered by the school are explored, and the book provides a detailed reflection on the nature of particular forms of behaviour (such as bullying) in schools in which a-symmetrical relationships of power are involved. What becomes evident is that the approaches to discipline as the regulation of behaviour towards the educational outcome of learning bear little relation to either the learning or the overt socialisation role of the school, which is to educate learners to assume responsibility for themselves (as learners, as citizens, as beings capable of controlling themselves to such an extent that collaboration towards the building of society is both a shared aspiration and a mutually beneficial outcome of adult life).

The role that teachers play, both as regulators of behaviour and exemplars of it, is a complex one. In this context, the phenomenon of bullying (characterised by the exertion of control and coercion) relates also to the teacher-learner relationship, relationships between parents, parents and teachers, and between teachers. Other factors impacting the discipline and conduct, such as class size, the competence, confidence and autonomy of the teachers, are also considered, and they call for further research and investigation. Discipline as a form of socialisation is also considered from the perspective of the 
institution of the school. What emerges is that the distinction between discipline (and associated non-aggressive measures) and punishment is not clearly understood by teachers.

The book spans not only schooling but also explores student misconduct and discipline issues in higher education contexts, where they manifest in the forms of substance abuse, harassment and truancy. What is revealed is that teachers, managers and even governance structures remain unsure of how to approach issues pertaining to discipline and misconduct and that there exist often discrepancies between the espoused values of the institutions, the procedural approaches adopted by authorities and teachers, and the experiences of discipline from all stakeholders concerned. Alternative approaches to discipline are explored in several chapters and although further larger-scale research concerning these must be undertaken, results are promising. To the extent that this is affirmed throughout the book, the problematic of discipline remains ambiguous and thus, unsurprisingly, also subject to widespread interpretation, abuse and misuse.

Drawing from a range of schooling systems, also in terms of performance, the book makes a profound case for the reconsideration of approaches to discipline and misconduct on the basis that conventional approaches seem to be not only ineffective at best but also damaging at worst; this recognition arises from an awareness evident in almost every chapter concerning the changing nature of teaching, learners, learning and societies. A compelling and scholarly account from beginning to end, this book makes a valuable contribution to the study of discipline in contemporary education. 



\section{Chapter 1}

\section{The future is upon us: Discipline in early 21st-century schools, with special reference to South Africa}

Johannes (Hannes) L. van der Walt

Edu-HRight Research Focus Area, Faculty of Education, North-West University, Potchefstroom, South Africa

Charl C. Wolhuter School of Professional Studies in Education, Comparative and International Education, Faculty of Education, North-West University,

Potchefstroom, South Africa

\section{Abstract}

Education is always future-oriented in that it prepares learners for their duties and responsibilities as grown-ups. It is, however, difficult to accurately predict the future; any attempt to do so 
would be fraught with many pitfalls. It is, nevertheless, incumbent upon educators and educationists to attempt to peer into the future, and they can do so by examining certain trends that are already discernible and that already have an impact on the discipline of teachers and learners in schools. The theory employed in this research suggests that 'discipline' should be seen as an ethically favourable response on the part of learners (students) to the engagement of their educators (teachers) with them. A number of specifically South African and also a multitude of international trends already seem to have a negative impact on discipline in South African schools, and this will probably continue into the foreseeable future.

\section{Introduction and problem statement}

Education, in both forms - as teaching and learning in contexts such as schools, and as the broader pedagogical formation of less mature people - is always future-oriented, as the future is what learners are being prepared for and guided towards. Educators, in the persons of teachers, parents and other significant people, therefore, always tend to have an eye on the future when educating young, less mature persons. However, the future is an unknown quantity about which we can only speculate or towards which we can extrapolate the currently existing trends. Such exercises are, however, fraught with pitfalls, as can be illustrated with reference to publications that saw the light of day only a few decades ago.

A book about the future of the school, written in the 1970s and edited by Schutte et al. (1975), touched upon topics such as the school, education as such, nationalism and internationalism, the teacher, the child, the parent, teacher education, didactics, the curriculum, the education system, physical facilities and technology in the 21st century. The authors, all teacher educators at the time, believed that a reflection about the future of the school was necessary because they were involved in the shaping 
of the leaders of the future (Schutte et al. 1975:1). Subsequent developments in the political arena in South Africa reveal, however, that the authors were not correct in their assumption that they were preparing the educational leaders of the future (they mention, amongst others, the future minister of education, school directors, inspectors and principals). In the four decades after the publication of the book, the South African political landscape underwent radical changes. The current education leaders in South Africa, from the ministers of Basic and Higher Education down to by far most of the principals, come from quite different population groups than those that Schutte and his coauthors were educating in the 1970s. Most of the educators trained in the institutions such as those of Schutte et al. (1975) have since left the profession, having either retired or resigned. Even teacher education institutions have undergone radical changes since the late 20th century.

What is also interesting about this publication is that no reference has been made to the issue of discipline in schools or in education in wider contexts. This can arguably be ascribed to the fact that the book was addressed to a section of the South African community in which ill-discipline was not an issue, possibly because of the patriarchal nature of that community. The authors, however, did not take cognisance, or were not aware, of political dissent in the black community at that time, which was on the point of erupting and which resulted in gross ill-discipline in schools from the mid-1970s up to the present day, initially mostly in historically black schools but nowadays in practically all South African schools.

Another book published in the 1970s, entitled Stepping into the Future: Education for South Africa's Black, Coloured and Indian Peoples (Van Rensburg 1976), underscores the point made about the pitfalls associated with extrapolating towards the future. The extrapolations made by the contributors to this book were predicated by statements such as, "[n]o one (in South Africa) seriously advocates a "common society" in the full sense of the term' (Van Rensburg 1976): 
Education (in South Africa) has always been and will always be crucial to the implementation of the policy of multinational development or any of the alternatives or variations that are being suggested both inside and outside Parliament [...] and [...]

Alternative constitutional forms are also being suggested and intensely debated as political developments gather pace and become irreversible. But they are all based, to a greater or lesser extent, on the concept of heartlands for each of the country's black peoples. (p. 7)

The irony is that Soweto started burning in reaction to such policies around the time of publication of this book. People's Education was proffered as an alternative to 'apartheid education' for black people in the 1980s. The situation subsequently became untenable for the government's 'heartland policy' and for apartheid in general. Negotiations with the black opposition became inevitable during the late 1980s and the early 1990s, and the 'common society' that the authors of this book were convinced would never be contemplated, emerged in 1994 and was constitutionally entrenched in 1996.

This problem of having to skirt many pitfalls when attempting to 'predict' the future is not restricted to South African authors. A case in point is the book authored by Egan (2008) in which he presented his ideals for education in the form of a 'future history' (Egan 2008:87), in other words what he foresaw (or perhaps hoped or strove for, cf. Rudin 1975:190-191) for education towards the end of the second decade of the 21st century in the form of a history, as if the events had actually taken place. By 2020, he wrote (or hoped), two major changes would have taken place in education in North America and Europe (Egan 2008:108), namely, the introduction of Imaginative Education in 'hundreds, perhaps thousands, of schools by a fairly enthusiastic group of teachers', and the development of (Egan 2008):

$[A] n$ enormously powerful lobby of academics whose determined aim was to influence the curriculum of, and teaching at, the schools [...] clearly the response from the audience in Salerno [where a conference about education supposedly took place] vividly revealed that those most concerned with the intellectual life of the time had 
come to see the public school as enemy rather than the ally it ought to have been. (pp. 106-107)

This movement arose because the public school was seen as the most anti-intellectual institution in our societies. Neither of these developments that Egan had 'predicted' or hoped for has been realised even in 2019.

Two other books that drew attention in the 1970s were Ivan Illich's Deschooling Society and Evert Reimer's Schooling Is Dead: Essays about the Future of Deschooling. These progressive authors predicted that the school as an institution was doomed to extinction and would not see the year 2000. These predictions also did not materialise; in 2019, the school as an institution is as alive as ever.

Despite all the pitfalls surrounding attempts to predict the future in and of education, educators, as mentioned, remain interested in what the future might hold for them and for those whom they educate. In the same year that Schutte et al. (1975) published their book about the future of the school, as they expected it to unfold, Rudin (1975) remarked:

Despite our keen interest in decoding social signs, and our growing sophistication in interpreting their meaning, prediction is fraught with pitfalls. It was Walpole who pointed out that prognostications do not always become prophesies. (p. 189)

Because the future does not yet exist as reality, the problems are open to imaginative solution. There are, in Rudin's opinion, no irrevocable mandates and no fixed specifications; we are free to envision and create the best schools our ingenuity can spawn (Rudin 1975:204). It is for this reason that all the authors contributing to the book, entitled The Future of Education: Perspectives on Tomorrow's Schooling, were cautious about predicting future developments (Rudin 1975). Most of their expectations for the future were restricted to possibilities within the parameters of what they understood in the 1970s about the human being, schooling and education. A case in point is Glaser's $(1975: 122-123,133)$ aspiration for an adaptive mode of education 
in schools. Although the selective mode of education and schooling in the 1970s was characterised by a minimal variation in the conditions under which individuals were expected to learn, an adaptive mode of education and schooling assumes that the educational environment (the school) can support many and varied instructional methods and opportunities for success. An adaptive environment (school) assumes that there are many ways to succeed and many goals available from which to choose. If an adaptive mode becomes prevalent and wider constellations of human abilities are emphasised, then success and achievement will need to be differently defined, and many more ways of succeeding will need to be appropriately rewarded than in the selective mode. It seems to have been realistic to expect schools in the 1970s to nurture more adaptive environments in the foreseeable future. Information technologies have since then opened up many modes of learning, including distance learning, web and Internet learning, open distance learning, open learning, blended learning, conventional residential learning, microteaching, mentorship, massive open online courses, flipped classrooms and so on; a combination of options are nowadays available to teachers and learners.

A simple Google search by using the keywords 'the future and education' performed on 10 October 2017 yielded 695000000 results, covering every conceivable topic that might have relevance to the future of education in all its different forms. An examination of some of these publications shows that most authors are wary of the pitfalls of looking too far ahead, and others prefer to go forward to the future by first looking back. Grossman and McDonald (2008), for instance, concluded that:

[M]oving forward will also involve reconnecting with the histories of our fields. Educational research in general tends to engage in a kind of historical amnesia, forgetting the past in the rush to invent the future. [...] Part of what also defines a field is its common shared history. In charting the future, researchers might pause to remember and build upon the work of the past. (p. 200)

It is clear from the above, and particularly from the above quote, that Future Studies as a subject has to deal with several intricacies 
which, however, do not have to be discussed in this chapter. Instead, we prefer to assume that 'the future is upon us' as educationists, and in doing so, we differ from Grossman and McDonald's (2008) 'back to the future' approach, which entails a looking back to historical developments in the field.

Now, what has all this talk about the future of education to do with the subject of this chapter, namely, discipline in the schools today? The answer is simply that the trends that were foreseen four to five decades ago, in the second half of the 20th century, are now crystallising in forms, shapes and as forces that have a significant impact today, in the second decade of the 21st century, on education, schools and schooling, and more particularly on discipline in schools and classrooms.

We use the phrase, 'the future is upon us', to capture the notion that developments in the world that could be seen taking shape since the middle of the 20th century, such as mass migration, internationalisation and globalisation, the phenomenal growth in communication and transport technology and neoliberal tendencies, such as managerialism and performatism are now, in the second and third decades of the 21st century, reaching culmination points and have thus begun impacting our lives in general and education, schooling and discipline in the pedagogical context in particular. Conditions that began taking shape five to seven decades ago are now reaching dimensions worthy of concern. They bring about new conditions that, as we will argue below, together with the new political dispensation in South Africa since 1994, are already impacting schooling in South Africa in such a manner and to such an extent that, amongst others, ill-discipline and antisocial behaviour in schools have become causes of concern. We agree with Rudin (1975:190) that schools mirror rather than create social trends.

The primary purpose of the discussion below is to describe and assess some of these 'new' conditions in which schooling in South Africa has to take place and to tentatively describe and assess the effects thereof on discipline in schools. A secondary 
purpose of the chapter is to allow some pointers to surface about how we might deal with such discipline problems.

The remainder of this chapter unfolds as follows. The next section contains the conceptual and theoretical framework that served as the lens through which the different forces impacting on South African schools (and schools worldwide) were examined, particularly as they impact on discipline in South African schools (and schools worldwide). The section thereafter gives an overview of the multitude of forces that have an influence on education and secondarily on discipline, and it is followed by a section in which their impact is assessed and discussed in terms of the theory. The chapter concludes with a number of recommendations and perspectives for the foreseeable future.

\section{Conceptual and theoretical framework}

According to the social space and ethical function or action theory as expounded by Van der Walt (2017a:endnote 5, 2017b: Section 6), all events, including the display of order and discipline, respectively, disorder and ill-discipline, occur in a particular social space. For the purposes of this chapter, the space in which order and discipline are considered is defined as 'a school classroom'. This space, as is the case with all distinguishable spaces, possesses a number of unique features:

- it is a physical space (with physical dimensions), equipped with chairs and tables and other amenities required for the teaching of young people below the age of 18 (with exceptions owing to having failed previous grades) as well as for their optimal learning (e.g. computers, tablets, chemicals and other teaching and learning aids)

- the activities in the space are usually planned and guided by a person known as the teacher (in theory adequately trained for teaching a particular subject or field of knowledge)

- the classes held in the space are attended by young people known as learners or students. 
The concept 'classroom' is so familiar to readers that we need not belabour this point any further. What is important is that this space is unique in that it is a structured, planned, formal teaching and learning space for young people typically under the age of 18. Because of the young age of the learners, this space differs from similar spaces at institutions of higher learning. School classrooms are also unique teaching and learning spaces in that they are intended to prepare learners for post-school life (for taking jobs, or going on to tertiary education).

The uniqueness of schools and school classrooms can also be observed in the uniqueness of the discipline displayed in schools. The learners and students, being young and on their way to maturity, are expected to apply themselves to the task of learning what they are being taught by their teachers in class, to be diligent and committed to the task and not to allow their attention to wander. Put differently, they are expected to display orderly and disciplined behaviour, behaviour that attests to their followership in the classroom, to the fact that they are applying themselves to the task of mastering that which is required for them to pass the particular grade.

The theory also emphasises the importance of ethically and morally justifiable action in the social space, in this case in the school classroom. The teaching and learning that occur in the social space of the classroom do not occur for their own sake, but for the sake of guiding, leading, equipping, forming and nurturing the learner (Nussbaum 2011:23) in order for him or her to be able to take up the responsibilities of life after having attended school for 12 years or more. Put in more technical terms, the didactical interaction between teacher and learner has to grow into a pedagogical interaction. The teacher should also become an educator and the learner has to become an educand; this is a process in which the innate abilities of the latter unfold towards full maturity, enabling the young person to respond to his or her calling in life and to develop a sense of agency and identity as a unique human being (De Muynck, Vermeulen \& Kunz 2017:34, 50). The ethical dimensions of this interaction should be 
observable in displays of love and care for the educand, of understanding and empathy and moral imagination (the ability to place oneself in the position of the other).

Discipline, defined for the purposes of this chapter as followership, can be seen as one of the expressions of maturity following the didactical-pedagogical engagement with the young person and hence also as an expression of ethical reciprocity (the readiness to follow where the educator leads and guides). Although very young children are not able to display discipline consciously, older children (learners as educands) are in theory able to display disciplined (followership) behaviour; they are in theory able to sit quietly and apply their minds to the task at hand, listen carefully when instructed about how to go about the task, and be punctual, diligent and committed. Disciplined behaviour on the part of the educand can therefore be described as reciprocal ethical behaviour, as an ethically positive response to the engagement of the educator.

It follows from the above that the social space and ethical function or action theory would suggest, conversely, that illdiscipline and asocial or antisocial behaviour could be described as an ethically negative response to the engagement and actions of the teacher as an educator. Such responses can be ascribed to a multitude of possible causes and complexes of causes and conditions. It will be argued in the remainder of this chapter that conditions in the modern world, a world in which a particular 'future is upon us', have impacted on individuals' personal existence and on conditions in schools and in society at large to such an extent that ill-discipline and unruliness in schools could reasonably be expected. We will attempt to show in the following section that the political conditions in South Africa since the late 20th century up to now have been conducive to the growth of ill-disciplined and unruly behaviour in schools. We will then cast the net wider and show how other developments in the modern world, where the future has virtually 'caught up with us', seem to reinforce such ill-disciplined behaviour of learners (who ideally should have been more disciplined educands) in schools. 


\section{The contribution of the prevailing sociopolitical conditions in South Africa in general, and in schools in particular, to the collapse or lack of discipline in schools}

The current societal and educational context in South Africa does not render it conducive to the maintenance of proper discipline in schools. The situation is exacerbated by corruption, violence and crime in the broader South African society and by the collapse of family life in many instances. Only $34 \%$ of South African children are currently living with both parents, 23\% are living with neither and around 148000 households are headed by a child aged 17 years or younger (Kenny 2009:13). In 2006, more than 72000 girls left schools because they were pregnant (Kenny 2009:13). Poverty is also rampant, particularly since 2008. The number of people living on less than US\$ 1.90 per day (the international poverty line) increased from 15.1 million in 2008 to 16.6 million in 2011 (World Bank 2016:58). The unemployment rate increased from $17.6 \%$ in 1995 to $25.4 \%$ in 2015 (Yu, Kasongo \& Mosesn 2016).

All such conditions, taken together, explain why South Africa has developed a de facto dual school system; the ex-model C schools (historically white schools) that compare, in terms of infrastructure, with some of the best schools in the world (cf. Wolhuter 1998), whereas the historically black schools that represent by far the majority of schools in South Africa are not only poorly endowed in terms of infrastructure and teacher qualifications but are also dysfunctional in many respects. Only $38 \%$ of South African schools have computers for Grade 8 learners, compared with 95\% in the Russian Federation, 99\% in Lithuania and $96 \%$ in Thailand (Law, Pelgrum \& Plomp 2008). The situation is exacerbated by the absence in many of these schools of a culture of teaching and learning. This is part of the heritage of these schools following the fact that during the sociopolitical turmoil in the years running up to the introduction of the new 
political dispensation in 1994, the schools were used as sites for political sensitisation in the struggle against the apartheid dispensation, amongst others, for making the country ungovernable. A recent study by the Centre of Development of Enterprise showed that $40 \%$ of instruction time in such South African schools is being lost owing to teacher absenteeism (Fengu 2017). The lack of proper infrastructure and the absence of a culture of teaching and learning are evident in poor results. Although $62 \%$ of Grade 3 learners can read and write on the required level in the historically white schools in the Western Cape province, only $3 \%$ can do so in schools in the black townships in the province (Bloch 2009:13). This explains, amongst others, why in the 2011 international Third International Mathematics and Science Study (TIMSS) science test, South African leaners obtained the second lowest score (332) of the 45 participating countries; only Ghana's (306) score was poorer (Martin et al. 2012:44).

The lack of appropriate infrastructure and the absence of a culture of teaching and learning in many of the historically disadvantaged schools are worsened by the administrative incompetence of the authorities. Only 16 of the 59 new schools that were to be built during the 2016-2017 financial year were in fact completed (Beukman 2017), and only 10 of the 280 schools that were to get running water systems installed received this facility. None of the 620 schools that were to get electricity received this facility. In the 2017 financial year, the Department of Basic Education incurred losses of R621 million because of unscrupulous contractors (owing to wrong appointments and possibly also corruption, self-enrichment, theft and state capture).

The problem of indiscipline in schools is exacerbated by the inadequate training and qualifications of teachers, particularly in the historically disadvantaged (black) schools. Around two-thirds of the 2017 teacher corps in South Africa (in total around 426000 ) possess a matric plus 3 years level of education, but only $15 \%$ possess matric plus 4 years or more (Centre for Development and Enterprise 2015:8). This level of qualification is low compared 
with the most advanced education systems in the world. In postBologna Europe, for example, the minimum requirement for teacher education is a master's degree or 5 years of teacher education.

All the above features, singly and in combination, militate against the maintenance of an atmosphere of disciplined behaviour in schools. Teachers furthermore are at a loss when faced with new and more appropriate methods of maintaining discipline in classrooms in a human rights environment (cf. Wolhuter \& Van Staden 2008). Before 1994, schools in South Africa used to rely heavily on corporal punishment for the maintenance of discipline (cf. Christie 1992). Many teachers still resort to this method despite the risk of being departmentally and even criminally charged (cf. Wolhuter \& Van Staden 2008). Many teachers need to be familiarised with methods for maintaining discipline that are not only consonant with the new legal environment (amongst others, that subscribe to the Creed of Human Rights), but also responsive to the new global societal context, the main features of which will be outlined in the next section.

\section{The contribution of global and local conditions and developments to the collapse or lack of discipline in schools}

\section{The exploitation of natural resources}

After millennia of subscribing - consciously or unconsciously - to a philosophy of conquering nature and of exploiting all available natural resources as if there were no tomorrow (cf. Haggett 1971; Mortimer 2015), the ecological crisis has reached alarming proportions. The global population growth and increasing industrial activity and consumption by an ever-growing affluent global population have resulted in the unprecedented use of and pressure on the available environmental resources, and also in 
increasing amounts of waste. The world of the 21st century is experiencing an environmental crisis in the form of air pollution (of which global warming, together with droughts, floods and natural disasters, is a result), pollution of the oceans, deforestation, soil erosion and the destruction of bio-diversity (cf. Steyn \& Wolhuter 2008:16-18). The following example of depletion of freshwater resources illustrates this point. The lower reaches of the River Nile used to carry 32 billion litres of water per year. By 2006, this was down to 2 billion litres per year (Lean 2006:16).

South Africans have also been feeling the impact of this global disaster in recent years. Long spells of drought are occasionally experienced, often replaced by devastating wind and rainstorms. Such weather conditions are not conducive to school attendance, particularly in the previously disadvantaged areas where fresh drinking water is not available at the best of times, where school buildings are constructed of unfired mud bricks and hence susceptible to collapse under the onslaught of heavy rain squalls, where children have to traverse long and difficult distances to get to school and back home again without any form of transport, even in the most adverse weather conditions. All such weather conditions understandably impact negatively on order and discipline in schools, particularly in far-flung rural schools, amongst others, in the form of weak school attendance, and the improper maintenance of learning materials issued to the learners and of school buildings and other facilities.

\section{The recent population explosion and changing demographics}

Although the rate of population growth has been decreasing in recent decades, the world is experiencing a population explosion. Around 84 million people are added every year to the global population of 7.35 billion (in 2015). This amounts to 230000 every day, or three people every second (UN Data 2016). At the same time, the age profile is changing. The Global North is ageing and the population in the Global South is maturing. One out of 
every 33 people in the world today is an international migrant (International Organization for Migration 2012), compared with one out of 35 in the year 2000 (Steyn \& Wolhuter 2008:16). The number of international migrants in the world rose from 79 million in 1960 to 175 million in 2000 (Steyn \& Wolhuter 2008:16), and to 214 million in 2012 (International Organization for Migration 2012). The differential population dynamics and the abject poverty in large parts of the Global South explain why this international migration displays two tendencies, namely, a flow from the south (Africa, Latin America) to the north (Western Europe and North America), and from the east (Turkey, Eastern Europe, Asia) to the west (Western Europe and North America).

South Africa, situated at the southernmost tip of the African continent, and having one of the most robust economies in Africa (despite struggling with many of its own problems and shortcomings), has not experienced the same outflow of its population (except for the relatively small number of whites who have emigrated after the demise of apartheid in 1994). Its population has increased from around 50 million in 1994 to around 54 million in 2017. It also has to provide for the basic needs of around 2 million Zimbabwean migrants and around 1 million migrants from the rest of Africa. This population growth has exerted many pressures on the government in terms of the provision of housing, shelter, food, education, school facilities and other basic necessities. The economic slump since 2008 and a certain degree of management ineptness of the new African National Congress government have not helped to assuage the situation. During 2017, the country had been plagued by riots owing to inadequate service provision by the local and provincial governments, and schooling in the historically disadvantaged areas was regularly interrupted as a result of such community actions. Understandably, the recent population growth and influx of migrants have made huge demands on the education authorities (notably the Ministry of Basic Education and the provincial departments of education) with regard to provision of schools and teachers as needed. The problem is compounded by 
the fact that the attrition rate amongst teachers is around 34000 per annum, whereas every year only 19000 teachers graduate from the universities, the only teacher education institutions in the country. This mismatch results in the appointment of underand unqualified teachers, which is another contributing factor to the dysfunctionality of some schools, and in the two-tier school system mentioned above (the historically advantaged schools, which still possess the financial and material means to afford good teachers, amongst others, paid by parents through the school governing body, and the historically disadvantaged schools, which do not possess this ability and hence perform under par). It stands to reason that discipline will not be up to the expected standard in the latter group of schools owing to the lack of adequately trained teaching staff. In such schools, the guidance of sufficient numbers of well-qualified teachers as educators is sorely missed; the learners as educands have few role models to emulate.

\section{The rise of neoliberalism in education}

The neoliberal approach to education and schooling has gradually risen in the world since the middle of the 20th century. In terms of this approach, the social and other aspects of reality, including education and schooling, are seen through the lens of economics and business only (Adams 2006:8). It tends to view education through the lens of economic growth (Maistry 2014:7). Education itself is expected to be cost-effective (Maistry 2014:63) and provide the human power for economic growth (Welch 1998:158) and hence be technologised, commodified and saleable (Welch 1998:160). In essence, schools are seen as business corporations in which the government and parents invest in knowledge as a commodity and in the future of young people. Acculturation through education has become redefined as the acquisition of social and human capital (Rustin 2016:149), and schools are seen as institutions for the sorting and grading of the human resources that the economy might need in the future (Rustin 2016:148). The purposes of education and of schooling should be in sync with 
these views of the essence of education and of the place and role of schools in society; education has to serve the needs of the economy (Maistry 2014:60) and therefore should aid in the formation of an individual who can possess, that is, who can create personal wealth for himself or herself, with the capacity to earn and pay wherever necessary, a possessor of private property and capital, intent on making money and profit, and focussed on self-interest and enrichment, individuals who will be useful to the (national) economy (Welch 1998:165), can serve 'conservative' (i.e. neoliberal) political interests and be useful to the industrialising economy (Welch 1998:164-165). It furthermore has to provide the workforce needed for the economy (Rustin 2016:150), including a new administrative elite (Rustin 2016:149) - individuals who can compete in the open market and can effectively participate in a global economy (Adams 2006:3; Rustin 2016:150).

This approach to teaching-learning, education in a formative sense and particularly schooling, has several implications for how human beings in education (homo educandus) are seen and hence also the discipline in schools. From a tender age, children are seen and educated as competitors and clients in the world market in which corporations do their business. From a very young age, they are educated to want more than what they 'need to have'; there are many 'nice to haves' in affluent societies (shops and markets) and often their parents and carers honour children's wishes to possess even relatively useless commodities. They soon learn in schools that they have to be strongly competitive and master the secrets of entrepreneurship to be successful as well as effective and efficient in this 'world' (cf. the entrepreneurship days held in even primary schools). They begin seeing themselves as human capital and the knowledge and skills that they attain in school as resources or commodities to help them get ahead in life, and also ahead of all competition. The school prepares them for job competition in the open market and to be able to meet market needs. In brief, their school education (and also beyond the schools, in the wider community as well as in their parental homes) moulds them into homo economicus [market actors] instead of homo educandus [fully educated human beings]. 
As homo economicus, they soon learn the 'value' of individualism, entrepreneurship, competition, profit-making, consumption, utility maximisation, accountability and performance.

The neoliberal approach seems to have a threefold effect on schooling and the teaching-learning process. Neoliberalism has, firstly, in many schools infused the entire atmosphere of schooling to such an extent that schools have lost sight of their basic pedagogical or formative mission and have adopted a 'metric fetish' policy, a policy of chasing qualifications and of measuring achievement, of measuring and cataloguing, of 'measuring madness', 'governance by data, disciplining and technologies of the self, of humiliation as organising value'. In the process, schools tend to become 'data-driven systems' intent upon rating and ranking, and their work becomes based on a 'materialisation of values' (Robbins \& Kovalchuk 2012:198-203). Secondly, this lack of insight into the basic formative task of educators, of those who fail to see that the youngsters have to be guided to maturity in the fullest sense of the word, leads to reactions on the part of the learners (students). As they are not being recognised as complete human beings in their own right but rather as homo economicus-in-the-making, they become disruptive, insubordinate and disturb the peace and order that the school requires for its operations, all of which can be seen as reactions to the neoliberal character and approach, to the consumerist idealism of the school. Thirdly, the disruptive actions of learners who react in such ways to the neoliberal tendencies in and of the school elicit a zero-tolerance approach and the institution of a 'curriculum of criminalisation' on the part of the school in response to ill-discipline and antisocial behaviour by the students. In some schools, this could take the form of organised violence against the perpetrators, even to the extent of using Taser guns against them (Robbins \& Kovalchuk 2012:199, 203, 214). It could be concluded on the basis of this outline of the impact of neoliberalism on schooling and education that an ideal for the school as formulated by Rudin (1976:203) more than four decades ago has not materialised in the meantime, at least not for those schools 
that identify with a neoliberal ethos. In his (Rudin 1976:203) opinion, the young in schools will be best prepared for the future 'by a school that itself is symbolic of the healthy society and that affords authentic engagement with real events'.

\section{Science and technology: The technological revolution}

The ever-expanding frontiers of science and the exponential increase in technological innovations, information, communication and knowledge technology (ICT) in particular, and the robot revolutions are already having an impact on schools and schooling. The ICT revolution, for instance, has brought an instant 24-h planetary information network, relatively cost-effective, to learners', pupils' and students' personal computers, laptops, tablets, fax machines, blue tooth devices and mobile telephones. There are in fact currently more mobile phones than people in the world: the global population of 7.2 billion uses around 7.3 billion mobile phones (Pelser 2013:2). With around 900 million Facebookers, more than 500 million Twitterati and 2.3 billion Internet users, a global digital culture has already emerged (Joubert 2012:3). It took Twitter a mere 5 months to go from 10 billion to 20 billion tweets. The first 10 billion took 4 years (Anon 2010:4). Much of this technology is available to young people, also in the most rural areas of the world, mainly in the form mobile phones, which they carry around on their persons. These instruments and the ICT technology keep them in touch with developments in their own communities (phone calls, messages, WhatsApp), their regions (through calls, tweets, messages, WhatsApp), their own countries and also worldwide (breaking news, websites). Video clips and other bytes of information keep them abreast with occurrences in the rest of the world, including the behaviour, dress and hair styles, music preferences, teen subcultures and behaviour as well as other bits of information about what their peers are doing elsewhere in the world. The cyber society has in fact permeated every aspect of 
young people's lives (Beal 2017), as evidenced by a large-scale survey of 8- to 18-year-olds in the United States. The survey showed that $21 \%$ of all 8 - to 18 -year-olds were heavy users of media (more than $16 \mathrm{~h}$ a day), 63\% were moderate users (3-16 h a day) and $17 \%$ were light users (less than 3 h a day) (Rideout, Foehr \& Roberts 2010:2). As mentioned, access to cyber media provides information and instantaneous connection with other people, including their peers.

As far as could be established, the impact of access to all this information has not yet been determined but could be considerable, and will arguably have an effect on how young people behave in their own schools and classrooms. To mention only one possibility, youngsters who observe on television, hear on radio or receive messages on their mobile phones about how other youngsters and even entire communities in South Africa (and elsewhere) take to the streets to object to occurrences in their lifeworld now have ready-made examples to emulate in their schools, at home, on the streets and other public places when dissatisfied with a particular state of affairs. The fact that young people can base their actions on incorrect and unverified information (false news and post-truth) is a cause of concern (Oxford Living Dictionary 2017). Furthermore, there is evidence that cyber media could hamper the development of higher-order cognitive faculties, such as synthesis, analysis, deduction, inductive thinking, evaluation, explanation, critical thinking, independent thinking, critical thinking and even the development of attention span (cf. Carr 2010).

\section{Political trends: Demise of the nation state and the shifting of the locus of power in two opposite directions}

The information and communication revolution discussed above, the globalisation of economies and the downscaling of the activities of the state are all currently contributing to the erosion of the power of the state, as can be seen in South Africa where 
the government and the ruling party frequently come under attack from all sides. The decline of the nation state can also be observed in sub-nationalist (regional) clamouring for independence from a nation state such as in Catalonia (Spain) and Scotland (the United Kingdom). The locus of power is gradually shifting from central states in two opposite directions: upwards towards supranational structures (such as the European and African Unions), international structures (such as the World Bank and the International Monetary Fund, both of which have contributed to the neoliberal economic revolution discussed above, and the United Nations that has mobilised the international community behind the Millennium Development Goals), and also downwards towards subnational structures, even to the level of the individual.

\section{Religious and life-conceptual trends: The persistent presence of religion, multicultural diversity, the values revolution and the rise of the Creed of Human Rights}

Despite frequent claims that the modern age has become a postreligious secular age, it can be shown that religion remains an important factor in the lives of people and in their social dynamics. A recent survey in 230 countries found that $84 \%$ of those populations still regard themselves as belonging to some or other religious affiliation (Pew Research Center 2012). In some cases, religious convictions find expression in socially unacceptable acts such as the terrorist attack on the World Trade Centre in New York in 2001; the attack on two Mosques in Christchurch, New Zealand; and on innocent citizens in Utrecht, The Netherlands, in 2019. The increasing individualism mentioned in the previous paragraph, the rise of minority interest groups owing to population shifts and mobility, the proliferation of mass media, increased democratisation, etc. all seem to combine to generate a range of value systems, thereby replacing the traditional, often 
religious-confessional, uniform and monolithic value systems of societies that were more homogeneous in a religious and lifeconceptual sense. An example of a new trend that is currently gaining momentum amongst the extant plurality of value systems is the occidental individualistic, materialistic, consumerist, selfcentred approach to life and the world. Another trend that can be discerned is the wide acceptance of the Creed of Human Rights, acceptance of the fact that every human being is entitled to a host of inalienable human rights that are untouchable even by a democratic majority (cf. the Universal Declaration of Human Rights of the United Nations [2016]). This Declaration has subsequently been complemented by a myriad of other manifestos at international, supranational and national levels.

The de facto advent of multicultural societies since the 1980s, the empowerment of minorities and societies where diversity is valued (and no longer supressed) and protected by human rights mean that a dominant culture cannot be foisted on minorities or on individuals anymore. Individuals and small social groups have resultantly become empowered; in other words, they have succeeded in increasing their power and ability to achieve the outcomes in life that they find meaningful (Eyben 2011), thereby increasing their self-determination and personal efficacy (Boehm \& Staples 2004). In many cases, technology is employed as an instrument of empowerment, for example, to gain access to knowledge and information (Adams, Blandford \& Lunt 2005).

\section{Internationalisation and globalisation}

Most of the trends discussed so far point to the fact that globalisation has become ingrained in young peoples' lives at the end of the second decade of the 21st century. Most (young) people understand that the planet Earth is their only home and that their fate is closely intertwined with those of all the other people who share life on this planet (Torres 2015). From a very tender age, particularly if they regularly surf the Internet, watch television or interact with other youngsters in their own 
surroundings and also further afield, children begin to understand that they are part of a world community and that they have much in common with their peers across the globe. Globalism and internationalism have ironed out many of the religious, cultural and other differences amongst youngsters between the ages of 8 and 18. Seasoned travellers can attest to the fact that adolescent subcultures across the globe nowadays display much the same characteristics with regard to dress code, mannerisms, sport, music, social activities and so on. Behavioural norms are similarly shared across the globe.

\section{Discussion}

We began the discussion in this chapter with the thought that 'the future is upon us', a phrase intended to capture the notion that a multitude of trends that have been surfacing four or more decades ago have in the meantime picked up pace and have today, towards the end of the second decade of the 21st century, gained such prominence that we have to take serious cognisance of them. In our outline of these trends in this chapter, we occasionally attempted to show how these trends have been exerting pressure on education, schools and schooling, and particularly discipline - the central theme of this chapter. Our piecemeal efforts in this regard have not been satisfactory by our own standards as all the inferences that we drew from the different trends pervading the 21st-century world and lifeworlds, even combined and closely interwoven, fall dismally short of painting a complete picture of what goes on in schools in terms of learners' behaviour and the degree of (ill-)discipline they display.

A multitude of variables, including those mentioned above, seem to have an impact on the discipline of learners in schools and in classrooms:

- social, environmental-ecological, demographic (migrations and changing population patterns), technological, political, local, regional, national, international and global variables 
- various forms of diversity (culture, religion, linguistic ability) and economics

- religious pattern shifts

- life-conceptual developments and shifts

- physical facilities

- rampant individualism

- philosophical shifts (neoliberalism)

- modern transport and social mobility

- many more.

In our opinion, schools worldwide, and hence also in South Africa, have been caught up in a maelstrom of such influences that impact on them from all sides, making it difficult to paint a coherent picture of the level of discipline displayed by learners in schools.

Our discussion nevertheless allows us to make two inferences. Firstly, all the conditions discussed in this chapter seem to point to the fact that if a certain form of behaviour can be regarded as asocial or antisocial or ill-disciplined in one corner of the world, it would also be regarded as such elsewhere in the world. The diversity of value systems and the de facto possibilities of individual choices mean we should be careful enforcing a 'one-size-fits-all' set of rules and prescriptions in schools. As we, the human species, all share the same planet and are part of the same global community, we require a minimum level of social capital for peaceful coexistence. This implies that we have to work towards a common template of discipline for all schools globally when at the same time allowing as much room as possible for individuality. At the same time, we have to be innovative and devise new methods and strategies to maintain sound discipline in schools, methods and strategies, taking into account the sorry state of many of our schools as well as the new contextual societal realities of the 21st century. The second inference is that everything that we discussed in this chapter points to a conclusion that it would be difficult to do an empirical research on discipline in schools that would yield a total and sufficiently nuanced picture of the situation in schools. Small segments of the discipline problem might be isolated and operationalised (i.e. broken up into measurable 
chunks) to be able to get an empirical grasp of the problem, but the question then still remains as to whether the whole will not remain immeasurably larger than all these operationalised components of empirical studies. The entirety of the discipline problem in schools might be larger as the sum total of the parts.

The theory that we invoked as lens for examining the issue of discipline in schools, and particularly in classrooms, casts light on this problem, however. Like a prism, the social space and ethical action and function theory draws all the different impactful 'rays' that we have been discussing in this chapter together and focusses them all on the particular and unique space referred to as school classrooms. As a result of this, we could not only see modern-day classrooms as microcosms of the world 'out there' that we have contrived to describe and assess in this chapter, but we could also get a grasp of much of the problem of indiscipline in schools. In view of our first inference above, we could furthermore conclude that the only differences in discipline in classrooms in South Africa as compared with all others worldwide could be ascribed to the local conditions (e.g. physical facilities, weather conditions, socio-economic status of the community) and to the anthropological uniqueness of the participants in a given classroom (the teacher and the learners). Each and every classroom should therefore be regarded as a unique social space. In the context of this uniqueness, as the theory suggests, the interactions taking place in the space ideally should be characterised by ethical reciprocity. Put differently, teachers (as educators) and learners (as educands) should display love, care, compassion and moral imagination towards all others, irrespective of the prevailing conditions. A neglect of this guideline in the social space constituted by a classroom would amount to illdiscipline and to asocial or antisocial behaviour.

\section{Concluding remarks}

This chapter will have achieved its aim if it succeeded in demonstrating that it is indeed very difficult, if not totally 
impossible, for educators to get a full and complete grasp of discipline as an issue in classrooms. Although a multitude of variables have been mentioned and briefly touched upon, a complete picture of the issue of discipline in classrooms could not be successfully painted. The discussion has, however, shown that the problem of (weak) discipline in classrooms should be viewed as a worldwide one, with personal, local and regional dimensions as far as individual classrooms as social spaces are concerned. The discussion has also shown that weak discipline could and should be construed as the manifestation of a lack of reciprocal ethics, a failure to express loving care, compassion and moral imagination, and hence as an impediment to education defined as the forming, guiding, leading, equipping and nurturing of the learner as educand. 


\section{Chapter 2}

\section{Interactive relational dynamics as experienced by learners involved in bullying incidents in three South African secondary schools}

Ansie E. Kitching a,b

aschool of Psycho-Social Education, COMBER, Faculty of Education, North-West University, Vanderbijlpark, South Africa

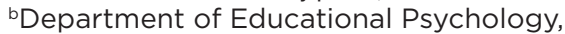
Faculty of Education, University of the Western Cape,

Cape Town, South Africa

Bianke van Rooyen

Provincial ASD Outreach Team, Western Cape Education Department, Vera School for Learners with Autism, Cape Town, South Africa

How to cite: Kitching, A.E., Van Rooyen, B. \& McDonald, Z., 2019, 'Interactive relational dynamics as experienced by learners involved in bullying incidents in three South African secondary schools', in C.B. Zulu, I.J. Oosthuizen \& C.C. Wolhuter (eds.), A scholarly inquiry into disciplinary practices in educational institutions (NWU Education and Human Rights in Diversity Series Volume 2), pp. 27-44, AOSIS, Cape Town. https://doi.org/10.4102/aosis.2019.BK157.02 


\section{Abstract}

Schools, as critically important social contexts, should focus on the relational dimension if they intend to address the prevailing problems with bullying behaviour and the challenge that this behaviour poses to the maintenance of discipline in these schools. Research conducted on bullying behaviour in the South African context to date mainly focusses on individuals who are involved in bullying behaviour either as victims, bullies or bystanders. The purpose of this chapter is to facilitate a shift from an individualist to a relational perspective on addressing bullying behaviour as part of maintaining discipline in secondary schools. The aim of the research was to gain a deeper understanding of learners' experiences of interactive relational dynamics in three secondary schools where bullying behaviour is evident. A qualitative phenomenological research design was applied to explore the experiences of 33 learners in three secondary schools in South Africa where bullying behaviour was regularly reported. The findings indicate that the interactive relational dynamics encompasses a dysfunctional reciprocal display of power, competitiveness, a lack of care, exclusion and an incompetence to deal with conflict across all levels of relatedness. The research contributes to an understanding of the relational dimension of maintaining discipline in secondary school contexts in South Africa.

\section{Introduction}

The increase in bullying behaviour in schools has been studied extensively both locally and globally (Burton \& Leoschut 2013:4; Ncontsa \& Shumba 2013:2; Pepler \& Craig 2007:2-3). The concern is that instead of being safe and enabling spaces, schools have become places where learners are at an increasing risk of being 
exposed to various forms of bullying behaviour (Lazarus, Khan \& Johnson 2012:134-135).

The construct 'bullying' was developed by Olweus (1993:8-9). He defined bullying as interactions during which a dominant individual acts in an aggressive manner towards a less dominant individual with the intention of causing distress to the latter. The individuals in such interactions are labelled as bullies and victims, and those who witness the interactions are referred to as bystanders. Menesini and Salmivalli (2017:240) identified three criteria that are relevant for defining aggressive behaviour as bullying, namely, repetition, intentionality and an imbalance of power. These interactions can take various forms. The two main categories are direct bullying and indirect bullying. Direct bullying refers to incidents where harm is directly aimed towards the victim and involves hitting, pushing, spitting, shoving or taking the victim's belongings (Lee 2004:9). Indirect bullying refers to harm indirectly aimed towards the victim either verbally or non-verbally (Sullivan, Cleary \& Sullivan 2004:5). Three forms of indirect bullying are identified in the research literature, namely, verbal bullying, non-verbal bullying and cyberbullying. Verbal bullying includes behaviour such as teasing, threatening with violence and intimidation.

Non-verbal bullying includes damaging the property of others, making rude gestures, making mean face, spreading rumours, gossiping and deliberate exclusion or withholding of friendships (Swart \& Bredekamp 2009:407). Another form of indirect bullying is 'cyberbullying' (Tustin \& Zulu 2012:1). This form of bullying can include phone calls, text messages, emails with an abusive tone or insults or threats posted on social media. Hymel and Swearer (2015:295) state that although physical and cyberbullying are the greatest concern, verbal bullying, also referred to as social bullying, is the more common form of bullying experienced in school contexts.

In the South African context, an alarming number of bullying incidents occur in school contexts. In a study by Tustin and Zulu (2012:1), 3 out of 10 learners reported that they had been bullied. A national study conducted on violence in schools in 2013 included bullying. The authors argue that although bullying does not 
constitute violence per se, it can cause serious psychological, emotional and/or physical damage (Burton \& Leoschut 2013:2). We therefore need to obtain a more in-depth understanding of what might underpin bullying behaviour to ensure that we can urgently address the impact of this phenomenon in a more efficient manner.

In this chapter, we present research conducted to explore interactive relational dynamics associated with bullying behaviour in three secondary school communities in South Africa. The research was conducted by the second author as part of a master's study. The study formed part of a series of master's studies aimed at exploring possible strategies to facilitate relational well-being in South African schools. The first and third authors supervised and co-supervised the study, respectively.

\section{Problem statement}

Concerns about the impact of bullying behaviour in South African schools have been highlighted in the literature. These concerns include the threat to the safety of children (Rossouw \& Stewart 2008) as well as the impact on the psycho-social well-being of students, and the overall culture and climate of schools (Juan et al. 2018). The strategies that have been developed to address bullying in the South African context mainly focus on controlling the behaviour of the bullies and protecting the victim and the bystander. The rationale is that bullies are perceived as impulsive, domineering, indifferent and aggressive (Greeff \& Grobler 2008:141; Kruger 2010:4), whereas victims are seen as weak and vulnerable with a low self-esteem and therefore easy targets (Neser et al. 2004:84; Parsons 2005:14). On the basis of these perceptions, bullies are punished in accordance with rules and procedures developed to maintain discipline (Venter \& Du Plessis 2012:6). This punitive approach to bullying emphasises the problem behaviour of the individuals rather than the interactive relational dynamics within the contexts in which the behaviour occurs. Kitching, Roos and Ferreira (2012:196) concur that a punitive approach is aimed at the identification of specific causes of the behaviour, which can be controlled according to a set of 
rules and regulations that do not necessarily consider the interactive relational dynamics.

The systemic developmental model developed by Pepler and Craig (2007:3) challenges the punitive approach that is informed by traditional linear causal models applied to explain human behaviour. The systematic developmental model applies a binocular perspective to obtain a deeper understanding of bullying behaviour. The application of a binocular perspective shifts the focus from the individuals to the relationships that exist between them, the interactions between them and the context within which the interactions occur (Craig, Pepler \& Atlas 2000:23; Swearer \& Doll 2001:42). Informed by a complexity theory perspective, Kitching et al. (2012:196) concur that the focus should rather be on relationships than on the behaviour of individuals if we intend to find solutions to bullying behaviour.

The relational dimension of bullying behaviour has been emphasised in international research, but research within the South African school context does not sufficiently address the role of interactive relational dynamics between the members of school communities in which bullying behaviour occurs. Myburgh and Poggenpoel (2009:457) refer to relationships as an important aspect in understanding violence in schools, but they do not investigate the interactive relational dynamics associated with the behaviour. A study conducted by Botha (2014) refers to key terms such as 'power' and 'control' as aspects that are related to the interactive relational dynamics between children. However, the main focus of the study is on the factors contributing towards the phenomenon of bullying rather than on the interactive relational dynamics involved. Future strategies suggested by these authors are mainly aimed at the improvement of individual skills and not on the relationships across the various levels of interrelatedness.

In the research presented in this chapter, we addressed this knowledge gap by exploring the relational experiences of leaners in secondary school contexts where bullying behaviour occurs. The aim of sharing the knowledge we gained is to contribute to the quest for strategies to address bullying behaviour as an 
essential part of enhancing discipline in schools. We specifically report on how learners who were involved in bullying in three secondary schools in South Africa experienced the interactive relational dynamics across the various levels of interrelatedness within school contexts.

\section{Theoretical framework}

The theoretical framework of this research comprises a combination of the holistic well-being perspective (Evans \& Prilleltensky 2007), the systemic developmental model (Atlas \& Pepler 1998:86) and complex responsive processes of relating theory (Stacey 2001; Shaw, 2002).

Nelson and Prilleltensky (2010) emphasise that well-being does not merely refer to the health and welfare of individuals. The promotion of well-being should focus on individual, relational and collective levels of being together in a particular context, that is, holistic in nature. Bullying behaviour poses a threat to the enhancement of holistic well-being on all three levels. Efforts to address bullying behaviour in schools should therefore not be limited to the development of individual skills, but should also engage with the relational and collective dimensions of wellbeing.

The systemic developmental model of Atlas and Pepler (1998:86) conceptualises bullying behaviour as a dynamic, nonlinear process that involves various interactions with different agents within a system. The variables identified as key to this model can be applied to analyse the individual characteristics of the bully and the victim, the way in which bullies and victims interact, the power imbalance derived from individual characteristics such as size or strength of the support from others such as onlookers who reinforce the bullying behaviour as well as the interactions with other agents within a system such as teachers and other peers. The model also allows for the integration of individual factors, inter-individual interaction, social relations 
and cultural and ecological conditions that might possibly contribute towards the development of bullying behaviour in children.

Schools, when viewed through the lens of complex responsive processes of relating theory (Stacey 2003, 2007a, 2007b), are complex interactive dynamic systems within which all the members continuously engage in the interactive processes that take place between them on a daily basis (Burr 1995:3). Human behaviour, including bullying behaviour, should hence be understood in terms of the web of relational interconnectedness and not as individual acts of the unconscious mind (Gergen 2009; Josselson 1996:1; Stacey 2001:55). In this web of interconnectedness, people continuously act in ways that evoke and provoke responses from each other and, in the process, patterns of being together develop in emergent, self-organising ways (Morrison 2002). The influences of the interaction between people are central to their responses and not the information that they share. When information is exchanged on a reciprocal basis, an ongoing process of influence between the two persons takes place, which involves the strength of the influence and the experience of each person in the interactions between them. Therefore, in the context of bullying, it is the strength of the influence of the interactions that will contribute towards the kind and the quality of the relationship experienced by both, rather than the information that is shared between them (Jörg 2004:133).

\section{a Contextualising the research}

The research was conducted in three secondary schools in a semi-urban area in the Western Cape. The learners' home languages include English, Afrikaans and isiXhosa. Instruction in these schools is given in both English and Afrikaans. The schools have limited infrastructure. Classrooms are not well-equipped, access to computers is limited and playgrounds are not effectively developed. The schools also provide limited access to afterschool activities owing to infrastructural restraints. The problems 
in infrastructure cannot be addressed by the school owing to their inability to charge additional school fees to augment the basic government funding that these schools receive, as many parents cannot afford the school fees. A concern about bullying behaviour in these contexts was reported during conversations with the principals and staff members as part of a community engagement project.

\section{Research design and methodology}

A qualitative, phenomenological research design was applied in this study. Phenomenological research focusses on the lived experiences of individuals as well as the meaning they attach to their experiences (Giorgi \& Giorgi 2003:27-28). The participants included 33 learners from Grade 8 to Grade 11. The participants were purposively selected based on their involvement in bullying incidents, either as persons accused of bullying, persons identified as victims or as persons identified as bystanders in the previous school year.

Data were collected in two phases. In phase one, participants were asked to complete a written assignment. The assignment comprised two sections. In section one, they had to respond to the question: 'write an essay in which you tell about a bullying incident in school in which you were involved either as the person who instigated a conflict situation, the person referred to as a victim or as a witness of an incident where bullying took place'.

Section two included 20 incomplete sentences that were openended to allow the participants to present their own interpretations of particular situations from a relational perspective.

In phase two, semi-structured interviews were conducted with six participants. The aim of the interviews was to obtain a more in-depth understanding of their relational experiences. The participants for this phase were selected with the aim of giving voice to all three positions in bullying incidents, namely, that of 
bully, victim or bystander. They were purposively selected based on the written assignments. It is important to note that the researcher did not refer to these positions during the interviews. The data obtained in the two phases were analysed thematically by reading and re-reading the data, followed by the generation of codes for the identification of themes and subthemes (Braun \& Clarke 2006:16).

Trustworthiness was enhanced through the use of a variety of data collection methods, the inclusion of learner voices representing the positions of the bully, the victim and the bystander in bullying incidents, as well as in-depth and detailed descriptions of the research context, methods and the research findings (Tracy 2010).

Ethical clearance for the research was given by North-West University (NWU-00060-12-A), and the Western Cape Education Department granted permission for the research. Senior staff identified prospective participants based on the information that they had on incidents that took place over a one-year period prior to the study. They were asked to refrain from labelling these learners as bullies, victims or bystanders. Parents or carers signed permission for the learners to participate; the learners also signed assent forms. The participants were protected against possible harm by refraining from reference to specific incidents. The sharing of data was limited to ensure confidentiality. Pseudonyms were used to protect the identity of the schools and the participants. Counsellors were identified to assist learners who needed support owing to the recalling of incidents.

\section{Dresenting the findings}

The findings of the study are presented with reference to:

1. interactive patterns evident in teacher-learner interactions

2. interactive patterns evident in learner-learner interactions

3. interactive patterns evident in the context of conflict. 


\section{Interactive patterns in the teacher-learner relationships}

The participants reported the following tendencies with reference to their experiences of teacher-learner interaction.

Firstly, teachers tended to become nasty when arguments arose between learners and teachers. The expected response from the teacher would be to try and defuse the situation. However, as evident in the statement below, a teacher insulted a learner, which led to a further conflict:

I had an argument with a teacher. He spoke about my age, I failed a year and he told me I could leave school, school was of no use to me, he made me angry and I wanted to hit him, but I left it. He cursed me and I walked out of the classroom. (Participant interview 4, location unknown, date unknown)

Secondly, teachers behaved incongruently by treating some learners more favourably than others. The participants ascribed the teachers' incongruent behaviour to their mood, their familiarity with parents of the learners, learners' appearances and academic performance, as evident in the statements below:

Say, for example, if the teacher is in a good mood and a learner asks permission to go to the toilet, he will be allowed to do so, but if another child asks, then the teacher will say 'no', if the teacher is in a grumpy mood.

I think that learners whose parents are friends with the teacher are benefited because the teacher is not going to know me that much, and he is also not going to make more effort to get to know me because I am just another number, I am just someone in school.

They sometimes just look at how you are physically built or at your physical characteristics, such as having long hair.

If a child performs badly with work ... you also get those teachers who will say you are just a number. (Participant interview 2, location unknown, date unknown)

Thirdly, some teachers tend to exercise a strict control and power over learners. These teachers expect obedience and when 
classroom rules are not obeyed, the teachers often apply punitive measures to control behaviour:

Teachers yell at you [...] That is how they show you that they have power over you because they are the parent at school and they expect you to be obedient, because they do their work and their work is to educate you and they can't educate you if there is no respect. (Participant interview 1, location unknown, date unknown)

Fourthly, teachers tend to display a lack of interest in children:

You also get those teachers who will say you are just a number, in case you do something, they are not even going to try and help you because they are almost like: 'I'm giving you work, you are not doing it, you are not attentive in class, so I am not going to do anything further. You are on your own'. (Participant interview 3, location unknown, date unknown)

\section{Interactive patterns in the learner-learner relationships}

The participants reported the following tendencies with reference to their experiences of learner-learner interactions.

Firstly, learners tend to assert power over one another as a means to obtain a higher status. One participant stated:

It almost works like this: the ruder you are or the more guts you have to do something to another person or take something from someone, the more influence you have. The more things you do that are considered wrong, the more likely you are to become the leader of the group. That is how it works. The other boys work under the leader because the leader is like the 'general' of the group. He has the most guts and power to take things from others and [They] don't think much of the learners they bully. They feel strong when they bully them because that is when they feel in control. (Participant questionnaire 28 , location unknown, date unknown)

Bad behaviour included continuous rudeness towards one another, having a 'macho' attitude so that others will become increasingly fearful, engaging in physical fights in public places and targeting younger and smaller children. 
Secondly, learners tend to exclude peers who are not part of or associated with the coo/ group:

If you don't belong to a particular group, the others won't care about your existence. It is almost like they don't even see you because you are not part of this group and then you are probably a misfit. You belong nowhere, so you are on your own. (Participant interview 3 , location unknown, date unknown)

Participants in the study emphasised that children who usually bully others tend to form part of the cool group:

The cool group is usually the ones who start it all. So most of the time we think that it is only the rude children that do it, but actually any child is capable to bully others. Like the cool group. They are THE group; they just want everybody to follow them. They want to make the decisions: you do this for me and if you don't want to do it, I'm going to show you what will happen; they threaten the children. (Participant interview 5, location unknown, date unknown)

Thirdly, various groups in the school tend to compete to determine which group is the strongest and hence the coolest:

For example, there might be two 'cool' groups, and they might want to compete against each other in touch rugby, soccer or cricket, so if there is a fight they will see or compete which of the two groups is the strongest. (Participant interview 2, location unknown, date unknown)

Fourthly, participants experienced that friends tend to violate the trust of one another by disclosing secrets to other peers, gossiping and spreading rumours. Essentially, learners do not know who they can and cannot trust:

$[B]$ ecause you never know who is trustworthy and therefore you don't know who you can talk to. Your best friend can be friends with your worst enemy and gossip to them, so there is not much trust amongst the children. (Participant interview 3, location unknown, date unknown)

\section{Interactive patterns in the context of conflict}

The participants reported that children often instigate conflict. One participant stated:

Everybody will be relaxed and then one learner might say: 'hear this, did you hear what this man said about your mother'; or 'hear what 
he is saying, he says you are queer'. See, so then you get offended and stand up and ask this guy what he said and he then says that he did not say it, then the one who started it, says 'yes he did say it' and then the fight starts. (Participant interview 3, location unknown, date unknown)

Once the fight starts, the conflict becomes a form of entertainment. The following brief excerpts from the data sets support this argument:

$[E]$ verybody runs to come and see and screams. They take videos and send it around to everyone so that children's self-image can be broken down. (Participant questionnaire 12, location unknown, date unknown)

Some children find it pleasurable, they will laugh. Most of the time they get pleasure from it. (Participant interview 5, location unknown, date unknown)

It is normal, no one cares about the other. (Participant questionnaire 15 , location unknown, date unknown)

Children laugh because they think it is funny. (Participant questionnaire 20, location unknown, date unknown)

Bystanders would often instigate conflict by spreading rumours, by cheering, screaming, taking videos, laughing or even joining in the fight.

In these conflict situations, teachers tend to display apathy and seemingly do not consider dealing with conflict as part of their duty:

Some teachers, when you tell them what has happened during break time, they might respond, saying something like: 'I'm not the police or the principal'. (Participant interview 1, location unknown, date unknown)

Consequently, children become apprehensive about reporting bullying incidents, seeing that nothing is done about it.

The participants also reported disputes between parents and teachers as evident in the following statement:

Parents and teachers disagree to a great extent. They yell at each other because if a learner does something he is not supposed to do, the teacher 
phones the parents and it becomes a thing. (Participant questionnaire 19, location unknown, date unknown; Participant questionnaire 8, location unknown, date unknown; Participant interview 5, location unknown, date unknown)

The blaming seems to be reciprocal as teachers tend to blame parents (or carers) for not disciplining their children, whereas parents stated that teachers are not doing their job properly. Parents who deny their child's role in conflict situations also aggravate the blaming by teachers:

If children violate the rules and parents have to come to school then it seems that parents want to fight with the teachers because their child is never wrong. (Participant questionnaire 11, location unknown, date unknown; Participant interview 3, location unknown, date unknown)

\section{Discussion of the findings}

The interactive patterns as reported by the participants in this study suggest that dysfunctional interactive relational dynamics is present across all levels of interrelatedness, that is between teachers and learners, amongst learners and between teachers and parents.

Regarding the teacher-learner interactions, participants reported reciprocal, rude and dismissive behaviour. Learners reportedly swear at the teachers and walk out of the classroom without permission during lessons, and teachers insult learners, swear at them or threaten to hit them. The dysfunctional interactive relational dynamics in these instances encompass a continuing cycle of reciprocal revenge in which learners act disrespectfully, and teachers retaliate with the same disrespect. Teachers' attempts to maintain control over their learners from an authoritarian position rather than through positive, healthy relationships with the children also contributed to the dysfunctional relational dynamics. Burton and Leoschut (2013:4) warn that the use of rude punitive measures to address disobedience might convey the 
message that it is acceptable to use force (physical or emotional) to deal with particular situations.

Favouritism as a form of discrimination against some learners was evident. A study by Aydogan (2008:164) concurs with the findings of this study that learners are treated more positively in instances where they are physically attractive and teachers know their parent(s) or carers. Teachers also do not seem to care much about learners. McDowell (2011:146, 155) suggests that when learners experience teachers as non-caring, learners tend to become more passive and have limited motivation to build positive relationships with teachers. Brown (2005:12-13) warns that incongruent interactions between teachers and their students can influence the quality of the relationship and enhance negative feelings between the teacher and the learner.

Regarding the interaction patterns between learners, the findings indicate that swearing at each other, insulting each other, degrading each other and engaging in physical fights had become part of daily interactions between learners. These dysfunctional ways of interacting might have become the norm rather than the exception in these schools. Being rude and aggressive seemingly provides a safe space for learners, as it indicates that they are strong and untouchable. If they refrain from being rude, learners often become an easy target for bullies. A serious concern is that, as being rude has become the norm, most learners tend to act rudely or even pretend to be rude in certain situations for fear of becoming victims of bullying. Learners are also very apprehensive about reporting bullying because they are likely to become targets of bullying if they do so. To stay away from harm, they remain silent. However, by being silent, they actually become powerless.

Another astounding pattern is the way in which various groups in the schools compete against each other as a means to gain status. Groups perceived as popular constantly challenge each other to either maintain their status or obtain a higher status. Closson (2009:410) also observed these competitive 
interactions between learners and groups of learners and expressed concern about the impact thereof in the relationships between learners.

Fighting with each other, particularly in public, has become a way to demonstrate how cool they are, as the group who 'wins' the fight is perceived as the strongest and therefore gains a higher status. A concern is that the need to be perceived as cool and popular (i.e. powerful) seems to outweigh the need for healthy and supportive friendships, as also found by Merten (2004:362). This is demonstrated by the violation of trust between friends. Learners gossip and disclose their friends' secrets to safeguard their position in the more powerful groups.

The fact that fighting, instigated by a conflict, is considered as entertaining presents a serious concern, as it confirms that bullying behaviour has become part of the everyday interactive relational dynamics in these school contexts. Kerbs and Jolley (2007:21) found that bystanders of bullying behaviour often find such incidents exciting and entertaining. The involvement of learners who are not even interested for fear for becoming victims themselves is indicative of the serious nature of the dysfunctional relational dynamics.

The findings regarding teacher's apathy in these conflict situations concur with the findings of a study by De Wet (2007:202) that teachers ignored bullying incidents. Joyce (2013:254) also reported that principals and teachers either ignored or dismissed the reporting of incidents where a conflict between children is involved.

The parent-teacher disagreements in contexts of conflicts indicate the absence of a shared understanding regarding ways to resolve conflicts. Instead of collaborating to solve the problems, they assert power in a dysfunctional manner by blaming each other for children's misbehaviour. Evidently, both teachers and parents appear to be more concerned about the positions they hold than about finding appropriate ways to resolve conflict between children. 
The findings suggest that the interactive relational dynamics in these contexts are characterised by dysfunctional power struggles across all levels of interrelatedness. Power defined as actions that induce others to act in a particular manner is present in all relationships (Foucault 1982). However, when power is used in a dysfunctional manner, it might facilitate a space in which bullying can thrive.

The evidence in this study indicates the concurrent presence of various power struggles. For example, teachers favoured certain learners that led to other learners feeling excluded. Learners formed groups and excluded others based on their group membership to avoid compromising their perceived social status. As learners do not know whom to trust, they tend to engage in a behaviour that creates a distance between them and the others, rather than developing strong connections. A power struggle between parents and teachers was also evident as they blamed each other for learners' behaviour. Parents blamed the teachers for not doing their job properly, and teachers blamed parents for not appropriately disciplining their children at home. In the event of such power struggles between adults, learners tend to emulate the adults in conflicts with their peers. In the absence of deep care and connectedness between learners, teachers and parents, learners who are perceived as popular and admirable by both teachers and peers seem to take over the social power.

The current state of affairs undermines the development of positive connections between teachers, learners and parents and creates a fertile ground for bullying behaviour. Any effort to address bullying behaviour should therefore address the dysfunctional power struggles that underpin the disenabling relational dynamics. We can no longer apply only the individualist and punitive approaches that evidently do not resolve the problem of bullying in schools. The implication is that policies focussed on the control of bullying behaviour should be adapted to accommodate the complex nature of human interactions that cannot be controlled (Stacey 2003). Teachers should be equipped 
to understand how the interactive relational dynamics associated with dysfunctional power emerges and contributes to bullying behaviour to maintain discipline in a more efficient manner.

\section{Conclusion}

In view of the findings of this study, we recommend that in seeking solutions to eliminate bullying behaviour in schools we should focus on the development of positive and healthy interactive relational dynamics between teachers, learners and parents. This can be achieved by facilitating open and spontaneous conversations across all levels of interrelatedness. By engaging in these conversational processes, school communities will gain a deeper understanding of the relational patterns that contribute towards nurturing or restraining of relationships in their contexts. Concurrently, the focus of our research on bullying behaviour should apply a complex interactive, relational dynamic perspective rather than a positivist perspective aimed at identifying and addressing the causes in a linear manner.

\section{Acknowledgements}

This chapter stems from B. Van Rooyen's dissertation, entitled 'Relational experiences of children involved in bullying incidents in secondary school communities', presented in fulfilment of the requirements for the degree of Magister Artium in Psychology at the Potchefstroom Campus of North-West University, South Africa. 


\section{Chapter 3}

\section{Teachers' and learners' perceptions of alternatives to corporal punishment: A human rights perspective}

Michael L. Marumo School of Commerce and Social Studies in Education, Faculty of Education, North-West University, Mafikeng, South Africa

Connie B. Zulu School of Professional Studies in Education, Educational Management, Faculty of Education, North-West University,

Mafikeng, South Africa

\section{Abstract}

Maintaining good learner discipline continues to be a battle in many schools amidst debates around the human rights of learners and the effectiveness of current systems of learner discipline.

How to cite: Marumo, M.L. \& Zulu, C.B., 2019, 'Teachers' and learners' perceptions of alternatives to corporal punishment: A human rights perspective', in C.B. Zulu, I.J. Oosthuizen \& C.C. Wolhuter (eds.), A scholarly inquiry into disciplinary practices in educational institutions (NWU Education and Human Rights in Diversity Series Volume 2), pp. 45-66, AOSIS, Cape Town. https://doi.org/10.4102/aosis.2019.BK157.03 
The purpose of this study was to investigate teachers' and learners' perceptions of alternatives to corporal punishment in Mahikeng Township secondary schools of the North-West province in South Africa. A qualitative research design based on the social constructivist or interpretive paradigm was adopted in this study. Teachers who had been in the field before the official banning of corporal punishment were purposefully selected from four schools. Grade 11 and 12 learners were also purposefully sampled on the basis of their 'maturity' as senior learners who had been in the school long enough to experience the new, alternative disciplinary measures. Data were collected through focus group interviews, four with educators and four with learners, and thereafter subjected to qualitative data analysis procedures. The findings showed conflicting perceptions. Although some teachers and learners felt that alternative forms of discipline were effective to a certain extent, the general perception was one of scepticism. Both teachers and learners expressed the need for a return to corporal punishment in cases of serious misconduct. Some learners applauded the introduction of alternative forms of discipline only because this system replaced what was considered to be an abusive system of corporal punishment. Although teachers attributed their negative perceptions to a lack of adequate training in the implementation of alternative forms of discipline, continuous repetition by learners of the same offences for which they had been 'positively' disciplined resulted in learners' negative perceptions. The main recommendation is that follow-up training and workshops on alternative forms of discipline should be regularly held for teachers to develop confidence in the use of these strategies and to improve perceptions.

\section{Introduction and background}

Maintaining order and good learner discipline in schools continues to be a problem in schools the world over, and debates surrounding the effectiveness of prevailing systems of learner 
discipline rage on. Very few studies have been conducted in South Africa to determine the effectiveness or success of alternatives to corporal punishment (ATCP) in schools or whether teachers are still using the South African Department of Education's (2000) ATCP disciplinary measures (Moyo, Khewu \& Bayaga 2014:3).

Moreover, in South Africa, differing perceptions exist on the effectiveness of the current system of discipline known as ATCP in the classroom (Department of Education 2000). In the year 2000, ATCP were introduced in schools following the outlawing of corporal punishment by legislation, namely, the South African Schools Act 84 of 1996 (Republic of South Africa 1996b) and Abolition of Corporal Punishment Act 33 of 1997. The South African Schools Act (Republic of South Africa 1996b) prohibits corporal punishment in Subsection 1 of Section 10, which states that, 'no person shall administer corporal punishment to a learner at a school'.

Corporal punishment is defined by the South African Department of Education (2000) as:

$[A]$ ny deliberate act against a child that inflicts pain or physical discomfort to punish or contain him/her. This includes, but is not limited to, spanking, slapping, pinching, paddling or hitting a child with a hand or with an object; denying or restricting a child's use of the toilet; denying meals, drink, heat and shelter, pushing or pulling a child with force, forcing the child to do exercise. (p. 6)

Alternatives to corporal punishment are disciplinary measures that can be used to maintain discipline in schools without inflicting pain on learners, and these may include alternatives such as verbal warning, demerits, written warnings, disciplinary talks, suspension from school, to mention a few (Department of Education 2000). As a measure to ensure fairness when applying the alternatives, the alternatives are divided into different levels ranging from level 1, which is the level for minor offences, up to level 5, for serious offences, with each level having specific disciplinary measures attached to it (Department of Education 2000). 
The rights of all living beings to a respectful and dignified treatment are enshrined in the Constitution of the Republic of South Africa (1996a) (Act 108 of 1996) under Sections 10 and $121(e)$, respectively:

Everyone has inherent dignity and the right to have their dignity protected and respected' and 'everyone has the right to freedom and security of the person', which includes the right 'not to be treated or punished in a cruel, inhuman or degrading way.

This constitutional right is in turn endorsed by the South African Human Rights Commission in its citation of Clause 139 (2) of the Children's Act Amendment Bill, 'no child may be subjected to corporal punishment or be punished in a cruel, inhuman or degrading way' (South African Human Rights Commission 2007). Children are protected by law from violence and exploitation as provided for in Section 28 1(d) of the Bill of Rights, 'every child has the right to be protected from maltreatment, neglect, abuse or degradation' (Republic of South Africa 1996a).

Hence, the development and implementation of ATCP were necessary to ensure 'the removal of corporal punishment and the elimination of other dehumanising practices in our schools [...] [as] [...] necessary steps towards the development of a culture of human rights [...]' in South Africa (Department of Education 2000). The recognition and upholding of human rights should be the foundation upon which decisions about disciplinary measures are taken. Following the implementation of ATCP, teachers were urged to adopt non-violent, constructive and positive disciplinary measures such as time-out, withdrawal of privileges and supportive methods (Department of Education 2000). Although many teachers are not in favour of ATCP, there are some teachers who use them in their schools to discipline learners (Marumo 2015:85). According to Dufrense et al. (2010:23), the most frequently used alternative measures were verbal warnings, giving learners extra work, calling parents, detaining learners during break, time-out, extra classes, community service, prohibition rules and modelling. 


\section{Discipline and the implementation of alternatives to corporal punishment}

A continuous decline in the level of discipline has been evident since corporal punishment was banned and replaced by ATCP (Ntuli \& Machaisa 2014:1781). According to Ntuli and Machaisa, the decline in discipline levels is attributed to a lack of thorough knowledge and information on how to implement ATCP. The Department of Education was largely blamed for not adequately training teachers on the use of these alternatives. A study by Lwo and Yuan (2011:157) showed that teachers are still finding it hard to manoeuvre between corporal punishment and ATCP. They also fail to distinguish between punitive and non-punitive disciplinary measures, indicating that the distinction between punishment and discipline is still blurred in the minds of teachers. This blurring of the distinction between the two terms contributes to the manner in which teachers discipline learners. Teachers feel helpless and powerless in the absence of corporal punishment (Mtshweni 2008 in Kalipa 2015:12). Studies such as those of Motseke (2010:130) and Morell (2001:292) have shown that even though corporal punishment was officially banned in South Africa in 1996 and the ATCP measures were introduced in the year 2000, corporal punishment is still being used in South African schools. This could mean that the alternatives have not been entirely successful in maintaining discipline in many schools. Some of the reasons for this perceived lack of success may be attributed to teachers' complaints regarding the time-consuming nature of implementing the alternatives, that the measures are ineffective in maintaining discipline, that there is non-compliance by the learners and that the teachers do not have the necessary skills to implement them effectively (Marumo 2015:88; Ntuli \& Machaisa 2014:1788).

Discipline in general, and classroom discipline in particular, is necessary to ensure that both private and public schools function effectively (Segalo \& Rambuda 2018:1). It plays a crucial role in the maintenance of a proper teaching and learning environment 
(Motseke, in Marumo 2015:18). Discipline is very important in education as it is the key instrument that ensures that there is order in the whole process of teaching and learning (Mulaudzi \& Mudzielwana 2016:7519). Without good discipline, there can be no conducive teaching and learning environment in schools. The claim, therefore, that discipline levels dropped in South African schools after the introduction of ATCP is a cause for concern as it implies a deterioration in teaching and learning in schools.

In the United States, debates about corporal punishment continue, as there are states that still use it as a disciplinary measure, whereas some states have abolished it and are in support of ATCP. Similarly, in African countries, such as Kenya, even though corporal punishment has been banned, there are some teachers that use it (Mwenda 2016:232). In Israel, a study conducted by Kassabri and Harush (2012:275) showed that teachers use both punitive and non-punitive measures when disciplining learners because they neither have the knowledge nor the skills to effectively implement alternative measures to discipline learners. The same problem is experienced in Sudan where despite the teachers knowing about the official ban of corporal punishment and the negative effects of corporal punishment on learner behaviour, they still fail to use the available ATCP measures as they prefer corporal punishment when disciplining learners (Elbla 2012:1662). Learners, however, are totally opposed to the use of corporal punishment, as it develops in them an element of fear, low self-esteem and lack of motivation to learn (Elbla 2012:1661). Corporal punishment tends to have short-term rather than long-term behaviour modification effects. As Elbla (2012:1657) points out, learners may display good behaviour in the presence of a teacher who has disciplined them, but fail to display prolonged disciplined behaviour in the absence of the teacher.

According to Burke and Sutherland (2014:62), in Jamaica, corporal punishment is viewed as the rightful, culturally and biblically correct way to discipline learners. However, it is also important to note that one key point emphasised by Burke and 
Sutherland in their study is that there are still debates about appropriate disciplinary measures, as it is believed by some that ATCP measures are a preferable form of discipline as they discourage violence amongst the children.

In India, even though corporal punishment has been officially banned, various forms of corporal punishment are still being used. According to Cheruvalath and Tripathi (2015:131), although some teachers are in favour of corporal punishment, teachers in private schools are able to manage learner behaviour through ATCP.

The problem of successfully implementing ATCP measures is also experienced in countries such as Taiwan where teachers have encountered serious problems of maintaining discipline since the banning of corporal punishment. Therefore, teachers have resorted to using corporal punishment, and this has resulted in some of them being prosecuted. Other teachers have resigned owing to pressure from learners' parents (Lwo \& Yuan 2011:7). Even though parents in Taiwan are not happy with the use of corporal punishment to discipline learners, Kindiki (2015:72) maintains that both teachers and parents in Kenya are not in favour of the abolishment of corporal punishment. The basis for their argument is that after the banning of corporal punishment, ATCP provided were insufficient. As a result, both teachers and parents developed a negative attitude towards this policy. In Zimbabwe, permission must be granted by the school head for a teacher to discipline learners by using corporal punishment. Teachers, however, often punish learners without the headmaster's permission (Shumba, Ndofirepi \& Musengi 2012:285).

In South Africa, ATCP measures were introduced in schools several years ago, but teachers are still finding it hard to maintain discipline by using these (Marais \& Meier 2010:41).

Problems encountered in connection with the implementation of ATCP internationally are also experienced in South Africa. The main reason cited for the problem of implementation is insufficient training. As a result, some teachers still firmly believe in the use 
of corporal punishment to discipline learners, whereas some rely on ATCP (Motseke 2010:130). Other research findings also show that many teachers have not been trained on how to effectively discipline learners through the use of ATCP (Busienei 2012:158; Mulaudzi \& Mudzielwana 2016:7522). They still support corporal punishment and still use it as a disciplinary measure. Some teachers are also under the impression that 'discipline' and 'punishment' mean the same. As a result, they tend to punish learners instead of 'disciplining' them (Joubert \& Serakwane 2009:120; Maphosa \& Mammen 2011:220).

Teachers are key implementers of policy and they are the key role-players when it comes to maintaining discipline in schools. Teachers also play an important role in developing schools' policies, classroom rules with learners and handling of administrative matters related to discipline amongst others (Ntuli \& Machaisa 2014:1784). Therefore, inadequate consultation with teachers on ATCP may have contributed to challenges of implementation currently being experienced in schools.

Alternative forms of learner discipline are in essence nonpunitive forms of discipline premised on the idea of positive behaviour management or Positive Discipline (PD). The study on the perceptions of teachers and learners regarding ATCP is based on the assumption that after more than 20 years of the banning of corporal punishment in South Africa, and the introduction of alternative forms of discipline, there would be certain perceptions regarding its implementation and use from those directly affected by it, namely, teachers and learners.

\section{Droblem statement}

Maintaining positive learner behaviour in schools without infringing upon learners' rights to 'respect and human dignity' calls for positive disciplinary measures such as those provided by ATCP. However, research has showed that even these alternatives have proved to be less effective (Moyo et al. 2014:7; Ntuli \& 
Machaisa 2014:1788). Many of the studies that have been conducted on the effectiveness of ATCP have used teachers and parents in their samples. Hardly any studies have looked at the problem from the perspectives of learners who are recipients of this PD. This study therefore introduces a much neglected perspective, namely, that of learners. The combination of learners' and teachers' perceptions has the potential to add valuable insight into the problem and to bring in the often neglected voices of learners. It is against this background that the investigation reported in this chapter examined teachers' and learners' perceptions of ATCP measures by seeking to answer the following questions:

- what are the perceptions of teachers and learners regarding the implementation of ATCP in schools?

- What are the views of teachers and learners regarding the effectiveness of ATCP in schools?

\section{Aims of the study}

The aims of the study were to explore teachers' and learners' perceptions of ATCP as well as to determine the challenges encountered in the implementation of this system.

\section{Theoretical-conceptual framework}

Skinner's (1938) Operant conditioning (Reinforcement theory) and Jones' (1987) PD model have the potential to explain teachers' and learners' perceptions of ATCP. This combination allows for a broader view of teachers' and learners' perceptions of ATCP.

The positive approach to learner discipline is 'rooted in respect for human rights ... and focuses on discipline rather than punishment' (Department of Basic Education 2012).

Positive discipline implies the use of proactive, constructive, educative and corrective methods to discipline learners (Department of Education 2000). It is 'a non-violent method of 
disciplining children which encourages the development of a child and supporting them through their personal growth' (Durrant 2011:2).

Positive discipline is (Assali 2015):

$[A]$ teaching and parenting model that strikes a balance between two main considerations: effective teaching on the one hand, and respecting the rights of the child on the other hand. [...] it focuses on reinforcing the good behaviours of children and reducing the bad behaviours without physical or verbal aggression. (p. 8)

Central to the PD model is the recognition of children's right to respect and dignity as well as protection of the child from all forms of violence such as physical and emotional punishment (Assali 2015:8). This model is relevant to this study because it encourages teachers to come up with constructive ways of disciplining learners when at the same time respecting their rights. It is a model that discourages the use of corporal punishment in maintaining discipline and is therefore relevant to this study.

Operant conditioning postulated by B.F. Skinner, an American psychologist, involves 'developing voluntary behavioural responses based on the perceived outcome of a given action' (Rohmann 1999:72). It 'is based on the mechanisms of reward and punishment and positive and negative reinforcement' (Rohmann 1999:73). According to Skinner, actions followed by reinforcement will be strengthened and are more likely to occur again in the future. In other words, behaviour followed by reinforcement or a desirable outcome is likely to be repeated, whereas actions that result in punishment or undesirable consequences will be weakened and are less likely to occur again in the future (Cherry 2018). For example, praising a child for committing a desirable action is likely to result in repetition (strengthening) of that action. Withdrawing or withholding a privilege as a consequence of an undesirable action is likely to result in weakening the likelihood of that action being repeated. 
Punishment involves discouraging a behaviour by either presenting or taking away a stimulus to weaken that behaviour (Cherry 2018). The substitution of physical forms of punishment with non-physical forms resulted in differing perceptions of the new disciplinary methods.

\section{Research design and methodology Research design}

The main study (a dissertation) utilised a mixed methods research approach, with a mainly qualitative (QUAL) and a supportive quantitative (quan) component. Qualitative and quantitative 'data are integrated in a mixed methods approach' (Creswell 2014:14). This chapter presents the qualitative component of this study, which was conducted within a social constructivist or interpretive framework.

\section{Methodology}

\section{$\square$ Participant selection}

Participants were purposively selected from four township secondary schools. Purposive sampling allows a researcher to select individuals or sites on the basis of their ability to inform 'an understanding of the research problem and central phenomenon in the study' (Creswell 2014:156). Township schools have a reputation for learner discipline problems, and for this reason they were selected for the study. Xaba (2006:566) asserts that, 'township schools are especially vulnerable to unsafe conditions and threats of violence due to, amongst other things, poor resources and infrastructure, their location, especially in and around informal settlements [...]'. The participants included 20 teachers (five from each school) and 32 learners (eight from each school). The number of teachers and learners selected followed the ideal number of participants recommended for 
focus groups (Krueger \& Casey 2000:74; Niewenhuis 2016:91). These authors recommend 6-8 participants and 5-12 participants for teachers and learners, respectively. Learners were selected from Grades 11 and 12, four from each grade level. They were selected from these grade levels on the basis of their maturity as learners having been in the school for at least 10-12 years in the post-corporal punishment era. Teachers were purposively selected from each school on the basis of the length of service at the school and their having been part of the school during the corporal punishment era and after the introduction of ATCP. This qualified them as 'knowledgeable' and 'information-rich' participants with regard to corporal punishment and ATCP because they had witnessed the transition that involved the banning of corporal punishment and introduction of ATCP as the new disciplinary measures in schools. They were pre-ATCP and post-corporal punishment era participants. Their experience of both types of disciplinary practices would provide a valuable insight into the problem under investigation. In addition, having been part of the corporal punishment era might have a strong influence on their views regarding alternative disciplinary measures. The teaching experience of the majority of participants ranged between 20 and 35 years, and their age ranged between 40 and 55 years. There was no gender balance as the majority of participants who met the researcher's selection criteria were female.

Learners were senior learners in the school and had at least 10-12 years of experience with the new disciplinary measures. They were post-corporal punishment era participants aged between 16 and 19 years.

\section{$\square$ Data collection}

Data from teachers and learners were collected by means of focus group interviews. A total of four focus group interviews were held with teachers. Each focus group consisted of five teachers. 
The interviews were held in a quiet environment in the school's boardroom, the principal's office or in a vacant classroom. They were held during class breaks when the teachers were free so that no interruption of teaching and learning occurred. The researcher moderated the sessions to ensure free and fair participation and a fair amount of debate on each issue. The issues pertained to:

- awareness of ATCP

- formal introduction of ATCP

- training on implementation of ATCP

- challenges encountered in the implementation of ATCP

- discipline levels since the introduction of ATCP

- views on effectiveness of ATCP

- views on corporal punishment.

The focus group interview for learners followed a similar pattern to that of teachers. All but one of the interviews was conducted after school hours so as not to interfere with teaching and learning. Vacant classrooms were used for the focus group interviews in all schools. Participants were given the opportunity to respond without undue pressure from the researcher or moderator.

To ensure fair participation, the moderator gently drew in quiet and reserved participants. Learners were given an opportunity to express their thoughts and feelings without fear.

\section{$\square$ Data analysis}

Before data analysis, it was necessary to transcribe the audio recordings verbatim to ensure that precise typed data were available for line-by-line coding and categorisation. In line with the qualitative tradition, data analysis began as soon as the first set of data were collected and continued throughout data collection (Merriam 1999:169, 171). Once the data had been 
transcribed and typed, they were read multiple times to get a good overview and to begin identifying instances or examples of the issues being investigated. Coding and categorisation and pattern-seeking were performed, and themes were noted and compared to arrive at key findings pertaining to the perceptions of learners and teachers regarding the implementation and effectiveness of ATCP.

\section{$\square$ Issues of trustworthiness}

To ensure credibility, the interview instruments were piloted before the focus group interviews were conducted. Member checking was completed, and this involved sharing of the findings and interpretations with the participants to judge the accuracy of the account (Creswell 2013:252, 2014:201). Triangulation of data sources was achieved by eliciting information from teachers and learners to obtain a balanced view of the problem.

\section{$\square$ Ethical considerations}

All the necessary permissions were obtained from the relevant University Ethics committees, the two area offices where the schools were located and the principals of the schools from which the participants were selected. Before the interviews began, the researcher distributed consent forms to participants and proceeded to explain the purpose of the study. He informed participants that they were not obliged to take part in the study and were at liberty to withdraw anytime during the process. To protect their identity, participants were given pseudonyms to use throughout the interview. Participants were also assured of the confidentiality of the information they shared and that a record of it would be kept safely by the researcher. The information would be used for research purposes only. The researcher was the only one with access to the information. Permission to audio record the interviews was requested, and participants were informed that additional notes would be taken during the interview. 


\section{—indings and discussion}

Firstly, the findings from teachers and learners on the implementation of ATCP are presented, followed by the findings from teachers and learners on the effectiveness of ATCP. Thereafter, a discussion of findings from both teachers and learners on each of the two main issues is presented. The last section presents the conclusion and recommendations.

\section{Perceptions regarding the implementation of alternatives to corporal punishment}

On the whole, perceptions regarding the implementation of ATCP in schools are largely negative. Teachers and learners from these four township secondary schools who participated in this study did not have a favourable impression of ATCP and the manner of its implementation in schools. A common perception was that the ATCP measures are time-consuming and difficult to implement. Learners seem to enjoy being disciplined this way and continue as if nothing has happened. In one learner's words:

They do not work, they are time-consuming especially ones whereby the learner is picking up papers or cleaning the school. (Learner, location unknown, date unknown)

A teacher's comment confirms the learner's perception with these words:

Learners continue with their ill-disciplined behaviour even after they have been punished [...].(Teacher, location unknown, date unknown)

The above comments are also confirmed in Ntuli and Machaisa's (2014:1788) study.

It appears from the findings that implementation differs across schools. Although in some schools ATCP disciplinary measures are already part of school culture, in others there is inconsistency in implementation and a sense of resentment at the banning of 
corporal punishment. One learner participant felt that application or implementation of ATCP is not consistent, stating that ' $[\mathrm{t}]$ here is no co-relation amongst teachers when it comes to disciplining learners and that is really needed' (learner, location unknown, date unknown).

A teacher participant had this to say:

Learners are no longer disciplined at all. About $80 \%$ of learners are ill-disciplined to an extent that they cannot take simple instructions and if there was corporal punishment the situation would have been much better. Teachers have no support at all from parents or the government, and this is also contributing towards low level of discipline because we are powerless. (Teacher, location unknown, date unknown)

Another teacher participant expressed her feelings at the deterioration of learner discipline to which she attributed teacher frustration, lack of joy in teaching and teacher turnover:

Learners' behaviour has totally changed. The way learners behave at school is a true reflection of how they behave at home and as a result parents tend to be protective of their children. The level of discipline is so low to an extent that it frustrates us and that is the key reason many educators leave the profession. (Teacher, location unknown, date unknown)

In addition, learner indiscipline had deteriorated to such an extent that, in the words of one teacher, 'we no longer enjoy teaching'.

Teacher frustration regarding learner behaviour is not only attributed to ATCP but also to parents who 'tend to be protective of their children', implying a tendency towards permissiveness by parents. The introduction of ATCP therefore appears to be highly resented by some teachers on the one hand and not taken seriously by some learners on the other hand.

This sense of helplessness and powerlessness is echoed in Mtshweni's study (cited in Kalipa 2015:12), '[t]eachers feel helpless and powerless in the absence of corporal punishment'.

Ntuli and Machaisa (2014:1781) echo the sentiments of teacher participants who bemoaned declining levels of learner discipline 
in schools. This decline was attributed by Ntuli and Machaisa to a lack of thorough knowledge and information on how to implement the ATCP measures. The Department of Education was largely blamed for not adequately training teachers on the use of these alternatives.

One of the key concerns raised by teachers in the study was lack of training in the implementation of the ATCP measures, which made it difficult for them to discipline learners appropriately. This concern is captured in this statement (Marumo 2015):

$[T]$ he whole implementation of alternative forms of learner discipline is difficult because [...] no knowledge of how to implement them successfully. (p. 66)

One question designed to gauge teachers' true perceptions of ATCP yielded a variety of responses. The responses confirmed teachers' true feelings about the current disciplinary measures in South Africa. Asked if they felt that corporal punishment should be re-introduced, teachers' responses ranged from an emphatic 'yes' to 'yes with certain conditions' to an emphatic 'no'. The majority of calls for the reintroduction of corporal punishment stemmed from desperation on the part of teachers as a result of their inability to handle 'out of control' learners. One teacher's comment captures the sense of desperation experienced by many teachers, with a resounding YES. 'Corporal punishment should be re-introduced in order to curb ill-disciplined behaviour by learners' (teacher, location unknown, date unknown).

Other teachers, however, felt that although there was a need to reintroduce corporal punishment, it should not be used as the sole disciplinary method. A strong sentiment was that it should not only be controlled and coupled with ATCP, but that strict limits should be set regarding its administration. The following comments best capture this perception:

Corporal punishment should be re-introduced, but they should be coupled with the alternatives to corporal punishment. If corporal punishment is re-introduced, teachers must be trained on how to practise it appropriately to avoid cases of assault. (Teacher, location unknown, date unknown) 
Another comment, which echoed similar sentiments, was that:

Corporal punishment should be re-introduced but with strict limitations. Not all educators should have the powers to practise it. There should be nominated individuals in schools who have the special right to discipline learners through the use of corporal punishment. (Teacher, location unknown, date unknown)

The conditions for the reintroduction of corporal punishment are training, joint implementation with ATCP and specific persons to administer it.

The idea of 'nominated individuals' concurs with the old disciplinary method that was used in Kenya where only the head teacher administered corporal punishment or a teacher with the head teacher present. Regulations further stated that there must be a specific place on the body where a specific punishment must be inflicted and records of such an act must be kept (Busienei 2012:156).

The final perception was an emphatic 'No' to corporal punishment, and in the words of a participant, '[c]orporal punishment should not be re-introduced because the provided alternatives to corporal punishment can be effective, but what is needed is teachers to be trained about them' (teacher, location unknown, date unknown).

\section{Perceptions regarding the effectiveness of alternatives to corporal punishment}

Studies such as those of Motseke (2010:130) and Morell (2001:292) have showed that even though corporal punishment was officially banned in South Africa in 1996 and the ATCP measures were introduced in the year 2000, corporal punishment is still being used in South African schools. This continued practice might be an indication of a prevailing perception about the effectiveness of ATCP. The findings show mixed perceptions. Although learners' perceptions lean more towards favouring ATCP, teachers are ambivalent. Some are very vocal on their negative perceptions 
regarding ATCP, whereas others support ATCP. It is evident from the perceptions of learners and teachers that in some schools, ATCP is well entrenched and supported, whereas in others, it is neither well promoted nor supported. Instead, there are calls for the reintroduction of corporal punishment. In schools where ATCP are supported, learners and teachers are positive about its effectiveness and feel that in comparison with other schools, they are able to cope despite deteriorating learner conduct. The following comment captures this sentiment:

Even though we are managing the situation, the level of discipline is bad because learners still repeat the same offences they were punished for. When compared with other schools in the surrounding areas our school is much better even though the level of discipline is bad. (Teacher, location unknown, date unknown)

It is interesting to note how learners value ATCP over corporal punishment. The following comments exemplify this, '[t]hey are a much better route for discipline than corporal punishment because they lead to better attitude' (learner, location unknown, date unknown). 'They are the tickets to the future when it comes to discipline' (learner, location unknown, date unknown).

These comments show the depth of maturity in the thinking of these learners. Their perceptions of ATCP as the disciplinary practice of the future with positive spin-offs in shaping a 'better attitude' are reminiscent of $P D$ and positive reinforcement principles. Comments indicating that ATCP are perceived as an effective tool for moulding character, developing a disciplined mind and enhancing performance in school are '[t]he measures undertaken build me as a person to behave properly in future. Being detained helped me to read during detention and that contributed positively to my grades' (learner, location unknown, date unknown).

Not only is ATCP instrumental in building good character in learners, it is also a conduit for the development of the intellect. '[lt] helped me read [...] and contributed positively to my grades' (Learner, location unknown, date unknown). 'The alternatives 
help the learners to better themselves at school as they effect change in learner behaviour' (Teacher, location unknown, date unknown).

Such perceptions may be attributed to the fact that the learners who made these comments came from a school that embraced ATCP. This fostered positive feelings in learners and an appreciation of the relevance of ATCP in maintaining discipline. Such an act demonstrates a school culture where learners are disciplined in a respectful manner that promotes PD and enables learners to experience positive effects of ATCP (Özan 2015).

For some learners, ATCP had an effect of reducing violence. In the words of one learner, '[a]lternatives to corporal punishment are effective as they reduce violence' (Learner F, undisclosed gender, date unknown).

This is an interesting comment especially in the light of escalating acts of violence in schools. It raises the question of the truth of the adage, 'violence breeds violence'. This view is also supported by Busienei (2012:158), who says:

Giving up corporal punishment does not mean giving up discipline. Children need clear limits and guidance on what is right and wrong and abandoning the short cut of violence is likely to produce better disciplined children. (p. 158)

Not all perceptions regarding the effectiveness of ATCP are positive. For instance, quite a number of negative perceptions regarding the effectiveness of ATCP were evident in the responses of teachers and learners in some of the schools. Ostensibly, the differing perceptions are a function of the culture of the school, as the majority of positive comments were more likely to come from schools that supported ATCP and the opposite was true of negative comments.

A typical negative perception from a learner was that:

Strategies such as detaining the learners and talking to the learners which are used against troublesome learners especially the smokers 
have not really changed their behaviour because they still continue to smoke in the school vicinity. (Learner, location unknown, date unknown)

\section{Discussion}

Findings from the study showed contradicting perceptions of ATCP. Although some learners believed ATCP was the best method of learner discipline, others felt that corporal punishment was more effective than ATCP. Interestingly, the majority of sceptical sentiments about ATCP seemed to be a result of the dominant disciplinary practice of the school (namely, corporal punishment). Where corporal punishment was still the norm, perceptions about ATCP were bound to be negative and vice versa. In some cases, however, the perceived ineffectiveness of ATCP was seen as a consequence of lack of training. This suggests that perceptions can improve with provision of appropriate training. It appears that for some learners, preference for ATCP was based on fear of the negative consequences of corporal punishment rather than on the positive effects of the new disciplinary measures.

Although some teachers viewed ATCP as the best form of disciplining, others viewed it as less effective (than corporal punishment). It is not surprising that pre-ATCP era teachers would still prefer a disciplinary measure to which they were accustomed and which they found to be simple and quick. For them, the transition was difficult as is the norm with any change.

Although some of the teachers interviewed admitted to using ATCP to discipline learners, they were not satisfied with the outcomes because learners still repeated the same offences they were punished for. Other complaints raised by teachers were that the ATCP measures were time-consuming and difficult to implement owing to inadequate training and poor parental support. Moreover, these measures are perceived to be ineffective in township schools because in many instances, learner misbehaviour does not always improve; instead, it is repeated. 


\section{- Conclusion and recommendations}

Changing entrenched behaviours is not easy. Consequently, some teachers still reportedly resort to punitive disciplinary measures despite the introduction of the ATCP measures that are built upon PD principles. Some explanations for this persistent behaviour might be an entrenched belief in the old traditional philosophy of 'spare the rod and spoil the child' as well as a belief in teacher authority and the concomitant fear of losing that authority. There seems to be some doubts and ambivalent feelings from both teachers and learners regarding the effectiveness of ATCP. Teachers are not confident about their ability of implementing ATCP effectively owing to a lack of thorough training. On the whole, teachers and learners at the participating township secondary schools appeared to be generally ambivalent regarding ATCP as a disciplinary method.

Training in appropriate implementation of ATCP is very important in changing perceptions about ATCP and to ensure understanding of the principles of PD as well as the need to respect human rights. It is therefore important for the Department of Basic Education to ensure that teachers are trained on how to successfully implement ATCP. There should be a system of constant communication between the Department of Basic Education and the schools as well as a monitoring mechanism to ensure successful implementation of ATCP. 


\section{Teachers' and learners' perceptions of the effect and effectiveness of corporal punishment as learner discipline practice in Botswana public secondary schools}

Amos T. Thebenyane School of Professional Studies in Education, Education Management, Faculty of Education, North-West University,

Mafikeng, South Africa

Connie B. Zulu

School of Professional Studies in Education, Educational Management,

Faculty of Education, North-West University, Mafikeng, South Africa

How to cite: Thebenyane, A.T. \& Zulu, C.B., 2019, 'Teachers' and learners' perceptions of the effect and effectiveness of corporal punishment as learner discipline practice in Botswana public secondary schools', in C.B. Zulu, I.J. Oosthuizen \& C.C. Wolhuter (eds.), A scholarly inquiry into disciplinary practices in educational institutions (NWU Education and Human Rights in Diversity Series Volume 2), pp. 67-87, AOSIS, Cape Town. https://doi.org/10.4102/ aosis.2019.BK157.04 


\section{Abstract}

Learner discipline issues have grabbed the attention of education stakeholders globally. Although some countries such as Botswana still use corporal punishment, others have opted for alternative forms of learner discipline. This chapter is based on a mixed methods (dissertation) study, which focussed on the investigation of teachers' and learners' perceptions of the effects and effectiveness of disciplinary practices in government secondary schools in Kanye, Botswana. This chapter presents the qualitative component of the study, which employed a phenomenological approach. The main research aim was to determine the effects and effectiveness of current disciplinary practices in Botswana public secondary schools guided by B. F. Skinner's (1938) behavioural modification theory of 'operant conditioning'. The study sought answers to the following questions:

- What are the effects of corporal punishment on learners?

- How effective is corporal punishment for learner conduct?

- What alternative disciplinary methods might be effective in curbing learner indiscipline?

Teachers and learners were purposively selected and interviewed by using semi-structured interviews, and the resultant data were subjected to content analysis procedures. The main findings were that corporal punishment tended to have short-term effectiveness in curbing learner misconduct and long-term negative psychological effects on the learner. Therefore, guidance and counselling were perceived to be effective alternative disciplinary methods, should the Botswana Ministry of Education provide adequate training for teachers with regard to alternative methods to corporal punishment to effectively deal with learner misconduct in their schools.

\section{Introduction}

Learner indiscipline is a major concern in education and has taken the 'centre stage' in education discourses (Bharadwaj 2012:1; Simuforosa \& Rosemary 2014:80). For the majority of teachers, 
acts of indiscipline have become a normal part of their daily lives; an 'intractable' part of their teaching experience (Rossouw 2003:416). Various acts of indiscipline committed by learners expose both teachers and learners to the risk of being victims and perpetrators (Moyo, Khewu \& Bayaga 2014:1). Learner indiscipline has destabilised teaching and learning to such an extent that in Botswana it has become a common trend for local newspapers to publish articles on spiralling acts of indiscipline in public secondary schools.

In an incident where a school was nearly burnt down by unruly learners (Kayawe 2017:5), the regional director for the south region in Botswana bemoaned the prevailing 'lawlessness' and that 'things had gotten out of hand'. Other reported incidents of unruly learner behaviour in Botswana involved a senior secondary school where chaos ensued following a fight between a teacher and a learner, and another where a group of disgruntled learners staged a demonstration causing damage to property and forcing teachers to flee for their lives.

The unruly behaviour of learners calls for all concerned parties to seek a working resolution (Oosthuizen 2010:3). However, in Botswana, teachers often resort to corporal punishment for resolving issues of learner misconduct. According to Masokola (2015), Setlalekgosi (2016) and Baputaki (2009), parents and government officials in the education sector, backed by the former and current president, have advocated for the use of harsh disciplinary measures to address the escalating problem of indiscipline. Botswana is amongst the few countries where corporal punishment is still legal. However, learner indiscipline still persists. According to Harber (in Mthanti \& Mncube 2014:72), corporal punishment is 'critical to school discipline' in Botswana and is widely used to bring about social control amongst the learners. Although the rules governing the use of corporal punishment are 'strict', they are, to a certain extent, not honoured by those who administer it (Kgomotso, Tshegofatso \& Boipono 2015:5; Mthanti \& Mncube 2014:72). 


\section{Droblem statement}

Learner disciplinary issues are a cause for concern in public secondary schools the world over. Incidents of learner misconduct in these schools have considerably increased in recent times. Many countries have expressed their concern regarding how learner indiscipline issues have affected their education systems (Maphosa \& Mammen 2011:143). Cases of learner misconduct in the United States have reportedly increased considerably in recent years (Boston Globe 2013). Media reports in Botswana (Selatlhwa 2016; Setlalekgosi 2016) and in South Africa (Govender 2018) show that learner discipline problems have escalated. Learners have become very violent. They are 'involved in serious misconduct, including using and dealing in drugs, bullying fellow pupils, assaulting teachers and pupils, theft and carrying dangerous weapons' (Govender 2018:6). The search for effective disciplinary practices is thus inevitable, and this has preoccupied researchers and practitioners alike over the years. Hence, several countries have adopted one disciplinary approach or the other to effectively address challenges of learner indiscipline. In Botswana, for example, the use of corporal punishment is still in force, despite an international call to ban it following the recommendations of the 1989 United Nations Convention on the rights of children. Conflicting arguments on the effectiveness of corporal punishment have been put forth by proponents and opponents of this system. However, the government of Botswana continues to support the use of corporal punishment in schools, as it is perceived to be an effective disciplinary strategy despite the deteriorating situation of learner conduct in public secondary schools in that country.

The deteriorating situation in learner discipline in Botswana prompted an interest in determining the effectiveness of the current disciplinary system of corporal punishment in the country. The aim of the research (reported in this chapter) was to provide answers to the following research questions:

- What is the effect of corporal punishment on learners?

- How effective is corporal punishment for learner conduct? 
- What alternative disciplinary methods might be effective in curbing learner indiscipline?

To achieve this aim of reporting on the research, the rest of the chapter starts with the conceptual-theoretical framework underpinning the study, followed by an empirical investigation, the findings and discussion of the findings, limitations, contribution of the study and key recommendations.

\section{Conceptual-theoretical framework}

The study was underpinned by B. F. Skinner's (1938) 'Operant Conditioning model'. Operant Conditioning is 'primarily concerned with consequences of behaviour and the establishment of functional relations between behaviour and consequences' (Maag 2004, in Thebenyane 2014:21). Skinner, a well-known American behavioural psychologist, developed this model, which is based on the 'mechanisms of reward and punishment, positive and negative reinforcement' (Rohmann 1999:73).

Skinner's operant conditioning model is well-suited to the study of corporal punishment, as this method of discipline is based on the premise that undesirable behaviour can be suppressed or weakened through punishment. Therefore, the belief is that punishment of undesirable behaviour can lead to positive consequences such as desirable behaviour. One of the basic tenets of operant conditioning is that 'actions that are followed by reinforcement will be strengthened and more likely to occur again in the future' (Cherry 2018:n.p.). In other words, reinforcement can be used to change behaviour and encourage the occurrence of it in the future. Conversely, actions that are followed by punishment are likely to be weakened and not repeated again in the future. Corporal punishment in schools is intended to discourage future occurrence of bad behaviour in learners through punitive rather than preventative or positive reinforcement measures.

Operant Conditioning is characterised by having to 'strengthen an operant in the sense of making a response more probable or 
in actual fact, more frequent' (Skinner 2005:65). Woolfolk (2004:204) outlined the four ways for changing behaviour as using positive reinforcement, negative reinforcement, positive punishment and negative punishment. If behaviour is followed by punishment, it is more likely to be repeated in a similar way in the future.

\section{Corporal punishment}

Corporal punishment as defined by the United Nations Committee on the Rights of the Child is 'any punishment in which physical force is used and intended to cause some degree of pain or discomfort, however light' (Veriava \& Power 2017:332).

Corporal punishment, which has formed part of many nations' cultural and religious practices, is as old as civilisation itself (Gershoff 2008:19; Kopansky 2002:2; Sajkouska \& Wajtaski 2005:7). According to Morrel and Moletsane (2002:243), parents feel that corporal punishment is a unique way to improve their children's behaviour. The interesting question is whether or not corporal punishment has the desired effect, which would then render it effective as a disciplinary practice. The effects of corporal punishment have been well documented, and its effectiveness is still subject to debate. The Merriam Webster Dictionary (n.d.) offers a helpful definition of the terms 'effect' and 'effectiveness', and these are utilised throughout this chapter. 'Effect' means 'a change which is a result or consequence of an action or other cause'; 'effectiveness' means 'producing or capable of producing a desired result' (Merriam Webster Dictionary n.d.:n.p.).

In Botswana, corporal punishment of children is lawful despite repeated recommendations to prohibit it by the Committee on the Rights of the Child, The Human Rights Committee and the Committee on the Elimination of Discrimination against Women (Global Initiative to End Corporal Punishment of Children 2017). This cultural group considers it the responsibility of the community to ensure proper discipline of all children in the community 
(Garegae 2008:49). Saunders and Goddard (2010:11) has also associated corporal punishment with the early development of the education system. With the introduction of the Western education system, schools integrated corporal punishment, a traditional method of discipline, into their systems. This transition of corporal punishment from homes to the classroom earned the support of parents, teachers and school administrators. It is hardly surprising, therefore, that there are schools that still believe in corporal punishment as a disciplinary measure.

However, over the last two decades, changes have been incorporated into children's social status (Sajkouska \& Wajtaski 2005:7). Human rights groups have argued that corporal punishment is harmful to children and that it must be abolished. As a result, in some countries, the use of corporal punishment has declined and some nations have totally abolished it (Gershoff 2008:7). Countries that responded positively to the call to ban corporal punishment did so as a result of the pressure on their governments by Human Rights groups and the United Nations Convention of 1989, which decreed that member states do away with such a disciplinary practice associated with torture and retribution (Global Initiative to End Corporal Punishment of Children 2010:8).

Botswana as a United Nations member state has not met the target date for total abolishment of corporal punishment unlike neighbouring countries, such as Namibia, Zambia, Angola, South Africa, Lesotho and Kenya. These countries showed compliance with the United Nations General comment number 8 of 2006, which declares ' $[\mathrm{t}]$ he right of the child to protection from corporal punishment and other cruel or degrading forms of punishment' (Global Initiative to End Corporal Punishment of Children 2010:8).

The government of Botswana however continues to support the use of corporal punishment in schools. The country has not amended the laws supporting the use of the stick even though international organisations advocate for total abolishment. Teachers in schools therefore have no option but to support 
corporal punishment. Jotia (2011:145) has condemned Botswana's education system stating that it is not democratic in the sense that teachers and school heads continue to run the show by using an authoritarian approach, 'while learners are expected to adhere to rules and regulations set' without opposition. If there is any resistance or challenge to the set regulations, 'corporal punishment is meted as a disciplinary measure and silence tactic' (Jotia 2011:145). This clearly indicates that teachers prefer the use of corporal punishment, and it is regarded as a simple and easy approach of ensuring discipline amongst learners.

Not surprisingly, in some countries where corporal punishment has been abolished, teachers are calling for it to be re-introduced arguing that its abolishment has deprived them of a simple method of maintaining discipline in school. According to Smit (cited in Veriava 2014:8), the rise in learner indiscipline cases, which has led to increased cases of violence in schools, could be blamed on the abolishment of corporal punishment. Similarly, Greydanus (2010:3) maintains that advocates of the use of this disciplinary method argue that it is effective in correcting a child's misbehaviour.

In Zimbabwe, the banning of corporal punishment following constitutional amendments, which outlawed corporal punishment (Mushoshwe 2015:1), resulted in an outcry from the public and from those in education. Their argument was that the ban would encourage unruly behaviour amongst children and leave those in authority with no means of disciplining children.

Conflicting arguments have been raised on the use, effect and effectiveness of corporal punishment. Some argue that corporal punishment is still an ideal method and when effectively applied could address the problem of learner misconduct (Kgomotso et al. 2015:5). According to Georshof (in Holden 2002:590) and Save the Children (2001:9), a number of research studies suggest that corporal punishment is effective in making learners comply for a short time. Maphosa and Shumba's (2010:6) study found that teachers who preferred the use of 
corporal punishment claimed that it had 'immediate deterrent effects'. Domjan (in Holden 2002:591) is of the view that punishment can be effective in changing behaviour if it occurs after a transgression, is immediate and intense. However, the effects of corporal punishment are of short term (Save the Children 2001:11), as compliance is often temporary - lasting only as long as the pain.

\section{The effect of corporal punishment}

Corporal punishment is still a highly controversial topic, with some in favour of it and others against it. Those against corporal punishment argue that it is inhuman and degrading because it can cause bodily harm and long-term psychological effects, resulting in poor anger management and violent behaviour (Bitensky 2006:8; Moyo et al. 2014:10; Tshukudu 2014). Kilimci (2009:242) discredits corporal punishment and sees it as a disciplinary practice that has negative effects and which does more harm than good. Some of these negative effects are physical consequences, psychological consequences, behavioural consequences and developmental consequences (Naker \& Sekitoleko 2009:12). According to Bitensky (2006:11), many child experts concur that spanking does not necessarily 'develop the child's conscience and inclination towards peaceful conflict resolution. It only halts transgression'. In other words, it does not contribute towards the moral development of the child or foster the child's understanding of right and wrong. Spanking merely stops the act of wrongdoing and does not teach the child how to resolve conflict peacefully. In a nutshell, many researchers concur that corporal punishment has no long-term effectiveness, nor does it reinforce desirable behaviour in learners (Porteus, Vally \& Ruth in Andero \& Stewart 2004:94; Thebenyane 2014:52).

Human Rights Watch (2009:5) maintains that corporal punishment may result in 'negative high risk adolescent behaviour'. The negative effects of corporal punishment may not 
always manifest immediately, but later on in their lives, victims may display forms of behaviour provoked by the harsh forms of discipline.

Besides physical injuries, psychological and mental trauma, corporal punishment may have behavioural consequences. Learners who are often physically punished tend to display aggressive behaviour towards their peers or even in retaliation to teachers. They also have low self-esteem and tend to play truant fearing the harsh disciplinary measures.

Naker and Sekitoleko (2009:13) argue that learners who are corporally punished often bully others and when they become adults engage in domestic violence as they 'regard violence as an acceptable way of imposing their views on some one less powerful than them'. From an early stage, children get to develop a perception that violence is an appropriate response to conflict resolution and unwanted behaviour (Banda 2006:2). Corporal punishment is a disciplinary method that is perceived as unhelpful in teaching learners to be self-disciplined. Instead, it tends to promote or perpetuate violent behaviour and 'poor anger management skills' (Moyo et al. 2014:10).

Long-term effects of violent behaviour brought about by the use of corporal punishment can negatively affect learners. Later on in their lives, learners may continue to display anger when confronted by certain situations and because they have not been equipped with the necessary skills to deal with such situations on their own, violence may be seen as the ideal option. According to Gershoff (2008:16), learners who have been corporally punished are more likely to report having beaten their partner.

According to Etheredge (2014):

$[A] n$ overly harsh punishment can actually result in greater reluctance to comply with school rules and norms, foster negative attitudes about school and result in alienation and psychological harm. At the same time the offender is not the only one who may experience negative consequences. (p. 11) 
Corporal punishment may also result in 'negative high risk adolescent behaviour' (The Human Rights Watch 2009:5). There are a number of negative outcomes resulting from the use of corporal punishment, which indicate learners may be exposed to immediate danger or later on in their lives display forms of behaviour provoked by the harsh forms of discipline.

Corporal punishment can have serious physiological consequences. Save the Children (2001:12) explains that learners may, as a result of corporal punishment, suffer injuries that could be severe and at times require medical attention. The injuries caused by corporal punishment may range from extensive bruising, severe muscle injury, ruptured eardrums, brain damage and whiplash damage (Banda 2006:1; Human Rights Watch 2007:41). Corporal punishment may not always just leave marks but can also cause permanent bodily harm and even lead to death. Already there are reported cases of learners who have died and some who have been paralysed because of being beaten (Garegae 2008:50; Tshukudu 2014).

\section{The effectiveness of corporal punishment}

Despite its continued use in some countries, such as Botswana, corporal punishment has generally been found to be ineffective as a disciplinary measure. Charles (2007:15) has advised that to be deemed effective, discipline must teach learners to take charge of their lives. The aims of discipline should be educative and nurture values of tolerance, respect and self-discipline in learners rather than victimise them (Department of Education 2000:24).

\section{Research design and methodology Design}

A convergent parallel mixed methods design was used in the main study with equal weightage given to quantitative (QUAN) 
and qualitative (QUAL) components (QUAN+QUAL). The main study was completed for the purposes of a dissertation, and for this chapter, only the qualitative component is reported on. A phenomenological approach was followed, the focus of which was teachers' and learners' perceptions of the effectiveness of corporal punishment in Botswana public secondary schools. Teachers and learners are best placed to share their perceptions on a disciplinary method, which is part of their lived experiences of discipline in Botswana schools. Their views based on their experiences of the phenomenon of corporal punishment provides a common and shared understanding of the effects and effectiveness of this phenomenon.

\section{Methodology}

\section{$\square$ Selection of participants}

Six teachers and three learners from three public junior secondary schools located in a village in the southern part of Botswana were purposively selected for this study. This area of Botswana has many secondary schools; hence, it was ideal to use it as a site for the study. The teachers were selected on the basis of their length of service at the school. Thus, from each school, two teachers with several years of teaching experience were selected. The head of the school assisted with information on teachers with long service at the school. The selection of learners was based on their disciplinary track record, which was provided by the guidance teacher at each school. Thus, the learner with the worst disciplinary track record was selected, as he was deemed to be the most informative regarding whether or not corporal punishment was effective. To avoid labelling the learner, he was not informed about the basis of his selection.

The six teachers consisted of four females and two males with an average of 18 years of teaching experience. They ranged in age between 33 and 46 years. With the exception of one teacher, $50 \%$ of the teachers were senior teachers. One was a head of 
department and the other a deputy principal. There was no deliberate attempt to select senior teachers or school officials, but these teachers happened to be the ones identified as having several years of teaching experience at the school. It stands to reason that they would have been senior teachers and even school officials at the time of the study. All the learner participants were male aged between 16 and 17 years from the same grade level, which is Form 3 in Botswana.

\section{$\square$ Data collection}

A semi-structured interview guide was developed to collect data from the selected teachers and learners. In all cases, interviews were conducted in the afternoons to avoid disruption of teaching and learning. Each school provided a quiet environment where the interviews were held without disturbance. Data were captured by using a mobile phone, and extensive notes were taken on key points raised and non-verbal information such as facial expressions (smiles, frowns) and body language. Transcription followed after completion of all interviews.

\section{$\square$ Data analysis}

Content analysis was used to analyse the data. Leedy and Ormrod (2014:150) defined content analysis as 'a detailed and systematic examination of a particular body of material for the purpose of identifying patterns, themes or biases'. Analysis of data in the study involved scrutinising the content of each data set to find instances that related directly to perceptions regarding effects of corporal punishment and its effectiveness, and to establish common themes and categories from the data of both teachers and learners. The integration of these themes and categories (Creswell 2014:115) eventually led to an 'exhaustive description of the phenomenon' of the effects and effectiveness of corporal punishment as a disciplinary method in Botswana public secondary schools. 


\section{$\square$ Ethical considerations}

Permission to conduct research was obtained first from the institution's research ethics committee, which issued an ethics certificate. Permission was then granted by the Botswana Ministry of Education research unit. After obtaining the permit, letters to individual schools were sent with the permit letter attached. In line with ethical interview practice (Creswell 2014:166), participants were provided individual informed consent forms before the interview to read and sign. Participants were assured anonymity and confidentiality. Data recordings were saved separately as audio files and stored in the phone memory in two appropriately labelled folders. Only the researcher had access to data.

\section{$\square$ Trustworthiness}

Trustworthiness issues in qualitative studies must be appropriately addressed. Seale (in Golafshani 2003:601) emphasised the importance of thoroughly examining aspects of trustworthiness in qualitative studies to establish good-quality studies. The importance of pilot testing and use of recording procedures (Creswell 2013:164-165) cannot be overemphasised.

To ensure trustworthiness in the present study, the interview instrument was piloted first before being administered, and feedback obtained from the pilot allowed further refinement of the instrument with the help of experts. Each participant responded to a similar set of questions, and interviews were conducted under similar conditions and audio recorded and transcribed verbatim.

Creswell (2014:201) recommends member checking and 'triangulating different data sources of information' as trustworthiness strategies in qualitative research. The findings and interpretations were taken back to the participants to allow them to assess the researcher's interpretation and accuracy of information they had provided. 


\section{Findings and discussion}

Teachers and learners responded to the following questions:

- What are the effects of corporal punishment on learners?

- How effective is corporal punishment for learner conduct?

- What alternative disciplinary methods might be effective in curbing learner indiscipline?

\section{$\square$ Teachers' perceptions on the effects of corporal punishment on learners}

Corporal punishment is known to have negative effects on victims. These effects may be physical, psychological, emotional and social. Its use has a negative effect, which is why some argue it causes more harm than good (Kilimci 2009:242).

Makhani (2013:12) is of the same view that corporal punishment has 'adverse physical, psychological and educational outcomes' amongst other effects.

Some of the teachers who participated in the study were also of the view that corporal punishment is not effective and their comments on its social and physical effects included that it affects teacher-learner relationships and causes injuries to the body' (teachers, location unknown, date unknown). These perceptions are consistent with findings in the literature on the negative effects of corporal punishment, such as physical consequences, psychological consequences, behavioural consequences and developmental consequences (Naker \& Sekitoleko 2009:12).

An interesting finding is that teachers are somewhat conflicted or ambivalent in their views about corporal punishment. On the one hand, they perceive it as effective in improving learner conduct and, on the other hand, they acknowledge its negative effects on learners, notably that, 'it can contribute to truancy and bullying, and it makes students stubborn' (South African Department of Education 2000:7; Naker \& Sekitoleko 2009:13). 
Judging from the teachers' perceptions, corporal punishment is likely to have a 'ripple effect' on learners, leading to other (behavioural and antisocial) problems and punishable offences such as absenteeism (truancy), bullying and disrespect.

\section{$\square$ Learners' perceptions on the effects of corporal punishment}

All the learners (three of three) perceived corporal punishment as having negative physical, personal, emotional and behavioural effects on them. Like their teachers, the learners' perception was that corporal punishment also has a negative effect on learnerteacher relationships. Corporal punishment can cause feelings of animosity and hostility between teachers and learners, 'it encourages hatred...', 'embarrasses learners' and causes them to be 'stubborn'. Learners' perceptions on the physical effects of corporal punishment are consistent with those of their teachers (and those of the literature), namely, that it causes bodily injuries (Banda 2006:1; Human Rights Watch 2007:41, 2009:5; Save the Children 2001:12). Corporal punishment, by definition, is intended to inflict pain and discomfort to the body. It is no surprise then that this effect would be the dominant perception of both teachers and learners.

The emotional and psychological effects of corporal punishment on the learners are a cause for concern. A hate-filled, embarrassed and stubborn learner can very easily develop into a problem learner and even a violent person (Banda 2006:2; Naker \& Sekitoleko 2009:13). Corporal punishment is a form of physical violence, and as the adage goes, 'violence breeds violence'.

\section{$\square$ Teachers' perceptions on the effectiveness of corporal punishment on learner conduct}

The study showed differing perceptions of teachers regarding the effectiveness of corporal punishment on improving learner behaviour. Although some thought it was effective because it 
resulted in learner compliance and cooperation, others thought it had short-term effectiveness (see Save the Children 2001:11), 'corporal punishment is deemed effective as it results in immediate compliance $[\ldots]$ something that is not long term'.

This view is shared by teachers in this study and is expressed in the following comment:

$[L]$ earners change behaviour only for that time after being lashed. Some learners do not take the stick seriously. They get used to it if it is done on a regular basis [...] it does not give much needed results. (Teacher 1, undisclosed gender, date unknown)

The majority of the teachers (five of six) commented on the negative physical consequences of corporal punishment, and four of six teachers remarked on its adverse effects on learner behaviour, whereas two of the six teachers seemed concerned about the effect of corporal punishment on learner-teacher relationships. Although the dominant perception is that corporal punishment has some effectiveness, albeit short-lived, 'it can change learner behaviour for a short time [...] Learners behave when it is administered [...]', 'learners cooperate, show respect and are obedient', the main concern is the absence of long-term results:

I doubt it has any effect. The way our students are beaten and yet they are still out of order [...] (Teachers 1, 2 and 5, undisclosed gender, date unknown)

Indeed, the literature shows that corporal punishment does not have long-term effectiveness on the conduct of learners (Maphosa \& Shumba 2010). Learners tend to refrain from acts of misbehaviour only as long as the effect of the punishment lasts. Opponents of corporal punishment view it as ineffective as a means of effecting long-term improvement in learner behaviour or for achieving a culture of learning and discipline in the classroom (Department of Education 2000:7). More often than not, learners who are corporally punished may display outwardly acceptable behaviour but inwardly harbour resentment and fear of the perpetrator. The teacher may believe the learner has 
actually changed and become respectful, cooperative and obedient, but the opposite may be true. As soon as the effect of the punishment disappears, the learner reverts to his or her old behaviour.

\section{$\square$ Learners' perceptions on the effectiveness of corporal punishment on learner conduct}

When asked about their views on the effectiveness of corporal punishment on improving learner behaviour, all three were unanimous in their perception that it was not effective. This is not surprising coming from (male) learners who had a track record of misbehaviour. One of the learners added a reason for his view of why he thought corporal punishment was not effective, saying 'it makes learners to only [sic] behave for a short while' (learner 3, undisclosed gender, date unknown). Again, this view is not surprising coming from learners with a track record of misconduct. It is interesting to note that both teachers and learners shared this perception, which is confirmed by findings in the literature as well (Porteus, Vally \& Ruth in Andero \& Stewart 2004:94; Thebenyane 2014:52).

Essentially, the perception of learners is that corporal punishment does not improve learner conduct; it only results in negative consequences such as injuries to the body, truancy, negative teacher-learner relationship, embarrassment and stubbornness (Thebenyane 2014:115).

The findings on the perceptions of learners and teachers on the effects of corporal punishment on learner conduct showed that the majority agree that it has negative effects on learner conduct rather than long-term effectiveness. Charles (2007:15) recommends that discipline must teach learners to take charge of their lives. The aims of discipline should be educative and should nurture values of tolerance, respect and self-discipline in the learner rather than victimise them (Department of Education 2000:24). 


\section{$\square$ Alternative disciplinary methods that might be effective in curbing learner indiscipline}

Notwithstanding the negative perception of learners and the ambivalent perceptions of teachers on the effects and effectiveness of corporal punishment, both learners and teachers were unanimous on their perception of effective alternative disciplinary methods. Consistent with Rossouw's view (Thebenyane 2014:112), guidance and counselling was perceived by teachers and learners as an effective alternative disciplinary method. In addition, teachers thought that the involvement of parents and other stakeholders as well as positive reinforcement would be effective alternative disciplinary methods (Thebenyane 2014:112). Learners also cited positive reinforcement (such as rewards) as an effective alternative to corporal punishment. In sum, teachers and learners had similar perceptions regarding the effectiveness of guidance and counselling and positive reinforcement in curbing learner indiscipline.

Some limitations of the study may be worth mentioning at this point. In Botswana, there are approximately 240 secondary schools. It was therefore not possible to cover all of the schools given the limited time. It was a challenge for learners to open up to discuss issues related to corporal punishment. Teachers, on the other hand, did not fully open up to giving a detailed view of their side of the story fearing that they might be victimised as some cases of abuse of corporal punishment have led to some teachers being taken to court. Notwithstanding the limitations, the inclusion of the Botswana study adds an international perspective to the argument on disciplinary methods and brings into sharp focus the extent of the problem of learner discipline and its concomitant debate on effective strategies. It also highlights the dilemma faced by teachers in the implementation of one method or the other in their quest to curb learner indiscipline. 


\section{Conclusion and recommendations}

Corporal punishment is not an effective disciplinary measure. Although there was a certain degree of consensus between teachers and learners on their perceptions of the effectiveness of corporal punishment for learner conduct, learners were unanimous in their discrediting of corporal punishment as an effective strategy, whereas most teachers thought it was effective despite its short-term effectiveness. Both teachers and learners were in agreement about the negative physical effects of corporal punishment such as injuries to the body. In addition, both teachers and learners cited truancy, stubbornness and disrespect towards teachers as consequences of corporal punishment.

The harm caused by the use of corporal punishment as indicated by all learners and some teachers shows that they do not support its use. However, it is evident that as an 'immediate deterrent', teachers will continuously opt for its use as long as it is regarded legal. However, the physical and psychological effects of this harsh disciplinary approach cannot be ignored as some have deteriorating lifelong effects. Botswana may continue to support the use of corporal punishment, but it would not be harmful to consider alternatives that may improve learner behaviour.

In the light of the findings, the following recommendations are made. Firstly, school discipline should not be the sole responsibility of teachers, school heads or the guidance department. All concerned stakeholders such as parents, community members and school secretaries, cleaners and maintenance staff must be actively involved in managing discipline of learners in their respective schools.

Policies must be drafted to serve as guidelines for teachers, and continuous in-service training must be offered to ensure schools have teachers who are able to deal with different forms of indiscipline. Schools must ensure that they include ways of 
improving learner discipline in their annual plans. This will enable sharing of ideas and refining of approaches on a continuous basis.

Government must ensure guidance teachers are properly trained before they are appointed. The elevation of teachers to the post of senior teacher guidance and counselling must not be compromised. Consideration must be extended only to those with the appropriate educational background for them to be effective in ensuring that learner discipline is well managed in their schools. 



\section{Chapter 5}

\section{A normative analysis of student misconduct at a Technical and Vocational Education and Training college in the Western Cape}

Louis J. Oosthuizen Trimester Programme, NATED Programme, West Coast College, Vredenburg, South Africa

Izak J. Oosthuizen Edu-HRight Research Focus Area, Faculty of Education, North-West University,

Potchefstroom, South Africa

\section{Abstract}

Research related to student conduct at Technical and Vocational Education and Training (TVET) colleges still constitutes virgin territory. As TVET colleges are a relatively new phenomenon on

How to cite: Oosthuizen, L.J. \& Oosthuizen, I.J., 2019, 'A normative analysis of student misconduct at a Technical and Vocational Education and Training college in the Western Cape', in C.B. Zulu, I.J. Oosthuizen \& C.C. Wolhuter (eds.), A scholarly inquiry into disciplinary practices in educational institutions (NWU Education and Human Rights in Diversity Series Volume 2), pp. 89-112, AOSIS, Cape Town. https://doi.org/10.4102/aosis.2019.BK157.05 
the South African educational landscape, very little research has been conducted with regard to these colleges. As far as related forms of student misconduct are concerned, no statistical data could be traced, leaving an essential research gap. Consequently, the aim of this chapter is to detect the various forms of student conduct, to analyse and synthesise them and finally to evaluate the conduct against a normative perspective.

\section{Introduction}

Student misconduct negatively influences students' academic performance at education institutions in general (Ehiane 2014:191). Likewise, educational goals at TVET colleges are disrupted by student misconduct (Manyau 2014:149). At TVET colleges, student misconduct contributes to poor academic performance. Student misconduct can be categorised into serious and ordinary forms (Oosthuizen, Russo \& Wolhuter 2015:89; Smit \& Rossouw 2015:63).

The Green Paper on Post-School Education and Training noted that as an element of post-school education, TVET colleges face numerous challenges, which include an inability to take up an increasing number of students, poor throughput of students and poor management of resources (SA 2012:9).

Corroborating statistics noted that of the 7624 students who enrolled for the National Curriculum Vocational (NCV) Level 4 final exams, only $34.4 \%$ passed at the end of 2014 (Ndebele 2016:529-530). The evidently poor academic performance at TVET colleges nationally needs to be addressed. The poor academic performance at TVET colleges may be attributed to student misconduct amongst other factors. However, the extent to which student misconduct affects students' academic performance can only be determined once the most frequent forms of student misconduct have been identified.

\section{Background}

The post-school education system in South Africa encompasses universities, TVET colleges, adult learning centres and the Sector Education and Training Authorities (SETAs) (SA 2013:xi-xvi, 8). 
The TVET sector provides vocational education to students who wish to qualify for the workplace. Technical and Vocational Education and Training colleges are the primary vehicle for the provision of vocational education and training (Pittendrigh 1988:108-109). The TVET sector is complex; it not only provides education and training to people but also prepares them for the workplace (Van der Bijl \& Lawrence 2016:342). Vocational education is also traditionally linked to education for the poor, the needy and the 'less able' (Gamble 2003:9). The TVET college sector underwent major restructuring during 2009 when 50 multi-campus colleges were established from the merger of 152 technical colleges (SA 2012:20).

The Department of Higher Education and Training (DHET), in its White Paper on Post-School Education and Training, strives to strengthen and expand TVET colleges and turn them into attractive institutions of choice (SA 2013:xi-xvi). The 'makeover' of TVET colleges would require improvement of management and governance, development of teaching and learning, improvement of student support and development of the infrastructure at TVET colleges. In the next section, the nature of student misconduct will be discussed.

\section{Student misconduct}

This section will discuss the nature of student misconduct. It can be classified into ordinary forms and other, more serious, forms of misconduct (Oosthuizen et al. 2015:89; Smit \& Rossouw 2015:63).

Ordinary forms of student misconduct include students not doing the required tasks, unruly talking and disrupting lessons, arriving late, absenteeism, truancy, not submitting work, neglect of work, disrespect, rudeness, forgery, disruptive behaviour, obscene language and using mobile phones in class. Ordinary forms of student misconduct also include leaving the classroom without permission, cheating in tests and neglecting to do their work (Oosthuizen et al. 2015:89; Smit \& Rossouw 2015:63). Ordinary forms of student misconduct, if left unchecked, could sometimes pave the way to serious forms of misconduct. 
In essence, serious forms of misconduct border on criminality and include, for example, physical violence and psychological violence, gender-based violence, fighting, bullying, intimidation, theft, vandalism, substance abuse and sexual harassment (Smit and Rossouw 2015:63).

\section{Manifestation of misconduct in other countries}

A study on student misconduct in Turkey identified a list of behaviours, which includes misconduct regarding academic tasks, inappropriate behaviour, negative attitudes towards educators and peers as well as disregard for institutional policies (Lozano \& Kizilaslan 2015:51).

In China, the most frequent form of student misconduct in schools is not paying attention in class. Ordinary forms of misconduct include disruptive behaviour in class, skipping class, swearing, vandalism, disobedience, intimidation and harassment of other students. Serious forms of misconduct in China include alcohol abuse, fighting, cheating in tests and stealing (Shen, Wang \& Zhang 2015:23). Student misconduct in China corresponds with student misconduct globally.

Ordinary forms of student misconduct in Australia include late coming, disruption of classes and insubordination. Serious forms of misconduct are fighting, theft, vandalism, bullying, truancy and possession of illegal drugs and dangerous weapons. Ordinary forms of student misconduct in Australia are directed at disruption of lessons (Squelch 2015:12). Student misconduct in Australia corresponds with student misconduct in other countries.

In the United Kingdom, bullying was identified as the most common form of student misconduct. In addition to physical bullying, one in every five youngsters in the United Kingdom has been a victim of cyber bullying. Female students were found to be affected more seriously by bullying than their male counterparts (Walker 2015:74-75). Bullying and cyber bullying in 
the United Kingdom seem to occur more frequently than in other countries. Bullying, a serious form of student misconduct, infringes on the rights of other students and results in psychological damage to victims.

In Malaysia, students from low-income, densely populated areas are most at risk. At-risk students tend to rebel, break rules and regulations, desire attention and are susceptible to negative peer influences. Truancy and absenteeism, bullying, theft, gangster activities, disruptive behaviour and insubordination are the most predominant forms of student misconduct in Malaysia (Tie 2015:38-39). Student misconduct in Malaysia corresponds with student misconduct elsewhere. Identifying the risk of students from low-income groups may be a key factor to better support at-risk students.

In Singapore, student misconduct is not only confined to the classroom but also extends to cyber bullying. Student misconduct in Singapore comprises online offences in the form of slandering by using blogs, emails and text messages, with cyber bullying being the number one ranked form of misconduct. Other forms of student misconduct are bullying in the form of fighting, extortion, theft, disrespect towards educators, disobedience, forging signatures of parents, sleeping in class, possession of drugs and truancy (Teh 2015:54-55).

\section{Student misconduct in South Africa}

Forms of learner misconduct in secondary schools in various other parts of the country relates to the research in this chapter in the sense that a big percentage of the students (the NCV students) who are studying at the TVET colleges in question are pre-matric coming from all over South Africa. Comparing the outcome of this study with that of secondary schools of other provinces places the findings of this research into perspective.

Research into serious student misconduct in the Free State, Eastern Cape and Vaal Triangle ranked theft first, violence second, 
vandalism third, alcohol abuse seventh, harassment eighth, drug abuse ninth and pornography tenth (Wolhuter \& Van Staden 2007:359).

Research in the North West province ranked violence first, theft second, vandalism third, drug abuse sixth, alcohol abuse eighth, harassment ninth and possession of pornography tenth (Oosthuizen 2007:4).

Research into serious forms of misconduct conducted in Jouberton, North West province ranked theft first, vandalism second, violence third, drug abuse sixth, alcohol abuse seventh and sexual harassment ninth (Serame et al. 2013:65). To a certain extent, the nature of student misconduct in South Africa corresponds with student misconduct elsewhere.

In terms of the code of conduct for students, at a particular TVET college in the Western Cape, misconduct is divided into categories depending on its seriousness. Category $A$ and $B$ infringements include ordinary forms of student misconduct such as unsatisfactory work, failure to hand in assignments, absence without notification, late coming and disruptive behaviour during class time. Category B infringements include rudeness, arrogance, bullying, chronic absence and not sitting in tests (West Coast College 2013:8-9). Student misconduct prohibited by the student code of conduct at West Coast College compares well with student misconduct in other countries of South Africa.

As with other forms of human behaviour, student misconduct may arise from different factors or motivations, depending on the circumstances in which a transgressing student finds himself or herself.

\section{- Conceptual-theoretical framework}

Hans Kelsen (1881-1973) was one of the leading German legal philosophers of the 20th century. The conceptual-theoretical framework of this chapter is embedded in the theories of 
Hans Kelsen's assumptions regarding the premises of law being a normative science (Hosten et al. 1995:154). He described it as normative science, as, according to him, norms constitute values. This philosophical assumption rotates around the theory of norms being the focal point of law. In other words, law is normative in the sense that it sets standards of action or conduct, which ought to be followed. It is interesting to note that the root of the word norm is found in the word norma (Latin), which was used to refer to a carpenter's square by means of which he performed all of his measurements (Postma 1985:203). In modern times, the word norm is rather applied, in the figurative sense of the word, for measuring human conduct. Consequently, Kelsen (quoted by Hosten et al. 1995) described legal norms as follows:

'Norm' is the meaning of an act by which a certain behaviour is commanded, permitted, or authorised. (p. 154)

In accordance with this point of view, Kelsen postulated the Grundnorm theory (basic norm). His point of view was that a provision of positive law (statutory provisions such as, for example, acts or regulations) needs to be validated by a basic norm. In other words, the basic norm (Grundnorm) supplies the final legal validity.

His ultimate depiction of the highest form of law was that it is to be a sterile, separate science detached from all of society's fashions and cultural inclinations of the day, elevated on a neutral podium emanating objective and clinically unpolluted justice to all. Therefore, he argued, law is not to define everyday life as a product of history or economics or as an instrument for social manipulation. And this is what he labelled reine Rechts/ehre [pure theory of law].

In this chapter, the authors strive to show the (possible) deviations from the norm of acceptable behaviour at this particular TVET college. And in the final instance, it will attempt to detect a Grundnorm for sound behaviour at TVET colleges in South Africa in general. 


\section{Research design and methodology}

The research design of this chapter is an explanatory mixed methods design, whereby a quantitative approach is followed by a qualitative approach (McMillan \& Schumacher, 2014:431). The quantitative approach is based on a non-experimental survey design, so as to obtain a broad overview of the nature and the most frequent forms of student misconduct at the particular TVET college. On the basis of the pointers distilled through the factor analysis of data obtained from the quantitative research, a qualitative, phenomenological design was developed to obtain a deeper insight into the phenomenon of student misconduct at this college. The purpose of the qualitative part was to elaborate upon issues emerging from the quantitative data and/or to explain some of the quantitative results to a higher level of understanding.

\section{Population, site selection and sampling}

A rural TVET college in the Western Cape was selected for this study. Four of the five campuses were selected for the purpose of convenience. The fifth campus was difficult to access during the time of the survey. All five campuses were requested to participate in the study. Unbiased feedback was obtained from students and lecturers regarding the nature of student misconduct.

The number of students registered at the particular TVET college was 4365 . For a population size of approximately 5000 individuals, a sample size of 400 is adequate (Leedy \& Ormrod 2010:214). Out of a total of 645 questionnaires sent out, 587 were completed and returned.

It was not feasible to let all of the respondents across this large area participate. By means of cluster sampling, the area was divided into clusters (Leedy \& Ormrod 2010:209-210). The different class groups (level 2-4 NCV students and levels N4-6 National Accredited Technical Education Diploma [NATED] students) from 
every campus were viewed as clusters and randomly selected for completion of the questionnaire.

On the basis of the outcome of a factor analysis of the data from quantitative research, which indicated the most frequent forms of misconduct, structured interviews were conducted.

\section{Data collection strategies}

The quantitative data were collected by means of a selfconstructed closed questionnaire based on the College Code for Student Conduct. The questionnaire provided a quantitative way of expressing the nature of student misconduct at the TVET college. A questionnaire in a Likert scale format was used, rating attitudes as well as perceptions on a continuum of very seldom, seldom, often and very often (Leedy \& Ormrod 2010:189).

Qualitative data for this study were collected by means of open-ended interviews with participants, by obtaining written essays from the participants and by noting observations. Interviews were voice-recorded and notes were taken down during the interviews.

\section{Data analysis}

Quantitative data collected were captured in the SPSS Programme for statistical analyses. The processed data were presented by means of frequency tables and bar graphs.

The qualitative data were analysed by means of thematic analysis. A thematic analysis of the interviews and essays was performed by taking apart paragraphs, sentences and words to make sense of, interpret and group the pieces of corresponding data, or the common constructs, into themes and categories.

\section{Quantitative reliability and validity}

The validity of the questionnaire as a quantitative instrument was confirmed to ensure that it did measure what was intended. 
Content validity of the questionnaire was ensured by submitting it to senior colleagues for review to determine whether the various questions were indeed relevant and measured what they were supposed to measure. The construct validity was satisfactorily secured by means of a statistical factor analysis by comparing inter-item correlations of the results from the questionnaire.

The application of the Cronbach's alpha coefficient, measuring inter-item correlations, demonstrates that an internal reliability of a high degree was obtained, showing that a similarity prevails amongst items that are supposed to measure a common construct. The items strongly correlate with one another, the internal consistency is high with the alpha coefficient being close to one. (Poorly formulated items do not correlate strongly, resulting in an alpha coefficient close to zero [Pietersen \& Maree 2014:216.])

\section{Qualitative trustworthiness}

Qualitative trustworthiness and credibility were ensured by comparing data codes to ensure that there is no drift in the definition of the codes. The coding was cross-checked by other researchers. Trustworthiness of the qualitative data was ensured by using member checking and providing thick, rich descriptions of the setting and the data, and spending prolonged time in the field (Creswell 2009:190-191).

\section{Ethical considerations}

As far as possible, ethical dilemmas that could possibly arise were avoided, endeavouring not to put respondents and/or participants at risk. For example, it was important to ensure that already marginalised groups (e.g. the poor) were not further disadvantaged by the research or that they did not misunderstand the purpose of the study (Creswell 2009:88-89). In this regard, research plans were reviewed by the institutional, college review 
board in an attempt to prevent such risks. Furthermore, the authors provided a letter of informed consent for participants to sign before engaging in the research (Creswell 2009:88-89).

For example, every questionnaire provided a note, ensuring confidentiality. Each person interviewed was briefed and provided with a letter of informed consent, which had to be signed prior to the interview being conducted.

In addition to individual approval, the Cape Peninsula University of Technology (CPUT) Research Committee and the principal of the college granted approval for this study to be conducted. Furthermore:

- Ethical clearance was sought and obtained from CPUT.

- Pseudonyms were used.

- The purpose of the study was explained to all participants.

- Participants were given the freedom to withdraw at any point.

\section{Findings}

\section{Gender of respondents}

The gender of the respondents is displayed in Table 5.1.

TABLE 5.1: Gender.

\begin{tabular}{lcc}
\hline Gender & Frequency & Percentage \\
\hline Male & 207 & 35.3 \\
Female & 372 & 63.4 \\
Missing & 8 & 1.4 \\
\hline Total & $\mathbf{5 8 7}$ & $\mathbf{1 0 0}$ \\
\hline
\end{tabular}

Table 5.1 shows that 372 of the respondents to the questionnaire were female (63.4\%), 207 respondents (35.3\%) were male and eight responses were missing. The majority of respondents were female.

\section{Position of respondents}

Table 5.2 shows the frequency and percentage of the respondents in terms of their position at the college. 
TABLE 5.2: Position of respondents.

\begin{tabular}{lcc}
\hline Formal position at the college & Frequency & Percentage \\
\hline Lecturer & 12 & 2 \\
NCV student & 188 & 32 \\
NATED student & 377 & 64.2 \\
Information on questionnaires incomplete & 10 & 1.7 \\
\hline Total & $\mathbf{5 8 7}$ & $\mathbf{1 0 0}$ \\
\hline
\end{tabular}

NATED, national accredited technical education diploma; NCV, national curriculum vocational.

Twelve lecturers (2\%) and $188 \mathrm{NCV}$ students (32\%) responded to the questionnaire. A total of 377 NATED students (64.2\%) responded to the questionnaire and 10 responses were missing. The majority of the respondents were NATED students.

\section{Campus}

Table 5.3 shows the campuses at which respondents were registered.

TABLE 5.3: Campus.

\begin{tabular}{lcc}
\hline Campus & Frequency & Percentage \\
\hline Campus 1 & 184 & 31.3 \\
Campus 2 & 82 & 14 \\
Campus 3 & 242 & 41.2 \\
Campus 4 & 79 & 13.5 \\
\hline Total & $\mathbf{5 8 7}$ & $\mathbf{1 0 0}$ \\
\hline
\end{tabular}

Table 5.3 shows that 184 responses (31.3\%) were received from Campus 1, and 82 responses (14\%) were received from Campus 2. A total of 242 responses (41.2\%) were received from Campus 3 , and 79 responses were received from Campus 4 . The majority of responses were received from Campus 3 followed by Campus 1, which are the largest campuses.

\section{The nature of student misconduct ranked}

Table 5.4 shows the frequency at which the different forms of student misconduct occur at the TVET college, according to ranking. 
TABLE 5.4: Nature of student misconduct ranked.

\begin{tabular}{llcc}
\hline Ranking & Nature of student misconduct & Mean & $\begin{array}{c}\text { Standard } \\
\text { deviation }\end{array}$ \\
\hline 1 & Absence without notification & 2.50 & 1.016 \\
2 & Use of mobile phones in class & 2.41 & 1.160 \\
\hline 3 & Late for class or practicals & 2.40 & 1.102 \\
\hline 4 & Unsatisfactory work by students & 2.25 & 0.919 \\
\hline 5 & Failure to hand in assignments & 2.24 & 0.989 \\
\hline 6 & Sleeping during class & 1.94 & 0.955 \\
\hline 7 & Undisciplined, disruptive behaviour in class & 1.94 & 0.980 \\
\hline 8 & Instigation & 1.92 & 0.937 \\
9 & III-mannered behaviour (e.g. rudeness, arrogance) in class & 1.86 & 0.960 \\
\hline 10 & Narcotic substance abuse on college premises & 1.81 & 1.037 \\
11 & Alcohol abuse on college premises & 1.73 & 0.986 \\
\hline 12 & College-related illegal strikes & 1.68 & 0.908 \\
13 & Dishonesty during examination or tests & 1.63 & 0.912 \\
\hline 14 & Bullying (e.g. physical, emotional or cyber bullying) & 1.60 & 0.931 \\
\hline 15 & Possession of pornographic material & 1.60 & 0.928 \\
\hline 16 & Harassment (e.g. sexual or racial harassment) & 1.55 & 0.922 \\
\hline
\end{tabular}

The nature of student misconduct at the TVET college is shown in Figure 5.1.

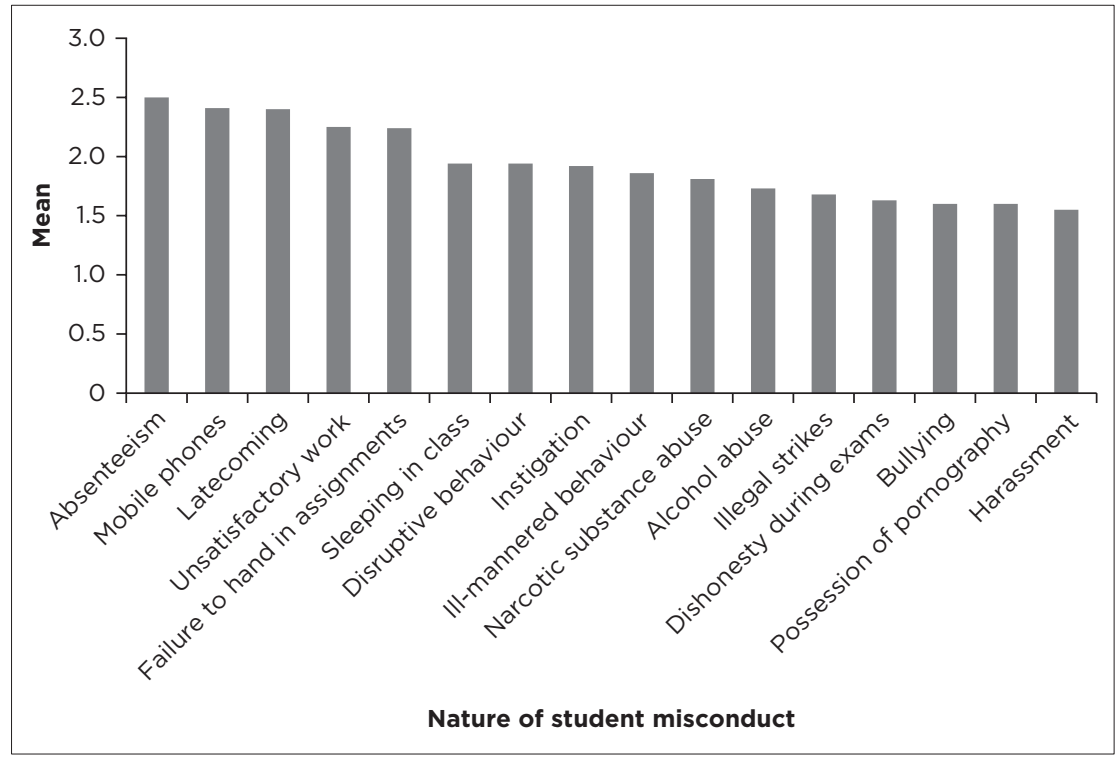

FIGURE 5.1: The nature of student misconduct ranked. 


\section{Absenteeism}

Absenteeism was ranked first (mean $=2.5$ ) as the most frequent form of student misconduct. Research in the North West province ranked absenteeism fourth (Oosthuizen 2007:4). Research in the Free State, Eastern Cape and Vaal Triangle ranked student absenteeism seventh (Wolhuter \& Van Staden 2007:359). Contrastingly, research in the township of Jouberton near Klerksdorp ranked student absenteeism second (Serame et al. 2013:65).

Absenteeism is not a serious form of student misconduct but may have a detrimental influence on students' academic performance as students who are not in class to receive tuition may not succeed academically. Absenteeism might possibly be the result of poorly presented lessons, students' lack of interest or students experiencing problems at home.

During interviews, a business studies lecturer in his middle forties agreed with ranking of absenteeism as the most frequent form of student misconduct:

The highest form of misconduct is absenteeism. Sometimes there is no reason but boring classes, work that is too difficult for students and students who find it difficult to concentrate are reasons that may contribute to absenteeism. (Lecturer, location unknown, date unknown)

Boring lessons may be the result of poorly qualified lecturers who lack subject knowledge and teaching skills (Smit \& Rossouw 2015:74). Lecturers lacking subject knowledge and teaching strategies may experience problems with student misconduct, including absenteeism. Students who find work too difficult may lack academic preparedness for school. Students who find it difficult to concentrate may have learning disabilities or experience problems at home. Interviews with participants also indicated that students who experience problems at home become chronically absent and in extreme cases cancel their registration at the college. 


\section{Use of mobile phones}

The use of mobile phones in class was ranked second (mean $=2.41$ ). In this regard, research conducted by Teh (2015:54-55) has also shown that electronic media contribute to student misconduct in Singapore. The use of social networks has become an issue in many classroom situations. Students seem to chat on their mobile phones without paying real attention to the outcomes of the lessons and therefore miss valuable content that is presented by the lecturer.

During interviews, a female senior lecturer specialising in business studies explained that she uses mobile phones positively rather than to focus on the negative:

Students like to use their mobile phones. I create WhatsApp groups to support students and send learning materials to students through WhatsApp and other applications. When I create the group for supporting students I lay down strict ground rules to students to understand that the purpose of the group is purely academic. (Lecturer, location unknown, date unknown)

The example cited above illustrates the important role wellqualified lecturers play in the TVET sector, and how a negative can be turned into a positive by being creative.

\section{Arriving late for class}

Students arriving late for lessons was ranked third (mean $=2.40$ ). Research conducted in Malaysia corresponds with this and shows a variety of reasons for students being late, including factors related to their socio-economic environments (Tie 2015:38-39). Students arriving late for class interrupt lessons and miss out on work that has already been covered during the first part of a particular period.

During an interview, a computer practice lecturer in her late fifties complained that a specific group of students always arrived late in her class: 
I have a group of students who always arrive late for class. When I ask them where they were, they do not even answer me and walk to their seats talking to each other. These students do not pay attention and talk when I explain work to them. Afterwards they come to me to explain the work I discussed when they were talking. Their behaviour makes me feel powerless and frustrated. (lecturer, location unknown, date unknown)

The lecturer explained that only certain students portray negative attitudes. The attitude of these students can be ascribed to indifference to academic work and can be described as deliberate misconduct aimed at disrupting classes. Students arriving late for classes disrupt lessons and fall behind as they miss out on content covered during the initial phases of a lesson.

\section{Unsatisfactory work}

Unsatisfactory work by students was ranked fourth (mean $=2.25$ ). Failure to hand in assignments was ranked fifth (mean $=2.24$ ). Research in North West ranked neglect of duty second (Oosthuizen 2007:4). Research at secondary schools in the Free State, Eastern Cape and Vaal Triangle ranked neglect of duty first (Wolhuter \& Van Staden 2007:359). Research in Jouberton ranked neglect of duty third (Serame et al. 2013:65). Students' unsatisfactory work therefore seems to be a recurring theme in South African education and training.

\section{Sleeping in class}

Sleeping in class was ranked sixth (mean $=1.94$ ). Sleeping in class can be related to the students' socio-economic background (Tie 2015:38-39). Another contributing factor for sleeping in class could possibly be boredom as a result of poor lesson preparation or the poor didactical skills of the lecturer.

\section{Disruptive behaviour}

Undisciplined, disruptive behaviour was ranked seventh (mean $=1.94)$. Ill-mannered behaviour was ranked ninth (mean = 1.86). Students who have learning disabilities or are academically 
behind may display disruptive behaviour to hide their embarrassment. Research in the North West province ranked disruptive behaviour seventh (Oosthuizen 2007:4). Research in Jouberton ranked disruptive behaviour sixth (Serame et al. 2013:65). Research in the Free State, Eastern Cape and Vaal Triangle ranked disruptive behaviour second (Wolhuter \& Van Staden 2007:359).

During an interview, a male senior lecturer in the engineering field of specialisation explained a noted difference between the behaviour of NCV students and that of NATED students. NCV students seem to be disinterested in their work, arrogant and disruptive during lessons, whereas NATED students cooperate and show interest in their work:

NCV students lack maturity in comparison with NATED students. I think the fact that NCV students receive everything for free lead to them not appreciating what they receive. NCV students are less mature compared with NATED students. NCV students receive bursaries covering their studies, accommodation and food, whereas NATED students are already working and pay for themselves. (Lecturer, location unknown, date unknown)

Disruptive and arrogant behaviour is more frequently encountered when dealing with NCV students. Therefore, lecturers need to employ a firmer approach when disciplining NCV students.

\section{Instigation}

Instigation was ranked eighth (mean $=1.92$ ). Students who have a personal problem or vendetta against someone or something and in most cases, towards the lecturers, use instigation to propagate their own agendas. Depending on the severity of the act, instigation may be viewed as an ordinary misconduct. However, when it spills over into violence, it can be seen as a serious misconduct and/or criminality (Oosthuizen et al. 2015:89; Smit \& Rossouw 2015:63). 


\section{Ill-mannered behaviour}

III-mannered behaviour was ranked ninth (mean $=1.86$ ). Students in Malaysia (Tie 2015:38-39) and the United Kingdom (Walker 2015:74-75) seem to be ill-mannered more often. Technical and Vocational Education and Training college students seem to be less inclined to ill-mannered behaviour than those in Malaysia and the United Kingdom.

\section{Narcotic substance abuse}

Narcotic abuse, which was ranked 10th, is considered a form of serious student misconduct and criminality (mean $=1.81$ ). Narcotic abuse can be referred back to the socio-economic backgrounds and to the peer pressure presenting itself in the TVET college sector. In research carried out in North West, narcotic abuse was ranked ninth (Oosthuizen 2007:4). Research in the Free State, Eastern Cape, Vaal Triangle and Jouberton ranked narcotic abuse sixth (Serame et al. 2013:65; Wolhuter \& Van Staden 2007:359).

\section{Alcohol abuse}

Alcohol abuse was ranked 11th and is considered a serious student misconduct (mean = 1.73). Research in the North West and Jouberton ranked alcohol abuse seventh. Research in the Free State, Eastern Cape and Vaal Triangle ranked alcohol abuse eighth (Serame et al. 2013:65; Wolhuter \& Van Staden 2007:359).

\section{Illegal strikes}

Staging college-related illegal strikes was ranked 12th and is considered a serious student misconduct (mean $=1.68$ ). This kind of misconduct usually occurs at TVET colleges when students are dissatisfied with situations that affect them directly, such as issues related to National Student Financial Aid Scheme (NSFAS) bursaries and/or other management-related disputes. 


\section{Dishonesty during tests and exams}

Dishonesty during exams was ranked 13th and is considered a serious student misconduct (mean $=1.63$ ). Misconduct during examinations highlights various factors that influence student behaviour, for example, students are unprepared for the examination, their socio-economic status, peer pressure, etc. (Tie 2015:38-39).

\section{Bullying}

Bullying was ranked 14th and is considered a serious student misconduct (mean $=1.60$ ). Bullying takes place in different forms and may include social media, slander and exclusion from groups. Research in the North West and Eastern Cape ranked bullying sixth (Wolhuter \& Van Staden 2007:359).

\section{Possession of pornographic material}

Possession of pornographic material was ranked 15th and could in some instances be considered a serious student misconduct (mean $=1.60)$. Research in the North West, Free State, Eastern Cape, Vaal Triangle and Jouberton ranked possession of pornographic material 10th (Serame et al. 2013:65; Wolhuter \& Van Staden 2007:359).

\section{Harassment}

Harassment was ranked 16th and is considered a serious student misconduct (mean $=1.55$ ). Harassment is the least frequent form of misconduct that occurs at colleges. Hence, harassment is not a frequent phenomenon of misconduct in the TVET college sector, but it is, however, forbidden under the code of conduct for students (WCC 2013:8-9).

A factor analysis was subsequently performed on the above forms of misconduct. A factor analysis is the grouping of items 
that correlate (Pietersen \& Maree 2014:216-217). Factor loadings below 0.3 were excluded. Through principal component analysis on SPSS, the different forms of misconduct that correlated were grouped under headings and labelled, as shown in Table 5.5.

TABLE 5.5: Factor analysis: The nature of student misconduct.

\begin{tabular}{|c|c|c|c|c|c|}
\hline \multirow[t]{2}{*}{ Nature of misconduct } & \multicolumn{2}{|c|}{ Eigenvalues } & \multicolumn{3}{|c|}{ Rotated component matrix } \\
\hline & Total & $\%$ Variance & $\begin{array}{c}\text { Factor 1: } \\
\text { Deliberate-ness }\end{array}$ & $\begin{array}{c}\text { Factor 2: } \\
\text { Negligence }\end{array}$ & $\begin{array}{c}\text { Factor 3: } \\
\text { Indifference }\end{array}$ \\
\hline $\begin{array}{l}\text { Dishonesty during } \\
\text { examination or tests }\end{array}$ & 0.502 & 3.140 & 0.746 & & \\
\hline $\begin{array}{l}\text { Possession of } \\
\text { pornographic material }\end{array}$ & 0.337 & 2.105 & 0.726 & & \\
\hline Harassment & 0.519 & 3.241 & 0.725 & & \\
\hline Bullying & 0.537 & 3.396 & 0.705 & & \\
\hline $\begin{array}{l}\text { Alcohol abuse on } \\
\text { college premises }\end{array}$ & 0.431 & 2.694 & 0.701 & & \\
\hline $\begin{array}{l}\text { Narcotic substance } \\
\text { abuse on college } \\
\text { premises }\end{array}$ & 0.402 & 2.512 & 0.682 & & \\
\hline $\begin{array}{l}\text { College-related illegal } \\
\text { strikes }\end{array}$ & 0.317 & 1.984 & 0.645 & & \\
\hline $\begin{array}{l}\text { III-mannered behaviour } \\
\text { in class }\end{array}$ & 0.670 & 4.185 & 0.566 & & 0.330 \\
\hline Instigation & 0.620 & 3.877 & 0.486 & & 0.379 \\
\hline $\begin{array}{l}\text { Undisciplined, } \\
\text { disruptive behaviour } \\
\text { in class }\end{array}$ & 0.755 & 4.716 & 0.446 & & 0.439 \\
\hline $\begin{array}{l}\text { Absence without } \\
\text { notification }\end{array}$ & 1.016 & 6.351 & & 0.763 & \\
\hline $\begin{array}{l}\text { Late for class or } \\
\text { practicals }\end{array}$ & 0.983 & 6.144 & & 0.695 & \\
\hline $\begin{array}{l}\text { Use of mobile phones } \\
\text { in class }\end{array}$ & 0.543 & 3.396 & & 0.685 & \\
\hline Unsatisfactory work & 5.584 & 34.903 & & & 0.831 \\
\hline $\begin{array}{l}\text { Failure to hand in } \\
\text { assignments }\end{array}$ & 1.975 & 12.345 & & 0.312 & 0.695 \\
\hline Sleeping during class & 0.808 & 5.051 & & 0.399 & 0.422 \\
\hline
\end{tabular}

\section{Factor 1: Deliberateness}

Table 5.6 shows the grouping of the forms of deliberate misconduct and the items that constitute serious misconduct. 
TABLE 5.6: Factor 1: Deliberate misconduct.

\begin{tabular}{lcccc}
\hline Nature of misconduct & Loading & Mean & Std. Deviation & $\boldsymbol{N}$ \\
\hline Undisciplined, disruptive behaviour in class & 0.446 & 1.94 & 0.980 & 555 \\
III-mannered behaviour in class & 0.566 & 1.86 & 0.960 & 555 \\
Instigation & 0.486 & 1.92 & 0.937 & 504 \\
Bullying & 0.705 & 1.60 & 0.931 & 563 \\
Harassment & 0.725 & 1.55 & 0.922 & 563 \\
Dishonesty during examination or tests & 0.746 & 1.63 & 0.912 & 568 \\
\hline Alcohol abuse on college premises & 0.701 & 1.73 & 0.986 & 568 \\
Narcotic substance abuse & 0.682 & 1.81 & 1.037 & 569 \\
\hline Possession of pornographic material & 0.726 & 1.60 & 0.928 & 558 \\
\hline College-related illegal strikes & 0.645 & 1.68 & 0.908 & 548 \\
\hline
\end{tabular}

The misconducts listed in Table 5.6 as deliberate misconduct constitute serious forms of student misconduct. Students guilty of using narcotic substances or alcohol may also display undisciplined, disruptive behaviour in class. These students may bully or harass other students in an attempt to divert attention from themselves. As a result of their disruptive behaviour, students displaying deliberate forms of misconduct may fall behind academically. During written exams, these students may resort to dishonest ways to pass. Deliberate forms of misconduct may be a cry for help or an attempt of academically poor students to hide their inabilities and draw the attention away from their work.

\section{Factor 2: Negligence}

The items grouped in Table 5.7 can be related to student negligence or disregard.

TABLE 5.7: Factor 2: Negligence.

\begin{tabular}{lcccc}
\hline Nature of misconduct & Loading & Mean & Std. Deviation & $\boldsymbol{N}$ \\
\hline Failure to hand in assignments & 0.312 & 2.24 & 0.989 & 556 \\
Absence without notification & 0.763 & 2.50 & 1.016 & 544 \\
Late for class or practicals & 0.695 & 2.40 & 1.102 & 549 \\
Sleeping during class & 0.399 & 1.94 & 0.955 & 565 \\
Use of mobile phones in class & 0.685 & 2.41 & 1.160 & 558 \\
\hline
\end{tabular}

Students who are absent often also seem to be late for classes and fail to hand in their assignments regularly. Absenteeism 
seems to have an influence on students' academic performance, as these students fall behind in their work and may therefore be unable to complete their assignments. Late coming and the use of mobile phones in class may have a negative influence on students' academic performance when they miss work or do not attend lessons. Negligent students may be absent, late or fail to hand in their assignments owing to forgetfulness caused by their personal problems.

During interviews, a female senior lecturer specialising in business studies explained how she assists students who are negligent:

I assist negligent students by providing them with notes to remind them of tasks they have to complete. I also make use of peers to assist these students. (Lecturer, location unknown, date unknown)

The efforts of this lecturer have seen many negligent students successfully completing their tasks and graduating.

\section{Factor 3: Indifference}

The items grouped in Table 5.8 represent students' indifference.

TABLE 5.8: Factor 3: Indifference.

\begin{tabular}{lcccc}
\hline Nature of misconduct & Loading & Mean & Std. Deviation & $\boldsymbol{N}$ \\
\hline III-mannered behaviour in class & 0.330 & 1.86 & 0.960 & 555 \\
Instigation & 0.379 & 1.92 & 0.937 & 504 \\
Undisciplined, disruptive behaviour in class & 0.439 & 1.94 & 0.980 & 555 \\
Unsatisfactory work & 0.831 & 2.25 & 0.919 & 541 \\
Failure to hand in assignments & 0.695 & 2.24 & 0.989 & 556 \\
Sleeping during class & 0.422 & 1.94 & 0.955 & 565 \\
\hline
\end{tabular}

Students who are indifferent, or do not really seem to care about their work, may therefore make themselves guilty of the forms of misconduct listed in Table 5.8. Students who are indifferent may provide unsatisfactory work, fail to hand in their assignments and sleep in class because they seem to lack motivation and do not care. In an attempt to draw attention away from their work, these students may display disruptive and 
ill-mannered behaviour in class. These students may also instigate their friends, with a view to avoid the embarrassment of being the only ones to submit unsatisfactory work.

\section{Dummary of findings}

On the basis of the factor analysis of the mean scores of the various forms of student misconduct on the four campuses of the TVET colleges, the following themes emerged, which can broadly be categorised as:

- Deliberate forms of misconduct

- Student negligence as a form of misconduct

- Student indifference as a form of misconduct.

In terms of the mean score frequencies of the various items, student negligence as a form of misconduct seems to be the most prevalent sub-theme of misconduct. The following were the rating of the different aspects involved:

1. absenteeism

2. use of mobile phones in class

3. arriving late in class

4. failure to hand in assignments

5. sleeping in class

6. undisciplined, disruptive behaviour in class.

\section{Discussion}

Although these forms of student misconduct are not acceptable, they cannot be classified as forms of serious misconduct bordering on (or in actual fact being) criminality as is the case with the sub-theme deliberate forms of student misconduct. Examples of criminality could very well include aspects such as illegal strikes, narcotic substance abuse, instigation, harassment, bullying, etc.

However, that being said and the ordinary forms of the subtheme student negligence as a form of misconduct being 
classified as lesser forms of misconduct, it still qualifies as misconduct, which is not acceptable. Neither does it meet the standard of the ordinary norms as depicted by the relevant TVET statutory provisions (WCC 2013:8-9).

More importantly, this kind of conduct does not meet the general statutory norms in the particular statutory provisions, nor does it meet the required validation vested in higher standard of conduct validated by the basic norm (Grundnorm) for education.

The Grundnorm for education is clearly vested in 'the supreme law of the Republic' - the provisions of the South African Constitution (SA 1996). In this regard, Section 29 of the Constitution determines that everyone has the right to basic as well as further education. One of the irrefutable tenets for sound education is an orderly teaching and learning environment needed for conducive education to be achieved. A disruptive, disorderly environment in the classroom or on campus is destructive for the Grundnorm of sound education.

Misconduct is destructive not only for the individual offenders themselves but also destructive of the rights of the compound depicted in 'everyone' in Section 29 of the Constitution. For example, my chronic absenteeism and my sleeping in class basically have a detrimental effect on my (individual) right to education, whereas my late coming in class and my disruptive behaviour in class have a distracting and disturbing effect on the right to education of everyone else in class (or on campus).

The poor results of TVET colleges dealt with in the first part of this chapter obviously need to be redressed. It might be a good thing for these institutions to clearly define the Grundnorm of their existence and to address seemingly small hindrances such as the so-called 'ordinary' forms of misconduct in the teaching and learning environment of the classroom.

As the English idiom goes, little leaks sink the ship. 


\section{Chapter 6}

\section{Application of due process in ensuring fair learner disciplinary hearings}

Nicholus T. Mollo

Department of Education Law, Faculty of Education, North-West University, Potchefstroom, South Africa

Rika Joubert

Edutel Higher Education, Roodepoort, South Africa

\section{Abstract}

Fair treatment of learners during disciplinary hearings is of paramount importance. Some critical incidents have been reported in newspapers and some incidents of unfair learner disciplining have led to litigation. The findings of a study investigating 'education managers' understanding and

How to cite: Mollo, N.T. \& Joubert, R., 2019, 'Application of due process in ensuring fair learner disciplinary hearings', in C.B. Zulu, I.J. Oosthuizen \& C.C. Wolhuter (eds.), A scholarly inquiry into disciplinary practices in educational institutions (NWU Education and Human Rights in Diversity Series Volume 2), pp. 113-140, AOSIS, Cape Town. https://doi. org/10.4102/aosis.2019.BK157.06 
implementation of due process during learner discipline' have highlighted the correct implementation of different aspects of due process. The main finding was that (Mollo 2015):

$[M]$ ost principals do not have sufficient conceptualisation of the due process and this, in turn, has a negative influence on the way in which they apply due process during learner discipline in schools. (p. 197)

This chapter draws from the study and outlines the nature and determinants of due process to facilitate its application during learner disciplining. It provides that proper conceptualisation of due process and learner disciplinary process will lead to an effective practical application of due process in all disciplinary actions. It also provides recommendations about role-players, strategies, tools and content that can be used to improve due process.

\section{Introduction}

Due process is an important concept in learner discipline because it ensures that learners are disciplined fairly. Section 33 of the Constitution of the Republic of South Africa (hereafter referred to as the Constitution) states that 'everyone has the right to administrative action that is lawful, reasonable and procedurally fair' (Republic of South Africa 1996a:n.p.). In learner discipline, administrative action may refer to the process that is followed to deal with a learner who has committed misconduct. As stated in Section 8(1) of the South African Schools Act (hereinafter referred to the Schools Act), 'it is a function of a governing body to follow the correct process of adopting a code of conduct for learners and, within this code, make provision for due process' (Republic of South Africa 1996b:n.p.). Although the concept of 'due process' is not explained in the Schools Act, it essentially means that fair steps are applied to obtain satisfactory disciplinary outcomes. Due process must be applied in investigations where the rights, privileges and freedoms of learners could be affected, for example, when a learner is temporarily or permanently removed from school. 
The South African education system has created a new legal environment, which requires that principals and governing bodies should be knowledgeable about learner discipline. Principals must ensure that learners are disciplined in a fair way. Section $16 \mathrm{~A}(2)(\mathrm{f})$ instructs principals to advise the 'governing body and the disciplinary committee on the correct procedure that must be followed when learners who have committed serious misconduct are disciplined' (Republic of South Africa 1996b:n.p.). Proper advice will ensure fair disciplinary hearings. That is why principals must have a 'proper conceptualisation of due process and ensure that learners are disciplined fairly to avoid the infringement of due process' (Mollo 2015:9).

\section{Durpose of this chapter}

In this chapter, the meaning and content of due process is explained, and practical guidelines on how to conduct a disciplinary hearing are provided. This chapter aims to provide a solution to the problems (findings) that were identified during the study that was conducted by Mollo (2015). These solutions are aimed at educators, principals, disciplinary committees and school governing bodies (hereinafter referred to as the governing body) to improve the application of due process and ensure fair learner disciplinary hearings.

\section{Background}

Numerous instances of the violation of due process during learner disciplining have been publicised in the media (Mollo 2015:5). These critical incidents include suspension and expulsion of learners from schools for improper hair style, bad behaviour, violence in schools, initiation activities, bullying, etc. In some of these cases, learners were suspended and expelled from schools without applying due process and in some the due process was applied incorrectly. As a result, the parent(s) decided to report these incidents to the Department of Basic Education and some 
even approached the courts. One example of litigation owing to a school not following due process is the court case of Antonie $v$ SGB, the Settlers High School and Head, Western Cape Education Department. 'The decision of the school to suspend a learner for the offence of wearing dreadlocks which does not constitute serious misconduct was set aside' (Antonie $v$ SGB, the Settlers High School and Head, Western Cape Education Department).

The findings of a study that was conducted by Mollo (2015) where he investigated 'education managers' understanding and implementation of due process during learner discipline' shed light on the correct implementation of different aspects of due process. This chapter draws from the above study to outline the nature and determinants of due process to support its application in ensuring fair learner disciplining. The chapter also looks at the practical application of due process by the governing body to ensure that disciplinary hearings meet the standards of fundamental fairness.

\section{Methodology}

Mollo's (2015) study had followed a qualitative research approach guided by an 'interpretative paradigm' in which a 'case study design' was used. The study was a single case study comprising eight high schools sampled purposively. These schools were experienced in dealing with learner misconduct. 'Four of the schools were urban schools, two were township schools and two were rural schools' (Mollo 2015:19).

Different data collection methods were used to ensure trustworthiness (Terre Blanche, Durrheim \& Painter 2006:287). 'The data collection methods that were used were interviews and document analysis' (Mollo 2015:114, 115). Data collected were also returned to participants so that they could comment on their accuracy (Struwig \& Stead 2001:146).

The participants were identified by means of purposive sampling, as 'qualitative researchers select participants or objects 
that will provide the most information about what is being investigated' (Leedy \& Ormrod 2016:262; Nieuwenhuis 2016:85). The study participants comprised a few members who held various positions in their school's management team, and were responsible for learner discipline in their schools, namely, head of department, deputy principal and principal. These participants were interviewed. Document analysis was also used for data collection. Documents that were analysed included unpublished 'documents such as schools' codes of conduct for learners, notices of hearings and minutes of disciplinary hearings' (Mollo 2015:18).

The correct ethical process was followed by obtaining ethical clearance and informed consent from all participants. 'Participants were made aware of the voluntary participation, informed consent, safety of participants, privacy and trust' (Mollo 2015:21).

The main finding of the study was that most participants struggled to understand and implement due process (Mollo 2015:197). The main challenge was that they could not understand due process as an aspect concerning the fairness of the process (Mollo 2015:124). Although some participants were trying to show an understanding of due process, the majority were not aware that due process entails both 'procedural due process and substantive due process' (Mollo 2015:187). Moreover, the participants considered procedural due process as just following a disciplinary procedure (Mollo 2015:187). In addition, most of the participants who took part in the interviews did not have a clear conceptualisation of 'substantive due process' (Mollo 2015:188). Lastly, most participants could not implement the learner disciplinary process as required (Mollo 2015:184). This was also evident when notices, minutes and code of conduct for learners were analysed. Most schools could not write detailed notices and minutes (Mollo 2015:142, 144). 'The majority of the code of conduct for learners did not sufficiently provide for due process' (Mollo 2015:141). Most schools did not have learner disciplinary policies (Mollo 2015:195). 
These findings as well as recommendations for applying due process in learner disciplinary hearings are integrated with the conceptual and theoretical perspectives presented further.

\section{- Conceptualisation of learner disciplinary process}

'The learner disciplinary process is the process whereby steps that are taken to educate learners on how to behave in an orderly manner will be acceptable to everyone' (Mbatha 2008:9). For these steps to be acceptable, they need to be fair. Even though the focus of this chapter is on applying due process, it is necessary to first conceptualise the learner disciplinary process in general. According to Joubert (2008:11), discipline is about helping learners to conduct themselves properly, encouraging selfdiscipline, self-control and taking responsibility for their actions.

The manner of looking at disciplining and punishing learners has changed over time. In South Africa, views and attitudes are influenced greatly by the norms and values embedded in the Constitution. The Constitution promotes values and norms that support human rights, which means that nurturing of a human rights culture must be one of the important goals to achieve in education in South Africa.

The process of disciplining learners should be taken as an activity that teaches learners to behave in an acceptable manner. The learners' behaviour should be in accordance with the code of conduct of a school. In terms of paragraph 10 of the Guidelines for the Consideration of Governing Bodies in Adopting a Code of Conduct for Learners (hereafter referred to as Guidelines) (DBE 1998), the disciplinary process should include the 'prevention, proactive advice, counselling, penalties and corrective measures'. Therefore, a disciplinary process in the school environment is about helping learners to behave in the correct way. Learners should know that self-discipline is one of their duties that they must fulfil on a daily basis.

Learner behaviour should be managed in a positive way to promote the 'child's best interest' (Republic of South Africa 
1996a:s. 28[2]). This should be achieved, so that the rights of learners and educators are not infringed upon in schools. Use of penalties and corrective measures requires due process, but corrective actions and punishment are not the only ways of disciplining learners. Preventative measures and counselling should form part of the disciplinary process.

\section{Human rights and the learner disciplinary process}

The Constitution commits everyone to the 'establishment of a society based on democratic values such as human dignity, equality and freedom' (Republic of South Africa 1996a:s. 7[1]). As with all the values contained in the Constitution, human rights are intended to avoid infringing on other people's rights. According to Chapter 2 of the Constitution (Bill of Rights; Republic of South Africa 1996a), these rights include:

$[D]$ emocracy; non-discrimination and equality; privacy, respect and dignity; non-violence and the freedom and security of a person; freedom of expression and right to demonstrate and present petitions; school environment and education. (Ch. 2)

The enjoyment of these rights by learners should not cause harm to others. Furthermore, Section 1 of the Constitution confirms the values of 'accountability, responsiveness and openness' (Republic of South Africa 1996a:s. 1).

\section{Managing the disciplinary process}

Managing learner behaviour in a positive way is important in creating a disciplined school environment. Serakwane (2007) provides that the proactive discipline strategies should include the:

$[C]$ reation of a good educator-learner relationship; empowering learners to make intelligent decisions; inculcation of values; working cooperatively with learners, their parents and other support structures and adopting a democratic style of teaching. (p. 137) 
Schools that manage the disciplinary hearings correctly have less negative occurrences that concern fairness.

\section{Stakeholders in the learner disciplinary process}

Implementing a disciplinary process in a positive way is the responsibility of the whole school. Educators, non-teaching staff and the school management team have different roles to play in the learner disciplinary process.

\section{Conceptualisation of due process}

This chapter is based on the conceptual framework as presented in Mollo (2015:12). Figure 6.1 shows the visual presentation of the 'conceptual framework that summarises the aspects involved in the conceptualisation and the practical application of due process and the way they interconnect' (Mollo 2015:11).

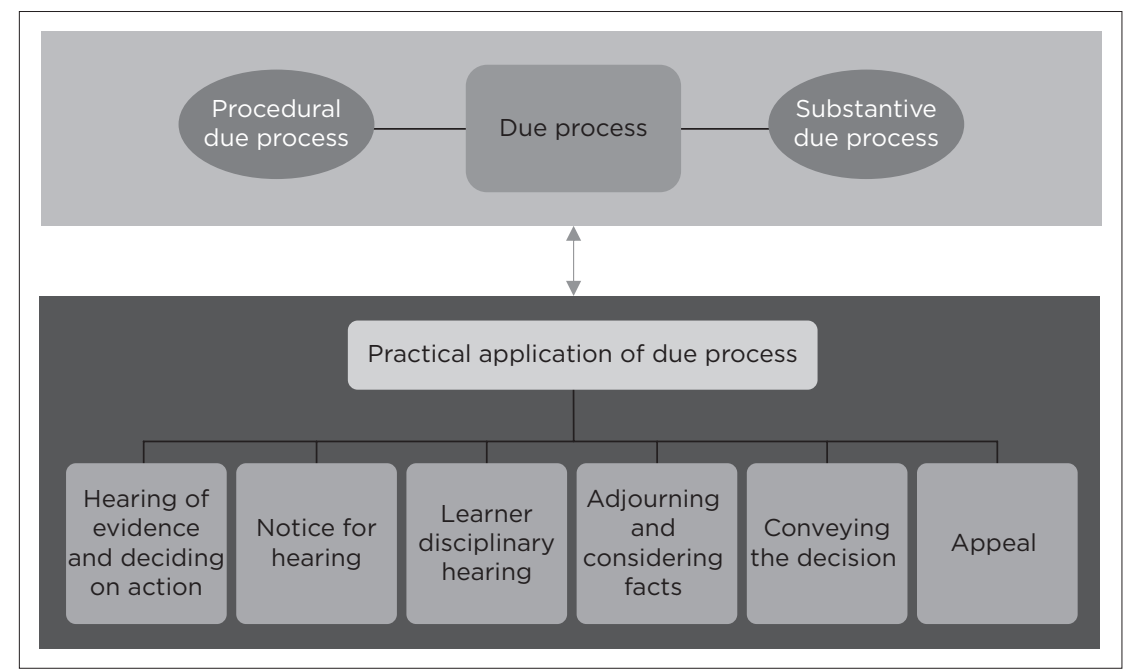

Source: Mollo (2015).

FIGURE 6.1: Conceptual framework of due process on learner discipline in South Africa. 
Two main interrelated issues - due process and the practical application of due process - are involved. 'These concepts are interrelated because a learner disciplinary process cannot be fair if principals do not conceptualise and cannot apply due process correctly' (Mollo 2015:12). The top block represents the nature of due process. The bottom block depicts the practical application of due process. Together, these provide an overview of the procedure principals should follow when disciplining learners.

\section{Due process}

The term 'due process' is uncommon in South African legal literature (Joubert 2008):

It is found in American legal literature and specifically the 5th and 14th Amendments to the United States Constitution, which require the state to provide due process to an individual prior to taking from that person life, liberty and property (U.S.A., 1788). (p. 43)

'Due process means fair treatment in accordance with the correct judicial system' (South African Concise Oxford Dictionary 2006:359). This means that the application of due process should meet the legal requirements. According to Joubert (2008:43) and Joubert (2015:129), 'due process refers to the fairness of the process'. The application of due process is not a new thing. The origin of due process is as old as the Magna Carta and can be 'traced back to 1215' (Orth 2003:7). Due process was introduced in South African schools 'in 1996 when the Schools Act was passed by parliament' (Republic of South Africa 1996b:n.p.). The purpose of including due process in the Schools Act was to promote fairness. Section 8(5) of the Schools Act provides that (Republic of South Africa 1996b):

$[T$ ]he governing body has a policymaking responsibility which involves the process of developing a code of conduct for learners and must ensure that this code contains provision for due process. (s. 8[5])

A code of conduct for learners that does not promote due process leads to negative discipline. A good clarification of the 
concept of due process is that 'it entails both procedural due process and substantive due process' (Alexander \& Alexander 2005:435; Dayton 2001, in Davidson 2003:14; Joubert 2008:130, 2015:130). This means that these two concepts should be applied concurrently during the disciplinary process.

\section{Procedural due process}

The disciplinary process cannot be fair if procedural due process is not applied. According to Patterson (1976:12), Rossow and Warner (2000:198), Russo (2001:19) and Joubert (2015:128), 'procedural due process means to follow a fair procedure, fair steps or fair methods when disciplining learners'. Procedural due process cannot be applied in isolation without being incorporated with 'substantive due process' (Mollo 2015:38). Leaders and managers who cannot apply these two concepts concurrently are likely to conduct an unfair disciplinary hearing.

\section{Substantive due process}

Substantive due process, on the other hand, requires that clear rules and regulations are followed to ensure a fair process. The standard of such rules and regulations should be appropriate and fair (Alexander \& Alexander 2005:435; Joubert 2008:45; Patterson 1976:12; Rossow \& Warner 2000:199). Having a proper conceptualisation of the 'due process and the two types of due process' will enable principals to apply the learner disciplinary process fairly (Mollo 2015:137).

\section{Practical application of due process}

Practical application of due process forms part of the whole disciplinary process in a school. Principals, governing bodies and disciplinary committees should be able to apply the disciplinary steps fairly. 


\section{Preliminary investigation}

Preliminary investigation is an initial investigation stage meant to determine whether the 'complaint has any substance and whether sufficient evidence is available that will ensure justice' (Oosthuizen, Smit \& Roos 2015:186). A learner cannot be referred to a hearing without there being a proper preliminary investigation. It is also called the 'hearing of evidence and deciding on action' (Mollo 2015:12). This is the stage where good investigative skills are needed. The purpose of conducting a preliminary investigation is to get 'evidence' so that the evidence leader (hereafter referred to as 'prosecutor') can make a correct decision (Squelch 2000:24). Mollo (2015) states that:

[/]t refers to a systematic or formal inquiry that is carried out by the principal in order to establish whether or not there are sufficient grounds for a formal disciplinary hearing. (p. 15)

If there is no evidence, a hearing should not be conducted.

Smith, Beckmann and Mampane (2015:2385) indicate that the evidence leader is tasked with conducting the 'initial investigation and collection of relevant evidence or artefacts in support of the case to be presented before the disciplinary committee'. According to Smith et al. (2015:2370), the principal can appoint the prosecutor in accordance with Section 4.1 of Chapter $A$ in Revised Personnel Administrative Measures (DBE 2016). A member of the teaching staff in a school is delegated by the principal the role of a prosecutor during the disciplinary hearings. The duty of the prosecutor includes conducting a preliminary investigation. In most of the schools, the task of the prosecutor is delegated to the deputy principal. It must be clear, however, that the deputy principal is not the only person who can be delegated the task of being a prosecutor. Such a delegation allows the principal to be part of a disciplinary committee to avoid being a 'witness, prosecutor and judge in the same case' at the same time (Michiel de Kock $v$ the Head of Education and Other, Province of Western Cape). 
Due process also plays an important role at this stage. For successful disciplinary proceedings, the preliminary findings should be informed by the procedural and substantial due process. Preliminary investigation activities that require the consideration of procedural and substantial due process include searching; urine testing; using tape recordings and CCTV footage as evidence; preliminary hearing where an accused learner and witnesses are interviewed, and the accused learner is required to confess that what they are saying is true.

As indicated above, the searching of learners is often necessary to help the principal find evidence of 'serious misconduct'. In terms of paragraph 3.8 of the Guidelines, 'serious misconduct' that may require a fair searching procedure during the preliminary investigation includes, but is not limited to, 'dangerous weapons, firearms, drugs, or harmful dangerous substances, stolen property, or pornographic material brought on to the school property' (DBE 1998:n.p.).

Conducting a search as part of a preliminary investigation requires that the principal conduct the search and seizure in a procedural and substantive fair way and that the confiscated items are handled with care. According to Section 8A(2), a search can only be conducted when there is substantially fair and reasonable suspicion. Suspicion has to do with saying something without basing it on facts. This means that a person says something without proof. According to Shabaan Bin Hussien and Others $v$ Chong Kam and another, 'suspicion arises at or near the starting point of an investigation of which the obtaining of prima facie proof is the end'.

Section 8A(4) of the Schools Act (Republic of South Africa 1996b:s. 8A[4]) indicates that a fair search procedure that should 'be considered by the principal or delegate include the fact that the search should be conducted by the principal or the delegate of the same gender as the learner'. It should be carried out in a place where others cannot see or hear. There must be a witnessing educator, of the same sex as the searched learner, in the 
searching place. The privacy of the learner's body should be respected during the process of searching. Section $8 A(5)$ states that the confiscated items should be handled with care.

Section 8A(5-7) (Republic of South Africa 1996b:s. 8A[5-7]) explains that the handling of confiscated items during a search includes the fact that the item 'must be clearly and correctly labelled with full particulars of a learner'. It has to be included in the record book of the school. Should it happen that the police decide not to go to the school to collect the confiscated item(s), the principal or the delegate must immediately take the item(s) to the police station and an official receipt must be issued by the police personnel receiving the item(s).

Urine testing can also provide evidence against the use of drugs and alcohol and is performed during the preliminary investigation. The procedure that is used when searching learners in terms of gender, privacy, adult witness and labelling is also applicable during the testing of urine. In addition, the device to be used is the one that has been identified and published by the minister.

Video and tape recordings can also serve as evidence of serious misconduct. Principals should be careful if they desire to use interception devices, CCTV footage and recordings of an accused learner during confession as evidence. They should not violate the rights of learners. Section 14 of the Constitution (Republic of South Africa 1996a), which is about the 'right to privacy', and Section 36 of the Constitution, which is about the 'limitation of rights', should be considered when using interception device, CCTV footage and tape recordings as evidence. Section 2 and 5(1) of the Regulation of Interception of Communications and Provision of Communication-Related Information Act 70 of 2002 (hereafter referred to as RIC 2002) states that no one except authorised personnel and based on reasonable grounds may intentionally intercept or attempt to intercept another person's communication without prior written consent. In addition, principals must make sure that the video footage has 
words and non-verbal communications that are accurate and clear ( $S \vee$ Baleka, 2005). The quality of the video must be good (Moloko $v$ Commissioner Diale and Others, 2004). Video footage must be relevant to the allegation (Afrox Ltd $v$ Laka and Others, 1999). It is suggested that there should be signage that indicates that the school is using the security surveillance cameras.

Most principals use the preliminary hearing to investigate learners' misconduct. As it involves a search and urine test, it is also important that the preliminary investigation hearing is conducted by the principal or the delegate of the same gender in a private area where there is a witnessing educator of the same gender as that of the investigated learner. Some of the activities that take place during the preliminary hearing include the hearing of the accused learner and witnesses. A preliminary hearing report should be written, which specifies the names of people who were present, date, time, venue, allegation, findings, evidence and a recommendation as to whether a learner should attend a disciplinary hearing or not.

The code of conduct for learners should be clear about what constitutes minor misconduct, serious misconduct and what the consequences of unacceptable behaviour are (High School Vryburg and the SGB of the High School Vryburg $v$ The Department of Education of the North West Province).

According to paragraph 11 of the Guidelines, offences that may be included in (DBE 1998):

$[A]$ code of conduct for learners which should be known by principals, staff, governing body, disciplinary committees, parent(s) and learners include but are not limited to the conduct which endangers the safety and violates the rights of others; possession, threat or use of a dangerous weapon; possession, use, transmission or visible evidence of narcotic or unauthorised drugs, alcohol or intoxicants of any kind; fighting, assault or battery; immoral behaviour or profanity; falsely identifying oneself; harmful graffiti, hate speech, sexism, racism; theft or possession of stolen property including test or examination papers prior to the writing of the tests or examinations; unlawful action, vandalism, or destroying or defacing school property; disrespect, objectionable behaviour and verbal abuse directed to educators or 
other school employees or learners; repeated violation of school rules or the code of conduct for learners; criminal or oppressive behaviour such as rape and gender based harassment; victimisation, bullying and intimidation of other learners; infringement of examination rules; and knowingly and wilfully supplying false information or falsifying documentation to gain an unfair advantage at school. (para. 11)

The above-mentioned examples of misconduct should be reported to the principal. The learner disciplinary policy should be clear about the procedure of reporting misconduct and procedures for conducting the preliminary investigation as indicated above. Principals should make sure that all learners who have been accused of having allegedly committed a serious misconduct attend a preliminary investigation. This will address the finding in Mollo (2015:130), which provides that some of the principals avoided conducting disciplinary hearings and some conducted hearings themselves alone in their offices. The principal must be able to separate minor misconduct from serious misconduct (Antonie $v$ SGB, the Settler High School and Head).

Certain forms of serious misconduct might require that a learner is removed or requested to leave the school premises immediately to ensure the safety of others (Phillips $v$ Manser). Although the principal will be safeguarding the lives of others, he or she must be careful to act fairly and not to act in an ultra vires manner. According to Bray (2005:134), 'ultra vires means to act beyond the legal powers'. Principals who perform their duties according to law avoid the ultra vires acts.

To avoid an ultra vires act, Section 9(1) of the Schools Act (Republic of South Africa 1996b:s. 9[1]) indicates that the principal should contact the chairperson of the governing body if there is a learner that is threatening the safety of others'. 'The chairperson may authorise an immediate suspension of such a learner from the school premises as a precautionary measure' (Mollo 2015:189). Such a learner should be granted a reasonable opportunity to represent himself or herself [audi alteram partem] before the immediate suspension can take place. Section 9(1A) of the Schools Act provides (Republic of South Africa 1996b:s. 
9[1A]) that in such a case 'the governing body must conduct disciplinary hearings against a learner within seven school days after the suspension of such a learner'. Section 9(1B) further provides that approval must be obtained from the head of department of the province if a hearing did not take place within seven school days after a learner was removed from school on a temporary basis. This means that the principal or his or her delegate must issue a notice for a disciplinary hearing soon after the preliminary investigation and immediate suspension.

\section{Issuing notices that have sufficient information}

A notice for a disciplinary hearing (hereafter referred to as notice) refers to a document that is issued to a learner and parents in advance inviting them to attend a disciplinary hearing. Detailed notice should be given to all learners and their parents who have been charged with misconduct that is serious and may require a school to conduct a disciplinary hearing. Issuing of a notice promotes the right to information. Gilg (2010:22) indicates that 'procedural due process requires that a government institution should provide notice whenever a liberty or property interest is at stake'. A notice should be clear and understandable. Burns (1999:169) mentions that, 'to enable the learner in question to be ready for the hearing, the school must give him/her notice that has appropriate information'.

The principal must make sure that notice is issued to the learner and his or her parents immediately after the preliminary investigation. The notice should be based on the preliminary investigation report.

The reason for encouraging principals to issue a detailed notice is based on the study conducted by Mollo (2015:138), which provides that most of the schools $(n=3 / 8)$ issued notice with insufficient information. On the basis of this finding, principals are advised to use the Example of a Code of Conduct 
for a School (DBE 2008:31). The notice that has sufficient information is the one that has a 'learner's name, ID number, subject and educator's name' (DBE 2008:31). In addition, it should specify the 'date, time, venue of hearing, date served, charge, date of offence and nature of the alleged offence' (DBE 2008:31). Furthermore, 'if the learner is suspended from class, the notice should provide a short statement that explains that a learner has been suspended from class' for a specific duration (DBE 2008:31). Afterwards, the notice must indicate what will be happening during the period of suspension from class. Finally, the notice should clarify whether the learner will be allowed in the school premises and what will be the condition for allowing the learner in the school premises.

Principals should use different methods to send the notice to parent(s). Depending on the schools' accessibility to different modes of communication, a notice can be sent via a school messenger, email or fax. The notice should request the parent(s) to acknowledge receipt of the notice. The principal must make sure that he or she receives an acknowledgement of receipt on the same day of sending the notice. This way the principal can ensure that the learner and parent(s) have been informed timeously about the hearing and they have enough time to prepare themselves.

\section{Disciplinary committee}

According to paragraph 13.3 of the Guidelines, 'a hearing must be conducted by a disciplinary committee' (DBE 1998). No other committee or individual can conduct a learner disciplinary hearing except the disciplinary committee. Paragraph 13.2 of the Guidelines provides that this 'disciplinary committee should consist of the members designated by the governing body' (DBE 1998). The inclusion of the governing body members on the disciplinary committee is intended to guarantee that the governing body participates in disciplining learners who have committed serious misconduct. It becomes easy for the governing 
body to take decisions because some of its members were part of the disciplinary hearing and have first-hand information. Joubert (2015:136) provides that 'a disciplinary committee should be selected for every hearing'. Members of the (Joubert 2015):

$[D]$ isciplinary committee should consist of at least the principal or deputy principal, the chairperson of the governing body, a parent member of the governing body, an educator and a learner in the case of a secondary school. (p. 136)

The reason for involving different stakeholders is to ensure fairness.

Mollo (2015) states that:

[/]t would appear from paragraph 13.2 and 13.4(e) of the Guidelines that, only once it has been ascertained that the members of the governing body would not conduct a hearing in a fair way, then a neutral person who is not a member of the governing body may chair a hearing. (p. 81)

Members of the governing body who have an interest in the case should recuse themselves from the hearings.

The learner disciplinary policy should indicate how the disciplinary committee should be formulated and who should be part of the committee. Section 30(1)(b) of the Schools Act (Republic of South Africa 1996b) allows:

$[T]$ he governing body to appoint persons who are not members of the governing body to serve in the committees on grounds of their expertise, but a member of the governing body must chair each committee. (s. 30.1.b)

Persons with expertise should assist the governing body in conducting fair learner disciplinary hearings. 'The disciplinary committee must be chaired by a member of the governing body' (Section 30(1)(b) of the Schools Act, 1996b).

The learner disciplinary policy should specify the roles of the members of the disciplinary committee. Smith et al. (2015) state that:

$[T]$ he role of the disciplinary committee in the disciplinary hearing is intended to ensure that the hearing is objective and unprejudiced and, 
crucially, that learners are treated fairly, justly and are safeguarded against unfair and arbitrary treatment. (p. 2373)

Staff members who conducted a preliminary investigation, whether being a principal or a deputy principal, should not be part of the disciplinary committee of the same case that they investigated (Michiel de Kock $v$ the Head of Education and Other, Province of Western Cape).

\section{Conducting the hearing process}

'A learner disciplinary hearing is an opportunity that is given to a learner to state his/her case during the disciplinary process' (Mollo 2015:16). It is important that members of the disciplinary committee listen to what the learner is saying during the disciplinary hearings. 'During a disciplinary hearing, the common law rules of natural justice, as developed and applied by the courts, should be considered' (Burns 1999:168-169; Joubert 2015:122; Shauer 1976:48). Oosthuizen and De Wet (2016) state that:

There are two basic rules of natural justice, namely, audi alteram partem and nemo iudex in propria causa. The common law principle of audi alteram partem such as the right to state your side of the story constitute the basis for reasonable and fair disciplinary action. (p. 84)

During the hearing, the principles of 'nemo iudex in propria causa, which means no one is able to be a judge in his or her own case' should also be taken into consideration (Oosthuizen \& De Wet 2016:84).

In addition to the members of the disciplinary committee, participants such as the prosecutor, accused learner, parent(s), representative(s) and witnesses should participate in the disciplinary hearing (DBE 2008:18; Joubert 2015:134-135).

'The best interest of a child' (Republic of South Africa 1996a:s. 28) is of paramount importance when conducting a hearing. This means that the hearing should aim at helping an accused learner to improve his or her behaviour. During the 
hearing, it should be in the mind of the disciplinary committee members that every decision that is taken should be corrective and be accompanied by a rehabilitation programme. The rehabilitation programme can be conducted by a school or a learner can be referred to an external service provider. Even when a learner is removed permanently from school, the principal should advice parents to take the learner to a rehabilitation centre when there is a need. Parents should pay for the external service provider if they do not offer free services.

In Mollo (2015:139), most of the participants ( $n=22 / 24$ ) were not able to mention the fair hearing procedure in detail. On the basis of this finding, it is important that principals should be knowledgeable about the 'procedures that should be followed during a disciplinary hearing', so that they can advise the disciplinary committee (Mollo 2015:82). The due process steps should form part of the policy that is used to instil a culture of obedience and self-control in schools. It is expected from the disciplinary committee chairperson that he or she makes sure that the hearing procedures are strict but fair.

At the beginning of the disciplinary hearing, the chairperson should welcome everyone present and introduce them. The chairperson must create an atmosphere that is conducive for a fair hearing. 'If there are preliminary matters, they should be dispensed with as soon as possible' (Oosthuizen et al. 2015:190). Avoidance of the preliminary matters can lead to the decision of the hearing being rendered null and void. Preliminary matters may include (Oosthuizen et al. 2015):

$[A]$ request for postponement, a request to summons or notify one of the witnesses to a hearing, or an objection because of partiality of one of the disciplinary committee members. (pp. 190-191)

If the objection is factual, the chairperson may postpone the hearing and if there is nothing that can lead to postponement, the hearing should proceed (DBE 2008:17; Oosthuizen et al. 2015:190-191). 
As the hearing proceeds, the 'chairperson must inform the learner of his/her rights' (DBE 2008:17). The rights that are applicable to the hearing include but are not limited to (Republic of South Africa 1996a):

[T] he right to equality (Section 9), human dignity (Section 10), freedom and security of the person (Section 12), privacy (Section 14), freedom of expression (Section 16) and the best interest of a child. (s. 28.2)

Members of the disciplinary committee should not violate these rights during the hearing. 'The chairperson is to explain the nature of the alleged breach or misconduct to those present at the hearing' (DBE 2008:18). The results of the preliminary hearing (charge sheet) should be read to the accused learner. The chairperson should ask the learner whether he or she is pleading guilty or not. The chairperson should ask a learner questions that will help the disciplinary committee to get more information and should find out whether the learner does accept that he or she is guilty or not. The accused learner should be advised by the chairperson to listen attentively to what the prosecutor will be saying. The prosecutor is given an opportunity to present evidence under oath by testifying and proving that the accused is guilty (DBE 2008:18; Oosthuizen et al. 2015:191; Smith et al. 2015:2376-2377). As soon as the prosecutor is finished, the accused learner and his or her representatives should be given a chance to provide clarity on certain issues (Oosthuizen et al. 2015:191). Smith et al. (2015:2387) state that 'according to the majority of the participants the most important factor is to give the learner ample opportunity to talk and to defend his/her case'. This is intended to ensure that the accused has a right to be heard.

The chairperson should allow the accused learner and the learner representative(s) an 'opportunity to cross-examine the witnesses' (Oosthuizen et al. 2015:191). The accused should be given an opportunity to present his or her main evidence. The prosecutor may then cross-examine the accused. It is important to give the learner another opportunity to provide clarity on what 
he or she said, especially where other statements are not clear, and to confirm that what he or she said previously is correct. Thereafter, both parties should summarise their cases by arguing the merits and the law (DBE 2008:18; Oosthuizen et al. 2015:191192). Smith et al. (2015) provide that the:

[M]ajority of the participants in a study that they conducted believed that parent(s) should be given an opportunity to ask questions to understand the disciplinary process, the charge, and the sanction given as well as the policies involved. (p. 2384)

This will allow all participants to be satisfied with the disciplinary process. The hearing process should be adjourned.

The study conducted by Mollo (2015:142) found that minutes of a disciplinary hearing were kept only in a few schools $(n=3 / 8)$. Very few $(n=1 / 3)$ of the schools managed to write detailed minutes, recording what the participants of the hearing said. Therefore, it is important for principals to advice scribes or secretaries of the disciplinary committees on how to write detailed hearing minutes (Michiel de Kock $v$ the Head of Education and Other, Province of Western Cape). As it might be difficult to write everything that is said during the hearing, the chairperson should ask for permission to tape record the proceedings, so that the scribe or secretary can ensure proper minutes are available for every disciplinary hearing. This means that even if the proceeding is tape recorded, the scribe or secretary should also write comprehensive minutes of every disciplinary hearing.

Minutes of a disciplinary hearing should contain the date; time; venue; purpose; names of attendees and their designations; opening and welcome; introduction of attendees and their roles; preliminary matters; informing attendees of their rights; explanation of the nature of the alleged serious misconduct; a plea of guilty or not by the accused; probing of questions to the accused and his or her responses; presentation of evidence under oath by the prosecutor; response by the accused and his or her representatives; cross-examination of witnesses by the accused learner and representatives; the presentation of evidence by the 
accused; cross-examination of witnesses by the prosecutor; final comments by parent(s) and representatives; adjourning of the hearing and consideration of facts; and recommendation of decision. Minutes should be accompanied by the attendance register and declaration of confidentiality.

\section{Process of adjourning and considering the facts}

'Adjourning and considering facts means to take a break after a disciplinary hearing with the intention of resuming it again' (Mollo 2015:16). Joubert (2015:137) indicates 'that the committee adjourns so that the chairperson can consider the facts of the case on hand'. At this stage, the chairperson of the disciplinary committee must release the accused learner, parent(s), representative(s), witness(es) and the prosecutor. The chairperson should inform the learner, parent(s) and the representative(s) that the governing body will inform them about the decision.

The disciplinary committee will meet again after a short adjournment to consider the facts. The principals must advise the disciplinary committee chairperson to ensure that the prosecutor is not part of the decision-making process. Even the principal who has been a prosecutor in the same case should not be permitted to form part of the decision-making process (Michiel de Kock $v$ the Head of Education and Other, Province of Western Cape).

As soon as the facts have been considered, the disciplinary committee should make recommendations to the governing body (Phillips $v$ Manser). The disciplinary committee should present an account of what transpired during the hearing to the governing body in writing. This can be in a form of the 'report' and 'minutes' (Michiel de Kock $v$ the Head of Education and Other, Province of Western Cape). The governing body should take a final decision, which will be conveyed to the learner and parent(s). 
It is also important that the learner disciplinary policy provides the procedure that should be followed during the adjournment and when considering facts. This will help the new, upcoming disciplinary committees in the process of considering facts and deciding on the appropriate sanction. This process should be recorded in the minutes in detail and in a factual way.

\section{Reason must be given for the decision}

It is important that the learner disciplinary policy provides the procedure that should be followed during the process of conveying the outcome of a disciplinary hearing.

'Conveying a decision means to relay the decision to the learner and his/her parents' (Mollo 2015:16).

The governing body will take a final decision based on the recommendations from the disciplinary committee. The governing body must make sure that the reason for the decision is substantively fair. The decision 'should be based on facts, evidence and code of conduct for learners that is appropriately formulated' and relevant legislation (Mollo 2015:89, 135, 193).

The governing body must prepare a written report or letter on the results of the disciplinary hearing and deliver it within a week to the parent(s) and the learner. Conveying the decision must be carried out in writing. The report or letter may be explained to the learner and the parent(s).

The content of the report or letter should consist of the date; time; venue; purpose; names of attendees and their designations; opening and welcome; introduction of attendees and their roles; preliminary matters; informing attendees of their rights; explanation of the nature of the alleged serious misconduct; findings from the disciplinary hearing; announcement of the decision taken by the governing body; and the reasons for the resolution and the right to appeal. 
If the governing body decides to recommend expulsion of the learner, the documents to be:

[S] ubmitted to the HoD of the province to enable him/her to make a decision should include a complete report of the circumstances leading to the resolution taken; the minutes of the meeting during which the decision was taken; and any written representation by the learner, parent(s), representative(s). (Michiel de Kock $v$ the Head of Education and Other, Province of Western Cape)

\section{Right to appeal}

'Appeal means to apply to a higher authority for the reversal of the decision of a lower authority' (Mollo 2015:16). During the conveying of the outcome of a disciplinary hearing, the chairperson of the governing body should inform the learner and his or her parents that they may only appeal if certain facts were not considered during the hearing, or they have reason to believe that the decision was not fair.

The appeal process should also be included in the policy. The parents of the learner should be informed of the steps to submit a formal, written appeal. The chairperson should explain to the learner and his or her parents that 'an appeal can be made to the Member of Executive Council for Education within 7 days' (Republic of South Africa 1996b:s. 9[4]).

\section{The model of the application of due process}

The model provides recommendations for improving due process. Firstly, it provides guidance about which role-players can help in improving the application of due process. Furthermore, it mentions some of the strategies that can be used in due process. Finally, it indicates the tools and content that can be used to improve due process.

The model shown in Figure 6.2 depicts how the application of due process can be improved. 


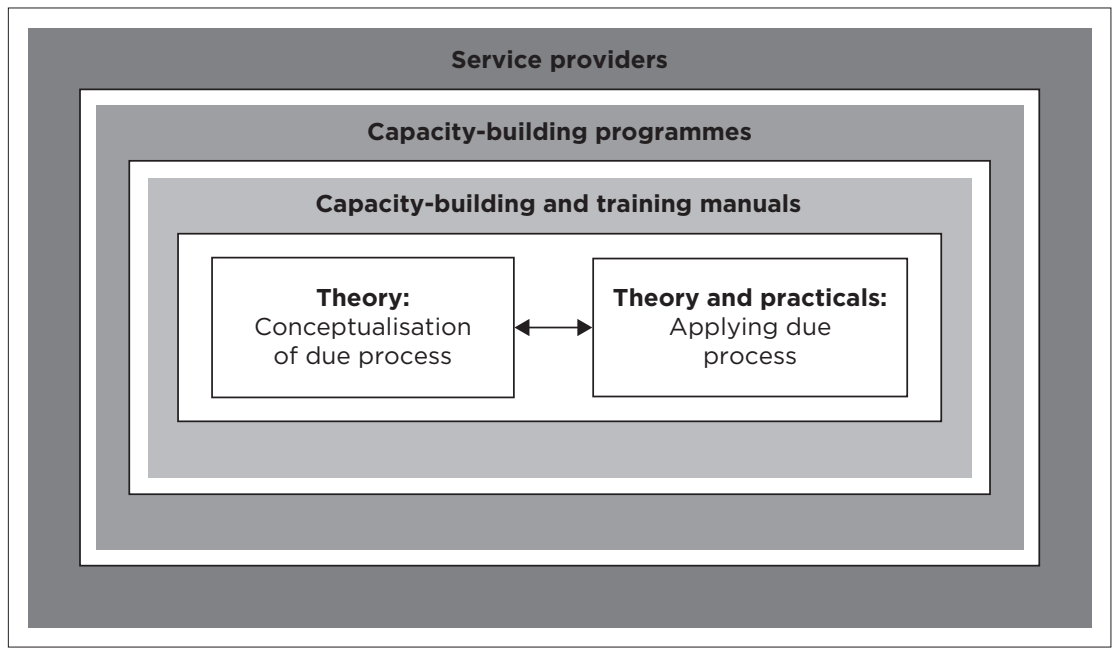

FIGURE 6.2: A strategy for improving the application of due process during learner discipline.

\section{Service providers}

The service providers should provide opportunities to inform educators, principals, disciplinary committees and governing bodies about the application of due process during learner discipline. As Mollo (2015) found that most of the participants cannot conceptualise and apply due process, it is important that this matter receives due attention (Mollo 2015:197). We suggest that the Department of Basic Education, in collaboration with the institutions of higher learning and non-government organisations, should provide material and short courses to support educators, principals, disciplinary committees and governing bodies to apply due process correctly during learner discipline.

\section{Capacity-building and training programmes}

The capacity-building and training programmes should be in the form of 'pre-service and in-service training' (Mollo 2015:197). 
These programmes should be of high quality. To motivate participants to attend these programmes about applying due process, the South African Council for Educators' (SACE) Continuing Professional Teacher Development points should be awarded to all who successfully complete training sessions. This means that these programmes should be registered and accredited by SACE.

\section{Capacity-building and training manuals}

The training manuals should contain theoretical and practical activities aimed at helping educators, principals, disciplinary committees and governing bodies in developing their knowledge and skills in applying due process correctly.

\section{Theoretical and practical activities}

The contents that should be included in the capacity-building and training materials are the conceptualisation of due process, procedural due process (following the disciplinary steps fairly) and substantive due process. According to Mollo 2015:

$[P]$ ractical activities may include, but are not limited to conducting preliminary investigation, writing of notice, conducting hearing, writing hearing minutes, adjourning and considering facts, making a decision, conveying a decision, writing a code of conduct for learners and a learner disciplinary policy that contains provisions of due process. (p. 45)

The mode of delivery for capacity-building and training can be face to face, from a distance and online.

\section{Conclusion}

Managing learner behaviours is a constant challenge to all schools. Managing positive learner behaviour by using 'preventative actions, proactive advice, counselling, penalties and corrective measures' should be performed in a positive way (DBE 1998:para. 10). Due process applies to disciplinary actions. 
Unfortunately, because of a lack of knowledge and a lack of proper application of due process, schools are not always following fair procedures when disciplining learners.

Proper conceptualisation of due process and learner disciplinary process will lead to the effective practical application of due process in all disciplinary actions. Principals should advise the educators, non-educator staff, school management teams, learners, disciplinary committees and governing body members to (Republic of South Africa 1996a):

$[P]$ romote human rights such as the right to equality (Section 9), human dignity (Section 10), freedom and security of the person (Section 12), privacy (Section 14), freedom of expression (Section 16) and the best interest of a child. (s. 28.2)

The suggested model for improving the application of due process should be used by different stakeholders in education to improve the application of due process during learner discipline. 


\section{Chapter 7}

\section{Disciplinary hearings: Legal principles and procedures}

Marius H. Smit

Department of Education Law, Faculty of Education, North-West University,

Potchefstroom, South Africa

\section{Abstract}

This chapter discusses the legal principles and requirements for procedural and substantive fairness when conducting school disciplinary hearings for learners who commit serious misconduct. This research comprised two phases. Firstly, a phenomenological study was undertaken to determine and interpret the experiences, opinions and perspectives of school principals and chairpersons of governing bodies of school disciplinary hearings; secondly, law research was undertaken to determine the legal requirements, principles and procedures for valid school disciplinary hearings.

How to cite: Smit, M.H., 2019, 'Disciplinary hearings: Legal principles and procedures', in C.B. Zulu, I.J. Oosthuizen \& C.C. Wolhuter (eds.), A scholarly inquiry into disciplinary practices in educational institutions (NWU Education and Human Rights in Diversity Series Volume 2), pp. 141-168, AOSIS, Cape Town. https://doi.org/10.4102/aosis.2019. BK157.07 
The study affirmed that participants have insufficient knowledge and feel unsure about the adequacy of the school's code of conduct, objections by lawyers and legal technicalities concerning the charge sheet, procedural and substantive fairness and evidentiary challenges, and the functions of disciplinary committee members. Case law provides clear confirmation that legal representatives of accused learners, who attempt to derail the process by grasping at straws or conceiving technical irregularities during a school disciplinary hearing, will not find much sympathy in a court of law because the disciplinary hearing should not be measured against the procedural rules and standards of a court trail. As long as school principals, educators and members of governing bodies comply with the minimum legal requirements for procedural and substantive fairness, a properly executed disciplinary hearing is an indispensable mechanism to address serious misconduct.

\section{Introduction}

Currently, the ultimate, effective and appropriate mechanism in dealing with serious misconduct by learners at schools is a formal disciplinary hearing to either suspend or expel guilty learners from schools. As the disciplinary hearing is a legal procedure, there must be substantive and procedural fairness when utilising this mechanism in dealing with serious learner misconduct. Accordingly, it is essential for all persons involved, be it as members of disciplinary committees, as witnesses, as the person responsible for investigating or prosecuting serious misconduct, to know and understand the legal requirements for conducting fair and lawful disciplinary hearings and to avoid possible pitfalls that may render the disciplinary hearing unlawful.

Accordingly, the purpose of this chapter is to explain and discuss the legal principles and requirements for procedural and substantive fairness when conducting disciplinary hearings for learners. 


\section{Droblem statement}

Learner disciplinary problems in South African schools manifest as physical violence, assaults, threats, theft, graffiti and vandalism, verbal abuse, gross disobedience and disrespect for authority, constant violation of the school's code of conduct, truancy, criminality, gambling, gangsterism, rape and substance abuse, and even murder in and around the school (Mabeda \& Prinsloo 2000:34; Van Wyk 2001:196). This is reported almost weekly in the newspapers (Fourie 2006:8; Nthite 2006:3). The report by the South African Human Rights Commission affirms that, in general, South African schools are characterised by very high levels of violence and are unsafe environments for learners and educators alike (SAHRC 2008).

Morrell (2001:292) asserted that discipline became a major issue as effective alternatives and adequate training were not immediately provided when corporal punishment was abolished in 1997. Educators contend that alternative disciplinary measures, such as proper classroom management, psychological interventions and restorative justice, are cumbersome and ineffective when dealing with instances of serious learner misconduct (Morrell 2001:292).

However, the ultimate method of dealing with serious misconduct by learners at schools is disciplinary hearings, but this also seems to be ineffective. Oosthuizen $(2006: 25,29)$ found that school principals and educators rank disciplinary hearings of learners only as the 10th most successful method of dealing with learner discipline. Informal discussions with members of governing bodies and disciplinary committees by the author over a number of years and anecdotal evidence suggest that disciplinary committees struggle to conduct the hearings correctly and are at times confronted by lawyers who demand strict procedural and evidentiary approaches. Findings have been reported that educators, departmental officials, school principals, school governing body members and union representatives have an inadequate or superficial knowledge of Education Law 
(Oosthuizen 2015; Smit 2008). This ignorance of the law applies to disciplinary hearings as well. Many a time, members of disciplinary committees do not know, understand or apply the law correctly. Obstructionist lawyers or representatives of learners opportunistically use this lack of knowledge to derail disciplinary hearings with demands for strict evidentiary formalism and proceduralism. Consequently, school principals, members of school management teams, members of school governing bodies and educators seem to be ill-prepared to navigate the legal issues that confront them in cases of serious learner misconduct.

Most of the jurisprudence on disciplinary hearings deal with workplace discipline and labour relations. There is little available case law that specifically addresses the technical and procedural legal issues that crop up during disciplinary hearings for learners in schools or educational settings. Nevertheless, the legal principles regarding fairness of disciplinary hearings that have been expounded in labour law cases are analogous and can be fruitfully applied to school disciplinary hearings.

A further aspect is that there has been an increase in litigation on issues regarding learner discipline and related educational issues. Unlike the pre-constitutional era in South Africa, when parents usually supported school authorities to discipline their children, the constitutional dispensation seems to have created a climate, which emboldens parents to side with their ill-disciplined children against the school authorities. At times, parents resort to legal action or appoint lawyers to represent their children at disciplinary hearings. When lawyers are involved, they tend to resort to legal technicalities and procedural formalism akin to criminal courts of law, to derail the disciplinary hearing. Members of school governing bodies are not necessarily trained lawyers and usually do not have professional knowledge or skills to navigate the complexities of disciplinary hearings. Educators and school principals may be inexperienced or ignorant of the legal aspects of disciplinary hearings. When disciplinary committees fail to conduct hearings effectively, school principals and 
educators become reluctant to use disciplinary hearings as a method to address serious misconduct by learners.

The parlous state of learner discipline at many public schools has resulted in a general lack of respect for educators and a corps of demotivated and demoralised educators (Wolhuter \& Van Staden 2008). As a result, many South African public schools have become dysfunctional (Taylor 2011:14-18) and are characterised by poor learner discipline and unprofessional conduct of educators. On the whole, the South African education system is performing poorly and some commentators suggest that education in South Africa is in a crisis (DBE 2010, Taylor 2011:14-18). A professional, functional, productive and efficient education system requires order, a safe and secure educational environment, fair procedures and reasonable administrative action. Unfortunately, it seems that the relationship between poor learner discipline, ineffective teaching and dysfunctional schools is a vicious cycle.

In view of the deterioration of discipline in schools; the seeming ineffectiveness of ordinary measures to deal with serious misconduct; the ignorance of the law by educators, disciplinary committees and school management teams; as well as the spectre of lawyers resorting to legal technicalities to derail the process, it was apparent that research was required to clarify the legal principles and procedures that apply to disciplinary hearings of learners. Therefore, the objective of this research, as reported in this chapter, was to answer the primary research question, namely, 'what are the legal principles and procedural requirements that underpin disciplinary hearings for learners at schools?'

\section{Research design and methodology}

The research was designed to include two phases. Firstly, qualitative research in the form of a phenomenological, empirical study, based on the interpretivist paradigm, was undertaken; secondly, law research was undertaken to investigate the legal requirements, principles and procedures for valid disciplinary hearings at schools. 


\section{- The phenomenological design}

A phenomenological study was undertaken to analyse the experiences, perspectives and understandings (Leedy \& Ormrod 2003:139) of members of disciplinary committees that had been involved in school disciplinary hearings. The sample of participants was non-random and purposely selected from the ranks of school principals and chairpersons of disciplinary committees who had definite administrative experience of conducting school hearings. Pre-research telephonic enquiries were made at potential schools to identify possible participants based on the selection criteria that the person should have had at least three years of experience of having served on a school disciplinary committee either as an investigator, prosecutor or member of the committee. Before the data collection commenced, consent and permission was obtained from the provincial Department of Education, the schools and the respective participants. All participants were given assurance of full confidentiality, and they in turn gave written consent to participate. An interview guide was used to direct the content of the semi-structured interviews (Merriam 2008:72). Leedy and Ormrod (2005:144) suggested purposive sampling of between five and 25 individuals in a phenomenological study, and the researcher conducted interviews with six individual participants until a level of saturation was achieved (Leedy \& Ormrod 2005:145).

The method of analysis and evaluation of the qualitative data is largely interpretative (Leedy \& Ormrod 2005:150). The following methods were used to enhance the validity and the reliability of the research:

- participant language verbatim accounts

- mechanically recorded data

- member checking (Mcmillan \& Schumacher 2014:408).

Interviews were conducted in English or Afrikaans. All the participants understood and were au fait with these languages. Digital recorders were used to record all the interviews, and the recordings were transcribed verbatim. After the interviews were 
transcribed and typed, the data were organised and classified into common categories and themes. The transcripts were reviewed by each participant and inaccuracies or errors were amended. Divergent perspectives or cases with discrepant views were identified to record the varying experiences regarding disciplinary hearings. The researcher augmented the interviews with field notes about non-verbal communications (Merriam 2008:113). The researcher probed the lived experiences, perceptions and opinions of the participants by, inter alia, posing open-ended questions about:

- the investigation and pre-hearing phase

- the notice and preparation phase

- the disciplinary hearing phase

- the corrective measures phase and enforcement of the decision of the disciplinary committee.

The process of analyses of the qualitative data involved the consolidation, reduction and interpretation by using open coding, axial coding and selective coding methods to arrive at common categories and themes (Maree et al. 2009:105-109).

\section{Law research from an Education Law perspective}

The law is categorised as a social science. Even so, the law differs from other social sciences such as education in that it is the object of its own science (Samuel 2003:42). As with all Western legal systems that are historically based on Roman Law, the South African legal system is an objective, self-contained system of knowledge (Samuel 2003:32). The epistemological importance of this is that it is different from the natural sciences or social sciences that utilise an empirical methodology to study phenomena and physical objects objectively. Put another way, the law is an abstract paradigm, characterised by atypical objects such as legal facts, legal norms or prescriptive propositions that escape the criterion of observability, and this can only be studied by means of its own legal methodologies (Samuel 2003:60). The 
autonomous nature of law as a science requires that abstract legal methods should be applied to describe, explain and predict the law scientifically.

However, in this research, the unit of analysis is disciplinary hearings at schools and not the law per se, and therefore the approach is from an educational perspective insofar the law applies to it. The phenomenological findings were simultaneously interpreted from a law perspective as well. This approach sheds a different light on the dilemmas facing education because the underlying values and interests of school and stakeholders receive different emphases than pure law research that is mainly positivistic in approach. The law research was employed to address and inform the empirical findings. In other words, although law research approaches a topic from the law as the research object, the ontological foundation of this research is education, with disciplinary hearings at schools as the specific research object. As the functionality and objectives of the legal system differ from the functions and purposes of the education system, the research approach of this research differed from pure law research methodologies.

The law research methodology applied in this study included the following (Samuel 2003):

- Application of hermeneutical methods to interpret legal texts such as the South African Constitution, relevant education legislation and law reports

- Analysis and synthesis of legal data

- Legal reasoning by applying descriptive, inductive, deductive and analogical modes of reasoning, as well as diverse types of legal argumentation with regard to evidence, social justice, precedents and metaphor. (pp. 32-60)

\section{Findings of the phenomenological study}

All the purposely selected participants had experience in serving on disciplinary committees or being involved in the disciplinary 
process for serious learner misconduct. The participants' responses provided qualitative data about their lived experiences, perceptions and opinions regarding disciplinary hearings at the respective schools.

\section{Investigation and pre-hearing phase}

Although all the schools in this study had their respective school's codes of conduct, some participants were of the opinion that their particular school's code of conduct was unhelpful, inadequate or needed to be updated ( $P 2$, In 23-24; P3, In 14-15). One participant expressed the expectation that a school's code of conduct should be detailed enough to enable any educator who is tasked to act as the 'prosecutor' or serve on a disciplinary committee to counter or deal with every possible legal technicality that may be raised by a learner's lawyer or representative (P5, In:45). A deputy principal who attended all his school's disciplinary hearings explained that the educators who were usually tasked to investigate instances of serious misconduct sometimes failed to ensure that items of evidence such as mobile phones, contraband substances (e.g. alcohol or drugs) or statements of eyewitnesses were properly obtained and secured. The participants all affirmed that their schools did not have a specific policy with regard to handling evidence and maintaining a register for recording such evidence (P2, In 25).

\section{Preparation phase}

The participants indicated that it was standard practice to give 5-7 days' written notice to the accused learner and that the learners were required to give these notices to their parents. Some of the schools have the practice of sending emails or messages (sms) to the parents about the pending disciplinary hearing as well. However, all the participants affirmed that some learners on occasion did not hand the written notices to their parents and either failed to attend the disciplinary hearing or came to the hearing without a parent or representative. In such instances, the 
hearing had to be postponed, which was frustrating to the disciplinary committee and all those involved with the hearing.

A recurring issue that was raised during the interviews with participants was that many educators and school leaders did not feel competent or adequately trained to conduct an investigation and prosecute certain cases of serious misconduct in accordance with the onerous requirements of the law (P1, Ln:111; P2, In:94; P4, In:120). A deputy head's response was that some eyewitnesses and learners were reluctant or entirely unwilling to testify or provide information about the instances of serious misconduct. An deputy principal, who had acted as an investigator and prosecutor during disciplinary hearings involving matters such as use of alcohol on school premises, assault and vandalism, indicated that he was uncertain whether witnesses could be compelled to provide written statements and explanations of the events (P4, In: 213). Furthermore, some educators that investigated cases of serious misconduct were uncertain whether the accused or the suspected culprits could be required to answer questions and to give their version of the matter prior to a disciplinary hearing in the absence of a representative or parent (P3, In: 56). The investigator or prosecutor then usually proceeded without the assistance of necessary evidence or testimonies.

Some participants that had been responsible for conducting investigations and arranging disciplinary hearings affirmed that it is good practice for the investigator or prosecutor to meet with the accused learner's parents or representative prior to the disciplinary hearing to discuss issues in a non-adversarial and reasonable manner ( $\mathrm{P} 1, \operatorname{In} 112 ; \mathrm{P} 5, \mathrm{In} 123$ ), although this was not common practice at all schools. Oftentimes, the parents came to the meeting with the a priori intent of fighting the disciplinary steps tooth and nail, but left with a change of heart after realising that the disciplinary hearing is primarily a measure to correct a learner's misbehaviour and not necessarily intended to act to the detriment of the accused learner (P5, In: 231). A participant explained that some lawyers who tend to object to any technicalities and to demand a strict formalistic procedure can 
often be persuaded to participate more constructively if the disciplinary hearing adjourns to facilitate an informal discussion about the purpose and format of the hearing ( $P 5, \operatorname{In}: 245$ ). A deputy principal ( $P 6$, In 39) was of the opinion that it was usually to the advantage of all parties concerned if the parents were persuaded to accept the goodwill of the educators and disciplinary committee and were willing to support the school to address instances of serious misconduct, even though their own child may be the accused.

\section{Disciplinary hearing phase}

A regularly recurring sub-theme was the notion amongst the participants that if a school's disciplinary procedure (in terms of its code of conduct) was inadequate or deficient in some sense, then the disciplinary committees were unsure of the legality of objections and were not able to withstand or counter any technical queries by obstructionist lawyers or representatives of the learners. All the participants (P1, In: 52; P2, In:101-153; P3, In: 43; P4, In:25; P6, In: 41-44) affirmed that it is fairly commonplace that parents or representatives of accused learners would lodge objections during the preliminary phase of the hearing based on various legal technicalities and issues, such as:

- vague or ambiguous charges on the charge sheet

- insufficient time to prepare a defence prior to the hearing

- non-receipt of notice of hearing

- inability to prepare a proper defence owing to interference with defence witnesses

- unlawful presence of the principal on the disciplinary committee

- non-compliance with the provincial department's guidelines or policy on disciplinary hearings

- unlawful searches and seizure of learner's private property

- etc.

A school principal who had been a 'prosecutor' in matters of serious misconduct by learners, indicated that the parents or representatives of learners at disciplinary hearings very often 
question the correctness of a procedural step or a punishment, if the school's code of conduct was silent on the issue (P5, In:53). During one such occasion, the lawyer who represented the learner objected to the fact that the disciplinary committee consisted of two parent members of the school governing body and the deputy principal ( $P$. In 54). The lawyer contended that the provincial regulations required that the school principal must initiate the disciplinary hearing and accordingly had to serve on the disciplinary committee. As a result of uncertainty on this issue raised by the lawyer, the prosecutor withdrew the case against the learner.

A participant with 35 years of experience (principal of a boy's high school) warned that parents can become very abusive and belligerent in misguided attempts to protect their children (P3, In 104-153). He cited an instance where the parent, whose child was accused of using alcohol in the hostel, was a lawyer and sent written threats by email to the principal and governing body members to 'leave my son alone or you will be sorry' and 'if you continue with your jungle law, this kangaroo court, I will obtain an interdict and hold you personally liable for all costs'. The lawyer-parent then forged ahead and applied for a harassment interdict in terms of the Prevention of Harassment Act on an ex parte basis (i.e. without giving notice to the school governing body) against the school to prevent his son from being evicted from the hostel. The magistrate erroneously granted the provisional interdict based on false assertions in the parent's affidavit. This effectively stymied the attempts by the school to deal decisively with serious misconduct. In the opinion of the participant, this action by the particular parent did immense harm to the authority of educators, deputy principal and the school principal, and effectively undermined the school's ability to maintain discipline and address serious misconduct. The participant indicated that he decided to go on early retirement after this 'ordeal' as he no longer was willing to suffer such abuse by parents and learners (P3, In 154). 


\section{Corrective measures and enforcement of discipline phase}

All the participants affirmed that the disciplinary committees usually decided to suspend the guilty learners for seven school days or put forth alternative corrective measures such as community service, attending a life-skills or rehabilitation programme in the event of use or possession of drugs. However, all the participants (P1, In:100; P2, In:167-170; P3, In: 180-185; P4, In:72-75; P6, In:305-308) affirmed that the disciplinary committees were very reluctant to recommend expulsion because the district offices or regional offices of the provincial departments of education refused to accept recommendations for expulsion. A principal explained that the departmental officials as a rule always refer the matter back to the school and give flimsy reasons such as 'not a fair hearing', 'learner must be referred to psychological services' or 'learner must be allowed to write the final exam' (Principal, location unknown, date unknown). The participants intimated that this practice by the Department of Education also undermines the ability of schools to maintain discipline and demoralises the persons that spent many hours fruitlessly conducting a disciplinary hearing.

It is clear from the phenomenological study that there is much frustration about the efficacy of disciplinary hearings and uncertainty about the legal principles that apply during the investigation, preparation and hearing phases. After analysing, evaluating and interpreting the qualitative data, the following legal issues and concerns became apparent:

- adequacy of the school's code of conduct

- uncertainties about the pre-hearing investigation and procedure

- legal technicalities: charge sheet and preliminary matters

- disciplinary hearing procedure - strict proceduralism versus flexible procedural fairness

- uncertainty about the roles and functions of persons involved in disciplinary hearings 
- issues of procedural and substantive fairness

- uncertainties about determining the appropriate corrective measure.

The correct legal principles that apply to these issues will be discussed sequentially in the following paragraphs.

\section{Adequacy of a school's code of conduct}

Section 8(5) of the South African Schools Act (Republic of South Africa 1996b) stipulates that a school's code of conduct must include a proper legal process to ensure fair treatment during the hearing. A properly drafted and updated code of conduct for the school is the first step towards ensuring procedural fairness in matters of serious misconduct by learners.

However, even though a school's code of conduct may be inadequate or even non-existent, the principles of administrative justice, procedural fairness and substantive fairness in terms of South African law will be sufficient to allow for fair disciplinary hearings. In the matter of Phillips $v$ Manser (2008) (EC), the court rejected the applicant's argument that a learner could not be expelled in the absence of a code of conduct as contemplated in Section 8(1) of the Schools Act (Republic of South Africa 1996a). In other words, even though Alexander Road High School did not have a code of conduct in this particular instance, Kroon $\mathrm{J}$ held that the disciplinary hearing of the learner had been fair according to the principles of administrative justice and affirmed the legality of the suspension of the learner.

The Guidelines for a Code of Conduct for Learners (DoE 1998; Republic of South Africa 1996b:Schedule 1) contain sufficient information and include the essential legal principles to ensure due process during disciplinary hearings. A school's code of conduct would be adequate if it contains details set out in the Guidelines for a Code of Conduct for Learners about categories and examples of misconduct; the disciplinary hearing procedure; rights and responsibilities of learners; rights and responsibilities of 
parents and educators; legal authority to conduct searches and seizures; measures to ensure an orderly, safe and secured school environment; guidelines on a uniform dress code; sanctions for serious misconduct and possible punishments according to the category of misconduct; dispute resolution procedure; and the procedure for applying for exemption from certain aspects of the code of conduct.

School governing bodies should avoid drafting overly technical, mechanistic and cumbersome school codes of conduct because the courts do not, in principle, require strict formalism, but simply require that the general principles of procedural and substantive fairness be adhered to during the hearing.

\section{Uncertainties about the pre-hearing investigation and procedure}

When initiating a disciplinary process, the school principal must see to it that the following steps are taken as expeditiously as possible following the complaint being lodged or the incident being reported:

- Obtain evidence such as physical items, documents and photographs as well as written statements from the complainants and witnesses (e.g. educator and learners).

- Ask for an explanation from the accused only if it is apparent that there are indeed sufficient prima facie grounds for a case. The accused learner cannot be compelled to make a statement. Instead, the accused learner should be warned of his right to silence and that everything he says may be held against him or her. The basic legal principle is that the accused is presumed to be innocent until proved guilty. If the accused learner is prepared to make a statement voluntarily (i.e. after the right to keep silence has been explained), then a statement may be recorded or documented. Usually, when alleged culprits have valid explanations and indemnifying excuses, they voluntarily give explanatory statements. However, the opposite also seems to be true, that is, the accused learners are usually not willing to give statements or to incriminate themselves if they are in fact guilty of the serious misconduct. 
Determine whether there has indeed been an infringement of the code of conduct or the school rules by interpreting the legal provisions and the Schools Act. If sufficient evidence exists for a prima facie case, then the investigator or prosecutor must proceed by giving written notice to the accused learner and warn the witnesses that the case will go ahead.

It is advisable and good practice for the prosecutor to meet with the parents of the accused learner before the hearing. Even if the parents refuse to attend such a meeting with the prosecutor, it is recommended that the chair of the disciplinary committee should require these parties to meet in a neutral office or outside the hearing venue before proceeding with the hearing. The purpose of such a meeting is not to discuss or thrash out the merits of the case or to compare the evidence, but to gauge the attitude of the parents, to provide copies of evidence and statements, and to discuss the corrective objectives of disciplinary hearings on an informal basis.

\section{- Legal technicalities and preliminary objections}

In general, this study showed that educators, school principals, deputy school principals and members of governing bodies do not possess sufficient knowledge about the validity of objections and the legal principles that apply to possible objections.

It is the duty of the chairperson of the disciplinary committee to deal effectively and expeditiously with such objections. However, the chairperson also has the right to demand respect for the disciplinary committee and insist that all should adhere to the disciplinary procedures. In cases where a parent or representative becomes abusive, insulting or obstructionist, it is the chair of the disciplinary committee that has the authority and duty to admonish such a conduct and to warn the person to desist from such a behaviour. If the person refuses to comply or accede to the rulings of the chairperson, then the person may be instructed to leave or be removed from the hearing venue. 
The chairperson may refuse to proceed as long as the person remains obstructionist and may even enlist the assistance of security personnel or the police to remove the obstructionist lawyer or representative.

In the paragraphs that follow, the legal principles that apply to some of the objections raised during school disciplinary hearings will be discussed.

\section{Objections against charge sheets and notices of disciplinary hearings}

The findings of the phenomenological study indicate that charge sheets are occasionally incorrectly drafted and that representatives of learners have an issue with the ambiguity of the charges. The prosecutor should strive to formulate the charge sheet by including the following mandatory essentials:

- the exact charges against the accused learner

- the date, time and place of the alleged infringements

- the seriousness of the infringements

- the time in which they have to prepare (notice period)

- the date, time and place of the intended disciplinary hearing

- the specific rule or rules of the school's code of conduct or the hostel's policy or code of conduct that have been infringed upon must be indicated

- warning of the possibility of suspension or expulsion from the school or eviction from the hostel.

Nevertheless, even in circumstances when the charge sheets are inelegantly worded, the following legal principles apply to objections.

\section{Substance and not form - The law does not require strict formalism in charge sheets}

The basic legal principle that applies to the wording and format of charge sheets, notices of disciplinary hearings and other procedural documents is that the substance of the wording is 
determinative and not the exact form or format. It is not the form but the understandability that is decisive in each particular case. In other words, the courts give maximum consideration as to whether the accused could reasonably understand the content and wording despite possible procedural or technical inaccuracies.

In the matter of Zeelie $v$ Price Forbes (Northern Province) (1)22 (LC), the court held that the purpose of a charge sheet is to ensure that the employee (or learner) is made aware of the allegations he is to face in the disciplinary hearing. Disciplinary charges are not intended to be a precise statement of the elements of an offence. The charges need only be sufficiently precise to allow the charged employee (or learner) to identify the incident, which forms the subject matter of the complaint for him or her to prepare a suitable defence.

In National Union of Mineworkers \& others v CCMA (2011) (LC), the court held that if charges are inelegant or poorly worded or not precisely as worded in disciplinary code, it will depend on the extent of the uncertainty in each case. The court commented that poorly worded charges are a common feature of disciplinary proceedings. If the parties understand the nature of allegations and activities accused of, then there is no procedural unfairness, even if the charges are poorly worded. There are occasions where the misdescription is of such a nature that it renders the ensuing disciplinary process unfair; however, there are also occasions when poorly worded charges do not lead to unfairness. The extent of the unfairness would depend on the particular facts and circumstances of each case.

In Botha v Gengold Ltd [1996] (IC), the court reminded that a person cannot be charged or disciplined for the same offence twice. Two disciplinary hearings are not allowed even if the outcome of the first one was not as expected or not correctly conducted.

It is suggested that the chairperson of the disciplinary committee should postpone a hearing and afford the prosecutor time to amend or remedy the charge sheet if it is vague, 
contradictory or inelegantly worded. It would be a mistake to withdraw the charges completely if the charge sheet could be remedied. In principle, procedural technicalities should not be allowed to derail the objective, namely, to teach the learner the consequences of misconduct and to encourage changes in behaviour. If a chairperson allows disciplinary hearings to be compromised or disrupted for no substantive reason, then the eventual effect would be that educators and school leaders become disheartened and negative about utilising the ultimate measure to deal with serious misconduct in schools.

\section{Objections about insufficient time to prepare a defence prior to the hearing}

It is suggested that, as a rule of thumb, 7 days would be a reasonable time for the accused learner and his or her representative to prepare for the hearing. However, depending on the circumstances of each particular case, the chair of the disciplinary committee should allow for a reasonable extension of the notice period in the event that the accused learner provides a reasonable and sufficient basis for requesting such a postponement. Examples of reasonable requests for a postponement include the unavailability of defence witnesses, the unavailability of a parent or representative owing to illness, unpreventable absence or prior important commitments, vague and unclear charges, and intimidation of defence witnesses.

However, in the matter of Seakamela and Magalies Water (2014) (CCMA), the arbitrator explained that the charge sheet had to be sufficiently clear for the parties to understand the charges, but it need not be drawn up with the precision of an indictment in a criminal trial. The arbitrator commented that it amounts to unethical conduct and inappropriate behaviour if representatives absent themselves or recuse themselves from the hearing, if they were insufficiently prepared or did not obtain all the evidence and charge sheets. An ethical representative has the duty to acquaint himself or herself with the evidence prior to the hearing. If a 
representative did not attend a pre-hearing meeting or ascertain the nature and content of the charges and evidence against the accused (audio recordings, documents, etc.), the representative only has himself or herself to blame. These legal principles apply to school disciplinary hearings by analogy.

\section{Strict proceduralism versus flexible procedural fairness}

It is clear from the phenomenological findings that lawyers who represent learners usually equate a disciplinary hearing with a criminal hearing and expect that similar rules of criminal procedure should apply to the school as well. However, this approach by lawyers representing accused learners is incorrect and legally flawed as a disciplinary hearing differs substantively from a criminal hearing.

In Le Monde Luggage CC t/a Pakwells Petje $v$ Dunn NO \& others (2007) (LAC), the Labour Appeal Court ruled that a measure of procedural flexibility is permissible in disciplinary hearings along with minor variations in procedure and that disciplinary committees should have a 'flexible, less onerous approach to procedural fairness'. In terms of the law, it is also clear that procedures for a fair disciplinary hearing need not to be followed mechanistically and the procedures are not immutable, but should be flexible to ensure a fair and timely conclusion of the matter. The court held that the disciplinary process should not be reduced to one of evidentiary formalism, which applies in an ordinary court of law. In other words, strict evidentiary formalism and proceduralism is inappropriate for school disciplinary hearings.

On the basis of these legal principles, a chair of the school disciplinary committee may confidently refuse to accommodate objections by lawyers or representatives of the accused learner that demands strict evidentiary formalism or proceduralism. The chair of a disciplinary committee should quote the abovementioned court cases and continue with the disciplinary hearing despite technical objections against insignificant deviations of the hearing procedure. 


\section{Uncertainty about the roles and functions of persons involved in disciplinary hearings}

The roles of the functionaries that are involved with school disciplinary hearings are:

- The complainant - the person who was harmed or reports the misconduct.

- The accused learner - the person who allegedly committed the serious misconduct.

- The school principal - the school manager responsible for initiating the disciplinary hearing based on initial evidence and complaints.

- The investigator - an educator or deputy principal responsible for investigating the incident, collecting evidence and witness statements, collaborating with the prosecutor to determine the prima facie merits of the case and testifying at the disciplinary on the merits of the case.

- The prosecutor - the person who is responsible for arranging the case on behalf of the school, notifying the accused learners and their parents of the disciplinary hearing and charges, drafting the notification in charge sheet, charging the accused learner, submitting evidence, submitting witness testimonies, questioning witnesses, cross-questioning defence witnesses, arguing procedural matters, recommending suitable sanctions and arguing the case before the disciplinary committee.

- The chairperson of the disciplinary committee - the person presiding over the disciplinary hearing; the person who must control the hearing procedure and decide on the substance and merits of preliminary objections by the accused learner or the representatives; the person who is responsible for discussing, questioning, reasoning and pronouncing the decisions on behalf of the disciplinary committee. The chairperson has the task of steering away from irrelevant matters (i.e. issues that are not applicable) and to ensure that the disciplinary hearing proceeds in a timely and procedurally fair manner.

- Additional members of the disciplinary committee knowledgeable persons, either educators or parents that 
constituted disciplinary committee together with the chairperson of the committee.

- Witnesses - persons who saw or experienced the events or outcome of the misconduct first-hand.

- Parents or representatives of the accused learner - the caretakers of the accused learner, as defined in Section 1 of the South African Schools Act (Republic of South Africa 1996a), or an adult representative of the learner who is responsible for speaking on behalf of and conducting the defence of the accused learner.

It is important to know the role and specific functions of the functionaries or persons involved in disciplinary hearings. Some provincial regulations, such as the Gauteng Province Exemplar of a Code of Conduct, contain the provision in Clause 11.10 (c) that 'only the principal may institute disciplinary action against a learner in respect of serious misconduct'.

The principal may institute disciplinary action against a learner in respect of serious misconduct only if (1) there is sufficient evidence to institute such proceedings; and (2) the principal considers it to be in the interest of the school and its community that such disciplinary action should be instituted.

Other provincial regulations such as Section 5 of the regulations relating to the disciplinary proceedings dealing with misconduct of learners of the North-West Schools' Basic Education Act (Republic of South Africa 2012) states that:

In respect of serious misconduct, only the Principal may institute disciplinary action against a learner if after an investigation, there is prima facie evidence of a contravention of the code. (s. 5)

Section 6 (3) (b) of the regulations specifically provides that:

$[T$ ] he remaining members of the Disciplinary Committee shall not be the Principal or a learner at the school. (s. 6.3.b)

However, the phrase 'only the Principal may institute disciplinary action' does not mean that the school principal must personally conduct the investigation or be part of the hearing (Republic of South Africa 2012:n.p.). The regulations state in Section 6(1) 
that '[u]pon the advice of the Principal that he has instituted disciplinary action against the learner, the governing body must appoint a Disciplinary Committee' (Republic of South Africa 2012:s. 6[1]). It is thus clear that instituting disciplinary action simply refers to the commencement of the disciplinary steps and that the principal must take the decision to commence, to set the ball rolling and then hand over the matter to the functionaries and the disciplinary committee to proceed with the disciplinary hearing.

The role and function of the school principal is therefore usually not to serve on the disciplinary committee but to conduct initial enquiries and make a decision, based on prima facie evidence, to initiate disciplinary proceedings against the accused learner. One of the technical objections that can thus be validly raised during a school disciplinary hearing is that of a school principal serving on the disciplinary committee. School principals should accordingly be informed of these regulations and advised to avoid serving on disciplinary committees, as such a step would be in contravention of the law.

\section{Procedural fairness}

Procedural fairness during the disciplinary process is determined by the following factors and legal principles:

The presumption of innocence - this legal principle is a foundational point of departure in our system of justice and underpins procedural fairness. It means that every person is considered innocent until proved guilty. In practical terms, it means that an accused person does not have to do anything to prove his innocence, as this is regarded as the default position. The onus or burden of proving the guilt of an accused rests on the prosecution. Therefore, unless the prosecutor can provide convincing, extrinsic, unbiased, credible, objective, first-hand evidence of sufficient weightage of the guilt of the accused, he or she will remain innocent and acquitted of the charges. 
Audi alteram partem - this legal principle of procedural fairness means 'hear the other side'. This long-standing basis of justice provides that no final decision on the merits of a case may be made until all interested parties, that is, the complainant, the witnesses and the accused have been given adequate, fair and timely opportunity to state their cases or tell their version of the story. To ensure procedural fairness, it is the duty of the chair of the disciplinary hearing to ensure that both the prosecutor and the accused have sufficient opportunity to present their case. In circumstances where the accused refuses to attend or is absent from the disciplinary hearing owing to unreasonable excuses, it is incumbent on the chairperson of the disciplinary hearing to carefully test the prosecutor's case by examining possible defences, arguments or vindications for the other side.

Impartiality and objectivity of the decision-makers - the third factor that underpins procedural fairness is the legal principle that requires impartiality of the members of the disciplinary committee. Any person who may have already decided that the accused learner is guilty before hearing the evidence is in effect biased and partial. Such a person should not be allowed to serve on the disciplinary committee. The requirement of impartiality also means that no witness or prosecutor or investigator or any person involved in the preliminary construction of the prosecution may be allowed to serve on the disciplinary committee. It is the ethical duty of any person that might be biased or creates the impression of partiality to recuse himself or herself from the disciplinary committee to ensure untainted procedural fairness.

Sufficient notice and time for preparation - depending on the circumstances, sufficient notice and time for preparation can vary from $48 \mathrm{~h}$ to 7 weekdays. Should a person complain that not enough time has been allowed, it is in principle fair and advisable to postpone the case or during the case to allow for additional time. However, there are limits to the number of postponements that may reasonably be granted, as it is not in the interest of justice and fairness to have the matter dragged on indefinitely. These limits must be considered on a case-by-case basis, taking 
into account factors such as the availability of witnesses and representatives, the nature of the misconduct, the possibility of more referrals to the school's disciplinary system and the availability of the disciplinary committee.

Proper and understandable charge sheet - see the paragraph above about the charge sheet.

A fair hearing and due process - the manner in which the chairperson of the committee handles the hearing may be decisive in ensuring a procedurally fair hearing. It is essential that the hearing be conducted in a strict yet fair and just manner. In this regard, it is advisable that the hearing should follow a tested format, so that there is no unnecessary deviation from the essence of the case on the one hand and yet there is adequate opportunity for the parties to present their cases. All the provincial departments of education have published regulations or guidelines about the disciplinary hearing procedure. It is beyond the scope of this chapter to elaborate and discuss each step of the disciplinary hearing in detail. The chairperson of the disciplinary committee and the prosecutor should inform themselves of these regulations and guidelines to adhere to the legal requirements.

\section{Substantive fairness}

Substantive fairness depends on the reasonableness and justifiability of decisions by the disciplinary committee on the merits and 'real' or substantive issues of the case.

In the matter of Sidumo \& another $v$ Rustenburg Platinum Mines Ltd \& others (2007) (CC), the court held that disciplinary hearings were substantively fair if the disciplinary committee had taken the totality of circumstances into account by considering the following:

- the importance of the rule that has been breached

- the reason(s) why the committee imposed the sanction or corrective action

- the harm caused by the accused or learner's conduct 
- whether additional training and education may result in the accused learner not repeating the misconduct

- the effect of dismissal on the employee (or by analogy expulsion of the learner)

- the employee's service record (by analogy the learner's school record).

Reasonable decision-making is based on valid, appropriate, convincing and sound reasons, and is not based on arbitrary or irrelevant considerations. Decisions must be consistently applied to similar circumstances, otherwise they tend to be arbitrary and capricious. Also, disciplinary committees should avoid 'making an example of a learner' for reasons other than the just outcome of the case. In other words, a learner who is found guilty must be punished according to his or her infringement and not because of an ulterior motive 'to send a strong message' to other learners.

In the matter of Herholdt v Nedbank Ltd (2012) (LAC), the court held that if the reasoning, which led to the decision, is unreasonable or if an irregularity occurred in reaching that decision, then the decision is unreasonable and thus substantively unfair.

\section{Reasonable determination of the appropriate corrective measures}

When a learner has been found guilty, the disciplinary committee has the duty to determine the suitable and appropriate sanction. The following principles apply when deciding on the appropriate corrective measure:

Consider all the relevant factors according to the extenuating and aggravating circumstances of each case. Possible aggravating circumstances can inter alia be the senior age of a learner (e.g. 18 years old), previous similar or relevant infringements and a pattern of misconduct, responsibilities owing to leadership positions held by the learner (e.g. student leaders serving on the student representative council should set an example and uphold the trust that was placed in them), possible attempts to undermine the disciplinary process, no remorse or unwillingness to apologise 
and take responsibility for the harm or misconduct and intimidation of witnesses and dishonesty during the hearing. Possible extenuating circumstances might be challenging personal or family background, remorse, cooperation during the investigation and hearing, willingness to take responsibility and to make amends for the misconduct.

When deciding on a suitable sanction, the disciplinary committee should bear in mind that alternative corrective sanctions can be utilised, including suspension or expulsion from school (e.g. Pearson High School $v$ Head of the Department Eastern Cape Province (1999) [Ck]), expulsion from the hostel (e.g. Tshona v Principal, Victoria Girls High School (2007) [EC]), demotion of rank (forfeiture of student leadership position, e.g. Van Biljon v Crawford, Grey Boys High [2007]), performing community service (repairing a broken window, painting a wall, washing dishes, cleaning places, etc.), apologising, paying a fine (e.g. Le Roux $v$ Dey [2001] [CC]), compensating the harm or damage caused and forfeiture of privileges (e.g. withholding the privilege of attending the matric farewell function). In the matter of Western Cape Residents Association obo Williams v Parow High School (2006) (WC), the dictum of Judge Mitchell is instructive. He said:

The two important things that a school must teach its learners are discipline and respect for authority. The granting of a privilege as a reward for good behaviour is one tool that may be used to teach such lessons. The withholding of a privilege can therefore not be claimed as an infringement of the right to equality or dignity. Indeed the privilege in the absence of it having been earned may well constitute an infringement on the rights to equality and dignity of those who have merited the privilege. The right to freedom of expression does not equate to a right to be ill-disciplined or rude. The system of rewards for good behaviour permeates all walks of life and to learn the system at an early age can only benefit a leaner later on in his or her life. (Western Cape Residents Association obo Williams v Parow High School [2006] [WC])

Disciplinary committees are thus in a position to find creative sanctions that fit the misconduct and teach a transgressing learner appropriate lessons of life. Justifiable decisions must be 
made in accordance with legal principles, based on sound legal policy decisions and appropriate values. Decisions should undergird the school's continued discipline and functionality and attach appropriate weightage to every aspect and factor in the case.

\section{Conclusion and recommendations}

This chapter emphasised the importance of conducting a proper disciplinary hearing in accordance with legal principles, as it is the ultimate mechanism available to schools to deal with serious misconduct by learners. The possible outcome of a disciplinary hearing can include suspension, expulsion or a lesser sanction for the guilty learner in accordance with the school's code of conduct.

The findings of the phenomenological study on which this chapter is partially based confirm that educators, school principals and members of governing bodies in general have insufficient knowledge of legal principles that apply to school disciplinary hearings. It is therefore recommended that educators, school leaders and members of school governing bodies undergo training and have regular updates on the law, as these relate to disciplinary hearings. In particular, it is recommended that chairpersons of disciplinary committees should avail themselves of the case law (that has been discussed in this chapter) that prevents an obstructionist lawyer or representative of the accused learner from derailing a disciplinary hearing with objections about legal technicalities or with demands for strict evidentiary formalism or proceduralism. It is reiterated that, in essence, the legal principles as clarified by the case law referred to in this chapter support a reasonably flexible approach to procedural variations in a disciplinary hearing.

As long as school principals, educators and members of governing bodies comply with the minimum legal requirements for procedural and substantive fairness, a properly executed disciplinary hearing can be a valuable mechanism in the arsenal of a school. 


\section{Chapter 8}

\section{The application of positive discipline at a Western Cape technical and vocational education and training college}

Louis J. Oosthuizen

Trimester Programme, NATED Programme, West Coast College,

Vredenburg, South Africa

Izak J. Oosthuizen

Edu-HRight Research Focus Area, Faculty of Education, North-West University,

Potchefstroom, South Africa

Andre van der Bijl

Teacher Professional Development, Faculty of Education, Cape Peninsula University of Technology, Cape Town, South Africa

How to cite: Oosthuizen, L.J., Oosthuizen, I.J. \& Van der Bijl, A., 2019, 'The application of positive discipline at a Western Cape technical and vocational education and training college', in C.B. Zulu, I.J. Oosthuizen \& C.C. Wolhuter (eds.), A scholarly inquiry into disciplinary practices in educational institutions (NWU Education and Human Rights in Diversity Series Volume 2), pp. 169-198, AOSIS, Cape Town. https://doi.org/10.4102/ aosis.2019.BK157.08 


\section{Abstract}

Vocational education is a term commonly used to describe education aimed at the world of work. A number of different names are used to describe vocational education, including industrial education, technical education, career education, further education and training, and TVET. The student population at TVET colleges is more mature than that of schools, and the courses are focussed on career-specific education and training.

Methods used to manage student misconduct differ from those of schools and tend to be more positive in nature. Ineffective management of student discipline leads to students losing track, teaching hours going to waste and, consequently, poor student performance. Various legal imperatives related to education emphasise the need for institutional codes for behaviour, with the aim of establishing a positive and orderly teaching and learning environment.

Lecturer attributes and measures for managing PD within TVET colleges were gleaned from a study at a TVET college in the Western Cape. Content was determined by means of a questionnaire and interviews with lecturers. The most significant lecturer attributes that contribute to a disciplined classroom environment were:

- being hard-working

- making effective use of their voice

- requiring high levels of output in a tolerant manner

- communicating effectively.

Significant measures for maintaining student discipline through PD were:

- student participation during lessons

- lecturers encouraging students and enhancing a sense of accomplishment amongst students

- lecturers being experts in their fields and presenting wellprepared lessons.

Well-prepared and well-presented lessons by lecturers who are specialists in their respective fields are important elements for 
maintaining a disciplined classroom atmosphere. They present lessons that are interesting and include many examples. Interesting lessons, with appropriate links to practice when engaging the students, capture the attention of students and contribute towards a disciplined classroom environment. Uninteresting and inappropriate lessons have a concomitant negative impact on discipline in the classroom.

It is in the interest of TVET colleges to provide training to lecturers, with the aim of encouraging awareness and an ability to apply measures to manage student misconduct by applying PD. Lecturers who lack commitment should be identified, mentored and upskilled.

\section{Introduction}

The word order is defined as (Oxford Dictionary 2006):

The arrangement or disposition of people or things in relation to each other according to a particular sequence, pattern or method; a state where the laws and rules regulating public behaviour are observed and authority is obeyed. (p. 1238)

The existence of order is essential for all human societies and their institutions. The tenets of a society and its institutions cannot function in harmonious coherence without the existence of an orderly normative system.

Human coexistence without the existence of a normative system defining and regulating their mutual actions is difficult. When ancient societies became aware of this, leaders came to the fore, guiding their social structures towards some kind of agreement on how to bring about an ordered dispensation that enhanced stability, harmony and ultimately safety. Societal leaders soon became functionaries responsible for ensuring harmony and safety. As societies became increasingly dependent on an orderly, structured and safe environment, a kind of tacit understanding emerged in which members conformed to leadership in exchange for a stable and safe environment. 
The relation between leaders and society paved the way for what we now call government in a dispensation in which the state rules a nation in an attempt to secure and regulate the peaceful well-being of the population. The tacit understanding between the state and the civil society is known as an unwritten social contract in which the civilian undertakes to obey the governing rules of society in exchange for state protection within an orderly arrangement (Kleyn \& Viljoen 2012:1).

The state, as functionaries of order, uses a variety of mechanisms in fulfilling its role. One of the mechanisms used by the state is by delineating norms, rules and legislation to regulate civilian life. To secure and enforce the normative structures, the application of some form of disciplinary measures is both needed and essential. The application of discipline in any society is a sine qua non for order.

The word discipline, derived from the Greek word, sophronismos (Vine 1985:172), means (Oxford Dictionary 2006):

The practise of training people to obey rules or a code of behaviour, using punishment to correct disobedience; the controlled behaviour resulting from such training. (p. 495)

As in other societal institutions, the application of discipline is an imperative in the world of orderly teaching and learning. Without order and discipline, vocational teachers and students lose track, precious hours go to waste, dreams of a lifetime come to nothing and a society is crippled.

Consequently, various legal imperatives related to education emphasise the need for institutional codes of conduct (such as the SA Schools Act) and require the establishment of an orderly teaching and learning environment. In addition, Section 1(6) of the Guidelines for a Code of Conduct for Learners (SA 1998b) notes the following pertaining to South African schools:

The code of conduct must be aimed at establishing a disciplined and purposeful environment to facilitate effective education and learning in schools. (n.p.)

Some of the traditional approaches, such as corporal punishment, as instruments for the establishment of a disciplined environment 
conducive for effective education are being questioned in the modern era (Veriava \& Power in Veriava, Thom \& Hogson 2017:337). For much of the 20th century, punishment in schooling was centred on physical punishment. However, non-physical forms of controlling and adapting human behaviour largely replaced physical forms in the latter quarter of the century. The general supersession of physical means of enforcing discipline by non-physical means is reflected in practices within schooling, through outlawing of corporal punishment in many countries and the promotion of PD at an international level. The supersession of physical with non-physical means of enforcing discipline has not necessarily resulted in the transformation of the discourse underlying discipline from being negative to positive.

Negative discursive practices associated with punishment in schools are not shared by vocational education institutions for a variety of reasons. Vocational education's point of departure as a route into trade and industry is more positive than schooling, with its roots in corporal punishment-based Victorian education. Furthermore, given the type of student traditionally drawn to or channelled into vocational education, the application of negative disciplinary practice is unlikely to result in the desired response. As a result, measures applied by TVET lecturers to manage student misconduct positively have not been studied and need further research.

\section{口 Problem statement}

The research problem addressed in this chapter is: how is student misconduct managed at a TVET college in the Western Cape through the application of positive disciplinary measures?

\section{- Conceptual and theoretical considerations}

Vocational education is a term commonly used to describe education aimed at the world of work. A number of names are 
commonly used to describe vocational education, including 'industrial education, technical education, career education and further education and training' (Van der Bijl \& Lawrence 2016:344). Currently, the most significant vehicle of vocational education in South Africa is the TVET colleges, dubbed further education and training colleges until 2013 and technical colleges before that. Vocational education at TVET colleges is located within higher education. Vocational education is also offered in out-ofmainstream school education.

Vocational education in South Africa has more than one point of origin, all of which influence the application of discipline. In the 1890s, schools for the mines and railways were established, as were dedicated classes at the colleges that would later be developed into the country's universities, technical colleges and private higher educational institutions (Van der Bijl \& Lawrence 2016:341-342). During the first half of the 20th century, institutions established for the 'poor, or indigent', and 'less able' (Gamble 2003:9) offered vocational programmes. In the 1970s, vocational education was assigned by the state for youth, which the policy called lower than average learners - labelled as 'stupid but normal' - in the early 1970s (Haasbroek \& Venter 1971:15-18).

The age of the students commonly enrolled in vocational education offered within higher education and methodologies associated with inclusive education does not lend itself to the application of reactive forms of discipline. Although the nature of the teaching and learning process applied in higher and special needs education negates the application of negative discipline, the nature of vocational education facilitates the application of PD.

Methodologically, the focus of both adult and higher education and special needs education is centred on the specific needs of their learners, which results in a positive approach towards teaching and learning. Adult education's focus on learners' accumulated experiences (Gravett 2005:14-16) results in an environment in which their experience 'can be utilised 
and affirmed'. Similarly, youth with either a need for acceleration or those with disabilities, if identified, can be provided with learning environments designed for their needs. Environments include 'special classes or schools exclusively for gifted children', or 'remedial programmes', 'a plain tranquil room with little diversion' or 'to proceed only when it (learning) is complete' (Mwamwenda 2004:339).

With reference to vocational pedagogy, the application of vocational education in the classroom, Lucas, Spencer and Claxton (2012:117-118) note the following five key elements:

- Learning occurs within the context of practical problemsolving.

- Learning takes place at a variety of levels at the same time.

- Learning within the classroom and work are 'blended' and not seen as being separate entities.

- Business practices within which expertise is embedded is modelled within vocational teaching.

- Vocational learning is similar to other kinds of practical learning.

Learning based on solving practical problems, aimed at the world of work, and embedded in and blended into real-world business practices, such as the one embedded in an adult psyche and the requirements of exceptional learners, creates an environment for the application of PD.

\section{Learning and behaviour modification within the context of vocational education}

Positive discipline is 'a form of discipline that is not punitive, but rather promotes punishment that facilitates constructive learning' (Veriava \& Power in Veriava et al. 2017:334). Positive discipline owes its existence to the work of Alfred Adler (1870-1937), an Austrian physician and pioneer of 'individual psychology'. Positive discipline focusses fundamentally on the cultivation of positive relationships with students. Positive discipline has been described 
as a discipline policy that places 'high expectations regarding student behaviour on a footing of consistent, stipulated and required conduct' (USDE 2014:11, cited in Oosthuizen 2018:145). The emphasis of PD is to create in learners a sense of belonging and of becoming responsible, respectful and resourceful (Gfoerer, Nelsen \& Kern 2013:296, cited in Oosthuizen 2018:145).

Adler is regarded as the creator of individual psychology (Adler 1969:52; Meyer, Moore \& Viljoen 1994:99). Adler's work emanated from a critique on the work of Sigmund Freud. In contrast to Freud's work, which is based on internal conflict, Adler's work is based on a belief that humans are purposeful beings, in possession of a free will and able to set objectives for their lives, steering it as determined by what he called a 'creative self'.

Adler argues that human nature strives towards perfection, finding itself on a continuous journey transcending towards a higher plane of functionality, often regarded as a striving to perfection in a quest to be a complete individual. Adler argues in favour of a teleological approach in which humans set goals for their lives, which in turn determine their behaviour towards attaining those goals.

Adler (1969:82) regards humans as an inferior species, given that humans are physically weak. Human weakness, he argues, has resulted in a quest for survival and superiority vested in intellect, technology and the reliance of humans on societal structures. Children, for example, rely on their families and school to support and protect them on their way to maturity and adulthood. Children's need for social support as well as the necessity to belong, according to Adler, is essential protective factors and crucial elements in their progress towards independence and maturity (Gfoerer et al. 2013:296).

For Adler, human maturity and adulthood are obtained when an individual's life reaches the point of survival and superiority. According to Adler, the quest for human superiority reaches its peak when a person is involved in the service of society and is 
driven to be involved in the future development of the surrounding world. He opines that only a human with a well-developed societal awareness is to be considered mentally healthy. Ansbacher and Ansbacher (1956) explained Adler's views of optimal human development as follows:

Social interest is the barometer of the child's normality [...]. The individual feels at home in life and feels his existence to be worthwhile just as far as he is useful to others and is overcoming common, instead of private feelings of inferiority. (p. 154)

In contrast to healthy mental behaviour, Adler regards antisocial behaviour and an excessive preoccupation with self as a characteristic of the mentally ill. Mentally unhealthy people are the ones who are unable to interact with others, as they only think of themselves and their problems.

Adler had a significant influence on education, especially in Austria. His psychotherapeutic methods in curing antisocial conduct was mainly aimed at trying to win a human's confidence by showing genuine interest in the person, in an endeavour to reeducate. His premise was to make an appeal to a person's insight, private logic and stimulating his or her social interests to restore their 'primary goal - to belong' (Nelsen 1999:35). With reference to Adlerian theories, Nelsen said that misbehaving youth are discouraged with incorrect ideas (faulty private logic) of how to attain their primary goal, which is: to belong. One of the major foci of PD is a sense of belonging, at home and in the school environment, and to make children 'feel better' to do better.

Although PD postulates an approach free of the use of physical methods in enforcing discipline, the absence of physical discipline enforcement should not be equated to PD. Discipline, from a Foucaultian perspective, is (Foucault 1979):

[/]dentified neither with an institution nor with an apparatus; it is a type of power, a modality for its exercise, comprising a whole set of instruments, techniques, procedures, levels of application, targets; it is a 'physics' or an 'anatomy' of power, a technology. (p. 215)

Foucault's work, particularly in the 1970s, included a focus on the evolution of the application of power within society from a 
process based largely on violence to it being exercised through the operation of social institutions and associate procedures, which he calls discipline. Behaviour in a classroom that is regarded within education as disciplined is therefore behaviour created by the expression of power that society provides to educational institutions and its agents. Foucault (1979:137) referred to this kind of disciplinary enforcement utilised by institutions such as 'monasteries, armies and workshops' as being based on violence and that all of these approaches became 'general formulas of domination'.

Although Foucault's work evolved and has been subjected to interpretation, his argument that behaviour modification, including behaviour in a classroom, is based on the exercise of power is generally accepted. Although the application of PD acknowledges the existence of power relations and its role in behaviour modification, PD emphasises the minimisation of negative aspects such as violence and the maximisation of positive aspects. For example, the establishment of self-discipline in a student would be motivated by the fruits of achievement and associated positive reinforcement and not by external chastisement or excommunication.

\section{Acceptance of positive discipline}

Adler's positive discipline-based approach has gained wide acceptance from policy developers, including the United States Department of Education (USDE 2014), the United Nations Children's Fund (UNICEF 2008), the proponents of Montessori education (Marshall, 2017:1-2) and, as a result of UNICEF's influence, in Jamaica (UNICEF 2008) and Iraq (Assali 2015). Allegiance with PD has resulted in a number of methods for the implementation of PD. The approach underlies the United States Department of Education's (USDE 2014) notion of the creation of a positive environment. Similarly, the UNICEF 'fact sheet' (UNICEF 2008) is based on a critique of 'negative punishment and its effects'. 
Approaches to PD postulated by Gfoerer et al. (2013:297-301) and Aboluwodi (2015:139) involve encouragement of students; positive time-out sessions; private communication and appealing to a student's private logic; meetings with parents, family and the class; group discussions; and the encouragement of student participation and involvement in community and/or group activities. Important factors involved in the application of PD, according to Gfoerer et al. (2013:297-301) and Aboluwodi (2015:139), include:

- the inculcation of communitarian principles

- building relationships

- building trust

- respect

- caring

- encouragement

- individualisation.

\section{Methods of applying positive discipline}

A number of methods of behaviour modification are associated with the application of PD. Methods include the application of proactive discipline, time-out, meetings, positive reward systems, the application of restorative justice and the creation of a teaching and learning environment, characterised by security and the acceptance of others without fear of abandonment. According to Pienaar (2011):

Proactive discipline involves the prevention of student misconduct by employing preventative strategies. In contrast to proactive discipline, reactive strategies are applied when disciplinary measures are implemented as a response to singular and reoccurring negative behaviour leading to disciplinary problems (Sprick 2013:2). When proactive discipline is applied, students are continuously encouraged to improve their self-confidence by creating a sense of accomplishment and success, and by enforcing the value of their contributions. Proactive reinforcement of positive behaviour paves the way to positive self-awareness, capability and resilience in the life of a student, and gives him/her a feeling of being connected and self-reliance. (pp. 159-161) 
Conflict between lecturers and students is commonly caused by disagreement and could erupt into a war of words in front of the class, causing damage to the general lecturer-student relationships. Positive time-out and private talks are positive methods of enforcing disciplined behaviour, thereby preventing conflict between lecturers and students in the classroom (Vakalisa 2012:354). In the case of an impending conflict, a time-out session affords the lecturer and the student time to calm down. Later, the lecturer could handle the point of disagreement amicably and democratically, affording the student the opportunity to explain his or her point of view. Conflict, Vakalisa (2012:354) argues, can be resolved if a student feels valued and heard.

Class meetings and what Whisman and Chapman (2013:vii) call group interventions, particularly if held regularly, are an effective tool for dealing with existing, potential and perceived disciplinary problems or other forms of negative student behaviour. During class meetings and group interventions, a lecturer and the class assemble to discuss challenges, problems or hindrances that are occurring in the classroom, in a democratic manner. Problems, challenges and hindrances are identified and discussed, and possible solutions are tabled. In the United States, a zero-tolerance approach to negative behaviour has been replaced by a practice of resolving disciplinary issues by communication between the parties concerned (Wachtel 2012).

Erdogan, Kursun and Sisman (2010) argue that expert subject knowledge is one of the most important factors that aid the lecturer to regulate student behaviour and ensure positive student conduct. Lecturers who are perceived to be lazy or to lack subject knowledge experience student misconduct more often than those who are perceived to be subject matter experts and appear to be prepared for lessons (Smit \& Rossouw 2015:74).

Sackey, Amaniampong and Abrokwa (2016:124) argue that a focus on and practice of rewarding positive student behaviour is more effective in dealing with student behaviour. Lecturers, they argue, tend to concentrate on students' mistakes, whereas positive 
efforts are neither rewarded nor noticed. Rather than focus on the negatives, lecturers could recognise students doing or behaving well and reward the behaviour appropriately. Common forms of reward include sincere recognition, encouragement, attention and approval, as they could prove to be building blocks for a sound self-image. A sound self-image is likely to pave the way for improved achievement (Sprick 2013:2).

Schacter (2010:27) argues in favour of a restorative justice model, as it appears to be one of the more flexible approaches in which a student is held accountable for a harmful behaviour by making it a learning event so that the same behaviour is not repeated. Restorative justice involves practices in which students are required to repair the harm caused by their wrong doing or inappropriate behaviour (Shah \& McNeil 2013:1).

A restorative justice system, as Shah and McNeil (2013) argue, commonly includes the following:

- A student is held accountable for harm meted out to others.

- A mediator or coordinator must be appointed to act as a gobetween amongst the offended and the offending students.

- Offending students need to be made to realise the negative effects of their actions.

- An opportunity for fellow students must be provided to express the impact that the bad behaviour had on them.

- Restoration must occur between the offended and the offending parties.

- The offending student must be reinstated.

Acceptable conduct could be facilitated by the creation of an environment that is safe, satisfying and characterised by relations of trust. Safety and security in the classroom has been associated with the German anthropological concept of geborgenheit (Oosthuizen 2015:4). Although the term (geborgenheit) can be translated as security, semantically the German word has a deeper meaning than any comparative English concept. Geborgenheit is associated with feelings of love, safety, satisfaction and trust (Oosthuizen 2015:4).

An environment of geborgenheit discourages student misconduct and encourages harmonious cooperation in the classroom setting. 
An environment of geborgenheit enhances an orderly and secure environment for the teaching and learning process. Student misconduct influences the peaceable atmosphere of geborgenheit negatively. The principle of geborgenheit requires the enforcement of student disciple in a manner that expresses behaviour concomitant with feelings of love, safety, satisfaction and trust.

\section{Research design and methodology}

The research design is a case study comprising a TVET college in the Western Cape. In addition, as the research theory of this chapter is grounded in the theory of geborgenheit, the principles associated with love, safety, satisfaction and trust are utilised as the basis for both the collection and analysis of data. Data collection and analysis imply an explanatory mixed methods approach, rooted in the pragmatic worldview by administering a quantitative questionnaire, followed by qualitative interviews. Aligned with an explanatory mixed methods approach (McMillan \& Schumacher 2014:431), quantitative data were collected first, whereafter qualitative data were collected with the intention of elaborating on and explaining the quantitative data collected.

Quantitative data were gathered by means of a questionnaire developed from a literature review. The questionnaire required pre-determined answers such as 'not' to 'always', or 'inadequate' to 'excellent'. The questionnaire facilitated numerical measurement of methods used to gauge student behaviour and misconduct through PD at the TVET college by means of a Likert scale. The questionnaire complied with Leedy and Ormrod's (2010:189) argument that a quantitative questionnaire with rating scales, or Likert scales, are useful for evaluating attitudes, behaviours and matters of interest on a continuum.

Quantitative data were collected to determine the most frequently used methods of PD at the TVET college that formed the sample for analysis. 
Following the collection of quantitative data, qualitative data were collected, enabling the elaboration of themes that emerged from quantitative data. The content provided by the qualitative data collected facilitated a better understanding and an elaboration of the statistical data collected. Qualitative data were gathered by conducting personal interviews. The themes identified by means of the qualitative factor analysis were arranged thematically to be incorporated in qualitative interviews, where methods of applying PD were investigated.

In accordance with Creswell's (2009:178) argument on qualitative research, a purposeful selection of participants and sites facilitated an understanding of the research problem and question. Similarly, by using interviews, qualitative data collection was undertaken in conformity with Creswell's (2009:180-181) argument that qualitative data could be collected through observations, interviews, documents and audio-visual materials. For this study, qualitative data were collected by conducting open-ended interviews with participants.

\section{Population, sampling and participant selection}

The bounded system in this case study was a campus of a TVET college in the Western Cape with a total registered student population of 1500. A convenience random sampling was conducted ( $n=253$ ). This particular campus was selected for financial reasons and also because the researcher is a lecturer on the campus.

Qualitative data were collected from two lecturers through personal interviews. Purposive sampling was employed, and two highly experienced lecturers who have been on campus for $10+$ years and therefore familiar with student behaviour were selected. Purposeful selection complied with Leedy and Ormrod's (2010:212) argument on the selection of participants for a particular purpose. 


\section{Data analysis}

Quantitative data collected by using the questionnaire (see Appendix A) were captured on SPSS for analysis. The processed data were summarised by means of frequency tables. The qualitative data were analysed in terms of emerging themes.

\section{Validity, reliability and trustworthiness}

The validity of a quantitative instrument refers to the extent to which an instrument actually measures what it is intended to measure. Types of validity include face validity, content validity, construct validity and criterion validity. In this instance, face validity was acquired by scrutinising the questionnaire to determine whether it would measure what it is supposed to measure (Pietersen \& Maree 2014a: 216-217). Content validity of the questionnaire was ensured by determining whether the questions included in the questionnaire were relevant and indeed measured what they were supposed to measure. In both cases, the questionnaire was submitted to specialists in the field to scrutinise after which it was tweaked to improve the content and face validity.

Quantitative reliability is the extent to which a measuring instrument is repeatable and consistent. Even if the instrument is used at different occasions, or on different subjects, the findings should be the same. Compliance with internal reliability requires a high degree of similarity amongst items measuring a common construct (Pietersen \& Maree 2014:216). If items strongly correlate with one another, the internal consistency is high and the alpha coefficient is close to one. Poorly formulated items do not correlate strongly, resulting in an alpha coefficient close to zero (Pietersen \& Maree 2014:216). The quantitative reliability of the questionnaire was tested by means of the Cronbach's alpha coefficient, a measure commonly used to measure inter-item correlations.

Qualitative trustworthiness and credibility were ensured by comparing data with codes to make sure there is no drift in the 
definition of the codes. Trustworthiness of findings, according to Creswell (2009:190-191), was ensured by member checking; the use of thick, rich descriptions; the use of multiple methods of data collection; and spending prolonged time in the field. Construct credibility was ensured by comparing the data with codes and requesting other researchers to cross-check the codes.

\section{Ethical considerations}

Ethical practice was aligned with Creswell's (2009:88-89) argument that researchers should anticipate and address ethical dilemmas that may arise during the research process. To prevent ethical risks, as Creswell argues, research plans should be reviewed by a review board of the institution where it is conducted. In addition, researchers should provide a letter of informed consent which participants sign before they engage in the research. The Department of Higher Education and Training (South Africa 2016) promulgated a policy similar to the view expressed by Creswell (2009:88-89).

Permission to conduct the research was sought from the department through the head of the sample college (Appendix B). The purpose of the research was explained to participants and confidentiality was guaranteed. Participants were informed of their freedom to withdraw at any time.

\section{The occurrence of the application of positive discipline at a Technical and Vocational Education and Training college in the Western Cape}

Student and lecturer views on lecturer behaviour and PD correlate strongly. This also correlates strongly with arguments presented in related literature discussed earlier. 


\section{Biographical detail}

The details of the students who answered the questionnaire concerning their programme are shown in Table 8.1.

More females $(n=175)$ than males $(n=80)$ completed the survey. More NATED students responded to questionnaires ( $n=112$ ) than NCV students $(n=97)$. The occupational programme offered by the college received the least responses $(n=44)$. The NATED and NCV programmes are largely academic, which made it easier to hand over questionnaires to students in classes. The practical nature of occupational programmes meant that students spent most time in workshops, which negatively influenced students' availability to complete the questionnaire.

\section{Attributes of Technical and Vocational Education and Training lecturers that contribute to a positive, disciplined teaching and learning environment ranked}

Technical and vocational education and training lecturer attributes that influence the teaching and learning environment are shown in Table 8.2.

The questionnaire required that students rate the items in terms of lecturer attributes that contribute towards a positive, disciplined teaching and learning environment. 'Lecturers are hard-working' was ranked first (mean $=3.29$ ). This question was

TABLE 8.1: Student programme.

\begin{tabular}{llcc}
\hline No. & Programme & Female & Male \\
\hline 1.2 .1 & NCV student & 97 & 37.2 \\
1.2 .2 & NATED student & 112 & 42.9 \\
1.2 .3 & Occupational student & 44 & 16.9 \\
\hline
\end{tabular}

NATED, national accredited technical education diploma; NCV, national curriculum vocational. 
TABLE 8.2: Lecturer attributes.

\begin{tabular}{llccc}
\hline No. & Attributes & Mean & Std. deviation & $\boldsymbol{N}$ \\
\hline 1 & Lecturers are hard-working. & 3.29 & 0.920 & 201 \\
2 & Lecturers make effective use of their voices. & 3.14 & 0.922 & 201 \\
3 & Lecturers require high output in a tolerant way. & 3.10 & 0.885 & 201 \\
4 & Lecturers communicate clearly. & 3.05 & 0.939 & 201 \\
5 & Lecturers have sound relations with students. & 3.00 & 0.919 & 201 \\
6 & Lecturers are at ease with themselves. & 2.99 & 0.900 & 201 \\
7 & Lecturers tend to their outward appearances. & 2.87 & 0.931 & 201 \\
8 & Lecturers are easily understood. & 2.83 & 0.908 & 201 \\
\hline
\end{tabular}

in line with the view expressed by Smit and Rossouw (2015:74), namely, that student behaviour is linked to their view of lecturers' level of work. Students notice the extent to which lecturers work hard and express and show interest in their work. Students tend to follow the positive example set by them. Similarly, when lecturers are lazy and appear disinterested, students also lose interest and as a result may behave in a manner that is considered as misconduct (Smit \& Rossouw 2015:74).

Information gleaned from the questionnaires concurs with Smit and Rossouw's view. 'Lecturers make effective use of their voices' was ranked second (mean $=3.14$ ). Lecturers who are presenting lessons should speak loud enough for all to hear and articulate their words clearly. Students who are unable to hear may become restless and frustrated, as they will not be able to follow the lesson.

'Lecturers require a high output in a tolerant way', ranked third (mean $=3.10$ ), was in line with the view expressed by Pienaar (2011:159-161). Pienaar (2011) argued that the failure to set goals may lead to students not knowing what is expected of them or what to expect of lessons. As a result, students may lose focus and become disinterested in their work, which is why it is important for lecturers to set clear, attainable goals to students and provide regular feedback on progress made. 
'Lecturers communicate clearly', also in line with the view expressed by Pienaar (2011:159-161), was ranked fourth (mean = 3.05). Lecturers' effective use of their voices was ranked second. It is important for lecturers to communicate effectively. Lecturers should not only speak out clearly and articulate words effectively, but they should also use simple language for explaining difficult terms.

'Lecturers have sound relations with students' was, as in the two previous questions, in line with the view expressed by Pienaar (2011:159-161). It was ranked fifth (mean $=3.00$ ). For lecturers to earn the trust, respect and cooperation of students, it is important to maintain sound relationships with students. Although lecturers are required to produce a high output in a tolerant way when maintaining sound relationships with students, they should, at the same time, expect students to perform.

'Lecturers are at ease with themselves', in line with the view expressed by Pienaar (2011:159-161), was ranked sixth (mean = 2.99). Lecturers who are at ease with themselves are more confident and, as a result, capture the attention of students more easily. When lecturers are stressed or lack self-confidence, it may have a negative influence on students, as students easily sense the emotional state of lecturers. Lecturers who are not at ease with themselves may lose the confidence students have in their abilities, which may lead to student misconduct.

'Lecturers tend to their outward appearances', in line with the view expressed by Pienaar (2011:159-161), was ranked seventh (mean $=2.87$ ). Lecturers who care for their appearances and dress accordingly create an impression of professionalism and interest in their work. Lecturers who do not tend to their appearance may appear slack in their work and lose the respect of students.

'Lecturers are easily understood', in line with the view expressed by Pienaar (2011:159-161), was ranked eighth (mean = 2.83) and last. Lecturers being easily understood was ranked fourth. Students should receive clear communication from lecturers and fully understand what is explained to them. 


\section{Measures that contribute towards a positive, disciplined teaching and learning environment ranked}

Statistical results for questions related to effectiveness of measures that contribute to a positive, disciplined teaching and learning environment are shown in Table 8.3.

Students were asked to rate questions related to the effectiveness of the measures used to maintain a positive, disciplined teaching and learning environment by completing a rating scale of one to four. 'Students are allowed to participate during lessons' was ranked first (mean = 3.24). Pienaar (2011:159-161) argues that students who are actively engaged during lessons are less likely to transgress because their attention is captured and lessons are interesting.

'Lecturers encourage students to enhance their self-respect' was ranked second (mean $=3.10$ ). When lecturers encourage students, they raise the morale and hope of these students and motivate them (Pienaar 2011:159-161).

According to Smit and Rossouw (2015:74), lecturers who are not prepared for class or lack subject knowledge tend to experience more frequent and serious student disciplinary problems. Similarly, lecturers who are experts in their particular fields and do effective lesson planning have less problems with student misconduct, as they possess the subject knowledge to present interesting lessons with adequate details and examples. The proposition 'lecturers are experts in their particular fields of knowledge' was ranked third (mean $=3.06$ ) and was followed by 'lecturers present well-prepared lessons' (mean $=3.03$ ). Both these propositions are concomitant with the view expressed by Smith and Rossouw (2015).

'Lecturers are accessible' was ranked fifth (mean = 2.96), indicating that lecturers should be accessible to students who need additional help with work or feel embarrassed to ask in front of the class. Lecturer workloads, however, present 
TABLE 8.3: Measures for maintaining PD.

\begin{tabular}{|c|c|c|c|c|}
\hline No. & Measures for maintaining PD & Mean & Std. Deviation & $N$ \\
\hline 1 & $\begin{array}{l}\text { Student participation: Students are allowed to } \\
\text { participate during lesson presentations. }\end{array}$ & 3.24 & 0.993 & 210 \\
\hline 2 & $\begin{array}{l}\text { Encouragement: Lecturers encourage students to } \\
\text { enhance their self-respect. }\end{array}$ & 3.10 & 0.971 & 210 \\
\hline 3 & $\begin{array}{l}\text { Lecturers as experts: Lecturers are experts in their } \\
\text { particular fields of knowledge. }\end{array}$ & 3.06 & 0.921 & 210 \\
\hline 4 & $\begin{array}{l}\text { Lecturers as experts: Lecturers present well-prepared } \\
\text { lessons. }\end{array}$ & 3.03 & 0.901 & 210 \\
\hline 5 & Lecturer approachability: Lecturers are accessible. & 2.96 & 0.982 & 210 \\
\hline 6 & $\begin{array}{l}\text { Encouragement: Lecturers enhance a sense of } \\
\text { accomplishment amongst students. }\end{array}$ & 2.92 & 0.806 & 210 \\
\hline 7 & Lecturer approachability: Lecturers are easy to talk to. & 2.82 & 1.038 & 210 \\
\hline 8 & $\begin{array}{l}\text { Restorative justice: Offenders are afforded the } \\
\text { opportunity to express regret and to apologise for } \\
\text { wrong actions. }\end{array}$ & 2.72 & 0.993 & 210 \\
\hline 9 & $\begin{array}{l}\text { Open communication channels: Open communication } \\
\text { channels exist between students and lecturers by means } \\
\text { of an open-door policy. }\end{array}$ & 2.69 & 1.014 & 210 \\
\hline 10 & $\begin{array}{l}\text { Lecturer approachability: Lecturers show kindness } \\
\text { towards students. }\end{array}$ & 2.67 & 1.146 & 210 \\
\hline 11 & $\begin{array}{l}\text { Lecturer approachability: Lecturers are patient with } \\
\text { students. }\end{array}$ & 2.66 & 1.155 & 210 \\
\hline 12 & $\begin{array}{l}\text { Class meetings: Lecturers meet with the whole class to } \\
\text { discuss disciplinary issues in a democratic way. }\end{array}$ & 2.62 & 1.083 & 210 \\
\hline 13 & $\begin{array}{l}\text { Building a relationship: Lecturers maintain a relationship } \\
\text { of trust with students. }\end{array}$ & 2.60 & 1.013 & 210 \\
\hline 14 & $\begin{array}{l}\text { Positive time-out: Lecturers have discussions with } \\
\text { transgressing students after class (not during class). }\end{array}$ & 2.50 & 0.999 & 210 \\
\hline 15 & $\begin{array}{l}\text { Involving parents: Lecturers allow parents to participate } \\
\text { in disciplinary matters related to students. }\end{array}$ & 2.44 & 1.093 & 210 \\
\hline 16 & $\begin{array}{l}\text { Student participation: Students are allowed to } \\
\text { participate in drafting classroom rules. }\end{array}$ & 2.42 & 1.184 & 210 \\
\hline 17 & $\begin{array}{l}\text { Open communication channels: Open communication } \\
\text { channels exist between students and lecturers through } \\
\text { WhatsApp. }\end{array}$ & 2.10 & 1.221 & 210 \\
\hline 18 & $\begin{array}{l}\text { Open communication channels: Open communication } \\
\text { channels exist between students and lecturers through } \\
\text { email. }\end{array}$ & 1.78 & 1.007 & 210 \\
\hline
\end{tabular}

PD, positive discipline. 
accessibility challenges, as workload influences availability and, as a result, time to be accessible to students.

'Lecturers enhance a sense of accomplishment amongst students' was ranked sixth (mean $=2.92$ ), indicating that satisfaction of task completion is experienced when students are allowed to solve problems within their abilities. This concurs with the argument made by Smit and Rossouw (2015:74), namely, that lessons planned around problem-solving, however, demands that students solve problems that are not too difficult or too easy. Lecturers who lack teaching qualifications may find it difficult to do effective lesson planning.

'Lecturers are easy to talk to' was ranked seventh (mean = 2.82), indicating that students should be able to approach lecturers for help without fear if and when they do not understand work covered or experience personal problems. Students will find it easy to talk to lecturers in those cases where lecturers maintain open relationships with them.

'Offenders are afforded the opportunity of showing regret and apologise for wrong actions' was ranked eighth (mean $=2.72$ ), indicating that there is sufficient opportunity for offenders to participate in restorative justice. Students registered at TVET colleges are focussed on advancing in their careers, as opposed to learners at schools, which may lead to fewer instances of harassment and bullying. The need for restorative justice may therefore be limited.

'Open communication channels exist between students and lecturers by means of an open-door policy' was ranked ninth (mean $=2.69$ ), indicating that students prefer speaking directly to lecturers, as opposed to being informed by social media such as WhatsApp, which was ranked 17th, or email, which was ranked 18th.

The fact that 'Lecturers show kindness towards students' was ranked tenth (mean $=2.67$ ) and 'Lecturers are patient with students' was ranked 11th (mean $=2.66$ ) indicates that students 
feel accepted and safe and have the confidence to approach lecturers, who are kind and patient, when they experience problems. This concurs with Oosthuizen's (2015:4) view that, when students feel safe and accepted in a classroom, and an atmosphere of geborgenheit is created, it will temper student misconduct.

'Lecturers meet with the whole class to discuss disciplinary issues in a democratic way' was ranked 12th (mean = 2.62), indicating that discussing disciplinary issues with students in a democratic way received a low ranking. The ranking of this question indicates that lecturers may not trust student views on disciplinary issues.

'Lecturers maintain a relationship of trust with students' was ranked 13th (mean $=2.60$ ), indicating the need to maintain relationships of trust with students received a relatively low ranking. Possibly, the time students spend with every lecturer per day may be too short for developing and maintaining a relationship of trust.

'Lecturers have discussions with transgressing students after class' was ranked 14 th (mean $=2.50$ ) and received a relatively low ranking, indicating that open discussions about individual transgressions may upset students who were not involved. This points to a preference to have discussions with transgressing students only, potently after class, which prevents conflict in the classroom and does not negatively influence the dignity of transgressing students.

'Lecturers allow parents to participate in disciplinary matters related to students' was ranked 15th (mean $=2.44$ ), indicating that the student is held responsible for his or her actions. The age of the student population makes them less dependent on their parents.

'Students are allowed to participate in drafting classroom rules' was ranked 16th (mean $=2.42$ ). The low ranking of this question indicates that students are not able to provide valuable inputs in drafting classroom rules. The majority of students, however, prefer a disciplined classroom atmosphere conducive 
to teaching and learning, and are more than capable of participating in drafting classroom rules.

'Open communication channels exist between students and lecturers through WhatsApp' was ranked 17th (mean = 2.10), indicating that the advantages that lecturers find in the use of social media for communication purposes are not shared by students.

'Open communication channels exist between students and lecturers through email' was ranked 18th and last (mean $=1.78$ ), for reasons similar to the use of social media. Many TVET students do not have access to the Internet at home, making it unsuitable to use as a channel of communication.

The questionnaire completed by students indicates that their behaviour is associated with competent, approachable lecturers who handle misconduct by means of direct communication with offenders. Students do not think it appropriate for individual misconduct to be made into public spectacles. Students do not believe that electronic communication is conducive for the development of sound student-lecturer relations.

\section{The views and experiences of lecturers on positive student disciplinary measures}

Interviews conducted supported the findings elicited by the questionnaires and will be discussed below.

A female senior lecturer in her late forties explained the importance of a well-prepared lesson as a measure for managing student misconduct through PD:

A lecturer should apply different disciplinary measures depending on the situation. Class group discussions are appropriate when disciplinary problems are experienced with the whole class like, for example, absenteeism and late coming. Private discussions with students are more appropriate when a student experiences personal problems.

A well-prepared lesson is the most important method to maintain student discipline. Students pick up when a lecturer come to class unprepared and read out of the textbook. You cannot keep a student 
quiet if you are not prepared for a lesson. When all learning styles are included in a lesson every student will be kept busy and interested. (Senior lecturer, female, date unknown)

A male lecturer who teaches Mathematics on a part-time basis at the TVET college maintains that well-prepared lessons are the most important method to maintain discipline:

If my relationships with students are good, they will come to class even if it is hot or raining. Once they are in class they need to know that they will learn something and that they will benefit. (Lecturer, male, date unknown)

The lecturer explained that students occasionally doubt whether they should come to class. If relationships with students are good, students will feel motivated to come to class because they do not want to disappoint the lecturer. The lecturer also emphasised the importance of showing to students that he is committed:

When students see that a lecturer is committed they feel that they must be committed as well and then they become afraid to fail the subject. Committed students do not want to disappoint their lecturers. (Lecturer, male, date unknown)

The lecturer makes use of rewards and encouragement to motivate students. He usually identifies students who have improved significantly, as well as well-performing students, and rewards such students in class.

\section{- Conclusion and recommendations}

The highest-ranking lecturer attributes that contribute to a disciplined classroom environment are that they are hard-working, make effective use of their voices, require high output in a tolerant manner and communicate effectively. The interview data confirmed the importance of lecturer commitment. When lecturers are committed and demand high outputs in a tolerant way, students will also become committed and have the desire not to disappoint the lecturer. It is, however, important for lecturers to communicate effectively for students to follow lessons. 
The high ranking of effective, clear communication and use of voice by lecturers may indicate that students who do not hear what lecturers are saying do not understand explanations and, as a result, become frustrated. When students can hear and understand lecturers' explanations, they are able to reach their objectives which are to succeed in their subjects.

The highest-ranking measures for maintaining student discipline through PD are:

- student participation during lessons

- encouragement of students and enhancement of a sense of accomplishment amongst students

- lecturers being experts in their fields of specialisation, presenting well-prepared lessons.

The accessibility of lecturers also received a high ranking.

A critical element for maintaining a disciplined classroom environment is the well preparedness of lecturers with the lessons they are going to teach. Lecturers who are specialists in their fields are able to present lessons that contain in-depth explanations and, in correlation with the interview data, include all the learning styles to facilitate student participation during lessons. Interesting lessons that engage students contribute towards a disciplined classroom environment by capturing the attention of students.

Significant lecturer attributes that contribute to a disciplined classroom environment were:

- being hard-working

- making effective use of their voice

- requiring high levels of output in a tolerant manner

- communicating effectively.

Significant measures for maintaining student discipline through PD are:

- student participation during lessons

- lecturers encouraging students and enhancing a sense of accomplishment amongst students 
- lecturers being experts in their fields and presenting wellprepared lessons.

When lecturers encourage students, it creates a sense of being appreciated and of having accomplished something, which motivates students to excel in their work. Lecturers should also be accessible to students and easy to talk to when students experience difficulties. Failure to accommodate students may cause struggling students being left behind.

It is recommended that TVET college lecturers receive training to make them aware of and be able to apply measures to manage student misconduct through PD. Especially, lecturers lacking teaching qualifications may benefit from such trainings. Lecturers who lack determination to be committed and motivated should receive mentoring and training aimed at improving their motivation and sense of commitment. 


\section{Appendix A}

\section{Questionnaire}

The purpose of the survey is to determine the application and effectiveness of positive disciplinary methods at the TVET college. Participation is voluntary and all information will be kept confidential and anonymity of respondents or participants is guaranteed.

\section{Section A: Biographical}

1. Please indicate your biographical details by crossing out the appropriate number.

\begin{tabular}{lll}
\hline $\mathbf{1 . 1}$ & Gender & \\
& Male & 1 \\
& Female & 2 \\
$\mathbf{1 . 2}$ & Position & 2 \\
& NCV student & 3 \\
& NATED student & 4 \\
& Occupational student & \\
\hline
\end{tabular}

\section{Section B: Lecturer attributes}

2. Kindly indicate how effectively the following lecturer attributes contribute towards a positive, disciplined teaching and learning environment by crossing the appropriate number

\begin{tabular}{llllll}
\hline 2.1 & Lecturers tend to their outward appearances. & 1 & 2 & 3 & 4 \\
\hline 2.2 & Lecturers are at ease with themselves. & 1 & 2 & 3 & 4 \\
\hline 2.3 & Lecturers communicate clearly. & 1 & 2 & 3 & 4 \\
\hline 2.4 & Lecturers are easily understood. & 1 & 2 & 3 & 4 \\
\hline 2.5 & Lecturers make effective use of their voices. & 1 & 2 & 3 & 4 \\
\hline 2.6 & Lecturers have sound relations with students. & 1 & 2 & 3 & 4 \\
\hline 2.7 & Lecturers are hard-working. & 1 & 2 & 3 & 4 \\
\hline 2.8 & Lecturers require high output in a tolerant way. & 1 & 2 & 3 & 4 \\
\hline
\end{tabular}




\section{Section C: Application of disciplinary measures}

3. Please indicate how effectively the following measures contribute towards a positive, disciplined teaching and learning environment by crossing the appropriate number

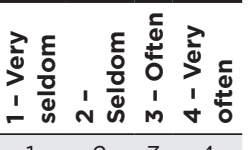

3.1 Encouragement: Lecturers encourage students to enhance their $\begin{array}{lllll}1 & 2 & 3 & 4\end{array}$ self-respect.

3.2 Encouragement: Lecturers enhance a sense of accomplishment $\begin{array}{lllll}1 & 2 & 3 & 4\end{array}$ amongst students.

$\begin{array}{llllll}3.3 & \text { Positive time-out: Lecturers have discussions with transgressing } & 1 & 2 & 3 & 4\end{array}$ students after class (not during class).

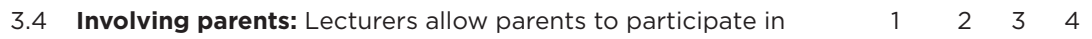
disciplinary matters related to students.

$\begin{array}{llllll}3.5 & \text { Class meetings: Lecturers meet with the whole class to discuss } & 1 & 2 & 3 & 4\end{array}$ disciplinary issues in a democratic way.

3.6 Open communication channels: Open communication channels $\quad \begin{array}{lllll}1 & 2 & 3 & 4\end{array}$ exist between students and lecturers through WhatsApp.

3.7 Open communication channels: Open communication channels $\quad \begin{array}{lllll}1 & 2 & 3 & 4\end{array}$ exist between students and lecturers through email.

$\begin{array}{llllll}3.8 & \text { Open communication channels: Open communication channels } & 1 & 2 & 3 & 4\end{array}$ exist between students and lecturers by means of an open-door policy.

$\begin{array}{llllll}3.9 & \text { Building a relationship: Lecturers maintain a relationship of } & 1 & 2 & 3 & 4\end{array}$ trust with students.

$\begin{array}{llllll}3.10 & \text { Lecturers as experts: Lecturers are experts in their particular } & 1 & 2 & 3 & 4\end{array}$ fields of knowledge.

$\begin{array}{lllllll}3.11 & \text { Lecturers as experts: Lecturers present well-prepared lessons. } & 1 & 2 & 3 & 4\end{array}$

$\begin{array}{lllllll}3.12 & \text { Student participation: Students are allowed to participate in } & 1 & 2 & 3 & 4\end{array}$ drafting classroom rules.

$\begin{array}{llllll}3.13 & \text { Student participation: Students are allowed to participate } & 1 & 2 & 3 & 4\end{array}$ during lesson presentations.

3.14 Lecturer approachability: Lecturers are accessible.

3.15 Lecturer approachability: Lecturers are easy to talk to.

3.17 Lecturer approachability: Lecturers are patient with students.

$\begin{array}{lllllll}3.18 & \text { Lecturer approachability: Lecturers show kindness towards } & 1 & 2 & 3 & 4\end{array}$ students.

$\begin{array}{llllll}3.19 & \text { Restorative justice: Offenders are afforded the opportunity to } & 1 & 2 & 3 & 4\end{array}$ show regret and apologise for wrong actions. 


\section{Chapter 9}

\section{The congeniality to sound learner discipline of the Finnish education system: Relevance for approaching learner discipline in South African schools}

Charl C. Wolhuter

School of Professional Studies in Education, Comparative and International Education, Faculty of Education, North-West University,

Potchefstroom, South Africa

How to cite: Wolhuter, C.C., De Wet, C. \& Van der Walt, J.L., 2019, 'The congeniality to sound learner discipline of the Finnish education system: Relevance for approaching learner discipline in South African schools', in C.B. Zulu, I.J. Oosthuizen \& C.C. Wolhuter (eds.), A scholarly inquiry into disciplinary practices in educational institutions (NWU Education and Human Rights in Diversity Series Volume 2), pp. 199-228, AOSIS, Cape Town. https:// doi.org/10.4102/aosis.2019.BK157.09 
Corene de Wet Open Distance Learning, Faculty of Education, University of the Free State, Bloemfontein, South Africa

\author{
Johannes (Hannes) L. van der Walt \\ Edu-HRight Research Focus Area, \\ Faculty of Education, North-West University, \\ Potchefstroom, South Africa
}

\title{
Abstract
}

Over the past decade and a half, the education system of Finland has appeared on the world stage as an exceptional education system, one worthy of emulation by other countries. Also, with respect to its success in securing good learner discipline in schools, the Finnish education system has set a noteworthy example. The purpose of this chapter is to report on research into how Finland's national education system developed to the level of being regarded as a beacon on the international education landscape, and also into how the Finnish education system could be an example for South Africa, particularly with respect to how good learner discipline could be maintained in South African schools. The success of the Finnish system can be explained in terms of a combination of factors, amongst others, the societal context in which the education system is embedded, the training of teachers as well as the professional autonomy enjoyed by teachers. The possibility of emulating the Finnish education experience in and for discipline in South African schools is spelt out in the conclusion.

\section{Introduction}

Since the 1960s, education has been regarded as the panacea for the social problematics that countries or societies might be grappling with. This view of the 'mission plenipotentiary of education' has intensified further as the move towards a knowledge society has gained momentum (World Bank 2002). 
In the current, increasingly competitive, globalising world, every country strives towards possessing the best possible education system. Although it is a universal phenomenon that people regard their own education system as lacking in various respects, and that those abroad (at least, some of them) seem to be better and worth emulating (Wiseman 2012), there can be little doubt that the education system of South Africa leaves much to be desired, even when compared with other higher middleincome countries (Bloch 2009). Not the least of the serious problems besetting South African schools is a lack of learner discipline (Wolhuter \& Van Staden 2008). Where should one then turn for a foreign education system worthy of emulation? The one education system that has arguably developed into such a model in recent years is the education system of Finland. Also, as far as learner discipline is concerned, Finland has been considered as a model for the rest of the world to follow (Dake, Price \& Telljohann 2003). A large-scale, comparativeinternational empirical study in diverse settings in more than a dozen countries showed, for example, that the incidence of bullying in elementary schools ranged from the lowest $(11.3 \%)$ in Finland, to the highest (49.8\%) in Ireland (Pellengrini, Bartini \& Brooks 1999).

Although it may be argued that Finland's level of economic well-being, its relatively homogenous population, socio-economic equality and amount of social capital render it incomparable to South Africa, these contextual features of Finland are all part of the vision South Africa has for itself. South Africa is, furthermore, like Finland, a liberal democracy in which social life is de jure regulated by a progressive Bill of Human Rights. Although South Africa and Finland differ widely in terms of the level of development, with the former being a developing country at the southern tip of Africa and the latter a highly developed country in Scandinavia, it can be argued that educators and education system planners and managers in South Africa should be prepared to look up to a situation that could be regarded worth emulating, 
to take over certain approaches and policies that might 'work' in the South African context and 'transplant' them in ways consistent to South African conditions and amenable to the South African national spirit.

The purpose of this chapter is to report on research into how the Finnish national education system became what is today, widely regarded as a beacon on the international education landscape, and also into how insights flowing from an examination of the Finnish education system could be employed for the reinstatement of learner discipline in South Africa.

The chapter commences with a survey of those factors that are deemed to affect, determine or at least correlate with the state of learner discipline in schools globally. That survey is followed by an appraisal of the state of learner discipline in schools in general, globally. That is in turn followed by a depiction of the rise of the Finnish education system on the world stage, and of its quintessential features. On the basis of these three sets of information, a number of conclusions are drawn regarding the possible emulation of the Finnish experience for the maintenance of learner discipline in South African schools.

\section{- Learner discipline in schools: Correlates or determinants}

It transpired from an international survey that the state of learner discipline in schools can be ascribed to the impact of six sets of factors, namely, learner-related factors, teacher-related factors, school-related factors, parent-related factors, society-related factors and education system-related factors (Wolhuter\& Van der Walt 2019).

Firstly, the incidence and nature of disciplinary problems appear to be connected to learner-related factors such as the ages of learners or the life-phases in which they find themselves. Discipline problems seem to occur more frequently and to be of 
a more serious nature at the secondary school level than in primary schools (National Centre of Education Statistics 2002; Wolhuter, Oosthuizen \& Van Staden 2010). Secondly, teacherrelated factors such as the level of competency of a teacher, the extent to which the teacher is a role model for learners and teacher-learner relationships also have a bearing on the state of learner discipline (De Klerk-Luttig \& Heystek 2007; Department of Education and Science and the Welsh Office 1989:67-72; Eloff et al. 2013). Thirdly, school-related factors such as school management arrangements, school leadership, school infrastructure, class size (i.e. the student-teacher ratio), organisation climate and organisational culture at the school all have an impact on the state of learner discipline in schools (Department of Education and Science and the Welsh Office 1989:12, 13, 17; Van der Westhuizen, Oosthuizen \& Wolhuter 2008). The fourth set of factors refers to parental involvement in and support of schools, parental modelling and child-raising styles and practices at home (Wolhuter\& Van der Walt 2019). Fifthly, society-related factors such as a lack of social capital in society could be detrimental to the maintenance of good learner discipline in schools (Van der Walt et al. 2009).

The sixth set of factors pertain to the education system. The (national) education system of a country provides the structural environment and parameters (as is evident in the governance in circuits, districts, provincial and national offices) particularly for the above-mentioned teacher- and school-related factors such as teacher competency, school infrastructure, authority, autonomy and the morale of the teachers in the system. With the exception of the legal environment, the education systemfactor in learner discipline in South Africa has not yet been subjected to research. This chapter can be regarded as a first step for exploring school-related factors in South Africa for the purpose of arriving at a fuller understanding of the learner discipline problematic in South African schools, and of ways of addressing that problem. 


\section{- Learner discipline in South African schools and the need for a change in approach}

Learner discipline constitutes a major problem in South African schools. This is evident from both regular reports in the media and from published research (Wolhuter \& Van der Walt 2019). The most pressing problem seems to be that teachers are at a loss regarding the methods available to them for the maintenance of discipline (Wolhuter \& Van Staden 2008). In research on the availability of methods for the maintenance of classroom discipline, PD emerged as one of the most important methods (Oosthuizen, Wolhuter \& Du Toit 2003; Van der Walt, Potgieter \& Wolhuter 2010a). Positive discipline, an approach developed by proponents such as Jane Nelsen, Lynn Lott, Cheryl Erwin, Kate Ortolano, Mary Hughes, Mike Brock and Lisa Larson, is designed for teaching young people to become responsible, respectful and resourceful members of their communities. Durrant (n.d.) defines PD as:

$[A] \mathrm{n}$ approach to teaching that helps children succeed, and [that gives] them the information they need to learn, and support[s] their development. It respects children's right to healthy development, protection from violence, and active participation in their learning. (p. 1)

Durrant (n.d.) further explains that PD is:

$[A]$ bout long-term solutions that develop students' own self-discipline and their own lifelong learning. It is about clear and consistent communication, and consistent reinforcement of your expectations, rules and limits. Positive discipline is about teaching non-violence, empathy, self-respect, human rights, and respect for others. (p. 1)

In line with this definition, Van der Walt et al. (2010a:152) regarded positive education as the utilisation of everything that is good and laudable within the learner to inculcate lifelong socially acceptable behaviour.

Nelsen (n.d.) summarises the essential features of PD as follows:

- Mutual respect. Adults personify firmness by respecting themselves and the needs of the situation, and kindness by respecting the needs of the child. 
- Identifying the belief behind the behaviour. Effective discipline recognises the reasons as to why children do what they do and works to change those beliefs, rather than merely attempting to change behaviour.

- Effective communication and problem-solving skills.

- Discipline that teaches (and is neither permissive nor punitive).

- Discipline that focusses on solutions instead of punishment.

- Disciplinethatencourages(instead of praising). Encouragement notices effort and improvement, not just success, and builds long-term self-esteem and empowerment. (n.p.)

In contrast to the above, the South African education system is currently beset with discipline problems, including that schools, school principals and teachers are, contrary to decentralisation and democratisation, being proclaimed as one of the foundation stones of the new education dispensation, subjected to a growing battery of very narrow prescriptions that often draw a line through any notion of professional autonomy (De Clerca 2013). The political leaders to whom education on a national and/or provincial level is entrusted, as political leaders are prone to do, are often inclined to lapse into populism, into the making of populist statements for the sake of their own political survival (Du Preez 2018). Such ceaseless, ill-considered and irresponsible outbursts of populism create policy uncertainty (Odendaal 2017). Schools, furthermore, are the suffering party in a system characterised by the workings of a cumbersome, dispiriting and paralysing bureaucracy; its administrative incompetence; and also the dysfunctionality of national and provincial education ministries, which characterise large sections of the civil service and administration (Wolhuter \& Van der Walt 2018). These circumstances are not only detrimental to teachers' self-esteem but also lead to a dejected spirit amongst teachers, thereby undermining their morale (cf. Wolhuter, Van Jaarsveld \& Challens 2018).

Not only is the set of circumstances currently prevailing in South Africa detrimental to the morale of the teaching corps and the learners, but it is also morally unjustifiable. The education offered, and the approach to discipline in schools, should be of 
such a quality that both teachers and learners are able to sort out the values by which they wish to live, thereby affirming their personal integrity and giving their lives sense and purpose. As Thompson $(2018: 9,11)$ correctly observed, all those involved in education, from the top of the system down to the most modest learner, should learn to understand what is right and wrong, morally acceptable behaviour or not, and on what principles, values and rules their society operates. They need reminding already in the course of school education that this understanding links to fundamental questions regarding the value and meaning of human life. Education of this quality, as Nolan (2009:13) observed, helps each person fulfilling a role in the education system (teacher, parent, learner and administrator) to become an integrated individual, a fully integrated person, able to transcend his or her self-centredness and to work towards unselfish altruism. Lusenga's (2010:17) views correspond with those of Thompson and Nolan. According to Lusenga (2010:17), educated people understand what is considered appropriate in living life, understand the demands of propriety, are committed to right action and comply with the country's laws and accepted principles. This is, in the context of the argument unfolding in this chapter, one of the keys to the eradication of anomie (lawlessness) and the lack of social capital currently prevalent in South Africa and other countries similarly afflicted.

The research reported in this chapter was based on the surmise that the education system of Finland, widely mooted as one of the best in the world, could be seen as an example of a system favourable for the implementation of PD in schools, and hence to the formation [Bildung] of the upcoming generations to become fully integrated persons, committed to the levels of moral understanding described above. The aim of the rest of this discussion is to attempt to show how the Finnish education system could be emulated in and by South Africa, so that it could provide an environment that is more congenial to the application of the best possible approaches to the maintenance of discipline in schools. 


\section{Ginland: The emergence of a noteworthy education system}

\section{The Programme for International Student Assessment studies}

The emergence of the international test series has come to the timely assistance of those concerned (amongst others, educationists, politicians, policymakers, the media and the broad public) about education quality and equality in the contemporary world. Although the International Association for the Evaluation of Educational Achievement (IEA) has been performing an international test series since 1959 (amongst others, the Trends in Mathematics and Science Studies - TIMMS), the IEA and its test series fall within the ambit of the (educational) sciences, and hence has been relatively removed from the interest of the general public. The tests also predominantly measure learning outcomes or achievements. It was the Organisation for Economic Cooperation and Development's (OECD) Programme for International Student Assessment (PISA) studies that moved the international test series into the centre of the public debate on the quality of education in different countries, competition amongst countries and education politics (Meyer \& Benavot 2013). The PISA is held every 3 years (the first series took place in 2000) and entails tests in the mother tongue, Mathematics, natural sciences, and knowledge and skills pertaining to problemsolving (each time these tests take place, the focus is on one of these four areas). The tests are for 15-year-old learners. In 2012, 65 countries participated in the test series (OECD 2013).

\section{Finland: An unlikely achiever}

During the first session of PISA testing in 2000, Finland was, amongst the family of developed countries, probably regarded as the most unlikely country to be the top achiever. Although it is a developed country, Finland was, at least till the early 1990s, 
according to per capita income, not economically a leader amongst the developed countries or at the forefront of technological or patent development. Of all the developed countries, Finland was industrialised relatively late. Until the 1950s, Finland was predominantly an agricultural and forestry country. Before 1990, its international economy was largely dominated by its economic ties with a neighbouring country, the Soviet Union. The collapse of the latter's economy in the years after 1990 hit Finland hard. Although the rest of the developed world experienced a two-decades-long economic boom, Finland was plunged into a serious recession during the 1990s. It was only during the middle to late 1990 s that the Finnish economy began to strengthen, amongst others, because of the emergence of mobile phones: the company Nokia placed Finland on the global map (Niemi 2010, 2012).

Also, in the political arena, Finland did not display the same stature, political maturity or independence as other Western European or North American countries. For centuries, it was caught between two aggressive superpowers, Russia and Sweden. It only became an independent state in 1917 - long after the other Western European nation states attained independence. Even then, until the late 1980s, Finland still had to tread very carefully, not to antagonise the Soviet Union. In order not to do so, it remained officially neutral during the Cold War era. It did not join the North Atlantic Treaty Organisation, could not profit from the Marshal Plan and had to remain outside the European Union and its predecessor, the European Economic Community (EEC), until Michael Gorbachev's coming into power in 1988. It was only after 1990 that it could really become politically autonomous. As mentioned, during the first years after 1990, its growth was hampered by an economic crisis (Niemi 2010, 2012).

Finland was also a backmarker in the education field as compared with other developed countries. Compulsory schooling was only instituted in 1921, a century after many other Western countries had accomplished so. Only in 1972 - nearly a decade 
after England and two decades after Sweden - a start was made to replace the hierarchic secondary school structure with comprehensive schools (Wolhuter 1997).

Against all expectations, Finland came out on top in the first PISA test series in 2000. This surprising result took even the Fins by surprise (Pehkonen 2007). The 2000 PISA test series consisted of three tests, namely, a reading test, a maths test and a natural sciences test. The test series was taken in 32 countries (29 OECD countries and three countries outside the OECD). Finland attained the best average mark in the reading test. Finland also did well in the other two tests, although not the best. The Finnish learners came fourth in the Mathematics test (behind Japan, South Korea and New Zealand) and third in the science test (behind South Korea and Japan) (Max Planck Institute 2002).

In the ensuing PISA test series, Finland retained its position as the leading achiever. In 2003, during the second test series, this time focussing on Mathematics, Finland came second (behind Hong Kong) (OECD 2004). In the 2006 test series, which focussed on science, Finnish learners attained the highest marks (PISA 2007). In 2009, when the emphasis was once again (as in 2000) on reading skills, Finland came third out of the 65 participating countries (behind Shanghai-China and Korea) (OECD 2010). During the most recent test series (taken in 2012), Finland slipped to the 12th position out of the 65 participating countries or jurisdictions (OECD 2013).

\section{The Finnish education system}

What follows is an exposition of the education system of Finland. It is a maxim in Comparative Education that national education systems do not have a random structure, but that they are formed under the influence and impact of the prevailing contextual social powers (geography, demography, social structure, language situation, economics, political system and religious-philosophical situation) within which the system functions. For this reason, the 
outline of the system offered below begins with an overview of these contextual factors. This is followed by a systematic overview of the education system of Finland. An attempt will then be made to identify the unique or outstanding features of the Finnish education system that seem to have contributed to the exceptional achievements of Finnish learners in the tests, as mentioned above.

\section{Form-giving social-contextual powers}

Finland is situated in the extreme north of Western Europe, and covers an area of $338000 \mathrm{~km}^{2}$. The country has a population of 5.4 million, with a growth rate of $0.2 \%$ per annum. Finland has a very low average population density, namely, only 16 people per square kilometre (World Bank 2013).

Finland is one of the most culturally homogenous countries in the world. More than $92 \%$ of the population speak Finnish as their first language. However, any statement regarding cultural homogeneity must be qualified in three ways:

1. $5.5 \%$ of the population are Swedish, living predominantly along the Swedish border. Swedish is officially a language of Finland and a compulsory second language in all schools.

2. 7000 Laps live in the far northern regions of Finland. Roma ('gypsies') comprise another minority group.

3. Although Finland historically had the reputation of being a very private community (owing to, amongst others, the fact that Finnish is neither an Indo-Germanic language nor is it related to any other language in Western Europe), globalisation had an effect also in and on Finland in that in recent years there has been a notable influx of immigrants (Statistics Finland 2011).

Finland's per capita gross domestic product is US\$44074 per annum, making it one of the world's high-income countries. Its Gini index (a yardstick for income equality) is low: 26.9, the third lowest in the world. Finland is therefore one of the most classless societies in the world. Politically, the country 
has been a multi-party democracy since the beginning of the 20th century, and its internal politics, despite the international pincer position in which the country historically found itself between the Soviet Union and Sweden, has always been stable (World Bank 2013).

Lutheranism is the mainstream religion cum life philosophy. Approximately, $90 \%$ of the population belong to the Lutheran Church (at least nominally). The Orthodox Church is the largest religious minority group. Western values, such as democracy, a free-market economy and high value attached to the individual, fit comfortably in with the typically Scandinavian socialist framework that guides the society (such as the Scandinavian economic model of free-market principles at the production level, accompanied by high taxes and socialist apportionment at the consumer level). Scandinavian democratic socialism is evident in the policies of the Social Democratic Party, which has been the Finnish minority party over the longest period in history (Niemi 2010, 2012).

\section{The education system: Historic development and current structure}

Compulsory education was only instituted in Finland in 1921. This relatively late date is because of the fact that the Finnish nation state came into being only in 1917. The date emphasises that Finland, at least in the Western European context, although a late bloomer in creating a national education system, relatively quickly caught up with its counterparts in the region. The reconstruction of Finland (and of Western Europe) after the Second World War and the role of education in the project gave impetus to major reform projects. The hierarchic system of secondary education was replaced with comprehensive schools [peruskoulo]. Legislation in this regard was promulgated in 1963, and since 1972, this policy was put to effect district by district, reaching completion in 1985 (Sahlberg 2010). This was approximately two decades after comprehensive school reform 
was achieved in most of the other Western European countries, and three decades after Finland's neighbour, Sweden, the pioneer of the comprehensive school movement, had implemented the same.

The Finnish education system is currently structured as follows: early childcare (ages: zero to five years) and one year of pre-primary education (age: six years) are, contrary to many other developed counties, not compulsory. Compulsory schooling starts when the child reaches the age of seven years. The nine years' comprehensive schooling starts that year (the age of seven is late, especially for a developed country). Upon completion of nine years of comprehensive schooling, one of the following two options in the national qualification ladder is open to the learner:

1. The learner could enter a senior secondary school, do the three-year senior secondary school course and sit for the matriculation examination (as the senior secondary final examination in Finland is known), followed by university studies. According to the Bologna Agreement, Finland follows the post-school education system of the European Union, namely, a three- or four-year bachelor's degree plus a twoyear master's degree plus a three-year doctoral degree.

2. Alternatively, after completion of the comprehensive school cycle, the learner could continue studying at a vocational training institution (vocational training by means of apprenticeship is also available), followed by a bachelor's degree and later a master's degree at a polytechnic institute. There are many opportunities for horizontal mobility between the two options (Finland 2013).

Education is free on all levels, from pre-primary up to the higher education level. Apart from free stationery and textbooks, learners in pre-primary schools and basic (comprehensive) schools also receive one free meal per day and free medical care. When parents live further away than a certain distance from the school $(3 \mathrm{~km}$ in the case of pre-primary schools, and $5 \mathrm{~km}$ in the case of basic schools), free transport to and from the school 
is provided. However, public education spending per learner is, at least when compared with that of the other OECD countries, not high - indeed, with regard to this figure, Finland lies on the average of the OECD countries (Reinikainen 2012).

The number of school days is 190 per annum. This is significantly less than in most of the other school systems in the world. The Finnish school day of $4-6$ h of teaching is also shorter than in most other systems, resulting in the fact that children in Finland between the ages of 7 and 14 years have only $5762 \mathrm{~h}$ of schooling, $1025 \mathrm{~h}$ less than the average for the OECD countries (Reinikainen 2012). Homework does not form part of the Finnish school education culture (Sahlberg 2010). Class sizes are not exceptionally small in Finland; on average 20.1 learners per class in comprehensive schools (Reinikainen 2010).

Assessment, in the form of tests and examinations as part of formative assessment, norm-directed assessment (assessment compared with the performance of other learners in the class) and criterion-directed assessment (assessment against a formulated external outcome) do not form part of the education system. Teachers are free to assess learners on an individual basis, formatively, according to their professional judgement, and against the learner's own abilities, interests and growth as frame of reference (Pehkonen \& Krzywacki-Vainio 2007). Standardised testing is also absent. The first important assessment is the national matriculation examination at the end of the comprehensive school cycle. The main reason for the assessment of learners on an individual basis during the comprehensive school cycle (before the examination at the end of their school careers) is therefore diagnostic by nature; it enables the teacher to draft a plan for the further studies of each individual learner (Kumpulainen \& Lankinen 2012).

With regard to teaching methods, Finnish educationists advocate learner-centred, interactive teaching, based on the theory of constructive learning (Lloyd 1999). Research shows that, despite official policy to the contrary, teaching in Finnish 
schools is still very traditional (Andrews 2013; Finland 2008; Lehtinen 2004). The Finnish system therefore does not differ much from other education systems, even education systems in developed countries, as far as the dominant, directional role of the teacher is concerned. However, Finland does distinguish itself from most other education systems in that the teacher enjoys more freedom regarding the setting of questions, assistance and interaction with learners, and in diagnosing and individualising according to their own judgement (Andrews 2013).

Regarding classroom management, teacher-learner relations in Finland are characterised by reciprocal respect and collaboration (Doyle 2016). Learners are seen as 'cherished individuals' who should be given opportunities by highly skilled teachers 'to have fun, giggle and daydream from time to time' (Doyle 2016:3). Doyle (2016:3) describes the school climate in Finnish classrooms as 'warm, safe, respectful and highly supportive. There are no scripted lessons and no quasi-martial requirements to walk in straight lines or sit up straight'. The Finnish learner-centred approach to classroom management corresponds with the quintessential features of PD, namely, respect for oneself and others, the ability to distinguish between right and wrong, self-discipline, mutual trust, warmth, structure, empathy and recognition of the individual needs of each learner (Van der Walt et al. 2010a). A positive approach to school discipline in Finland is promoted by the country's decentralised education system in that every school and teacher can approach school and classroom discipline as they see fit.

A distinguishing feature of the education system of Finland is strong decentralisation, from the central (national) to the local education level and individual schools, particularly to the level of the individual teacher, who is seen as a professional who possesses an exceptional (compared with other countries) measure of autonomy (Finland 2013; Pehkonen, Ahtee \& Lavonen 2007). The National Ministry of Education and Culture drafts a core curriculum for all public schools. Local education authorities as the next level (a local education authority can be likened to 
a municipality) then make decisions pertaining to the use of funding, the drafting of curricula appropriate for local conditions and the appointment of staff (Finland 2008). The local authorities also have the right to delegate these powers to individual schools, something which is often performed. Principals, for example, are typically responsible for the recruitment and appointment of teachers. Schools compile their own curricula in accordance with the guidelines provided in the national curriculum framework, and teachers are free to select their own teaching and learning materials, methods and textbooks (Pehkonen et al. 2007). Locally compiled curricula must take into account the environment within which the school functions as well as local values and resources (Niemi 2012). According to the national core curriculum, the objective of schooling is to ensure a high standard of education and also respect for the local environment and ownership of the local community (Niemi 2012). A clearly formulated and very flexible curriculum framework encourages local communities and individual schools and teachers to find local and individual solutions to national issues, as well as optimal learning opportunities for each learner, based on the respective teachers' professional judgement (Sahlberg 2010). This approach enables teachers to draft an individual plan of learning (syllabus) for each learner (Vitikka, Krokfors \& Hurmerinta 2012).

There is no external control. The school and education inspection system was completely abolished in the early 1990 s (Finland 2013; Pehkonen et al. 2007). Teachers and their performance are not evaluated (Kumpulainen \& Lankinen 2012). The Finnish education system is built on trust in the teacher as a professional.

Closely linked with the individualisation in the Finnish education system is coping with diversity. As media of tuition in the comprehensive school, five languages, namely, Finnish, Swedish, Sami, Romani and Finnish Sign Language, are legally entrenched (Mantila \& Sulkala 2010). More than 80 other languages, each with more than 100 speakers, are also recognised as languages of learning and teaching. Their speakers are mostly 
recent immigrants. For these learners, there is the choice to study their first language as an optional subject, but they have to study the Finnish or Swedish languages as a subject and all other subjects through the medium of either Finnish or Swedish. The study of three languages is compulsory in the comprehensive school: Finnish, Swedish and a foreign language. Ninety per cent of the learners select English as the foreign language, with German, French and Russian as the next most popular options (Hilden \& Kantelinen 2012).

Lastly, something must be said about the training of educators. In contrast to many other countries in the world where teacher education is often the last choice amongst university students, teacher education is a sought-after choice of study in Finland (Harris-van-Keurder 2010; Silova \& Kazimzade 2010). Only one out of every 10 applicants is admitted to the course (Niemi 2010; Sahlberg 2010). This aspect of the education system probably explains why the teaching profession enjoys such a high status in Finland. In addition to the status attached to initial teacher education, it has since 1979 been a requirement for all teachers to possess a master's degree (implying 5 years of further university training). This is a higher requirement for the teaching profession than in any other education system in the world (Niemi 2010). The curriculum for teacher education consists of the same components as elsewhere, namely, academic (school subject) disciplines, Education studies and practicums in schools. The importance of research training, culminating in a master's thesis is the distinguishing mark of teacher education in Finland. This requirement results in research-based education practices in schools (Niemi 2010).

\section{Reasons for the success of the Finnish education system}

The obvious question now is to what could the success of the Finnish system be ascribed, given the fact that the Finnish approach to education seems to be counter-intuitive to what 
would be expected to emerge from a scholarly investigation of the system coordinates of schools with exemplary learner discipline levels. The reduction of the number of school days per year, of the number of teaching hours per day, the lowering of the intensity of homework and assessment, the increase in class sizes, the recognition of the autonomy and de facto professional status and space accorded to teachers, and the absence of control mechanisms such as school inspectors all seem to be counter-intuitive as far as school success is concerned. Counterintuitive or even contradictory to standard pedagogical wisdom as the Finnish system might seem to be at a first glance, there seem to be a number of circumstances that work in favour of its system.

The socio-economic background of Finnish learners (availability of books, television, mobile phones and other teaching resources, as well as highly educated parents), for instance, is conducive for high levels of achievement (Finland 2008). A comprehensive multi-level statistical analysis (which involved more than 600 variables) of the total 1999 TIMSS test data set of Finland showed that learnerrelated variables explain $90 \%$ of the variation in the TIMSS test marks, and school-related factors account for the remaining 10\% (Kupari, Reinikainen \& Törnroos 2007). Finland is not only a high-income country but also one of the most egalitarian societies worldwide (World Bank 2013). One could therefore argue that the combination of favourable social background with high income and equal income distribution could have had a positive influence on the performance of Finnish learners.

Researchers have also examined the (historically) Lutheran religious background of Finland as a possible reason for the success of its education system. They took note of the fact that the Protestant churchgoers were expected to be able to read and interpret the Bible in their mother tongue (Duggan 1916). Researchers such as Andrews (2013) and Sahlberg (2010) furthermore argue that Finland's cultural and political isolation 
and threats from neighbouring countries, combined with its very cold climate, have fostered a culture of reading and respect for education.

Apart from the socio-economic and cultural factors enumerated above, factors directly related to teachers and their profession probably also play a part in Finnish learners' achievements. Not only the nature and duration of teachers' training but also the high measure of autonomy enjoyed by teachers provides them with the knowledge and opportunity to apply their research skills in teaching practice and to individualise effectively. Assistance and support programmes are developed and adapted in accordance with each learner's unique needs (Niemi 2012; Sahlberg 2010). Unlike the case of socio-economic family status, authors (amongst others Niemi 2012; Sahlberg 2010) do not quote statistics to prove this point. They seem to depend on the simple logic that a teacher's success is influenced and even determined by his or her level of training. However, there is very little published research in this regard (in or outside Finland). The only comprehensive research project recently performed in this regard seems to support this logic. The COACTIV project used the 2003/2004 PISA study results and observations of teachers in Germany to research the correlation between forms of knowledge and outcomes in Mathematics teaching. They found, amongst others, that knowledge of teachers is a stronger determinant of results than teachers' experience (Kunter et al. 2011).

Another important factor to which the success of the Finnish education system can be ascribed to is the degree of supplying education through the medium of the mother tongue, which distinguishes the Finnish education system from most other national education systems in the world, including those of Western Europe. Speakers of Finnish, Swedish, Romani, Sami and Sign Language have the advantage of education through the medium of their mother tongue. This approach can be contrasted with, for example, the situation in Bulgaria, where there are more speakers of Romani than in Finland $(4.2 \%$ of the 18 million 
inhabitants of Bulgaria speak Romani). As the official point of view of the Bulgarian government is that all the citizens of the country are Bulgarians and that there are no minorities in Bulgaria, no provision is made for the Romani language as a medium of tuition in the education system (Ignatova 2005). Although the ample provision for speakers of the above-mentioned four languages in Finland cannot be seen as the instrument for the entire smoothing out of differences in scholastic achievement, nor of big differences between the achievements of children of recent immigrants and indigenous Finnish learners (Finland 2008), the provision for minority language speakers in the Finnish education system could be regarded as a strong force in the equalisation process.

We conclude this section with a conjecture about the state of discipline in Finland and in Finnish schools that will in due course have to be empirically verified by means of, for instance, interviews with education authorities, parents, teachers, school principals and administrators, learners, members of the public and other interested parties or education stakeholders in Finland. An EBSCO-host computer search for recent publications on the state of discipline in Finnish schools yielded only one article that touches on this subject, namely, that by Arnesen, Elstad and Christopherson (2017). Their project compared instructional factors related to students' academic self-discipline in Norway and Finland; in other words, it did not directly address the issue of discipline in Finnish schools. A Google Scholar search yielded more articles touching on discipline in Finnish schools, but none that embraces the entirety of this conjecture.

As mentioned, Finland has a relatively small population, thinly spread over the country. It could be argued that the social sanctioning of behaviour will be somewhat easier to exercise in a smaller group of people than in a geographically huge country with a large population. That this might be the case is supported by the fact of the physical homogeneity in building style and lifestyle arrangements observable across the length and breadth of Finland. As also mentioned, the population is relatively 
homogenous, with the language and other rights of the small minorities duly respected. This approach promotes mutual respect amongst the members of the population and could be one of the reasons why discipline problems are rare. The recent influx of immigrants did not affect Finland as much as other European countries because of the remoteness of the country and its unfavourable climatic conditions. The relatively low number of newcomers will therefore have a relatively low impact on the current lifestyle (including the level of discipline) of the indigenous population. Another factor that might contribute to the low prevalence of discipline problems in Finland in general, and in the schools in particular, could be the long dark Scandinavian winters. Children and young people have to stay indoors for long periods of time (although not in school as long as their counterparts in other European countries) and hence might experience long exposure to the influence and guidance of a variety of educators. During these long periods of exposure to their educators, they learn about behaviour that would be socially acceptable or morally justifiable, and what it means to become a respectable member of the Finnish society. Finnish youngsters seem to grow up in the context of clear-cut social arrangements, a definite social structure with particular expectations regarding acceptable behaviour.

In addition to all these social circumstances, the teachers are exceptionally well-prepared for their profession, and tend to base their interactions with the learners on their own research for advanced degrees. Life in the schools is characterised by non-insistence on a military-style discipline (although not to the extent of a laissez-faire approach), which allows the learners more freedom to express themselves and what they have mastered in terms of what is socially acceptable or would be socially sanctioned by their educators and their peers. Simple logic leads to the conclusion that if no strict military-style discipline is imposed or expected, less discipline problems might surface; every individual will know and understand the boundaries of acceptable behaviour as socially sanctioned by educators 
and peers. Add to these circumstances the fact that Finland is a technologically advanced country, that the standard of living is high and that the learners therefore possess the infrastructure to keep themselves constructively busy, particularly during the long, dark winters. Keeping busy in this manner will arguably contribute to self-discipline. The absence of externally imposed disciplinary measures might arguably leave more space for the exercise of human kindness, the flourishing of individuals (absence of bullying, for instance) and hence for the establishment and growth of a peaceful modus vivendi. The well-trained teachers plying their profession in the schools are able, in the absence of externally imposed disciplinary measures, to apply alternative ways of sanctioning unacceptable or deviant behaviour, a skill that is of great importance when dealing with young people intent on testing the limits.

As mentioned, the above account is a conjecture about the state of school discipline in Finland that will have to be verified in the form of a large-scale empirical project.

\section{What insights could be gleaned from the Finnish experience for the purposes of addressing shortcomings regarding discipline in the South African education system?}

The second objective of this chapter, as outlined above, is to report on research into how insights flowing from an examination of the Finnish education system could be employed for approaching learner discipline in South Africa. In attempting to arrive at an answer to this question, it was necessary to discuss the factors deemed to have contributed to the success of the education system in Finland. The Finnish education experience seems to suggest that the solution for problems encountered in the education system might be found in deeper, more profound factors than in taking recourse to simple, easy and obvious 
answers, such as simply increasing the education budget, prescribing more assessment, more control measures or extending the period of compulsory schooling or the length of the school day. Finland's education success lies in a combination of a multitude of factors, extending over a wide area, even to outside of the education system itself. An understanding of these factors and of their interplay will arguably give an insight into how the Finnish education system reached the levels of success that it so far has attained in terms of international measuring instruments, and in the process will arguably also provide an insight into how this form of success could be regarded as the substratum and a sine qua non for effective school and classroom discipline. Logic suggests that education system, school and classroom effectiveness play into the hands of effective school and classroom discipline, and vice versa. Learners kept busy in meaningful ways might find less time and opportunity for antisocial and deviant behaviour; conversely, learners not guilty of aberrant behaviour might arguably be more committed to meaningful school tasks. Although, as far as could be ascertained, this hypothesis regarding school effectiveness and good school and classroom discipline reciprocally feeding off each other has not been researched, the Finnish experience seems to point in this direction.

The broad social context in which the Finnish education system is embedded contributes significantly to the country's education success. With regard to the socio-economic level and the equal income distribution of the population, Finland's success in the PISA tests confirms that socio-economic context determines education and not the other way around. Despite this evidence, there seems to be a persistent belief (amongst others, policymakers, the public, media and business leaders) in the power of education to improve the socio-economic condition of the population. In South Africa, for instance, the post-1994 education system was implemented for the purpose of pursuing a whole range of social objectives. Amongst these objectives were economic objectives (such as the eradication of poverty 
and the promotion of economic productivity and growth); social objectives (such as the building of a society free from racial, gender and other forms of unfair discrimination, the creation of a socially mobile society free from artificial hierarchies in the way of prosperity and mobility); and political objectives (such as the empowerment of the citizenry to participate in the processes of democracy, building of a common value system, characterised by the values of democracy, equality, freedom, peace, justice, tolerance and stability) (Wolhuter 2011). The Finnish experience seems to indicate that the power of education should not be overestimated; to do so is to 'put the cart before the horse'. Socio-economic context determines education, and not the other way around, is what the Finnish experience seems to indicate. Although it cannot be denied that an outstanding education system is a prerequisite for a knowledge society (i.e. a society where the production and consumption of new knowledge is the driving force behind the economy) and a sound economy, South African thinking needs a Copernican revolution in the light of the Finnish education experience: the deficiencies in South African society such as a lack of social capital in the socio-economic context must first be addressed before an exceptional (disciplined) education system can be thought of.

The next issue centres on the teacher. The level of teacher education is often singled out as a success factor in the Finnish system, in particular the fact that a master's degree is regarded as the minimum qualification. There has been, in fact, a worldwide tendency over time to increase teachers' qualifications. In Western Europe, in particular, there is a tendency to regard a master's degree as the minimum qualification for teaching in the most elite senior secondary schools (such as the Gimnasia and Atheneums in the Netherlands). South Africa and Namibia are the only two countries in Africa where a university degree (bachelor's) is currently the minimum level to qualify as a teacher. The decisive factor in education system success in Finland, however, is not the duration of teacher education programmes, but rather the research training as part of this programme, and 
also the professional autonomy teachers enjoy in applying their research skills and expertise in support of and in assisting learners and providing individualised guidance and support. At the time of writing here, faculties of education in South Africa are busy recurriculating their BEd degree programmes and, according to the most recent requirements pertaining to teacher education programmes issued by the Department of Higher Education in South Africa, research should also find a place in the BEd degree programmes (DHET 2011). This requirement warrants two important caveats. Firstly, the situation at teacher education institutions in South Africa differs from those in Finland. According to the United Nations Educational, Scientific and Cultural Organisation (UNESCO 2014), statistically, the student to lecturer ratio at Finnish universities is 13:5. This is in stark contrast to South Africa, where the student to lecturer ratio in teacher training programmes is close to 500:1. It is hard to assume that quality research training can take place in such a situation. Secondly, research training in Finnish teacher training programmes is not in the form of a separate module in the programme; the research training is integrated with the student's pedagogic and subject knowledge, and is directed at the investigation of practical classroom situations and problems as well as the enhancement of the teachers' teaching practice. A feature of the Finnish education system is that the teacher is allowed the professional freedom to apply his or her research skills for the purpose of offering individualised support to learners. South African teachers are not similarly allowed to apply their research skills for the purpose of improving their teaching practice. They are expected to work in a narrow, confined and prescriptive environment. Van der Walt et al. (2010b), for example, pointed out that teacher educators (i.e. lecturers in faculties of education) in South Africa do their work under a complex umbrella of no less than 13 parliamentary acts. The same applies for schoolteachers who are expected to work within closely defined parameters that not only impede their freedom but also their sense of professionalism. The Finnish experience shows that to prescribe such a regulated environment 
is the wrong route to take when aspiring for education success. The South African experience attests to this: a professional work ethic is absent in sections of the teaching corps of South Africa. Attempting to combat this with yet more control and prescriptive measures (Rademeyer 2013) would, in the light of the Finnish experience, be counterproductive.

Lastly, an important factor to which the Finnish education success could be ascribed is its recognition of language diversity. The positive consideration of indigenous languages, such as Swedish, Sami and Romani, as well as Sign Language, forms a stark contrast with recent practice in South Africa where the education authorities seem to be continually targeting the singlemedium Afrikaans schools and strive towards the Anglicisation of the historically Afrikaans universities, coupled with a decline in the teaching of the indigenous African languages as subjects at universities. Afrikaans as well as all the indigenous African languages is experiencing various forms of stress owing to the official drive towards English as the lingua franca. Although Finland (like South Africa) still has to decide on a formula for handling the language diversity brought about by the increasingly stronger influx of immigrants in recent times, Finland has already adopted a workable model with regard to the educational coping with language diversity, something worth taking notice of by education policymakers in South Africa.

\section{What insights could be gleaned from the Finnish experience for the purposes of addressing shortcomings in school and classroom discipline in South Africa?}

A number of pointers flow from this study regarding the creation of an environment congenial to the development of positive learner discipline in schools. In the first place, the Finnish school track record seems to point to the importance of a high and 
rigorous level of teacher education, of granting the teachers optimal professional freedom in a context of high levels of school autonomy. Rather than attempting to micro-manage the affairs of schools in the form of a plethora of policy documents, education authorities could, on the basis of the Finnish experience, do much better by attending to their own shortcomings, thereby contributing to a clean government and the restoration of social capital in society. Education authorities in South Africa should consider relinquishing the premise that schools as such can be used for the creation of social capital (especially in a society where such capital is already in short supply). Schools as such cannot create social capital. On the basis of the Finnish experience, (education) authorities should provide in official education policy for a strong place for religion and Religious Education in South African schools instead of its current policy and practice of banning religion and confessional Religious Education from schools. The return of Religious Education will arguably provide a strong religious base for the restoration of morality in schools and society in general, provided that the presentation of religious ideas in classrooms can be pedagogically justified. This is an important topic for a separate discussion.

South Africa has a centralised, highly structured education system that leaves little freedom for teachers to try innovative strategies in their classrooms (which at any rate are often in disarray owing to a lack of discipline). Finnish teachers, on the other hand, are recognised as autonomous professionals. They enjoy ample opportunity to create a positive classroom climate where mutual respect and self-discipline prevails. South African education authorities wishing to improve learner discipline should therefore consider decentralising education, begin trusting the teachers and regard them as professionals instead of persisting with a policy of relentlessly evaluating their performance; they should also divert more power to the teachers (contrary to the current education structure where power is concentrated in the provincial and national education authorities) and encourage 
teachers to integrate the different aspects of PD into their classroom practices. Teachers who are respected and acknowledged as skilled professionals will respect their learners and teach them self-discipline and self-esteem. Conversely, again on the basis of the Finnish experience, the learners will respect their teachers as competent professionals, will behave in socially acceptable ways, will achieve in accordance with expectations (not coerced to do so) and will be in a position to contribute to the country's store of social capital.

Finally, Finland's handling of language diversity in education is also instructive for South Africa, where the inimical marginalisation of Afrikaans as the language of learning and teaching, the imposition of English as the sole language of learning and teaching, and failure to empower the other eight official languages stand in vivid contrast to Finnish theory and practice. The current practice in South Africa of switching from first or home language to English as the medium of learning and teaching after the fourth school year is not conducive for good school and classroom discipline. In an extensive empirical study, MacDonald and Burroughs (1990) found as far back as 1990 (no recent research could be discovered that gainsays these findings) that the average non-English first language South African learner had a vocabulary of some 800 English words, whereas the Grade 5 curriculum required a vocabulary of at least 5000 English words. It does not take much to understand that learners who are not able to follow what is taking place in terms of teaching in classrooms will be prone to misbehaviour and ill-discipline.

\section{Concluding remark}

The optimal empowerment and autonomy of teachers, various improvements in teacher education theory and practice, greater school autonomy, a more profound appreciation of the role of religion in schools, improvements in the education structure and 
a more positive accommodation of language diversity in schools stand out as possible insights from the Finnish education system and education experience that policymaking authorities in South Africa could take to heart in their quest to approach learner discipline in schools and particularly in classrooms. 


\section{The neoliberal context and the demand for increased access as the Scylla and Charybdis for developing an agenda for the restoration of (student) discipline at South African universities}

Johannes (Hannes) L. van der Walt Edu-HRight Research Focus Area, Faculty of Education, North-West University, Potchefstroom, South Africa

How to cite: Van der Walt, J.L., Potgieter, F.J. \& Wolhuter, C.C., 2019, 'The neoliberal context and the demand for increased access as the Scylla and Charybdis for developing an agenda for the restoration of (student) discipline at South African universities', in C.B. Zulu, I.J. Oosthuizen \& C.C. Wolhuter (eds.), A scholarly inquiry into disciplinary practices in educational institutions (NWU Education and Human Rights in Diversity Series Volume 2), pp. 229-257, AOSIS, Cape Town. https://doi.org/10.4102/aosis.2019.BK157.10 
Ferdinand J. Potgieter

Curriculum Studies, Faculty of Education, North-West University, Potchefstroom, South Africa

Charl C. Wolhuter School of Professional Studies in Education, Comparative and International Education, Faculty of Education, North-West University, Potchefstroom, South Africa

\section{Abstract}

This chapter is an attempt to put on the research map the issue of student discipline at higher education institutions, particularly universities, in South Africa. The aim of the chapter is to outline the principles for (student) discipline at South African universities, framed by the mission of the university as it is currently unfolding in the South African context. The thesis of the chapter is that the idea of what a university is or should be, particularly in the contemporary South African context, is the outcome of a long history of interplay between several forces, amongst others, of an intellectual, economic, social and political nature. This interplay between forces has culminated in two (often more opposing than mutually reinforcing) ideas; one can be subsumed under the collective term 'the neoliberal economic context', the other by the call for social justice. This interplay manifests in the higher education sector as, on the one hand, the interests of the university in a neoliberal context, and on the other, the demand for opening and widening of student access to higher education. The evolution of these two forces and their historical roots are discussed in this chapter. It is argued that caving in to either of them (e.g. allowing one of them to completely dictate the terms) will not only be detrimental to (student) discipline at universities but will also effectively signify the end of the university (in terms of what is required of a university).

\section{Introduction}

This chapter departs from the axiom that discipline, or adherence to a set of commonly agreed rules, is a sine qua non for any 
teaching-learning institution, including the university. Teaching and learning, at the university in particular, cannot take place in a situation of anarchy or chaos. Learner discipline constitutes an acute problem in South African schools. During the past two decades, the issue has been researched intensively from a multitude of perspectives (cf. Wolhuter \& Van der Walt 2019). The problem of (student) discipline at universities manifests itself as an equally serious problem, and this has de facto been the case for a long time. Since 1976, the problem has gained increased momentum, especially at the historically black higher education institutions, where destructive, asocial activism has been a signature feature of these institutions during the post-1976 era (cf. Cele \& Koen 2003). For example, one spate of violent activism, which broke out on South African campuses at the end of 2015, with the \#Fees must fall turmoil, caused damages to the tune of R150 million to university buildings and infrastructure (Tandwa 2016). Unlike learner discipline at the primary and the secondary school level, the issue of student discipline at the higher education level has never featured on the international Higher Education research agenda. In fact, it has been totally absent from the South African higher education research agenda (cf. Wolhuter 1997, 2014). The present volume (this chapter and another on student discipline at a Further Education and Training College) is a first time attempt to put on the research map, student discipline at higher education institutions in South Africa.

Van der Walt (2003) explained that the principles on which discipline in schools and institutions of higher learning is based are not absolute but context-contingent (e.g. the 21st century context calls for the setting of limits to behaviour, and for measures to secure discipline in these institutions that are markedly different from those that were acceptable in the 19th century). Universities have their own unique mission in society and hence their student profile differs from that of other education institutions such as primary and secondary schools. What has emerged from public discourse, litigation and scholarly analyses over the past two decades regarding the development of sound discipline in South African schools has, therefore, at best limited 
value for a discussion of discipline at the higher education level, particularly the university level. The construction of a supporting scaffold of principles for (student) discipline at universities in South Africa should depart from the distinctive and unique mission of the university, and from what the particular South African societal context might be for its mission to be achieved. The aim of this chapter as a first step towards a scholarly discourse regarding university student discipline in South Africa is to discuss and outline the principles for student discipline at South African universities in the light of the mission of the university in the South African context at this point in time.

The thesis of the chapter is that the idea of what a university is or should be, particularly in the contemporary South African context, is the outcome of a long history of the interplay amongst forces, amongst others, of an intellectual, economic, social and political nature. This collection of forces has culminated in two (in many cases more opposing than reinforcing) ideas; one of these forces can be brought together under the collective term of 'the neoliberal economic context' and the other under the term 'the call for social justice', translated for purposes of the higher education sector as 'the demand for giving greater access to higher education'. These two forces and their historical roots are discussed below. The key argument that emerges from the discussion is that when both should be maximally accommodated in the outline of a set of principles for student discipline, caving in to either (e.g. allowing one to completely dictate the terms) will mean the end of the university (in terms of what is required of a university) and will effectively defeat the object of the higher education project.

For many, 'the' university represents the pinnacle of the education system. In the contemporary world, this perception is increasingly being reinforced by the demands of globalisation and of knowledge economies. The university as a societal institution resultantly has gained importance in terms of expectations regarding increased and more affordable student 
access as well as in terms of adapting its mission in society. (Its mission could be summarised as the advancement of various branches of higher learning - a teaching as well as a research function; then, emanating from these, the university also possesses a service function and a cultural function, i.e. the task of preserving, transmitting and developing culture; and also a social critique function, the duty of being the conscience of society) (cf. Wolhuter 2012).

The purpose of this chapter is to report on an investigation into the current status of the modern university - particularly the modern South African university - which is, at the beginning of the 21st century, progressively being caught up in the tensions between increased insistence by prospective students to gain access to university training for the purpose of procuring a perceived better future, on the one hand, and the traditional elitist and exclusive academic status of the university as the flagship of national education systems, on the other hand. Over the past four decades, this notion of the elitist and exclusive status of the university has been bolstered (or has been steered in that direction) by neoliberalism. At the same time, prospective students' insistence on greater and more affordable access to higher (university) education could be justified on the grounds of the Creed of Human Rights that forms part of the South African Constitution, particularly stipulations regarding the right to education. Universities' sometimes seeming unwillingness, apathy and inability to accede to this demand could be ascribed to two background conditions that have been determining the nature and status of the university through the years: its history and tradition. It is arguably on the basis of these two conditions that (at least some) South African universities have become (and persist in being) elitist and exclusive institutions, as will be demonstrated below. The neoliberal view of life and reality that has taken hold at universities and amongst their managements during the past three or four decades has reinforced this elitism and exclusivism to some extent. 
The rest of the chapter is devoted to an examination of the thesis outlined above. The next section will deal with the problem of access to education, particularly higher education, in the context of the Creed of Human Rights. The history and tradition that led to the university becoming an elitist and hence exclusive institution and the impact that the neoliberal life and worldview has had on this status are then examined. This is followed by a discussion of the predicament in which universities, particularly those in South Africa, currently find themselves: insistence on greater student access on the one hand, and a seeming unwillingness and/or inability on the part of universities to accede to these wishes on the other hand. It will be argued that South African students' \#FeesMustFall and other campaigns could be understood in the context of the impasse resulting from the clash between these two forces.

\section{- Students' right to (higher) education in the context of the Creed of Human Rights}

In 2008, Schwartz concluded (with specific reference to Australian universities) that '[...] a university education should help students to answer the question: "Why are we here?"' $\mathrm{He}$ (Schwartz 2008) then argued that questions like: 'why are universities here?' and 'What are universities for?' call for a change in perspective and that the significant differences between what he referred to as 'Hamburger Universities' and respectable universities lie not in what they do but in their purpose; not in the state of their art, but in the state of their hearts. It is against this backdrop that it has become necessary to examine how, for example, South African students' agitation for greater and more affordable access to university education could be justified as a basic human right, namely, the right to education, as well as how this and other human rights came into existence. This will also explain where the right to education, including higher education, comes into play. 


\section{The rise of the Creed of Human Rights}

During the Middle Ages, European society was generally theocentric: God was regarded as the centre and the final goal of everything. In post-Medieval times, humanism as philosophy of life and of the world became prominent. This philosophy, which placed humankind in the centre, subscribed to the principle of equality and implied a ban on any form of discrimination based on race, gender, religion, age or descent. This turn in Western life and world philosophy was reinforced by the scientifictechnological development, which accelerated in the centuries after the Middle Ages.

These developments had a radical impact on the Western mind. It caused traditional structures of authority to be undermined. It also resulted in a reorientation of causality: the emphasis shifted from a vertical causality (where all phenomena and events were ascribed to the will of some kind of deity) to horizontal causality (where reality was empirically and rationally explained). A parallel shift in moral authority occurred, from deriving moral absolutes from religion or from (a) God to the idea that human beings possessed natural and inalienable rights.

It is difficult to pinpoint the first person to enunciate this view, but it can be found in the writings of 18th century writers such as John Locke (1632-1704), Immanuel Kant (1732-1804) and Johann Gottlieb Fichte (1762-1814). A Creed of Human Rights holding that every human being, by virtue of being a human being, is entitled to particular inalienable human rights, culminated in the Declaration of Human Rights in France during the French Revolution in 1789 as well as in the Bill of Human Rights that was included in the Constitution of the United States of America in 1791 (originally ratified in 1789).

These two declarations, both embodying a Creed of Human Rights, were aimed not only against the tyranny of kings but also against the intolerance of democratic majorities. The latter is a 
form of collective behaviour that, according to Carson (2012:13), reflects three fundamental features:

- There is an objective truth and all members of a democratic majority must find it.

- In a democratic state, the majority as well as all minority parties engage in dialogue with one another, believing they all know - independently from one another - where the truth lies. They therefore differ strongly from one another and they consequently believe that the other party must be wrong.

- The best way of discovering the truth lies in rigorous reasoning (dialogue) and the unfettered exchange of ideas, irrespective of how correct or wrong those ideas might be.

According to the human rights documents mentioned above, the protection of human rights is based not on the wishes of governments or democratic majorities but is derived from a higher authority: the natural rights of human beings. Natural rights are regarded as inalienable: they exist independently of the will of a majority or the goodwill of a government.

The international community realised the dangers of disregarding these human rights in the wake of events during the 20th century, especially the two World Wars. The issue of human rights became internationalised after the Second World War, inter alia, through the involvement of International Jurists in the discourse (1951) and the Universal Declaration of Human Rights by the United Nations in 1948 (United Nations 2016). Recognition of fundamental human rights associated with the freedom of the individual became the hallmark of a free society. The United Nations' Declaration specifies the basic human rights as being the right to life, liberty, protection against discrimination, due process in jurisprudence, security (of person and of property), privacy, the right to freedom of movement, nationality, freedom of thought, conscience and religion, freedom of opinion and expression, free choice of employment, just and favourable conditions of work, a standard of living adequate for the health and well-being of the individual, and the right to participate freely in the cultural life of the community (United Nations 2016). 
The declaration also contains a section on education, which will be discussed in the next section.

In addition to the above document on human rights, a number of other human rights manifestos have been accepted by the United Nations, national governments and supranational organisations. Other declarations drafted and ratified by the United Nations include the International Convention on the Elimination of Discrimination in Employment (1965) and the International Convention on the Elimination of Discrimination against Women (1958). In 1989, UNESCO ratified the UNESCO Convention on the Rights of the Child (UNESCO 2016). Other supranational manifestos of human rights include the Charter of Fundamental Rights of the European Union (2016), the Organisation of African Unity's (precursor to the African Union) Covenant of Human Rights and the Inter-American Convention of Human Rights (dating from 1969). At a national level, the doctrine of human rights came to be acknowledged in many countries, including South Africa, in the form of either constitutional clauses or human rights acts.

\section{Human rights and higher education}

Section 26 of the United Nation's Universal Declaration of Human Rights deals with education as such. It states that everyone has a right to education, and that at least elementary education should be free and compulsory (United Nations 2016). Higher Education should be equally accessible to all on the basis of merit. Education shall, furthermore, be directed to the full development of the human personality and to the strengthening of respect for human rights and fundamental freedoms (United Nations 2016). The Constitution of the Republic of South Africa echoes these rights in Chapter 2 by guaranteeing all South African citizens a number of specified fundamental human rights. With regard to education, Section 29 of Chapter 2 of the Constitution states that everyone has a right to basic education. The state should take reasonable measures to make education at further levels progressively available and accessible to all (Republic of South Africa 2016). 
Although not directly addressing the higher education sector, the United Nations' Creed of Human Rights implies that the higher education sector should be as accessible as possible on an equitable basis; unfair discrimination may not be practised regarding the admission of students to institutions of higher education. Section 9(3) of the South African Constitution (Ch. 2, Bill of Human Rights) likewise stipulates that no one may be discriminated against on grounds of race, gender, sex, pregnancy, marital status, ethnic or social origin, colour, sexual orientation, age, disability, religion, conscience, belief, culture, language or birth (Republic of South Africa 2016).

Human rights such as those regarding maximum equitable access to (higher) education imply that governments are obliged to commit financial resources for higher education (topical in South Africa at present, in view of the \#FeesMustFall campaign). These imperatives furthermore imply that governments should take special care to facilitate access to higher education for potential students coming from lower socio-economic strata. In the case of South Africa, the NSFAS is rooted in Constitutional Human Rights, as is the exemption from increases in tuition fees for the 2017 academic year for students from households with an annual income below R600000.

Human rights imperatives are not limited to access to higher education only. With respect to especially (but not only) residential higher education students, the campus environment should guarantee the security of persons (including guaranteeing students' safety from violence) and the safeguarding of their property (cf. Section 12 of the Constitution of South Africa). It should also guarantee that the environment is not in any way harmful to their health or their well-being (cf. Section 24). Other Human Rights entrenched in the South African Constitution (and in other comparable documents worldwide) include the right to housing (Section 26); the right to health care, food and water (Section 27); the right to access to information needed to exercise other rights entrenched in the Constitution (Section 32); and the 
right to just administrative action (Section 33). It is, however, debatable how far the university can legally be held accountable for the realisation of all these rights, especially in situations and in societal contexts where even the government is unable to provide such rights.

It is commonly acknowledged that higher education curricula should inculcate knowledge and respect for human rights, and that they should offer positive recognition of, as well as promote the full spectrum of cultures, languages and religions in a particular society, and also respect for all in that society, irrespective of gender, socio-economic background or sexual orientation. Methods of teaching and learning employed at the university level should likewise be consonant with the stipulations of the Creed of Human Rights. Rather than facilitating an authoritarian handing down of knowledge and rote memorisation and regurgitation of knowledge, methods of teaching, learning and assessment should be such that they develop faculties of reflective thinking and expression in such a way that students might always remain respectful of the rights of others. The academic profession and the managers of universities should in the execution of their duties and management practices always be mindful of the human rights of everyone involved in the higher education environment as well as in society outside the gates of the university. The university should also conduct its research function within the parameters of the Creed of Human Rights - this relates to issues regarding research ethics and research agenda.

A university is an advanced educational institution for the promotion (through teaching and research) of various branches of science. It fulfils its functions (teaching, learning, research, service, innovation, culture preservation, transmittance and progress, and social critique) in symbiosis with its societal context (Wolhuter 2012:285). Subscription to the Creed of Human Rights has therefore implications for the execution of each of these functions, as has been explained above with respect to the teaching, learning and research functions. 


\section{The historical roots of the elitist and exclusivist nature of the university}

Although the university has over the course of its long history come to assume a series of generic functions (teaching, learning, research, service, innovation, cultural preservation and progress, and social critique), the idea of 'a' university is shaped by the dynamics of the national contexts in which respective universities are embedded. This understanding of how a particular university is being (or has been) shaped by its contextual factors has implications for the role that the university will or can play with respect to the imperatives flowing from the Creed of Human Rights. To understand why South African universities have demonstrated a measure of inertia in 2015 and 2016 (even to the extent of appearing unwilling and unable to respond favourably) when confronted by a student demand for greater and more affordable access, it is necessary to examine briefly the history and tradition of the university as a societal institution.

\section{The historical roots of the university}

The question as to which is the oldest university in the world is not easy to answer. Eurocentric historians of education usually assign this honour to the University of Paris and give 1080 as its year of establishment. On the other hand, many Islamic and African historians of education regard the University of Karouine in Fez in Morocco, founded in 859, as the first university. Most universities in the contemporary world nevertheless seem to carry the stamp of its European progenitors (the notion of 'the' university as an institution having spread from Europe to the rest of the globe during the era of colonisation). The Medieval European university was foremost a teaching university, as teaching and learning were its basic function. This is perhaps why the word university is derived from the Latin universitas magistrorum et scholarium, roughly meaning 'community of teachers and students' (Duggan 1916). 
The next major event in the evolution of 'the' university was the founding of the University of Berlin in 1810. This university was not intended to be an addition to the set of universities that already existed at the time. Instead, it was to be the embodiment of a totally new concept of university. Emphasis was primarily on searching for answers to the fundamental question: 'why are we here?' (cf. Schwartz 2008). It therefore favoured scientific research, rather than teaching. The opening of Johns Hopkins University in the United States in 1876 served to spread the research university model to the entire United States and eventually to the rest of the world.

The next milestone in the development of the modern university was the establishment of the 'Land Grant Colleges' in the United States, following the Land Grant Act (or the Morrill Act) of 1862. The Morrill Act funded educational institutions by granting federally controlled land to the states for them to sell as a means of raising funds to establish and endow 'land grant' colleges. The mission of these institutions was to focus on the teaching of practical or utilitarian subjects such as agriculture, science, military science and engineering. These institutions strengthened the nexus between the community and the university and elicited another function of the university, namely (community) service.

\section{The liberal-humanistic idea of a university}

The liberal idea of 'the' university is based on the belief that education is an endeavour worthwhile in itself, and that knowledge should be pursued for its own sake - that is, for the sake of knowledge acquisition per se. This contention eschews an instrumental view of education: that education should be restrictively understood as preparation for a vocation. In as far as an aim or objective of education does exist, it should be seen as the character formation and inculcation of the upcoming generations into the mores, habits, customs and practices of the social structures of which they are novice members 
(Potgieter 2015:56) and not so much preparation for a profession or a career. In as far as knowledge, per se, serves a purpose, it is in seeking truth. Knowledge furthermore serves to mould the cognitive faculties of students, such as critical and independent thinking. The British universities of Oxford and Cambridge are examples of universities, perhaps the two prototypes that embody this liberal-humanistic idea of a university. The idea of the liberal-humanistic education university was for the first time extensively articulated in the work of Newman (1853, 2009) and was still very prominent in the Report of the Robbins Commission of 1963, which set the course for the massive expansion drive of universities in the United Kingdom in the 1960s. This idea was also defended in a work by Jaspers (1959).

\section{The Humboldtian idea of the university as part of the national project}

The next ideal-type view of the university was embodied by Humboldt University in Berlin, founded in 1810. This university was characterised by the combination of teaching and research and had a strong influence on the development of universities throughout the world in the 19th and 20th centuries.

A crucial step in the historical development of European universities embodied in Humboldt University is what Guy Neave termed the process of the nationalisation of universities - bringing the university formally into the public domain as a national responsibility. With the rise of the nation state, the university was set at the apex of education institutions that were generally understood to define national identity (Neave 2001):

$[T]$ he forging of the nation state went hand in hand with the incorporation of academia into the ranks of state service, thereby placing upon it the implicit obligation of service to the national community. (p. 26)

The emergence of the Prussian and French (Napoleonic) models of the university also meant a shift from revealed knowledge characteristic of Medieval (and early modern) universities - to verifiable, scientific knowledge (Kwiek 2006:7). 


\section{The developmental university}

The classic university model was criticised for failing to help countries in the Global South, as it did not produce the kind of graduates who could deal with the developmental problems these countries faced. This gave rise to the idea of the developmental university (Fredua-Kwarteng 2016). The distinguishing feature of this type of university is its mission to develop and to transmit knowledge for developmental purposes. The university is expected to use suitable media such as radio and community hall meetings to communicate research findings or outcomes to the target stakeholders (Fredua-Kwarteng 2016).

\section{The ethnic-oriented developmental university}

The idea of a university serving a particular sociocultural community was pivotal in the creation of all universities that came into being in South Africa from 1948 to 1994. While currently totally discredited, vestiges of this idea can still be seen in the geographical positioning and other features of most universities in South Africa. This ethnic-oriented idea as the founding philosophy of a university can also be detected in variant forms in other parts of the world, such as the historically black colleges in the United States (especially those created in the segregation era before 1964), the Hispanic-Serving Institutions in the United States (cf. Excellencia in Education 2014), the Nunavut Community College in Canada (catering for the needs of the First Nation People) (cf. Gaviria 2012) and Kurdish University in Iraq (cf. Mojab \& Hall 2003).

\section{The Africanist university}

The notion of the Africanist university originated in the black intellectual community. Scholars in Africa developed this notion of what the African university should be after their countries became independent in the 1960s. Yesufu (1973) outlines this 
notion extensively in his landmark publication, entitled Creating the African University. The idea of the Africanist university also links with the broader philosophies of Pan-Africanism, Négritude and the Black Consciousness Movement and resonated well with national aspirations in the era of the decolonisation of Africa and with the African nations and countries coming of age. Leading intellectuals in Africa active in the years and decades after independence, such as Franz Fanon, Walter Rodney, Steve Biko, Cheik Anta Biop and Okot p'Bitek, all envisaged a pivotal place for a transformed, Africanised University in their schemes for the post-independent evolution of Africa. This idea is present in the discourse on higher education in Africa to this day, as for example in the student call to \#DecoloniseOurUniversities in South Africa (cf. Prinsloo 2016).

The Africanist idea of a university strives to transform the university as imported from the West to Africa into an indigenised institution reflecting African values and philosophy, playing a role in the shaping of an authentic African identity and in combating post-colonialism or neo-colonialism. In view of these aims, it envisages a university curriculum that reflects and teaches the natural and cultural heritage of Africa, instead of teaching curricula adopted from Western universities. The university should also not be an 'ivory tower' in society that only trains a small elite. Those who have been through university education should be equipped with what is needed to be of service to communities in Africa (cf. Izevbaye 2008; Wolhuter \& Mushaandja 2015:220).

\section{The revolutionary university}

In the aftermath of the student unrest during the 1960s in Western Europe and North America, a school of thought developed which held that the academic community (students and lecturers) should constitute a potential active force for societal critique and for the corresponding revolutionary transformation of society (cf. Cunningham 2013:537; Habermas \& Blazek 1987). In view of 
this conviction, Marcuse (1964) advocated for a college education empowered by a form of praxis that extended education outside the university into the realms of critical thought and action.

This is also the view amongst eminent scholars of higher education in Africa such as Balsvik (1998), who concluded that students have been a major driving force in the second liberation of the continent of Africa - that is, democratisation since 1990 in countries such as Ethiopia, Nigeria, Kenya, Cameroon, Tanzania, Uganda, Côte d'Ivoire and Zambia. The \#DecoloniseOurUniversities movement in South African student politics (e.g. Maluleke 2016) could have drawn inspiration from this view of higher education.

\section{The current era}

It is difficult to position current South African universities in terms of the categories discussed above. It is probably safe to say that most of them reflect a mixture of all these models, and that some of them strive towards the embodiment of a particular model. Most South African universities still seem to exude the traditional form and appearance of classic universities, although with various admixtures of liberal-humanistic ideals, a focus on teaching and learning, and some with a stronger inclination to research and development. Some universities apparently attempt to be oriented more towards African identity, with some of them even being inclined to break away from the classic mould, and to transform themselves into revolutionary and more indigenised institutions. Most universities in South Africa nevertheless experience problems to accede to the demands of students for greater and more affordable (even free) access and tuition, as illustrated at the beginning of the academic year at most universities in South Africa; only a relatively small percentage of them could be accommodated.

Although each of the above range of ideas or ideal types of universities has protagonists in the scholarly community of today as well as in the public discourse, and when vestiges of all these ideas can be detected in the international higher education 
landscape, they all are facing the onslaught of the compelling force of the neoliberal economic revolution that has been sweeping through the world during the past four decades. The neoliberal economic revolution seems to have its own idea of a university. In the next section, this revolution and its effect on higher education are discussed.

\section{The neoliberal economic societal context}

One of the most prominent features of the past two to three centuries was the rise of the nation state. The nation state was already a power factor in the world by the beginning of the 20th century, although its pervasiveness in the lives of citizens was strengthened with its transformation into the welfare state during the first three quarters of the 20th century (Redwood 1993:41-44). The term 'welfare state' refers to a state or government or public sector that assumes responsibility for taking care of the individual citizen 'from the cradle to the grave', that is, the (almost) exclusive supply by the state of a wide range of services such as health care, (higher) education, retirement provision and unemployment insurance.

By the early 1980s, the welfare state (suffering from mounting budget deficits in Western Europe and North America, the implosion of planned economies in the East Bloc, escalating foreign debt in the Global South) had proved to be financially unsustainable (cf. Davidson \& Rees-Mogg 1992:394). Forced by these contextual imperatives, the neoliberal economic revolution was spearheaded by the Conservative Party, when it became the governing party in the United Kingdom under Prime Minister Margaret Thatcher in 1979; when Ronald Reagan became President of the United States in 1980; and when Helmuth Kohl's Christian Democratic Party came to power in West Germany in 1983. From this point on, the neoliberal economic revolution spread to the rest of the Western world; after the collapse of the Berlin Wall in 1989 to the East Bloc; and soon thereafter to the Global South as well. 
The neoliberal economic revolution entailed scaling down the range of activities of the state to the core functions of the state, such as the security of citizens, the managing of foreign relations and the privatisation of other functions such as health services, pension provision and also to a large extent (higher) education (cf. Brenner 2004). Those functions that were retained by government were managed according to market principles. The end result was that free-market principles were carried into a wide range of societal domains, including (higher) education. These principles include granting the individual or the consumer more freedom of choice, an obsession with efficiency, the profit motive, competition, performativity and reducing the human being to a production and consumption unit. Other features of the neoliberal economic revolution include an increased affluence in the world, materialism, individualisation and inequality. In the 10-year period, from 2005 to 2014, the global economic output has more than doubled, from US $\$ 29.6$ trillion to US\$78.3 trillion (World Bank 2016), and so has inequality (cf. Piketty 2014). Although these trends accompany the neoliberal economic revolution, the weight of neoliberalism as a causal factor in these trends remains a moot point, the evaluation of which, however, falls beyond the scope of this chapter.

\section{The neoliberal economic revolution and the university}

As explained above, the neoliberal economic revolution has had an effect in societal sectors far beyond the economic and the political. The university sector could not escape the force of this revolution either; the principles of the neoliberal economic revolution have also been carried into the university environment. The downscaling of the range of activities and responsibilities of the state resulted in an ever-diminishing allocation of public funds for higher education. The private higher education sector has mushroomed as a result. In the sub-Saharan Africa region, the number of private higher education institutions has increased from 24 in 1990 to 468 in 2007; 24\% of students in the region 
studied at private higher education institutions in 2007 (World Bank 2009).

An obsession with efficiency, profit-making and performativity has furthermore replaced the unhindered quest for truth as the defining feature of the university, and has created a culture of managerialism. The sole purpose of the university has increasingly come to be understood as preparing (or actually training) students for the labour market (cf. Reddy 2016:32), to the neglect and even negation of other functions of the university such as the preservation of cultural treasures of humankind, the promotion of culture, the education of a critical and independent thinking citizenry or acting as the conscience of society (cf. Van der Walt, Potgieter \& Wolhuter 2014).

\section{The stand-off between South African students' right to access to higher education and the current situation of South African universities}

Clearly, the South African students' insistence on greater access to university study for the purpose of ensuring a better and more prosperous future for themselves than the previous generations have enjoyed is at odds with the current status of South African universities.

On the one hand, universities are mostly run in accordance with the tenets of neoliberalism. In other words, they are run and managed as large business corporations intent on making profit (in the form of tuition fees, registration fees, sponsorships and state subsidies, third stream income, etc.), and they are focussed on effectiveness and efficiency, and on their academic status (based on rankings and ratings). Hence, they are driven by the norms of performativity, consumerism and managerialism. In the process, the human beings involved in all these processes have become 'economised', 'consumerised' and even dehumanised: 
staff members are viewed as 'human capital' and 'human resources'; the supporting community as 'sponsors'; the students as 'clients and consumers'; knowledge, teaching and learning as 'saleable commodities'; and the physical infrastructure as 'assets and resources'. As a result of this neoliberal orientation, universities do not see their way clear to afford greater access to the students clamouring at their gates. During the student campaigns in 2015 and 2016, universities' spokespersons repeatedly claimed that to do so would be unaffordable, and that free tuition would lead to the inevitable demise of the universities.

It is clear from this brief sketch regarding the confrontation between universities and students that South Africans particularly South African universities and prospective students are in a predicament that would be difficult to resolve. The current weak (and progressively weakening) South African economy seemingly prevents the government from supporting the universities with more funds. Furthermore, the students are poor and cannot afford the constantly rising university tuition fees, and the universities are understandably hesitant to allow large numbers of students who might not make a success of their studies. The South African university sector seems to find itself painted into a proverbial corner.

What universities and students are experiencing in South Africa is, however, not a localised problem. This confrontation between universities and students is arguably another instance of a worldwide backlash against neoliberalism, recently referred to as 'post-truth', that is, the tendency not to believe the 'rational arguments' offered by the powerful and elitist establishment but rather to depend on one's own intuition, perception, personal 'feeling' and emotions. This was evidenced by amongst others the presidential victory of Trump in the United States (on the basis of an appeal to the middle-class and worker-class sections 
of the electorate) and the unexpectedness of the Brexit result. ${ }^{2}$ South African students, Trump supporters and proponents of Brexit all seem to form part of an anti-neoliberal ground swell: they all seem to have felt that the liberal elite in charge of their countries or universities are looking down upon the poor and ordinary people' and are not concerned about their welfare. ${ }^{3}$ The anti-neoliberal revolution, which has manifested in South Africa in the shape of various campaigns, such as \#FeesMustFall, \#ZumaMustFall, \#OutsourcingMustFall, \#RhodesMustFall, \#ColonisationMustFall, can be seen as a democratic uprising of the 'ordinary people' (cf. political scientist Brown in an interview with Shenk 2015:n.p.) against an established power dispensation (in the case of the students, the universities being governed along neoliberal lines). They see the liberal elite in charge of institutions as a small minority with inordinate amounts of power at their disposal, who are more concerned about their own interests than those of the 'small people out there'. A huge divide has developed between these two interest groups, and it is difficult to predict how this can be bridged in the short to medium term (Buys 2016:22).

2. According to Viljoen (2016: 21), Trump's success can be ascribed to his 're-discovery of how politics should be practised at ground level', and this, he avers, follows shortly after Brexit. Both of these events, he argues, attest to a rejection of a continuance of the status quo. Trump associated himself with the American middle-class and worker-class sections of the electorate who felt that there was something radically amiss with the status quo. Schreiber (2016:8-9) and Buys (2016: 22) concur with this analysis, whereas Du Plessis (2016:6) goes a step further by stating that 'political populism is alive and well, as Trump's victory has spectacularly demonstrated. Drake University Professor of Law, Anthony J Gaughan (2016) agrees with Du Plessis by referring to Trump's victory as a 'populist revolt against immigration and trade'.

3. According to Buys (2016:22), the current leadership has lost touch with the 'ordinary people', looks down upon them and only uses them as voting stock. Pienaar (2016: 2016) and Holzapfel (2016:7) concur with this analysis by writing that through Trump's victory, 'conservative' Americans have sent a message to the progressives in Washington that they felt betrayed by the status quo: their culture, identity, children's future and their value system have all been under threat as a result of globalisation (which, as argued above, is a reference to neoliberalism). Trump represented a potent anti-establishment spirit in America (Gaughan 2016). 


\section{Towards an agenda for the restoration of student discipline in South African universities}

On the basis of the discussion so far in this chapter, an agenda for the possible restoration of student discipline at South African universities could consist of a number of questions and tentative answers such as the following:

- What is meant by the term 'student discipline'?

- What does this term mean in a South African university context?

- Whose views regarding student discipline and good order should prevail in the attempt to restore student discipline?

- Whose duty is it to inculcate these values and norms in students at universities?

- Who should be held responsible and accountable for the enforcement of good discipline and order at universities?

- What are the implications of neoliberalism and of the insistence on the part of students to gain access to universities for student discipline at South African universities?

The following tentative answers to these six questions could provide those in charge of universities and other institutions of higher learning in South Africa and elsewhere with a possible agenda for the restoration of student discipline.

\section{What is meant by the term 'student discipline'?}

On the basis of the South African experience, this question elicits two answers, one negative and the other positive. The negative answer is that students should refrain from disorderly conduct such as attempting to apply for admission to a university on a walk-in basis when the university has expressly announced that it follows a policy that no such applications for admission will be accepted, or such as storming the security gates, or the looting and destruction of university property, if they are being repelled 
by the security staff. The positive answer to the question is that they should behave in an orderly and civilised manner when seeking admission. This entails timeous application for admission (well in advance, at most universities) and also for bursaries, grants and loans (including grants offered by the NSFAS). They should, as most universities nowadays stipulate, apply online for admission (every student today possesses a smart phone on which this can be performed) and submit the necessary supporting documentation according to the prescribed time schedule. When on campus, they should conduct themselves in an orderly manner, apply themselves to their studies, indulge in their pastimes in ways that would not disturb others, respect university property and the possessions of others, and contribute to the general order and welfare of the university community.

\section{What does this term mean in a South African university context?}

The previous answer already touched upon this aspect. In general, students are expected to be well-behaved and to play 'the higher education game' within the strictures of the national legislative and constitutional framework as well as within those of the higher education system and of the specific university that the student wishes to attend. The anomie and unruliness that have characterised life on South African university campuses since around 1976 call for a renewed plea for order and adherence to university structures and rules. (This of course applies to all universities worldwide similarly affected by social and political unrest.) Generally speaking, university life should be characterised by calm academic collectedness and a spirit of academic collegiality and purpose.

\section{Whose views regarding student discipline and good order should prevail in the attempt to restore student discipline?}

This is a moot point. As discussed above, universities in South Africa and in other developing countries have agendas, rules 
and stipulations that they deem necessary to ensure meaningful academic life on campus. Any transgression of their rules has so far been consistently condemned as unacceptable by university spokespersons. The students, on the other hand, have a quite different and even conflicting set of ideals, future plans, interests, values and norms. They are intent upon gaining access to higher education to ensure a better future, if possible free of charge, as promised by the previous president of South Africa. These two sets of interests lead to confrontations between university authorities (security personnel usually have to bear the brunt) and the students (mostly in the person of outspoken leaders or, in some cases, bellwethers). To reach a compromise between these two conflicting sets of interests is no simple matter, as the South African experience has shown.

The answer to the question in the heading of this subsection should be sought in asking what can be regarded as morality and as morally acceptable behaviour. This is a momentous question that cannot be dealt with in a single short paragraph. Suffice it to say that no rational human being can escape moral responsibility, for refusing to decide whether some act is morally right or wrong is in itself a moral choice. All those involved in the current struggles in the university context therefore have to sharpen their moral consciousness: they have to be more keenly aware of the values and the principles they choose to live by, how these influence the decisions that they take and how their choices will shape not only their own future but also that of the university in question. A person's moral choices are also determined by what he or she regards as 'the good life' for himself or herself and for the entire (university) community (Thompson 2018:1-6). This approach to life in general, and to conduct or behaviour in particular, implies that short-term gains like breaking down the university's gates and fences, and destroying university property will not contribute to a good life in the future. All stakeholders also have to be aware of the fact that the moral choices that people make may vary between groups. That this is the case was amply demonstrated during the \#FeesMustFall campaign in 2015-2016. 


\section{Whose duty is it to inculcate these values and norms in students at universities?}

The previous sections have already proffered the following answer to this question: everyone somehow involved in university life, from the university authorities (the council, the vice-chancellor and the student dean) to the students and the ground staff, and also the prospective students seeking admission - all these stakeholders should apply their minds and energies to the restoration of a settled, disciplined and predictable life on campus, to the promotion of a situation that is conducive to academic achievement and the fulfilment of ideals for the future.

\section{Who should be held responsible and accountable for the enforcement of good discipline and order at universities?}

One could argue that the previous answer also applies here. All the stakeholders involved in university life, as mentioned, are responsible and accountable for good discipline and order at universities. In addition, the central government of the country, in the shape of its Department of Higher Education, should provide the context for good discipline and order to prevail. In view of this perspective, it is patently irresponsible for people in high offices to make unattainable promises such as that all those having achieved a National Senior Certificate with bachelor's degree admission will be admitted to institutions of higher learning and that their studies will be free of charge to them and their parents provided they earn less than a specified amount. This is to invite chaos and unruliness at university gates as the universities are not in a position to fulfil the politicians' promises. Persons in authority should be careful about the promises they make to prospective students. Proper research should first be conducted to see whether such promises can be honoured by the universities on the ground. 


\section{What are the implications of neoliberalism and of (the call for) increased student access to universities for student discipline at South African universities?}

As explained in rather great detail above, the neoliberal agenda to which many universities worldwide and also in South Africa have committed themselves since the middle 1970s has put them at odds with the ideals of prospective students, particularly in developing countries where resources remain scarce and the numbers of prospective students are constantly growing. Governments committed to a neoliberal philosophy tend to concentrate on their own key functions and hence are less inclined to provide for universities or for the tuition of students (as used to be the case in social welfare states). They expect students and their parents to pay for their tuition at universities and other institutions of higher learning. (South Africa can be regarded as an exception in this case; the previous president promised free tuition to all qualifying students, but seemed to have merely pass the buck to his Department of Higher Education and to the universities that now have to cope with masses of qualifying students clamouring for admission at their gates.) Neoliberalism has also led to a tendency towards the privatisation of universities. State subsidies for South African universities have dwindled to such levels that most public or state universities can today be regarded as semi-privatised. As a result, students (or institutions such as NSFAS) have to pay for their studies. In addition, many universities are managed along capitalist, free-market principles, implying that they wish only to enrol students whose future achievements will contribute to increased subsidies. At the same time, the school system seems to roll out large numbers of students qualifying for higher education studies that according to the universities' own standards might not be successful with their studies. Students possessing good potential are seen as consumption units and allowed to study as they can be expected to attain their degrees and be absorbed by the labour market 
(Andresen \& Van der Walt 2018:114). All of the above results in a stand-off between the various parties involved in the university sector. The situation has been exacerbated by the weak world (including South African) economy since 2008: rising fees prevent poor students from attending universities and hence from upward mobility, and this in the long run exacerbates the social inequality in society.

\section{Conclusion}

The current dilemma of universities and students in South Africa is clearly not only a matter of a lack of funds or resources. It seems to be a stand-off between two power blocs: those still caught up in the throes of neoliberalism, and those feeling themselves 'defanged' by the small neoliberal elite in charge of important societal institutions, including universities. This chapter tapered down into an agenda for the restoration of discipline in universities, particularly South African universities. It is clear from this agenda that the problems that higher education in South Africa has to grapple with are of enormous proportions and will not be easy to address. The best that can be executed at this point in time is to appeal to all involved in higher education in South Africa (and elsewhere, where applicable) to respect the moral principle of diligent care of and for the interests of all others involved in the university sector, particularly those closely involved with life at a particular university or a particular campus. This, as Andresen and Van der Walt (2018:119) recently argued, is particularly important in the current situation where neoliberal principles are being indiscriminately applied in a sector (such as university life) where they do not belong. Neoliberal principles do not belong in the university environment; university authorities should instead expend their wisdom and energies on the application of pedagogical (formative) principles on the societal life of their institutions. Governments as unique societal relationships should also refrain from encroaching on the competency spheres of other societal relationships such as 
universities by adopting policies that confront the latter with virtually insurmountable difficulties. The only solution to the stand-off between students and neoliberal-inclined universities, as far as can be seen at this point in time, is to concentrate on the development of a keen moral consciousness in the hearts and minds of all concerned. Moral awareness might help to develop compassion and moral empathy with all other parties and the difficulties they have to deal with. 



\section{Chapter 11}

\section{The turn to positive discipline in education: Existentialist and other contributions}

Johannes (Hannes) L. van der Walt

Edu-HRight Research Focus Area,

Faculty of Education, North-West University,

Potchefstroom, South Africa

Izak J. Oosthuizen

Edu-HRight Research Focus Area, Faculty of Education, North-West University,

Potchefstroom, South Africa

Charl C. Wolhuter

School of Professional Studies in Education, Comparative and International Education, Faculty of Education, North-West University, Potchefstroom, South Africa

How to cite: Van der Walt, J.L., Oosthuizen, I.J. \& Wolhuter, C.C., 2019, 'The turn to positive discipline in education: Existentialist and other contributions', in C.B. Zulu, I.J. Oosthuizen \& C.C. Wolhuter (eds.), A scholarly inquiry into disciplinary practices in educational institutions (NWU Education and Human Rights in Diversity Series Volume 2), pp. 259-281, AOSIS, Cape Town. https://doi.org/10.4102/aosis.2019.BK157.11 


\section{Abstract}

This chapter deals with the issue of discipline from a PD perspective. After arguing that discipline in pedagogical context is essentially an ethical problem, the authors discuss the meaning of the concept 'PD' and then proceed to examine the background to this alternative to retributive punishment. In the process, they examine the role of a number of existential psychological thinkers who contributed to the notion of PD, and then also the philosophical and Zeitgeistliche background to the adoption and the current theory and practice of PD.

\section{- Introduction and problem statement}

It has been repeatedly stated that South Africa is suffering from what can be referred to as a moral laxity problem that expresses itself in general lawlessness and ill-discipline. According to Nation Master (2019a), 'South Africa [was] one of the least lawful countries in the world, with the 5th highest number of total crimes reported in 2002'. Compared with another country that has since 1990 also gone through a period of sociopolitical transformation, Hungary, South Africa did not perform well: in 2016, for instance, its total crime rate per 100000 of the population amounted to 58.94 as opposed to 41.42 for Hungary (Nation Master 2019b). A survey by the United Nations' Office on Drugs and Crime for the period 1990-2000 ranked South Africa second for assault and murder (by all means) per capita, and first for rape per capita in a data set of 60 countries. The total crime rate per capita was 10 th of the 60 countries in the data set. During the period 24 October 2017 to 10 October 2018, the number of reported murder cases in South Africa was 20336; attempted murder 18223; aggravated robbery 138364; and sexual offences 50108 (Van Heerden 2018:850).

The situation in the schools reflects these numbers. According to the South African Minister of Basic Education, Angie Motshega, 'there is a correlation between high levels of criminality in the 
community which is transported into schools. Guns come from communities; the knifing and anger come from communities' (Daniel 2018). Harris (2017) correctly concludes that each discipline problem, like every student, stems from a set of circumstances directly linked to the child causing the problem. Ngwokabuenui (2015:64-71) concurs with this diagnosis and refers to causes of indiscipline that his research has located in the parental home, in society as such and those related to a poor value system. Mabuza (2018) also arrives at the conclusion that a change of values is needed in the fight against discipline problems in schools (with reference to sexual abuse).

These references to values, particularly the holding of an 'incorrect' or inappropriate system of values (those held by the perpetrators of violence, sexual abuse, general ill-discipline and gangster activities, to mention only some instances of individuals and groups entertaining perverse value systems), bring us to the central argument of this chapter, namely, that the core of the problem of ill- and indiscipline is more of an ethical nature than anything else. In the past, the problem of ill- and indiscipline was addressed by examining the place, role and possible contribution of the education system as such (cf. Wolhuter, De Wet \& Van der Walt 2019), those of the principal and other educational leaders (cf. Wolhuter, Van Jaarsveld \& Challens 2018), those of the teaching staff (cf. Eloff et al. 2013), those of the learners themselves (cf. Wolhuter, Oosthuizen \& Van Staden 2010), those of the society (cf. Van der Walt, Potgieter \& Wolhuter 2009) and those of the parents (cf. Acar et al. 2018) and of the parental home (cf. Cramer 2002). The study reported in this chapter went somewhat further than many of the previous studies in that it examined the problem from an ethical and moral perspective; it concentrated not so much on the causes of ill-discipline and unruly behaviour but on discipline as a positive preventative measure, particularly on the contributions to the turn from retributive justice and punishment to PD.

The study reported in this chapter examined the hypothesis that the perpetrators of unacceptable behaviour tend to entertain 
a weak or inappropriate value system based on inappropriate views of the world and of the human being and his or her place in the world, particularly in society. The same applies for the punishment meted out for transgressions against individuals and society. Around three decades ago, it was realised that retributive justice and punishment also could not be ethically justified, irrespective of how one defines ethics and morality, whether in terms of the Biblical Ten Commandments, the Kantian categorical imperative, the Rousseauian 'sublime maxim' (ComteSponville 2005:5-9), the Socratic standard, Aristotle's virtue ethics, the Confucianist or the Taoist standard (Gray 2003:112, 198), or whatever other standard or norm. This realisation arguably became one of the main driving forces in pedagogy behind the turn from retributive justice and punishment towards the approach known as PD. On the basis of the view that Alfred Adler (18701937), the Austrian existentialist psychological thinker, could be regarded as the trail blazer as far as the notion of PD is concerned, a number of questions were raised. Firstly, what should be understood by the term 'PD'; secondly, what contribution did Adler and his co-existentialist psychological thinkers make towards the turn from retributive discipline to PD; thirdly, to what extent can these existentialist psychological thinkers be said to owe their views to 'pure' philosophical existentialism, and finally how did the turn in philosophical-ethical-penological beliefs in society take root in a new approach to discipline in schools around the world, namely, in the form of PD?

The structure of the remainder of this chapter reflects our efforts to arrive at answers to these four questions.

\section{Positive discipline and its adoption in pedagogical contexts in the 21st century}

During the last three or four decades, a shift in thinking has been taking place regarding measures for dealing with student misconduct. There appears to have been a shift away from 
reactive, punitive methods of disciplining towards proactive, positive ways of dealing with learner misconduct. This observation was confirmed in a 2015 survey conducted in 10 countries on six continents (Russo, Oosthuizen \& Wolhuter 2015: xi, 89). The aforementioned trend proved to have occurred especially in the Western countries, and to be embedded in the modern human rights culture.

Positive discipline has been described as a formal disciplinary approach based on positive expectations of and approaches towards students (USDE 2014:11). It has also been described as a positive approach for dealing with unacceptable learner conduct by means of preventative measures. In other words, this approach is prospective rather retrospective, and remedial in nature rather than retributive (Oosthuizen, Rossouw \& De Wet 2019:145).

The following subsections contain a few examples of such positive disciplinary measures.

\section{Codes of conduct}

In terms of Section 8 of the SA Schools Act, school governing bodies have to adopt a code of conduct for schools. Such a code is essentially a proactive, positive measure for dealing with learner conduct as it is to provide the basis not only for discipline but also to establish a 'purposeful school environment, dedicated to the improvement and maintenance of the quality of the learning process' (Republic of South Africa 1996b:s. 8). The Guidelines for a Code of Conduct for Learners specifically stipulates that the code of conduct is to enhance 'positive discipline, self-discipline and exemplary conduct' (Republic of South Africa 1998:n.p.).

A sound and orderly environment, conducive for teaching and learning, also pertains to students' physical and cognitive safety. Section 5 of the Guidelines for a Code of Conduct for Learners therefore permits the drafting of classroom rules for sound 
student conduct in the classroom. Amongst others, it provides opportunities for all learners to participate and/or to contribute to the drafting of class rules within the small circle of a classroom to try and make a difference in that small world they 'live in'.

In addition to the above, Department of Higher Education directives refer to student absenteeism at tertiary institutions as a form of misconduct and as a huge problem because of its negative impact on academic results (Oosthuizen 2018:297). A survey conducted by Oosthuizen (2018) to determine the main reasons for student absenteeism at a tertiary institution showed that the two main reasons were problems at home and also financial constraints. This is an issue that calls for positive disciplinary intervention.

\section{'Catch them doing good'}

One form of PD entails the teacher concentrating on detecting students doing something right or good and to follow up by rewarding it with appropriate credit. In this regard, Sackey (2016:124) remarked, '[t]eachers so often concentrate on the identification of mistakes that the positive efforts go by largely unnoticed'. Although there are various kinds of rewards, Derek Jackson once said that sincere (not shallow or superficial) recognition, encouragement, attention and approval serve as building blocks in the lives of students.

\section{The remedial application of positive reintegration}

The shameful reintegration of a student after misconduct in the form of, for example, rejection, could have a detrimental effect on the perpetrator (Lee \& Kavanaugh 2015:504). Everybody stumbles and falls from time to time, including students. Everybody experiences occasions where they misbehave, including students. Even some of the top students in the class make mistakes. Sometimes, when the teacher or lecturer applies 
the wrong method of punishment, and at the wrong time, it could cause more harm than good. An approach such as total rejection by the teacher or lecturer could be a dead-end for both.

\section{Positive time-out}

Occasionally, teachers and lecturers might have the unpleasant experience of a fall-out with a student in front of the whole class. Sometimes, this is because of a male student trying to show off in front of his friends or trying to demonstrate his manhood in front of females. Or it might be because of a difference of opinion. Whatever the reason for the conflict, the teacher or lecturer should not enter into a war of words in front of the class. In the heat of the moment, insulting words might be said that possess the potential of not only disturbing the teacher-learner relationship but also of harming the self-concept or self-esteem of the student. The teacher or lecturer has to keep in mind that students rely on others (especially people in authority in their lives such as teachers and lecturers) for them to develop their own self-esteem. In situations like this, the teacher or lecturer should rather call for time-out and in a calm and collective manner speak to the particular student after class, and in the event of misconduct, explain to the student why he or she had been wrong. Even more important, in the event where the teacher or lecturer was out of order, he or she should show integrity by apologising to the student.

\section{Building a positive relationship with the students}

A good relationship between a teacher or lecturer and a student is very important. This does not entail an over-friendly relationship owing to the teacher or lecturer trying to win popularity. It should be a professional relationship of trust demonstrating that the teacher or lecturer cares for the students and wishes to promote their best interests. The feeling that the teacher or lecturer really 
cares about the student will enhance the latter's self-esteem and will make him or her feel valued. Sun (2015:100) observed that punishment is a short-term measure 'to control' student behaviour, whereas a good teacher-student relationship, characterised by patience and care, is a long-term strategy to 'facilitate changes' in student behaviour and attitudes.

This brief outline of PD enables us to now proceed to an overview of the thinking behind PD. The next section contains an outline of the contributions that a number of existentialist psychological thinkers have made to PD.

\section{A selection of existentialist psychological thinkers who might have had an influence on the turn towards positive discipline}

In the group of psychological thinkers whose contributions are examined below, existentialism as a philosophy lives on, primarily in their attempt to combine the basic structure of 'pure' existentialism with other, less philosophical or metaphysical, ideas (see the next section for a discussion of existentialism as such). According to Baldwin (2005):

$[T]$ he general feature of these hybrids (between psychological thinking and existentialist philosophy) is an emphasis on the irreducibility of the perspective of human agents, whose activities, emotions and thoughts, it is supposed, are to be understood in terms of their aspiration to 'become an individual', as Kierkegaard would have put it. (p. 280)

This approach has turned the attention to the uniqueness of the individual as distinguished from abstract universal human qualities (McBride 2005:296) and to the importance of human agency and the aspiration to become an individual in the sense that positive steps have to be taken to enable the perpetrator of a crime or of indiscipline to become accountable for his or her own agency, thereby contributing to his or her growth into a 
full-fledged human being. The purpose of disciplining a young person, therefore, is not so much to punish the perpetrator or to correct his or her behaviour but to guide him or her positively in the desired direction, in the process helping him or her to assume accountability for own agency, thereby contributing to his or her growth as an individual.

According to Nelsen, Lott and Glen (2019:4), PD can be seen as based on the work of particularly Alfred Adler (1870-1937) and his student and assistant Rudolf Dreikurs (1897-1972). The Adlerian-Dreikursian PD approach stands in contrast to the current mainstream (behaviouristic) approach inspired by Pavlov, Thorndike and Skinner. As will be argued, the Adlerian view also found support in the psychological thinking of Frankl, Rogers and Maslow, to mention only three other existentialist psychological thinkers.

\section{Alfred Adler}

According to Nelsen et al., Adler's (1870-1937) theory and practice were influenced by living in a poor neighbourhood in [a] highly class-structured society, by his indigent patients and his traumatic experience as a psychiatrist for the Austrian Army during World War I. After the war, Adler initiated a series of child guidance clinics to teach parents and teachers more effective methods for working with young people, by using the democratic principles of dignity and respect. He believed that children needed both order (structure and responsibility) and freedom to grow into responsible, contributing citizens of their community. Adler (1969:97) saw human behaviour as movement towards or striving towards a sense of belonging (connection) and significance. Although he developed his philosophy almost a century ago without the aid of modern technology, current brain science supports his theories, which were based on his careful observation of human behaviour.

Dreikurs was a student of Adler and headed one of the latter's guidance centres. 
Adler, an Austrian medical doctor and psychotherapist, also was the founder of the school of individual psychology. Maddi (1978:183) observed that a remarkable similarity can be detected between Adler's individual psychology and existentialism, and also that he later in his career became even more inclined towards existentialism. Adler, in terms of his earlier writings, is classified as a second-generation psychoanalytical thinker. He and Carl Gustav Jung, both students of Freud, are the main figures of the second-generation school of psychological thinkers (with Freud as the central figure in the first-generation school). The quintessential feature of the psychoanalytical school is its contention that human behaviour is shaped by (irrational) unconscious drives, desires, instincts and motives.

Adler later drifted towards an existentialist position. Humanistic existentialists believe that behaviour is shaped by conscious needs and desires which are typically human, and not the irrational unconscious drives the psychoanalysts maintain. Many regard the desire for meaning as the strongest of these desires.

Adler identified feelings of belonging as a basic human trait that serves as a fundamental motivational drive in the lives of human beings (Aboluwodi 2015:139; Gfroerer, Nelsen \& Kern 2013:294). He saw the human being as goal oriented, and hence as continually striving towards perfection. He furthermore regarded the fully developed, mature person as somebody whose search for perfection is not only directed at himself but also at the interests of the society of which he or she is a member. Misconduct was seen by him as the result of actions of a discouraged person, one who is not able to grow towards perfection, not able to contribute constructively towards society or incapable of measuring up to its expectations (Meyer 1990:108-109).

In his theory of fictional finalism, he further contended that human behaviour was determined by the life goals a person sets for himself or herself and strives towards. He referred to this 
inclination amongst human beings as fictional finalism as he was convinced that many of the goals that humans strove for were based on imaginary thinking, and did not actually exist. Although many of their goals are imaginary, people nevertheless feel guided by them, and this occasionally might lead to disjointed behaviour.

Adler was also responsible for the private logic theory (Aboluwodi 2015:139), the view that each child has a particular, unique set of (private) values and principles of life that he or she wishes to live by. Persons of authority in their lives (for instance, their parents and teachers) play an important role in the child and young person's life and efforts at detecting, defining and explaining such private values and principles to the youngsters. It is therefore incumbent upon the parent and/or teacher to assist the young to not only gain a good grasp of their particular private logic but also to help them live in accordance with it. The values and principles associated with the private logic of the person progressively become his or her guiding lights in the process of growing up.

\section{Victor Frankl}

Another proponent of existentialism in the psychological field was the Holocaust survivor Frankl (1905-1997), an Austrian neurologist and psychiatrist. He saw humankind as pre-eminently spiritual in nature. He maintained that the human being was not merely a highly developed animal determined by his or her genes and/or environment but rather a spiritual being with unique qualities that differentiated them from animals. Individuals have the freedom to choose, and as one is responsible for one's choices, one cannot simply blame wrong actions on animal drive or instinct. One has to bear the consequences of the choices one makes (Frankl 1965:ix-x).

Frankl furthermore held that the human being is a spiritual being that develops himself or herself through self-forming of his 
or her personality through the choices and decisions they make in life. Even if they have to go through suffering and the situation in which they find themselves cannot be improved, the individual still possesses the ability and the freedom to change himself or herself. What matters above all in unchangeable situations is their attitude towards suffering, the attitude with which they bear misery (Frankl1978:43).

Frankl also maintained that, although a child is born with the core of his personality, he or she has to develop their personalities during the rest of their lives. The decisions they make during the rest of their lives will determine how this development proceeds, how their personalities develop and mature, and what they in the end become. Only later in life are they actualised as persons. All of this depends on the decisions they make. For example, a child (and later as adult) has the freedom to choose between right and wrong; between good and evil. Permissiveness can be seen as freedom without direction, a freedom that could pave the way to juvenile delinquency and substance addiction (Frankl 1959:46). Without a sense of responsibility, freedom is meaningless. For this reason, it is of the utmost importance when training up the young that they are not only confronted with, but also inspired by, values and a sense of responsibility.

Frankl also operated with the notion of the 'will to meaning' as a strong drive in humankind. He seemed to find this drive to be stronger than any other, and typified it as 'man's most fundamental and important motive' (Frankl 1959:154-155). He saw the human being as striving towards meaning in life, wanting to know that his or her life is special, and meant to contribute to something worthwhile. Human beings not only wish to maintain homeostasis or to satisfy their basic needs, but they also desire a life filled with meaning. Regarding his own search for meaning in life, he stated (Frankl 1978):

Without meaning there is no real reason to continue living. I would not be willing to live merely for the sake of my own defence mechanisms, nor would I be ready to die merely for the sake of my reaction formations. Man, however, is able to live and even to die for the sake of his ideals and values. (p. 111) 


\section{Carl Rogers}

American psychologist Rogers (1870-1937) was the father of the self-concept theory and a proponent of existentialist psychotherapies as an application of humanistic psychology. He emphasised the idea that humans have the freedom to make sense of their lives. This implies that human beings are free to define themselves and do whatever they wish to do. In terms of this orientation, Rogers stressed that the individual plays a pertinent role in actualising his or her integral potential against the background of environmental factors (which also play a role). Potential is best actualised in an environment where the individual feels unconditionally accepted for who he or she is and possesses the freedom to develop without restriction. A positive self-regard plays an important determining role in the individuals' behaviour. Rogers (1966:166) emphasised the fact that an individual's positive self-regard strongly depends on positive regard by others.

Rogers idealised an environment for the human being, which will let him or her see and accept themselves for who they are as a prerequisite for full actualisation (Boeree 2006:5). All of creation, humans, animals and plants, have an inherent propensity to enhance and develop all of their ability despite possible hindrances. Unlike the rest of creation, the human being possesses the ability to assess his or her experiences and also to strive towards self-development and ultimately to self-actualisation (Boeree 2006:4).

During all of these life experiences, the human being develops a self-concept through becoming aware of himself or herself as they begin to realise who and what they are. On this journey, there has to come a state of equilibrium between self-concept and potential. If not, they might not actualise their full potential. An individual who does not believe in his or her own capabilities will struggle to actualise his or her full potential and will not be able to use their talents to actualise their potential. Amongst others, a person develops a positive self-concept on the basis of 
positive feedback, especially from parents and teachers. However, along the way, as they get conditioned to a positive self-regard, they tend to accept themselves only if they live up to the standards that others (e.g. parents, teachers or society) have set for them. When their ideal self does not live up to these standards set by others and by society, a discrepancy emerges between the actual self and the ideal self, and this might pave the way for anxiety, stress and even neurosis (Boeree 2006:5).

\section{Abraham Maslow}

American psychologist Maslow (1908-1970) was born in Russia of Jewish parents. The writings of Adler had a strong influence on him and Rogers, especially his theories regarding the human need to belong and to be loved. Both Adler and Maslow emphasised the human need to strive towards perfection, the higher existence called self-actualisation, in Maslow's terminology.

Maslow postulated the human's inclination to self-actualisation and added that the need to self-actualise is the very motive that underpins all behaviour. The human's striving towards selfactualisation is a steppingstone in his or her need for gratification. Once one's need for gratification is fulfilled, another need appears. A fulfilled need is a means of relieving frustration and tension, but more importantly, it becomes a strong basis for the individual's growth and subsequent realisation of full potential (Maslow 1970:23).

Maslow became famous for his theory regarding the hierarchy of human needs. He distinguished five basic human needs divided into two categories, the first set being deficiency needs (biological or physiological; safety and security; affiliation and love; selfesteem needs) and the second being growth needs (need for self-actualisation) (Maslow 1970:44; Moore 1990:360). Once all of the deficiency needs are satisfied, the need for self-actualisation becomes apparent. The 'lower' needs on the hierarchy of needs are primary needs, which have to be fulfilled before considering the higher level of self-actualisation (Moore 1990:357-358; 
Taormina \& Gao 2013:156-162). The optimal development of the individual is embedded in the growth need of self-actualisation. A person who not only succeeds in fulfilling his or her deficiency needs on the first four lower levels but who also succeeds to the level of self-actualisation is the one who functions optimally. He or she overcomes the restrictions of the environment and is able to meet his or her deficiency needs regularly and efficiently (Maslow 1970:153-180).

The insights flowing from this discussion of existentialist psychological thinkers who had made contributions to PD inspired us to cast our 'philosophical net' wider to see whether we could detect deeper and more profound explanations for the emergence of PD in the 21st century. The first step in that direction was to examine the ideas of the existentialist precedents of the existentialist psychological thinkers whose ideas were portrayed above. The final step will be to recount our findings regarding our examination of the Zeitgeist, which also might have contributed to its adoption.

\section{The possible contribution of 'pure' existentialists in this turn to positive discipline}

The 'original, pure' (philosophical, metaphysical) existentialists paved the way for the psychological existentialists discussed above in that they drew the attention away from abstract reasoning (such as those of Kant and Hegel) to the irreducibility of the subjective, personal dimension of human life, by drawing attention to the actually 'existing individual', from objective understandings of the universe (as philosophers with a rationalistic bent are accustomed to doing) to the individual's concern for his or her own life and existence. One cannot, as Kierkegaard argued, resolve one's ethical questions by subjecting one's moral consciousness to an impersonal deliberative perspective. Ethical questions essentially concern oneself; in asking oneself how one 
is to lead one's life, we deceive ourselves if we pretend that the adoption of an objective, impersonal understanding of our situation will provide an answer. Ethical questions and issues are essentially of the first-person-type; the real subject is also the ethically existing subject, as Kierkegaard puts it (Baldwin 2005:279). Our ethics (morality) needs to be developed if we are to achieve our full potential as individuals; we cannot avoid firstperson practical questions. And how is one to become such an individual? Not by acquiring more pure knowledge, Kierkegaard insists, but by engaging the will, by making choices and commitments we can give our lives an ethical structure. Kierkegaard ([1846] 2008) explained this approach as follows in his Concluding Unscientific Postscript:

[/]n the ethico-religious sphere, the accent is on the 'how' [...] [this] refers to the relationship sustained by the existing individual, in his own existence, by the content of his utterance. [...] Only in subjectivity is there decisiveness; to seek objectivity is to be in error. [...] the subject is an existing individual [...] who finds himself in the temporal order. (p. 381)

The emphasis in this process is constantly on the individual and his faith, his passion, his subjective experience and decision-making. Amongst others, Kierkegaard ([1846] 2008:378) avers that '[...] decisiveness adheres in subjectivity alone. Through engaging the will and decision-making, one can gain a sense of own identity, and in that way become an "existing individual"'. The basic idea here is that one is able to make sense of one's life as a whole only through personal conduct and relationships with others, which manifest the virtues (Baldwin 2005:279).

Heidegger likewise emphasised the individual's mode of being-in-the-world, which he refers to as Dasein. According to him, Dasein is 'the manner of Being that man himself possesses' and 'understanding of Being is itself a definite characteristic of Dasein's Being' (Heidegger [1927] 2008:116-117). He goes on to explain the importance of Dasein's Being (i.e. the existence of the human individual) (Heidegger [1927] 2008): 
That kind of Being towards which Dasein can comport itself in one way or another, and always does comport itself somehow, we call existence. And because we cannot define Dasein's essence by citing a 'what' of the kind that pertains to subject matter, and because its essence lies rather in the fact that in each case it has its Being to be, and has it as its own, we have chosen to designate this entity as 'Dasein', a term which is purely an expression of its being. (p. 117)

For each person, his or her being-in-the-world is an issue, and the way we face up to this issue determines the nature of our existence. There is no fixed human essence with gives structure to human life; each person has to inquire into the 'existential' constitution of his or her Dasein, that is, human life. Dasein's existence therefore involves a practical concern for and with itself. Therefore, Heidegger insists, our fundamental being-inthe-world is action in the 'existential space' of everyday life; spatiality is, therefore, conceived in essentially egocentric and practical terms. In this space, into which we find ourselves just 'thrown into', both our decisions and what we prefer not to choose are important. Human beings exist without justification, hence 'absurdly', in a world into which they have been 'thrown', condemned to assume full responsibility for their actions and for the values according to which they act and behave (McBride 2005:298). Only people with a self-conscious awareness of this process can conduct an authentic existence (Baldwin 2005:280).

Unlike Heidegger, Sartre presents existentialism as an ethical doctrine; according to him, existential choice is essentially ethical, and choice is absolutely fundamental to human existence. A person's choices and decisions should be aimed at respect for the authenticity and freedom of others (Baldwin 2005:280).

Another existentialist, Camus, developed the image of the existentialist anti-hero who acts, as individual in his or her own right, out of authenticity, that is, in freedom from any conventional expectations about what the so-called human nature supposedly requires in a given situation, and with a sense of personal responsibility and absolute lucidity that precludes the lying to oneself that characterises most conventional human behaviour 
(McBride 2005:297). Camus ([1927] 2008) concludes his discussion of futility and defiance with the following words regarding Sisyphus and his rock:

The absurd man says yes and his effort will henceforth be unceasing. If there is a personal fate, there is no higher destiny or at least there is but one which he concludes is inevitable and despicable. For the rest, he knows himself to be the master of his days. At that subtle moment when man glances backward over his life, Sisyphus returning towards his rock, in that slight pivoting, he contemplates that series of unrelated actions which becomes his fate, created by him, combined under his memory's eye and soon sealed by his death. Thus, convinced of the whole human origin of all that is human, a blind man eager to see who knows that the night has no end, he is still on the go. The rock is still rolling. (p. 799)

Simone de Beauvoir also used a category familiar in Sartre to produce an existentialist ethics based on the notion of radical freedom as 'projected' to an open future and on a rejection of inauthenticity whereby individuals identify themselves with certain fixed qualities, values, tenets or prejudices. In her feminist work, she pleads for transcendence, that is, the active and free testing of one's possibilities with a view of redefining one's future (McBride 2005:297). In the process, she avails herself of Sartre's Heidegger-derived model of the struggle between subjective consciousnesses - each seeking to avoid objectification and to be the looker rather than the looked-at (O'Grady 2005:191).

\section{Synopsis: Existentialist perspectives that arguably influenced the existentialist psychological thinking, thereby giving impetus to the turn to positive discipline}

The following is a list of the existentialist precepts flowing from this brief discussion of existentialist philosophers that arguably might have influenced the existentialist psychological thinkers whose contributions were presented above in their thinking about the human being, his or her relations and conduct, and 
that might have played a role in the turn from retributive discipline to PD.

Our analysis of the ideas of the 'pure' existentialists showed that the following can be regarded as central to the shift from punitive or retributive discipline to PD. The 'pure' existentialists regarded the notion of the human being as a free agent and as an individual of central importance. The human agent is both free from, and free to: free from conventional social expectations, and free to choose throughout his or her life, existence, Dasein. Choice-making is of great importance in human existence; through constant choosing, the individual ensures authentic (hence not absurd) existence for himself or herself, and in this manner progresses towards complete individuality and human existence. Through choosing, the subject (agent) grows as an individual and develops to his or her full potential.

As mentioned, existentialists regard individuality as of great importance, particularly the individual as a unique subject free to choose and grow. An individual's main concern is with the self, the concern is of the first-person-type. A core task of the individual is to develop an identity and to become an individual that truly exists in a particular time and space. Individual, ethical conduct and behaviour within particular social contexts are also recognised. When a person, also in the process of growing towards maturity, responsibility and accountability, transgresses, positive steps should be taken to help the person address the problem. Key to existentialist ethics is responsibility, accountability and the development of moral conscience and awareness. In cases of transgression, positive steps should be taken to correct the 'problem'.

It is clear from this catalogue of pure existentialist ideas and notions that the psychological thinkers whose ideas have been reported above could have been inspired towards thinking positively about human behaviour and about addressing misconduct and deviant behaviour in positive ways rather than punitive ones. 


\section{A wider casting of the net: the Zeitgeistliche developments that might have promoted the chances of adopting positive discipline in pedagogical contexts}

We are convinced that to end the argument about which philosophy hides behind PD at this point would not only be unsatisfactory but also rather simplistic. The background to the rise of PD is much too complicated for that. A detailed outline of the entire Zeitgeistliche and philosophical background is not possible, however, given the space constraints of a book chapter. The following paragraphs nevertheless provide a broad outline of some of the broader influences that might have resulted in a movement away from punishment practices such as caning, spanking, pinching, threatening, pleading, bribing, yelling, commanding, name-calling, forced labour and other even more humiliating actions, towards a more positive pedagogical approach (UNESCO 2006:1).

(Humanistic) secularism, that is, the tendency amongst people to distance themselves not only from religious institutions but also from religion as such (Mohler 2008:29), including Christianity with its Biblical injunctions regarding discipline (for instance, 'a rod is for the back of him who lacks judgement' [Prov 10:13]; 'he who spares the rod hates his son, but he who loves him is careful to discipline him' [Prov 13:24]; 'do not withhold discipline from a child; if you punish him with the rod, he will not die' [Prov 23: $13,14]$ ), arguably can be seen as the overarching life-view or Zeitgeist influence behind the PD approach. Secularism, according to Van der Walt (2007:256-257), makes belief and disbelief in God and his revelation in the Bible irrelevant to the practice of everyday life, including in education. In these areas, autonomous human authority reigns supreme and the human being takes the centre stage. In fact, he (Van der Walt 2007:256-257) contends, secularism has become the dominant spirit (Zeitgeist) of the world, stating that ' $[\mathrm{j}]$ ust as one is unaware of the air one breathes, 
many people breathe the spirit of secularism without ever having heard the word "secularism"'. As Strauss (2009:379) has aptly observed, modern secularism (secular humanism) has burdened the human subject (the 'agent' referred to in previous sections of this chapter) with the heavy responsibility of becoming the lawgiver, the constructive agent, of his or her own world, also with respect to discipline in pedagogical context. In a human rights context, for instance, as will be argued below, new 'laws' in the shape of PD had to be adopted regarding discipline that will demonstrate respect for the learner as a person in his or her own right. For this purpose, many educators and educationists resorted to the ideas about education and discipline as expounded by Adler and others.

It is interesting to note that although Kierkegaard initially attempted to contemplate about the human being and his or her place in the world with reference to Biblical perspectives, he soon abandoned this approach for a more secular one. None of the other existentialists or existentialist psychological thinkers discussed above similarly referred to Biblical perspectives but, as Strauss (2009:379) observed, attempted to become the 'lawgivers, the constructive agents, of their own "worlds".

The postmodernism that has risen after the middle of the previous century, and could be seen as a manifestation of secular humanism, is arguably another influence on PD. According to McGrath (2005:218), the excesses, failures and ultimately the uninhabitability of modernity led to a loss of enthusiasm for clear-cut rationalistic goals (and in this, it dovetails with existentialist convictions) and eventually a total inversion of many of its leading ideas. Instead, postmodernism began stressing the limits to human knowledge and encouraged a toleration of those who diverge from the 'one-size-fits-all' philosophy of modernity, also with respect to discipline in pedagogical situations. This view, as explained, also chimes with the existentialist conviction that one's concerns are always of the first-person-type.

The world in which we now live is seen as a place in which nothing is certain, nothing is guaranteed and nothing is 
unquestionably given, not even injunctions about discipline given in Holy Books. Worldviews are frowned upon, even 'anathemised', because they are considered as euphemisms for ideologies with their respective dogmatisms (Olthuis 2012:1/7).

Bower (2005:181) goes so far as to state that it is a tenet of the postmodern perspective that people 'invent' their own stories and allow them to masquerade as history, to create meaning for themselves regarding their identities, values and purposes, and discipline. The relativism associated with postmodernism arguably has allowed space for every individual to decide for himself or herself the approach to be adopted for discipline in the classroom. Closely related to postmodernism is libertarianism. Libertarian theorists have argued that the public space should be kept neutral. Religious and life-view convictions and assumptions should not be allowed to influence that space (De Botton 2012:87). The combined influence of secular humanism and the human rights culture might have given impetus to educators and educationists to adopt a PD approach.

The third (and the last that will be discussed here) philosophical influence is the rise of a human rights culture, and the staunch belief that these rights are basic and inherent in humanity. Human rights, according to Brand (2011:8), are not apportioned to people, but are inherent in being human. Everyone possesses these rights, irrespective of whether others respect their rights or not. As all people's rights, including those of learners in school, have to be respected, traditional approaches to discipline have to be eschewed in favour of PD. This is understandable as, based on close inspection, PD techniques seem to conform best to a human rights dispensation. All the following tenets of PD, as identified by Nelsen et al. (2019:4), seem to comply with the recognition of the basic human rights of the learner: a learner seeks a sense of belonging (connection) and significance (meaning) in the social context, in an ongoing relationship founded on mutual respect; he or she experiences empathy, understanding of the perspective of the student, collaborative problem-solving, kind and firm 
follow-through; mutuality in relationships in which each person is equally worthy of dignity and respect; naming without shaming and blaming, the focus on solutions; follow through, addressing the belief behind the behaviour when allowing students to experience the results of their actions; the student feels belonging and significance in the classroom.

\section{Concluding remark}

The outline and the discussion above of PD and of the philosophies behind this development in pedagogical context seem to point in the direction of a confluence of a variety of influential factors: the conception of existentialist ideas put forward by a number of 'pure' existentialist philosophers such as Kierkegaard, Heidegger, Sartre, Camus and others; the groundbreaking contributions of existentialist psychological thinkers such as Adler, Dreikurs and others; the exponential growth of secular humanism since the second half of the previous century; the rise of postmodernism in the same period; and the widespread acceptance of human rights manifestos across the world have all in some way converged in, and contributed to, the adoption of PD as arguably the most acceptable approach to discipline in schools and other pedagogical contexts in our own time. 



\section{References}

\section{Chapter 1}

Adams, A., Blandford, A. \& Lunt, P., 2005, 'Social empowerment and exclusion: A case study on digital libraries', ACM Transactions on Computer-Human Interaction 12(2), 174-200. https://doi.org/10.1145/1067860.1067863

Adams, F., 2006, 'Managerialism and higher education governance: Implications for South African universities?', South African Journal of Higher Education 20(1), 3-14. https://doi.org/10.4314/sajhe.v20i1.25554

Anon, 2010, 'Numbers', Time, 16 September, p. 3.

Beal, V., 2017, 'Cyber', Webopedia, viewed 10 February 2017, from http://www. webopedia.com/TERM/C/cyber.html.

Beukman, B., 2017, 'Die stembrief praat harder as die staat', Bee/d, 11 October, p. 7. Bloch, G., 2009, 'A blueprint for learning', Sunday Times, 23 August, p. 13.

Boehm, A. \& Staples, L.H., 2004, 'Empowerment: The point of view of consumers', Families in Society: Journal of Contemporary Social Science 85(2), 270-280. https://doi.org/10.1606/1044-3894.314

Carr, N., 2010, The Shallows: What the Internet is doing to our brains, Norton, New York, NY.

Centre for Development and Enterprise, 2015, Teachers in South Africa: Supply and demand, CDE, Parktown.

Christie, P., 1992, The right to learn: The struggle for education in South Africa, Ravan, Braamfontein.

De Muynck, A., Vermeulen, H. \& Kunz, B., 2017, Essenties van christelijk leraarschap, een kleine onderwijspedagogiek, Driestar educatief, Gouda.

Egan, K., 2008, The future of education: Reimagining our schools from the ground up, Yale University Press, New Haven, CT.

Eyben, R., 2011, Supporting pathways of women's empowerment: A brief guide for international development organisations, viewed 08 February 2017, from http://r4d.dfid.gov.uk/Output/188696/.

Fengu, M., 2017, 'Skooltyd "gemors": Evaluering van onderwysers gebrekkig', Beeld, 26 August, p. 8.

Glaser, R., 1975, 'Future adaptive environments for learning', in L. Rudin (ed.), The future of education: Perspectives on tomorrow's schooling, pp. 121-133, Allyn and Bacon, Boston, MA.

Grossman, P. \& McDonald, M., 2008, 'Back to the future: Directions for research in teaching and teacher education', American Educational Research Journal 45(1), 184-205. https://doi.org/10.3102/0002831207312906

Haggett, P., 1971, Geography: A modern synthesis, Harper and Row, London. 
International Organization for Migration, 2012, Facts and figures, viewed n.d., from http://www.iom.int/jahia/Jahia/about-migration/facts-and-figures/lang/en.

Joubert, S., 2012, 'God in digitale era: Sewe feite', Beeld, 03 September, p. 3.

Kenny, A., 2009, 'Fathers and roots of failure', The Citizen, 11 August, p. 1.

Law, N., Pelgrum, W.J. \& Plomp, T. (eds.), 2008, Pedagogy of ICT use in schools around the world: Findings from the IEA SITES 2006 study, Springer and the Comparative Education Research Center, The University of Hong Kong, Hong Kong.

Lean, G., 2006, 'Wasteful dams, irrigation and global warming are the chief culprits', The Sunday Independent, 19 March, p. 16.

Maistry, S., 2014, 'Education for economic growth: A neoliberal fallacy in South Africa!', Alternation 21(1), 57-75.

Martin, M.O., Mullis, I.V.S., Foy, P. \& Stanco, G.M., 2012, TIMSS 2011 International Results in Science, TIMSS \& PIRLS International Study Center, Boston College, Chestnut Hill, MA.

Mortimer, I., 2015, The human race: 10 centuries of change on earth, Vintage, London.

Nussbaum, M.C., 2011, Creating capabilities, The Belknap Press, Cambridge.

Oxford Living Dictionary, 2017, Post-truth, viewed 14 February 2017, from https:// en.oxforddictionaries.com/definition/post-truth.

Pelser, W., 2013, 'Sulke matrieks kan maar Google', Rapport, 01 September, p. 2.

Pew Research Center, 2012, The global religious landscape, viewed 30 December 2012, from www.pewforum.org/2012/12/18/global-religious-landscape-exec/.

Rideout, V.J., Foehr, U.G. \& Roberts, D.F., 2010, Generation M2: Media in the lives of 8-18 year olds: A Kaiser Family Foundation study, viewed 10 February 2017, from http://files.eric.ed.gov/fulltext/ED527859.pdf.

Robbins, C.G. \& Kovalchuk, S., 2012, 'Dangerous disciplines: Understanding pedagogies of punishment in the neoliberal states of America', Journal of Pedagogy 3(2), 198-218. https://doi.org/10.2478/v10159-012-0010-z

Rudin, L. (ed.), 1975, The future of education: Perspectives on tomorrow's schooling, pp. 121-133, Allyn and Bacon, Boston, MA.

Rustin, M., 2016, 'The neoliberal university and its alternatives', Soundings 63(63), 147-176. https://doi.org/10.3898/136266216819377057

Schutte, B.C., Kruger, H.B., Van Wyk, J.H. \& Van Zyl, P.J., 1975, Die skool van die een-en-twintigste eeu, Christelike Opvoedkundevereniging van Suid-Afrika, Potchefstroom.

Steyn, H.J. \& Wolhuter, C.C., 2008, 'The education system and probable societal trends of the twenty-first century', in H.J. Steyn \& C.C. Wolhuter (eds.), Education systems of emerging countries: Challenges of the 21st century, pp. 1-40, Keurkopie, Noordbrug.

Torres, C.A., 2015, 'Neoliberalism, globalization agendas and banking educational policy', Paper prepared for a keynote at the University of British Columbia Research Week, Vancouver, 12th May. 
UN Data, 2016, Population growth rate (percentage), viewed 31 May 2016, from http://data.un.org/Data.aspx?q=world+population+growth+rate+1970\&d=Po pDiv\&f=variableID\%3a47\%3bcrID\%3a900\%3btimelD\%3a104\%2c105.

United Nations, 2016, The universal declaration of human rights, viewed 17 January 2016, from http://www.un.org/en/universal-declaration-human-rights/.

Van der Walt, J.L., 2017a, 'Some recent responses to neoliberalism and its views on education', HTS Teologiese Studies/Theological Studies 73(3), a4493. https://doi.org/10.4102/hts.v73i3.4493

Van der Walt, J.L., 2017b, Vergifnisonderwys: Is dit (voor)teoreties toereikend begrond?, viewed 25 September 2019, from http://www.litnet.co.za/ vergifnisonderwys-dit-voorteoreties-toereikend-begrond/.

Van Rensburg, C., 1976, Stepping into the future. Education for South Africa's black, coloured and Indian peoples, Erudita Publishers, Marshalltown, Johannesburg.

Welch, A.R., 1998, 'The cult of efficiency in education: Comparative reflections on the reality and the rhetoric', Comparative Education 34(2), 157-175. https:// doi.org/10.1080/03050069828252

Wolhuter, C.C., 1998, 'Spektroskopie van die Suid-Afrikaanse onderwysstelsel binne die internasionale ry van onderwysstelsels [Spectroscopy of the South African education system within the international education system]', SuidAfrikaanse Tydskrif vir Opvoedkunde 18(1), 9-19.

Wolhuter, C.C. \& Van Staden, J.G., 2008, 'Bestaan daar 'n dissiplinekrisis in SuidAfrikaanse skole? Belewenis van opvoeders [Is there a discipline crisis in South African schools? Experience of educators]', Tydskrif vir Geesteswetenskappe 48(3), 389-398.

World Bank, 2016, World development indicators, The World Bank, Washington, DC.

Yu, D., Kasongo, A. \& Mosesn, M., 2016, 'How two crucial trends are affecting unemployment in South Africa', The Conversation, viewed 24 May 2016, from https://www.google.com/url?sa=t\&rct=j\&q=\&esrc=s\&source=web\&cd=1\&cad $=$ jja\&uact $=8 \&$ ved $=2$ ahUKEwjD2 JqmilLIAhXAUxUIHeZLA4wQFjAAegQIABA B\&url=http\%3A\%2F\%2Ftheconversation.com\%2Fhow-two-crucial-trendsare-affecting-unemployment-in-south-africa-56296\&usg=AOVVaw1pd B1BYM8NamByUte6xVdX.

\section{Chapter 2}

Atlas, R.S. \& Pepler, D.J., 1998, 'Observations of bullying in the classroom', Journal of Educational Research 92(2), 86-99. https://doi. org/10.1080/00220679809597580

Aydogan, I., 2008, 'Favouritism in the classroom: A study on Turkish schools', Journal of Instructional Psychology 35(2), 159-168.

Botha, J., 2014, 'Relational aggression: The voices of primary school learners', South African Journal of Education 34(2), 1-15. https://doi.org/10.15700/201412071212 
Braun, V. \& Clarke, V., 2006, 'Using thematic analysis in psychology', Qualitative Research in Psychology 3(2), 77-101. https://doi. org/10.1191/1478088706qp063oa

Brown, F., 2005, 'The significance of congruent communication in effective classroom management', The Clearing House 79(1), 12-15. https://doi. org/10.3200/TCHS.79.1.12-15

Burr, V., 1995, An introduction to social constructionism, Routledge, London.

Burton, P. \& Leoschut, L., 2013, Results of the 2012 national school violence study, Centre for Justice and Crime Prevention, Cape Town.

Closson, L.M., 2009, 'Aggressive and prosocial behaviours in within early adolescent friendship cliques', Merrill Palmer Quarterly 55(4), 406-435. https://doi.org/10.1353/mpq.0.0035

Craig, W.M., Pepler, D. \& Atlas, R., 2000, 'Observations of bullying in the playground and in the classroom', School Psychology International 21(1), 22-36. https:// doi:10.1177/0143034300211002

De Wet, C., 2007, 'Educators' perceptions on bullying prevention strategies', South African Journal of Education 27(2), 191-208.

Evans, S.D. \&Prilleltensky, I., 2007, 'Youth and democracy: Participation for personal, relational and collective wellbeing', Journal of Community Psychology 35(6), 681-692. https://doi.org/10.1002/jcop.20172

Foucault, M., 1982, 'The subject and power', Critical Inquiry 8(4), 777-795. https:// doi.org/10.1086/448181

Gergen, K.J., 2009, Relational being: Beyond individual and community, Oxford University Press, New York, NY.

Giorgi, A. \& Giorgi, B., 2003, 'Phenomenology', in J.A. Smith (ed.), Qualitative psychology: A practical guide to research methods, pp. 25-49, Sage, London.

Greeff, P. \& Grobler, A.A., 2008, 'Bullying during the intermediate school phase: A South African study', Childhood 15(1), 127-144. https://doi. org/10.1177/0907568207086840

Hymel, S. \& Swearer, S.M., 2015, 'Four decades of research on school bullying: An introduction', American Psychology 70(4), 293-299. https://doi.org/10.1037/ a0038928

Jörg, T., 2004, 'Complexity theory and the reinvention of reality of education', in B. Davis, R. Luce-Kapler \& R. Upitis (eds.), Proceedings of the 2004 Complexity Science and Educational Research Conference, Alberta, Canada, n.d., pp. 121-146.

Josselson, R., 1996, The spaces between us. Exploring the dimensions of human relationships, Sage, Thousand Oaks, CA.

Joyce, T.M., 2013, 'School violence: Reimagining schools as safe havens', Journal of Social Sciences 37(3), 249-258. https://doi.org/10.1080/09718923.2013.118 93223

Juan, A., Zuze, L., Hannan, S., Govender, A. \& Reddy, V., 2018, 'Bullies, victims and bully-victims in South African schools: Examining the risk factors', 
South African Journal of Education 1(38), S1-S10. https://doi.org/10.15700/ saje.v38ns1a1585

Kerbs, J.J. \& Jolley, M., 2007, 'The joy of violence: What is fun about violence in middle school?', American Journal of Criminal Justice 32(1\&2), 12-29. https:// doi.org/10.1007/s12103-007-9011-1

Kitching, A.E., Roos, V. \& Ferreira, R., 2012, 'Towards an understanding of nurturing and restraining relationships in school communities', Journal of Psychology in Africa 22(2), 187-200. https://doi.org/10.1080/14330237.2012.10820517

Kruger, L., 2010, 'Incidence and gender differences in bullying behaviour in a South African high school', Dissertation- Master's, NWU, Potchefstroom.

Lazarus, S., Khan, M. \& Johnson, B., 2012, 'Towards safer schools', in A. Van Niekerk, S. Suffla \& M. Seedat (eds.), Crime violence and injury in South Africa: 21st century solutions for child safety, pp. 134-147, Psychological Society of South Africa, Johannesburg.

Lee, C., 2004, Preventing bullying in schools: A guide for teachers and other professionals, Paul Chapman, London.

McDowell, K.R., 2011, 'Who cares? Who doesn't: An exploration of perceptions of care based on the experiences of secondary school students from different economic groups', PhD- thesis, Simon Fraser University.

Menesini, E. \& Salmivalli, C., 2017, 'Bullying in schools: The state of knowledge and effective interventions', Psychology, Health \& Medicine 22(Suppl. 1), 240-253. https://doi.org/10.1080/13548506.2017.1279740

Merten,D.E.,2004, 'Securing herexperience:Friendshipversuspopularity',Feminism \& Psychology 14(3), 361-365. https://doi.org/10.1177/0959353504044635

Morrison, K., 2002, School leadership and complexity theory, Routledge, London.

Myburgh, C. \& Poggenpoel, M., 2009, 'Meta-synthesis on learners' experience of aggression in secondary schools in South Africa', South African Journal of Education 29(4), 445-460. https://doi.org/10.15700/saje.v29n4a290

Ncontsa, V.N. \& Shumba, A., 2013, 'The nature, causes and effects of school violence in South African high schools', South African Journal of Education 33(3), 1-15. https://doi.org/10.15700/201503070802

Nelson, G. \& Prillelentsky, I., 2010, Community psychology: In pursuit of liberation and well-being, 2nd edn., Palgrave Macmillan, New York, NY.

Neser, J., Ovens, M., Van der Merwe, E., Morodi, R., Ladikos, A. \& Prinsloo, J., 2004, 'Pre disposition to, reasons for and measures against peer victimisation in schools', Acta Criminologica 17(2), 83-98.

Olweus, D., 1993, Bullying at school: What we know and what we can do, Blackwell Publishers, Oxford.

Parsons, L., 2005, Bullied teacher, bullied student: How to recognise the bullying culture in your school and what to do about it, Pembroke, Ontario, CA.

Pepler, D.J. \& Craig, W., 2007, Binoculars on bullying: A new solution to protect and connect children', viewed 05 July 2012, from http://www.voicesforchildren. com. 
Rossouw, J.P. \& Stewart, D., 2008, 'Student/learner discipline and bullying: A comparative analysis of legal risk management in schools in Australia and South Africa', Acta Academica 40(2), 244-274.

Shaw, P., 2002, Changing conversations in organisations. A complexity approach to change, Routledge, London.

Stacey, R.D., 2001, Complex responsive processes in organisations: Learning and knowledge creation, Routledge, London.

Stacey, R.D., 2003, Complexity and group processes: A radically social understanding of individuals, Brunner-Routledge, New York, NY.

Stacey, R.D., 2007a, Strategic management and organisational dynamics: The challenge of complexity to ways of thinking about organisations, 5th edn., Pearson Education, London.

Stacey, R.D., 2007b, 'The challenge of human interdependence: Consequences for thinking about the day to day practice of management in organisations', European Business Review 19(4), 292-302. https://doi. org/10.1108/09555340710760125

Sullivan, K., Cleary, M. \& Sullivan, G., 2004, Bullying in secondary schools: What it looks like and how to manage it, Sage, London.

Swart, E. \& Bredekamp, J., 2009, 'Non-physical bullying: Exploring the perspectives of grade 5 girls', South African Journal of Education 29(3), 405-425. http:// www.ajol.info/index.php/saje/article/view/45180.

Swearer, S.M. \& Doll, B., 2001, 'Bullying in schools: An ecological framework', Journal of Emotional Abuse 2(2-3), 7-23. https://doi.org/10.1300/J135v02n02_02

Tracy, S.J., 2010, 'Qualitative enquiry: Eight big tent criteria for excellent qualitative research', Qualitative Enquiry 16(10), 837-851. https://doi. org/10.1177/1077800410383121

Tustin, D.H. \& Zulu, G., 2012, Bullying (cyber bullying) among the increase the Gauteng youth, viewed 27 September 2012, from http://www.unisa.ac.za/ contents/faculties/ems/docs/Press_Bullying_July\%202012.pdf.

Venter, E. \& Du Plessis, E.C., 2012, 'Bullying in schools: The educator' role', KoersBulletin for Christian Scholarship 77(1), 1-7. https://doi.org/10.4102/koers. v77i1.34

\section{Chapter 3}

Assali, M.A., 2015, Developing positive discipline in Iraq: Positive discipline strategy implementation guidelines, 2nd draft, consultation workshop, 19 \& 20 December, Al Rachid Hotel, Bagdad.

Burke, J. \& Sutherland, O., 2014, 'The meanings Jamaicans associate with corporal punishment', Psychology and Developing Societies 26(1), 59-89. https://doi. org/10.1177/0971333613516229

Busienei, A.J., 2012, 'Alternative methods to corporal punishment and their efficacy', Journal of Emerging Trends in Educational Research and Policy Studies 3(2), 155-161. 
Cherry, K., 2018, What is operant conditioning and how does it work? How reinforcement and punishment reinforce behaviour, viewed 17 October 2018, from https://www.verywellmind.com/operant-conditioning-a2-2794863.

Cheruvalath, R. \& Tripathi, M., 2015, 'Secondary school teachers' perception of corporal punishment: A case study in India', The Clearing House 88(4), 127-132. https://doi.org/10.1080/00098655.2015.1045821

Creswell, J.W., 2013, Qualitative inquiry \& research design: Choosing among five approaches, 3rd edn., Sage, Los Angeles, CA.

Creswell, J.W., 2014, Research design: Qualitative, quantitative \& mixed methods approaches, 4th edn., Sage, Los Angeles, CA.

Department of Basic Education, 2012, Positive discipline and classroom management, viewed 23 May 2019, from http://www.cjcp.org.za/ uploads/2/7/8/4/27845461/positive_classroom_discipline_and_classroom_ management_workbook.pdf.

Department of Education, 2000, Alternatives to corporal punishment, Government Printers, Pretoria.

Dufresne, A., Hillman, J.A., Carson, C. \& Kramer, T., 2010, Teaching discipline: A toolkit for educators on positive alternatives to out-of-school suspensions, Connecticut Voices for Children, New Haven, CT.

Durrant, E.J., 2011, Positive discipline: What it is and how to do it, 2nd edn., Keen Media Co. Ltd., Bangkok.

Elbla, A.I.F., 2012, 'Is punishment (corporal or verbal) an effective means of discipline in schools?: Case study of two basic schools in greater Khartoum/ Sudan', Social and Behavioural Sciences 69, 1656-1663. https://doi. org/10.1016/j.sbspro.2012.12.112

Jones, F.H., 1987, Positive classroom discipline, MacGraw-Hill, New York, NY.

Joubert, R. \& Serakwane, J., 2009, 'Establishing discipline in the contemporary classroom', Journal of Educational Studies 8(2), 125-137.

Kalipa, V.C., 2015, 'Supporting the implementation of alternatives to corporal punishment in the Eastern Cape secondary schools: Towards a framework for school management teams and teachers', PhD thesis, University of Fort Hare.

Kassabri, M.K. \& Harush, A.B., 2012, 'Discipline methods within the Israeli education system: Arab and Jewish teachers' attitudes', International Journal of Children's Rights 20(2012), 265-278. https://doi.org/10.1163/157181811X573084

Kindiki, J.N., 2015, 'Investigating policy implications for the abolition of corporal punishment in secondary schools in Kenya', International Journal of Educational Administration and Policy Studies 7(3), 72-82. https://doi. org/10.5897/IJEAPS2009.080

Krueger, R.A. \& Casey, M.A., 2000, Focus groups: A practical guide for applied research, 3rd edn., Sage, Thousand Oaks, CA.

Lwo, L.-S.L. \& Yuan, Y., 2011, 'Teachers' perceptions and concerns on the banning of corporal punishment and its alternative disciplines', Education and Urban Society 43(2), 137-164. https://doi.org/10.1177/0013124510380232 
Maphosa, C. \& Mammen, K.J., 2011, 'Educators' disciplinary capabilities after the banning of corporal punishment in South African schools', South African Journal of Education 30(3), 387-399. https://doi.org/10.15700/saje.v30n3a361

Marais, P. \& Meier, C., 2010, 'Disruptive behaviour in the foundation phase of schooling', South African Journal of Education 30(1), 41-57.

Marumo, M.L., 2015, 'Exploring the implementation of alternatives to corporal punishment in secondary school in Mahikeng: A positive discipline approach', MEd dissertation, North-West University.

Merriam, S.B., 1999, Qualitative research: A guide to design and implementation, Jossey-Bass, San Francisco, CA.

Morell, R., 2001, 'Corporal punishment in South African schools: A neglected explanation for its persistence', South African Journal of Education 21(4), 292-299. https://doi.org/10.1177/1097184X01004002003

Motseke, M., 2010, 'Learner discipline after corporal punishment in the Township Primary Schools', Interdisciplinary Journal 9(2), 117-133.

Moyo, G., Khewu, N.P.D. \& Bayaga, A., 2014, 'Disciplinary practices in schools and principles of alternatives to corporal punishment strategies', South African Journal of Education 34(1), 1-14. https://doi.org/10.15700/201412120952

Mtshweni, J., 2008, 'The role of educators in the management of discipline in the Nkangala region of Mpumalanga', MEd dissertation, University of South Africa.

Mulaudzi, L.M.P. \& Mudzielwana, N.P., 2016, 'Assessment of gender understanding of classroom discipline in South Africa: The case of Thohoyandou Community', Gender and Behaviour 14(2), 7519-7524.

Mwenda, K.J., 2016, 'Taking student protection to the next level: Are the alternatives to corporal punishment effective?', International Journal of Educational Research 4(10), 223-234.

Niewenhuis, J., 2016, 'Qualitative research designs and data gathering techniques', in K. Maree (ed.), First steps in research, Revised edition, pp. 70-97, Van Schaik, Pretoria.

Ntuli, T.L. \& Machaisa, P.R., 2014, 'Effects of banning corporal punishment on discipline in South African schools: A case study of secondary schools in Sekhukhune District, Limpopo Province', Mediterranean Journal of Social Sciences 5(23), 1781-1790. https://doi.org/10.5901/mjss.2014.v5n23p1781

Özan, M.B., 2015, 'The importance of positive discipline approach in making students gaın multimedia course content', Educational Research and Reviews 10(3), 320-327. https://doi.org/10.5897/ERR2014.2056

Republic of South Africa, 1996a, Constitution of the Republic of South Africa 1996, Government Printer, Pretoria.

Republic of South Africa, 1996b, South African Schools Act 84 of 1996, Government Printer, Pretoria.

Republic of South Africa, 1997, Abolition of corporal punishment Act 33 of 1997, Government Printer, Pretoria. 
Rohmann, C., 1999, A world of ideas: A dictionary of important theories, concepts, ideas and thinkers, Ballantine Publishing Group, New York, NY.

Segalo, L. \& Rambuda, A.M., 2018, 'South African public school teachers' views on right to discipline learners', South African Journal of Education 38(2), 1-7. https://doi.org/10.15700/saje.v38n2a1448

Shumba, A., Ndofirepi, A.P. \& Musengi, M., 2012, 'An explanatory study of corporal punishment by teachers in Zimbabwe schools: Issues and challenges', International Journal of Educational Science 4(3), 279-287. https://doi.org/10. 1080/09751122.2012.11890054

Skinner, B.F., 1938, Behaviour of organisms, Appleton-Century-Crofts, New York, NY.

South African Human Rights Commission, 2007, Submission on the children's act amendment bill [B19B -2006] clause 139 - Discipline of children to the Portfolio Committee on Social Development, viewed 24 May 2019, from https:// www.sahrc.org.za/home/21/files/39\%20SAHRC\%20Submission\%20on\%20 Childrens\%20Bill\%20Clause\%20139\%20Discipline\%20\%28Parl\%29\%20 Aug\%202007.pdf.

Xaba, M., 2006, 'An investigation into the basic safety and security status of schools' physical environments', South African Journal of Education 26(4), 565-580.

\section{Chapter 4}

Andero, A.A. \& Stewart, A., 2004, 'Issues of corporal punishment: Re-examined', Journal of Instructional Psychology 29(2), 90-96.

Banda, L.H., 2006, Negative effects of corporal punishment on children, viewed 28 March 2013, from http://www.cyc-net.org/features/viewpoints/ c-corporalpunishmenteffects.html.

Baputaki, C., 2009, 'zzeveve New education minister reveals her plan', Mmegi 26(173), viewed 04 April 2013, from www.mmegi.bw.

Bharadwaj, M., 2012, 'Undisciplined behaviour of students and the role of parents', Global Research Methodology Journal 6, n.p.

Bitensky, S.H., 2006, The end of the rod: A human rights violation, Transnational Pub., New York, NY.

Boston Globe, 2013, 'Student misconduct report up in MIT', The Boston Globe, viewed 25 June 2014, from http//bostoneglobe.com/metro/2013/03/31. reports-student-misconduct-mit/ubcGALHEqHuDHyQDPBUDJN/story. html.

Charles, C.M., 2007, Today's best classroom management strategies: Paths to positive discipline, Pearson, Boston, MA.

Cherry, K., 2018, What is operant conditioning and how does it work? How reinforcement and punishment reinforce behaviour, viewed 17 October 2018, from https://www.verywellmind.com/operant-conditioning-a2-2794863. 
Creswell, J.W., 2013, Qualitative inquiry \& research design: Choosing among five approaches, 3rd edn., Sage, Los Angeles, CA.

Creswell, J.W., 2014, Research design: Qualitative, quantitative \& mixed methods approaches, 4th edn., Sage, Los Angeles, CA.

Department of Education, 2000, Alternatives to corporal punishment: The learning experience, Government Printer, Pretoria.

Etheredge, C.L., 2014, 'Willingness to adopt restorative discipline in schools: An analysis of northwest justice forum pre training on restorative justice and school survey data', Masters thesis, University of Oregon.

Garegae, K.G., 2008, 'The crisis of student discipline in Botswana schools: An impact of cultural conflicting disciplinary strategies', Gaborone: Educational Research and Review 13(1), 48-55.

Gershoff, E.T., 2008, Report on physical punishment in the United States, Centre for Effective Discipline, Columbus, $\mathrm{OH}$.

Global Initiative to End Corporal Punishment of Children, 2010, Campaigns manual: End corporal punishment and other degrading punishment of children through law reform and social change, Global Initiative to End Corporal Punishment of Children, London.

Global Initiative to End Corporal Punishment of Children, 2017, Prohibiting all Corporal Punishment of Children: Answers to frequently asked questions, Global Initiative to End Corporal Punishment of Children, London.

Golafshani, N., 2003, 'Understanding reliability and validity in qualitative research', Qualitative Report 8(4), 597-607.

Govender, P., 2018, 'Teachers at the frontline of a battle with hostile pupils', Sunday Times, 08 April, p. 6.

Greydanus, D.E., 2010, Corporal punishment in schools and its effect on academic success: Testimony before the U.S. House of Representatives, Committee on Education and Labor, Subcommittee on Healthy Families and Communities, p. 15, U.S. House of Representatives, Washington, DC.

Holden, G.W., 2002, 'Perspectives on the effects of corporal punishment', American Psychological Association Bulletin 128(4), 590-595. https://doi. org/10.1037/0033-2909.128.4.590

Human Rights Watch, 2007, World report 2007, viewed 12 April 2013, from http:m. hrw.org/de/reports/2006//01/17/world-report-2006.

Human Rights Watch, 2009, Corporal punishment in schools and its effect on academic success, viewed 28 August 2013, from http://m.hrw.org/de/ news/2010/04/14/corporal--punishment-schools-and-its-effect-academicsuccess-joint-hrwaclu-statement.

Jotia, L., 2011, 'Education for democratic engagement in Botswana's democracy. Challenges of promoting democratic education', Journal of social Development in Africa 26(9), 135-160. https://doi.org/10.4314/jsda.v26i1.68504

Kayawe, B., 2017, 'Goodhope SSS nearly burns', Mmegi, viewed 22 October 2017, from www.mmegi.bw. 
Kgomotso, M., Tshegofatso, A. \& Boipono, M., 2015, 'Perceptions of teachers on the use of corporal punishment in schools: A case of Kang Secondary School', Research Journal of Education Science 3(6), 1-6.

Kilimci, S., 2009, 'Teacher's perceptions on corporal punishment as a method of discipline in elementary school', The Journal of International Research 2(8), 242-251.

Kopansky, T.M., 2002, Corporal punishment in school: A hit or miss preposition, viewed 12 April 2013, from http//www.geocities.com/forkidsake/kopansky. html.

Leedy, P.D. \& Ormrod, J.E., 2014, Practical research, planning and design, Pearson new International edition, 10th edn., Pearson, Essex.

Maag, J.W., 2004, Behaviour management from theoretical implications to practical application, 2nd edn., Wadsworth/Thomson Learning, Hampshire.

Makhani, C.S., 2013, 'Corporal punishment in schools. A medicolegal view', Journal of Forensic Medicine, Science and Law 22(2), 1-7.

Maphosa, C. \& Mammen, K.J., 2011, 'Disciplinary measures used in South African schools: How do learners view their effectiveness', Journal of Social Science 29(2), 143-149. https://doi.org/10.1080/09718923.2011.11892964

Maphosa, C. \& Shumba, A., 2010, 'Educator's disciplinary capabilities after the banning of corporal punishment in South African schools', South African Journal of Education 30(3), 1-9. https://doi.org/10.15700/saje.v30n3a361

Masokola, A., 2015, 'Khama warns unruly students', Weekend Post, 27 July, n.p.

Merriam Webster Dictionary, n.d., Effective, viewed 18 December 2018, from https://www.merriam-webster.com/dictionary/effective\#other-words.

Morrel, R. \& Moletsane, R., 2002, 'Inequality and fear: Learning and working inside Bantu education schools', in P. Kallaway (ed.), The history of education under apartheid 1948-1994, pp. 224-242, Pearson Education, Cape Town.

Moyo, G., Khewu, N.P.D. \& Bayaga, A., 2014, 'Disciplinary practices in schools and principles of alternatives to corporal punishment strategies', South African Journal of Education 34(1), 779, 1-14. https://doi.org/10.15700/201412120952

Mthanti, B. \& Mncube, V., 2014, 'The social and economic impact of corporal punishment in South African schools', Journal of Sociology and Social Anthropology 5(1), 71-80. https://doi.org/10.1080/09766634.2014.11885611

Mushoshwe, B., 2015, Ban on corporal punishment opens new era for children, viewed 17 July 2015, from http://www.unicef.org/html.

Naker, D. \& Sekitokel, D., 2009, Positive discipline: Alternatives to corporal punishment. Creating a good school without corporal punishment, Raising Voices, Kampala.

Oosthuizen, I.J., 2010, A practical guide to discipline in schools, Van Schaik, Pretoria.

Rohmann, C., 1999, A world of ideas: A dictionary of important theories, concepts, ideas and thinkers, Ballantine Publishing Group, New York, NY. 
Rossouw, J.P., 2003, 'Learner discipline in South African public Schools - A qualitative study', Koers 68(4), 413-435. https://doi.org/10.4102/koers. v68i4.350

Sajkouska, M. \& Wajtaski, L., 2005, Protecting children against corporal punishment: Awareness- raising campaigns, Council of Europe, s.l.

Saunders, B.J. \& Goddard, C., 2010, Physical punishment in childhood: The rights of the child, Wiley-Blackwell, Hoboken, NJ.

Save the Children, 2001, End corporal punishment of children; making it happen, viewed 20 April 2014, from www.savethechildren.net.

Selatlhwa, I., 2016, 'Kagiso senior student murdered', Mmegi, viewed 22 October 2017, from www.mmegi.bw.

Setlalekgosi, O., 2016, 'Students- teachers fight sparks violent protest', The Voice, 27 June, n.p.

Simuforosa, M. \& Rosemary, N., 2014, 'Learner indiscipline in schools', Review of Art and Humanities 3(2), 79-88.

Skinner, B.F., 1938, Behaviour of organisms, Appleton-Century-Crofts, New York, NY.

Skinner, B.F., 2005, Science and human behaviour, viewed 14 April 2014, from http:/www-bfskinner.org/books4sale.asp.

Thebenyane, A.T., 2014, 'Perceptions of teachers and learners on the effects of corporal punishment on learner conduct in Kanye junior secondary schools', MEd dissertation, North West University.

Tshukudu, I., 2014, 'ST Joseph's teachers under investigations', The Voice, viewed 25 July 2014, from http://www.thevoicebw.com/2014/07/11/st-josephsteachers-investigation/.

Veriava, F., 2014, Promoting effective enforcement of the prohibition against corporal punishment in South African schools, Pretoria University Law Press (PULP), Pretoria.

Veriava, F. \& Power, T., 2017, 'Corporal punishment', in A. Thom, F. Veriava \& T. Fish (eds.), Basic education rights handbook: Education rights in South Africa, SECTION27, Johannesburg.

Woolfolk, A., 2004, Educational psychology, 9th edn., Pearson Ed Inc., Boston, MA.

\section{Chapter 5}

Creswell, J.W., 2009, Research design. Qualitative, quantitative and mixed methods approaches, 3rd edn., Sage, London.

Ehiane, O.S., 2014, 'Discipline and academic performance', International Journal of Academic Research in Progressive Education and Development 3(1), 181-194.

Gamble, J., 2003. Curriculum responsiveness in FET colleges, HSRC Press, Cape Town. 
Hosten, W.J., Edwards, A.B., Bosman, F. \& Church, J., 1995, Introduction to South African law and legal theory, Butterworths, Durban.

Leedy, P.D. \& Ormrod, J.E., 2010, Practical research planning and design, Pearson, Boston, MA.

Lozano, R. \& Kizilaslan, I., 2015, 'Legal aspects and practical application of disciplinary actions in the Turkish public educational system', in C.J. Russo, I.J. Oosthuizen \& C.C. Wolhuter (eds.), International perspectives on student behaviour, pp. 51-61, Rowman \& Littlefield, London.

Manyau, T., 2014, 'Perspectives of students and lecturers on student misconduct and classroom management', Nuances of Teaching, Learning and Research 3(1), 149-166.

McMillan, J.H. \& Schumacher, S., 2014, Research in education evidence based enquiry, 7th edn., Pearson, Essex.

Ndebele, T., 2016, 'Education', in F. Cronje (ed.), South Africa Survey 2017, pp. 459-538, Institute of Race Relations, Johannesburg.

Oosthuizen, I.J., 2007, Report on learner discipline in the Kenneth Kaunda District, North-West University, Potchefstroom.

Oosthuizen, I.J., Russo, C.J. \& Wolhuter, C.C., 2015, 'Reflections and recommendations', in C.J. Russo, I.J. Oosthuizen \& C.C. Wolhuter (eds.), International perspectives on student behaviour, pp. 89-96, Rowman \& Littlefield, London.

Pietersen, J. \& Maree, K., 2014, 'Standardisation of a questionnaire', in K. Maree (ed.), First steps in research, pp. 307-303, Revised edition, Van Schaik, Pretoria.

Pittendrigh, A., 1988, Technikons in South Africa, The Building Industries Federation South Africa, Johannesburg.

Postma, F., 1985, Beknopte woordeboek: Latyn-Afrikaans, HAUM, Cape Town.

Serame, N.J., Oosthuizen, I.J., Wolhuter, C.C. \& Zulu, C.B., 2013, 'An investigation into the disciplinary methods used by teachers in a secondary township school in South Africa', Koers: Bulletin for Christian Scholarship 78(3), 65-70. https://doi.org/10.4102/koers.v78i3.450

Shen, S., Wang, J. \& Zhang, R., 2015, 'Student discipline in China', in C.J. Russo, I.J. Oosthuizen \& C.C. Wolhuter (eds.), International perspectives on student behaviour, pp. 21-35, Rowman and Littlefield, London.

Smit, M.H. \& Rossouw, J.P., 2015, 'Student discipline from authoritarian apartheid to constitutionalism: South Africa as a society in transition', in C.J. Russo, I.J. Oosthuizen \& C.C. Wolhuter (eds.), International perspectives on student behaviour, pp. 63-89, Rowman and Littlefield, London.

South Africa, 1996, Constitution of the Republic of South Africa, Government Printer, Pretoria.

South Africa, 2012, 'Department of Higher Education and Training', Green paper on post-school education and training, Government Printer, Pretoria.

South Africa, 2013, 'Department of Higher Education and Training', White paper on post-school education and training, Government Printer, Pretoria. 
Squelch, J., 2015, 'School discipline and the law in Australia', in J. Russo Charles, I.J. Oosthuizen \& C.C. Wolhuter (eds.), Global interest in student behaviour, pp. 7-28, Rowman and Littlefield, London.

Teh, M.K., 2015, 'The changing shape of misdemeanour in Singapore schools', in J. Charles, I.J. Oosthuizen \& C.C. Wolhuter (eds.), Global interest in student behaviour, pp. 51-67, Rowman and Littlefield, London.

Tie, F.H., 2015, 'The law regulating student discipline in Malaysia', in C.J. Russo, I.J. Oosthuizen \& C.C. Wolhuter (eds.), International perspectives on student behaviour, pp. 35-50, Rowman and Littlefield, London.

Van der Bijl, A. \& Lawrence, M., 2016, 'The theory and practice of vocational teaching', in C. Okeke, J. Abongdia, E. Olusola Adu, M. Van Wyk \& C. Wolhuter (eds.), Learn to teach: A handbook for initial teacher education, pp. 33-50, Oxford University Press, Cape Town.

Walker, P., 2015, 'The United Kingdom - Managing behaviour to optimise learning because "Every child matters", in J. Charles, I.J. Oosthuizen \& C.C. Wolhuter (eds.), Global interest in student behaviour, pp. 69-84, Rowman and Littlefield, London.

West Coast College, 2013, Code of conduct for students, WCC, Malmesbury.

Wolhuter, C.C. \& Van Staden, J.G., 2007, 'Learner misconduct in the Free State, Eastern Cape and Vaal Triangle', in Potchefstroom: Conference Proceedings, Potchefstroom, South Africa, April 02-04, 2007, pp. 54-70.

\section{Chapter 6}

Alexander, K. \& Alexander, M.D., 2005, American public school law, 6th edn., Thompson Learning, Belmont, NC.

Bray, W., 2005, Human rights in education, CELP, Pretoria.

Burns, Y., 1999, Administrative law under the 1996 constitution, Butterworths, Durban.

Davidson, E.R., 2003, 'An analysis of the law concerning due process, and student suspension and expulsion in Georgia public schools', Unpublished doctoral dissertation, University of Georgia.

Department of Basic Education (DBE), 1998, Guidelines for the consideration of governing bodies in adopting a code of conduct for learners, Government Printers, Pretoria.

Department of Basic Education (DBE), 2008, Example of a code of conduct for a school, Department of Education, Pretoria.

Department of Basic Education (DBE), 2016, Revised Personnel Administrative Measures (PAM), Government Printer, Pretoria.

Joubert, R., [2005] 2008, Learner discipline in schools, Centre for Education Law and Education Policy (CELP), Pretoria.

Gilg, D.R., 2010, Know your rights: A guide to the United States Constitution, s.n., s.l. Joubert, R., 2015, 'School discipline', in R. Joubert (ed.), The law of education in South Africa, pp. 117-151, Van Schaik Publishers, Pretoria. 
Leedy, P.D. \& Ormrod, J.E., 2016, Practical research: Planning and design, 10th edn., Pearson Education, New York, NY.

Mbatha, N.F., 2008, 'The perceptions of school governing body with regard to their role of supporting schools in maintaining discipline', Unpublished MEd dissertation, University of Johannesburg.

Mollo, N.T., 2015, 'Principals' understanding and implementation of due process during learner discipline', Unpublished thesis, University of Pretoria.

Nieuwenhuis, J., 2016, 'Qualitative research designs and data-gathering techniques', in K. Maree (ed.), First steps in research, pp. 71-102, Van Schaik, Pretoria.

Oosthuizen, I.J. \& De Wet, A., 2016, 'International law, legislation and common law as sources of education', in I.J. Oosthuizen (ed.), Introduction to education law, 3rd edn., pp. 69-85, Van Schaik Publishers, Pretoria.

Oosthuizen, I.J., Smit, M.H. \& Roos, M.C., 2015, 'Education and learner discipline', in I.J. Oosthuizen (ed.), Aspects of education law. Second impression, pp. 179-209, Van Schaik Publishers, Pretoria.

Orth, J.V., 2003, Due process of law: A brief history, University Press of Kansas, Lawrence, KS.

Patterson, L.B., 1976, The principal, the student and the law: A prosecuting attorney's view, National Association of Secondary School Principals, Washington DC.

Republic of South Africa, 1996a, Constitution of the Republic of South Africa, Government Printers, Pretoria.

Republic of South Africa, 1996b, South Africa Schools Act 84 of 1996, Government Printers, Pretoria.

Republic of South Africa, 2002, Regulation of interception of communications and provision of communication-related information act, Government Printers, Pretoria.

Roos, M.C. \& Oosthuizen, I.J., 2003, 'Common law', in I.J. Oosthuizen (ed.), Aspects of education law, 3rd edn., pp. 49-62, Van Schaik, Pretoria.

Rossow, L.F. \& Warner, L.S., 2000, The principalship: Dimensions in instructional leadership, 2nd edn., Carolina Academic Press, Durham, NC.

Russo, C.J., 2001, The yearbook of education law 2001, Education Law Association, Cleveland, $\mathrm{OH}$.

Schimmel, D., Fischer, L. \& Stellman, L.S., 2008, School law: What every educator should know - A user-friendly guide, Pearson/Allyn and Bacon, Boston, MA.

Serakwane, J.M., 2007, 'Establishing discipline in the contemporary classroom', Unpublished dissertation, University of Pretoria.

Sharp, S. \& Tompson, D., 1994, 'The role of the whole-school policies in tackling bullying behaviour in schools', in P.K. Smith \& S. Sharp (eds.), School bullying, pp. 1-5, Routledge, New York, NY.

Shauer, F.F., 1976, 'English natural justice and American due process: An analytical comparison', William and Mary Law Review 18(1), 47-72.

Sivagnanam, T.S., 2009, Principles of natural justice, Tamil Nadu State Judicial Academy, Chennai. 
Smith, A., Beckmann, J. \& Mampane, S., 2015, 'Experiences and challenges of evidence leaders ("Prosecutors") in learner disciplinary hearings in public schools', PER: Potchefstroomse Elektroniese Regsblad 18(6), 2365-2403. https://doi.org/10.4314/pelj.v18i6.10

South African Concise Oxford Dictionary, 2006, Oxford University Press Southern Africa, Dictionary Unit for South African English, Rhodes University, Grahamstown.

Squelch, J.M., 2000, Discipline, Centre for Education Law and Education Policy (CELP), Pretoria.

Struwig, F.W. \& Stead, G.B., 2001, Planning, designing and reporting research, Maskew Miller Longman, Cape Town.

Terre Blanche, M., Durrheim, K. \& Painter, D., 2006, Research in practice: Applied methods for the social sciences, University of Cape Town Press, Cape Town.

\section{Court cases and South African law reports}

Afrox Ltd v Laka and Others (1999, 20 ILJ 1732).

Antonie $v$ Governing Body, the Settlers High School and Head, Western Cape Education Department 2002 (4) SA 738 (WC).

Governing Body, Tafelberg School v Head, Western Cape Education Department 20001 SA 1209 (C).

Kroon, J., 1999, Phillips v Manser [1999] 1 All SA 198 (SE).

Michiel Josias de Kock $v$ the Head of Education and Other, Province of Western, heard in the Supreme Court of South Africa (Cape of Good Hope Provincial Division). Case No. 12533/98.

Moloko v Commissioner Diale and Others (2004 25 ILJ 1067)

Mose $v$ Minister of Education in the Provincial Government of the Western Cape: Gabru (13018/08) [2008] ZAWCHC 56; 2009 (2) SA 408 (C) (13 October 2008).

High School Vryburg and the SGB of the High School Vryburg $v$ The Department of Education of the North West Province

Phillips v Manser and another (1999) 1 All SA 198 (SE)

S v Baleka (January 2005, Contemporary Labour Law) Vol.14 No.6, 57

Shabaan Bin Hussien and Others $v$ Chong Kam and another [1969] 3 All ER 1627(PC).

\section{Chapter 7}

Department of Basic Education (DBE), 2010, South African country report: Progress on the implementation of the Regional Education and Training Plan (2011) at 18-19, Government Printer, Pretoria.

Department of Education (DoE), 1998, Guidelines for the consideration of governing bodies in adopting a code of conduct for learners. Government Notice 776, Government Gazette 18900, Government Printer, Pretoria. 
Fourie, C., 2006, 'Onderwysers verlaat beroep in strepe; krisis dreig', Rapport, 27 May, p. 8.

Leedy, P.D. \& Ormrod, J.E., 2005, Practical research: Planning and design, International edn., Pearson Educational International, Upper Saddle, NJ.

Mabeda, M.Z. \& Prinsloo, E., 2000, 'Perceptions of discipline and ensuing problems in secondary education', South African Journal of Education 20(1), 34-41.

Maree, K., Creswell, J.W., Ebersöhn, L., Eloff, I, Ferreira, R., Ivankova, N.V. et al., 2009, First steps in research, Van Schaik Publishers, Pretoria.

Mcmillan, J.H. \& Schumacher, S., 2014, Research in education: Evidence-based inquiry, Pearson Education, Harlow.

Merriam, S., 2008, 'Qualitative research methods workshop manual', Manual for training workshop held at North-West University, Potchefstroom Campus, 09-19th June.

Morrell, R., 2001, 'Corporal punishment in South African schools: A neglected explanation for its persistence', South African Journal of Education 21(4), 292-299. https://doi.org/10.1177/1097184X01004002003

Nthite, T., 2006, 'School violence is a threat to SA's future', The Star, 22 November, p. 3.

Oosthuizen, I.J., 2006, Preliminary report on learner discipline in the Southern Region, North-West Department of Education, s.l.

Oosthuizen, I.J. (ed.), 2015, Aspects of education law, 4th edn., Van Schaik Publishers, Pretoria.

Republic of South Africa, 1996a, South African Schools Act 84 of 1996, Government Printer, Pretoria.

Republic of South Africa, 1996b, Guidelines for a code of conduct for learners, Schedule 1 to the South African Schools Act, Government Printer, Pretoria.

Republic of South Africa, 2012, North West Extraordinary Provincial Gazette, viewed n.d., from https://www.google.com/url?sa=t\&rct=j\&q=\&esrc=s\&s ource $=$ web \&cd $=3 \& c a d=r j a \& u a c t=8 \& v e d=2$ ahUKEwj5p 8 adp 4 LIAhUkWhU IHfpjC78QFjACegQIAxAC\&url=https\%3A\%2F\%2Farchive.opengazettes. org.za\%2Farchive\%2FZA-NW\%2F2012\%2Fprovincial-gazette-ZA-NW-vol255-no-7014-dated-2012-07-05.pdf\&usg=AOvVaw3ysXBOpzg9wPbjOKiS g1CD.

Samuel, G., 2003, Epistemology and method in law, Ashgate Publishing Limited, Aldershot.

Smit, M.H., 2008, 'A model for improving democratic school governance in South Africa', PhD thesis, North-West University, Potchefstroom.

South African Human Rights Commission (SAHRC), 2008, Report of the public hearing on school-based violence, SAHRC, Pretoria.

Taylor, N., 2011, Priorities for addressing priorities for addressing South Africa's education and training crisis - A review commissioned by the National Planning Commission, pp. 1-67, JET Education Services, Cape Town.

Van Wyk, N., 2001, 'Perceptions and practices of discipline in urban black schools in South Africa', South African Journal of Education 21(3), 195-201. 
Wolhuter, C.C. \& Van Staden, J.G., 2008, 'Bestaan daar 'n discipline krisis binne Suid-Afrikaanse skole? Belewenis van opvoeders [ls there a discipline crisis within South African schools? Experience of educators]', Tydskrif vir Geesteswetenskappe 48(3), 395.

\section{Case Law:}

Botha $v$ Gengold Ltd [1996] 4 BLLR 441 (IC).

De Kock NO v Departementshoof van Onderwys, Provinsie Wes-Kaap en andere. Unreprted Case no. 12533/98 (CP).

Governing Body, Tafelberg School v Head, Western Cape Education Department 2000 (1) SA 1209 (C).

Le Monde Luggage CC t/a Pakwells Petje v Dunn NO \& others, (2007) 28 ILJ 2238 (LAC).

Le Roux \& others vDey (Freedom of Expression Institute\& another as amici curiae) [2011] JOL 27031 (CC)

Mose $v$ Minister of Education, in the Provincial Government of the Western Cape and others. Unreported Case no. 13018/08 (C).

Herholdt $v$ Nedbank Ltd (2012) 33 ILJ 1789 (LAC).

Phillips $v$ Manser and another [1999] 1 All SA 198 (SE).

Pearson High School $v$ Head of the Department Eastern Cape Province and others. 1999 JOL 5517 (Ck).

Queens College Boys High School v Member of the Executive Council, Department of Education, Eastern Cape Government 2008 JDR 1289 (E).

Seakamela and Magalies Water (2014) 35 ILJ 1132 (CCMA)

Sidumo \& another $v$ Rustenburg Platinum Mines Ltd \& others (2007) 28 ILJ 2405 (CC)

Tshona v Principal, Victoria Girls High School and Others 2007 (5) SA 66 (EC)

Van Biljon v Crawford, Grey Boys High an others. Case no. 475/2007 (SEC)

Western Cape Residents Association obo Williams v Parow High School (2006)(3) SA 542 (C)

Zeelie $v$ Price Forbes (Northern Province) (1)22 (LC)

\section{Chapter 8}

Aboluwodi, J., 2015, 'Teaching resources utilization and academic performance in Technical Colleges in Oyo State, Nigeria', Kampala International University Research Digest 1(2), 109-116.

Adler, A., 1969, Understanding human nature, Faber \& Faber, New York, NY.

Ansbacher, H.L. \& Ansbacher, R.R., 1956, The individual psychology of Alfred Adler: A systematic presentation in selections from his writings, Basic Books, New York, NY. 
Assali, M.A., 2015, Developing positive discipline in Iraq: Positive discipline strategy implementation guidelines, 2nd draft, consultation workshop, 19-2Oth December, Al Rachid Hotel, Bagdad

Creswell, J.W., 2009, Research design. Qualitative, quantitative and mixed methods approaches, 3rd edn., Sage, London.

Creswell, J.W., 2014, Research design. Qualitative, quantitative and mixed methods approaches, 4th edn., Sage, Thousand Oaks, CA.

Erdogan, M., Kursun, E. \& Sisman, G.T., 2010, 'A qualitative study on classroom discipline problems, reasons and solutions: A case of information technologies class', Educational Sciences: Theory and Practice 10(2), 881-891.

Foucault, M., 1979, Discipline and punish. Birth of the prison, Vintage Books, New York, NY.

Gamble, J., 2003, Curriculum responsiveness in FET colleges, HSRC Press, Cape Town.

Gfoerer, K., Nelsen, J. \& Kern, R.M., 2013, 'Positive discipline: Helping children develop belonging and coping resources using individual psychology', The Journal for Individual Psychology 69(4), 294-303.

Gravett, S., 2005, Adult learning: Designing and implementing learning events: A dialogical approach, Van Schaik, Johannesburg.

Haasbroek, J.B. \& Venter, B.A., 1971, Koördinasie of nasionale grondslag van leerplanne, kursusse en eksamenstandaarde en navorsing, ondersoek en beplanning op die gebied van die onderwys, HSRC Press, Pretoria.

Kleyn, D. \& Viljoen, F., 2012, Beginnergids vir Regstudente, Juta \& Kie, Claremont.

Leedy, P.D. \& Ormrod, J.E., 2010, Practical research planning and design, Pearson, Boston, MA.

Lucas, B., Spencer, E. \& Claxton, G., 2012, How to teach vocational education: A theory of vocational pedagogy, City \& Guilds, London.

Marshall, C., 2017, 'Montessori education: A review of the evidence base', npj Science of Learning 2(10), 11. https://doi.org/1038/s41539-017-0012-7

McMillan, J.H. \& Schumacher, S., 2014, Research in education, Pearson, Boston, MA.

Meyer, W.F., Moore, C. \& Viljoen, H.G., 1994, Personality theories: From Freud to Frankl, Lexicon Publishers, Johannesburg.

Mwamwenda, T., 2004, Educational psychology: An African perspective, Heinemann, Sandton.

Nelsen, J., 1999, Positive time-out: And over 50 ways to avoid power struggles in the home and the classroom, Three Rivers Press, New York, NY.

Oosthuizen, I.J., 2015, 'The essence of education law', in I.J. Oosthuizen (ed.), Aspects of education law, 4th edn., pp. 3-12, Van Schaik, Pretoria.

Oxford Dictionary, 2006, Oxford University Press, Oxford.

Pienaar, G.E., 2011, 'Creating a learning environment conducive to the effective mediation of learning', in M.M. Nieman \& R.B. Monyai (eds.), The educator as mediator of learning, pp. 159-174, Van Schaik, Pretoria. 
Pietersen, J. \& Maree, K., 2014a, 'Standardisation of a questionnaire', in K. Maree (ed.), First steps in research, Ch. 13, Van Schaik, Pretoria.

Pietersen, J. \& Maree, K., 2014b, 'Statistical analysis II: Inferential statistics. Standardisation of a questionnaire', in K. Maree (ed.), First steps in research, pp. 270-290, Van Schaik, Pretoria.

Republic of South Africa, 1998, Guidelines for the consideration of governing bodies in adopting a code of conduct, Government Gazette No. 18900, Government Printer, Pretoria.

Republic of South Africa, 2016, Approval to conduct research in public colleges, Government Gazette, 8 January 2016, No. 39583, Government Printer, Pretoria.

Sackey, E., Amaniompong, K. \& Abrokwa, J.E., 2016, 'Analysis of the state of discipline in Kwinanyarko Senior High School in the Central Region of Ghana', Journal of Education and Practice 7(6), 124-139.

Schacter, R., 2010, 'Discipline gets the boot', District Administration 6(1), 27-32.

Shah, N. \& McNeil, M., 2013, 'Discipline policies squeezed as views on what works', Education Week 32(16), 4-11.

Smit, M.H. \& Rossouw, J.P., 2015, 'Student discipline from authoritarian apartheid to constitutionalism: South Africa as a society in transition', in C.J. Russo, I.J. Oosthuizen \& C.C. Wolhuter (eds.), International perspectives on student behaviour, pp. 63-89, Rowman and Littlefield, London.

Sprick, R.S., 2013, Discipline in the secondary classroom: A positive approach to behaviour management, Josey-Bass Publishers, San Francisco, CA.

United Nations International Children's Emergency Fund (UNICEF), 2008, Fact sheet UNICEF Malaysia Communications, Oct 2008, Positive discipline negative punishment and its effects, UNICEF Malaysia Communications, Putrujaya.

United States Department of Education (USDE), 2014, Guiding princip/es: A source for improving school climate and discipline, US Department of Education, Washington DC.

Vakalisa, N.C.G., 2012, 'Classroom management', in M. Jacobs (ed.), Teachinglearning dynamics, 4th edn., pp. 336-364, Pearson, Cape Town.

Van der Bijl, A. \& Lawrence, M., 2016, 'The theory and practice of vocational teaching', in C. Okeke, J. Abongdia, E. Olusola Adu, M. Van Wyk \& C. Wolhuter (eds.), Learn to teach: A handbook for initial teacher education, pp. 342-344, Oxford University Press, Cape Town.

Veriava, F., Thom, A. \& Hogson, T.F., 2017, Basic education rights handbook education rights in South Africa, Section 27, Johannesburg.

Vine, W.E., 1985, Vine's expository dictionary, Thomas Nelson Publishers, New York, NY.

Wachtel, T., 2012, A shift away from zero tolerance will improve schoo/discipline, viewed n.d., from https://www.csmonitor.com/Commentary/Opinion/2012/0927/Ashift-away-from-zero-tolerance-will-improve-school-discipline

Whisman, A. \& Chapman, D., 2012, Improving school discipline data collection and reporting: 2012-2013, West Virginia Department of Education, Charleston, SC. 


\section{Chapter 9}

Andrews, P., 2013, 'Finnish Mathematics teaching from a reform perspective: A video-based case-study analysis', Comparative Education Review 57(2), 189-211. http://www.jstor.org/stable/10.1086/669124.

Arnesen, T., Elstad, E. \& Christopherson, K.A., 2017, 'Comparing instructional factors related to students' academic self-discipline in Norway and Finland', Nordic Journal of Comparative and International Education 1(1), 18-35. https:// doi.org/10.7577/njcie.2111

Bloch, G., 2009, The toxic mix: What is wrong with South African schools and how to fix it, Tafelberg, Cape Town.

Dake, J.A., Price, J.H. \& Telljohann, S.K., 2003, 'The nature and extent of bullying at school', Journal of School Health 73(5), 173-180. https://doi. org/10.1111/j.1746-1561.2003.tb03599

De Clercq, F., 2013, 'Professionalism in South African education: The challenge of developing teachers' professional knowledge, practice, identity and voice', Journal of Education 57, 31-54.

De Klerk-Luttig, J. \& Heystek J., 2007, 'Discipline in schools: Are our student teachers ready for the challenge?', in Proceedings of Perspectives on learner conduct: First International Conference on Learner Discipline, Potchefstroom, South Africa, April 02-04, 2007, pp. 1-13.

Department of Education and Science and The Welsh Office (United Kingdom), 1989, Discipline in schools: Report of the Committee of Inquiry chaired by Lord Elton, HMSO, London.

Department of Higher Education (DHET), 2011, National qualifications framework (67/2008): Policy on minimum requirements for teacher education qualifications, Government Gazette, no. 34467, Government Printer, Pretoria.

Doyle, W., 2016, 'Why Finland has the best schools', London Times, viewed 28 December 2018, from http://www.latimes.com/opinion/op-ed/la-oe-0318doyle-finnish-schools-20160318-story.html.

Duggan, S.P., 1916, A student's textbook in the history of education, Appleton, New York, NY.

Du Preez, M., 2018, 'Cyril's choice: Populism or the South African Economy', News24, viewed 21 December 2018, from https://www.news24.com/ Columnists/MaxduPreez/cyrils-choice-populism-or-the-south-africaneconomy-20180109.

Durrant, J.E., n.d., Positive teaching in everyday teaching, viewed 28 December 2018, from https://resourcecentre.savethechildren.net/sites/default/files/ documents/4802.pdf.

Eloff, C., Oosthuizen, I.J., Wolhuter, C.C. \& Van der Walt, J.L., 2013, 'Bydraende Faktore tot Leerderdissipline: 'n MultiveranderlikeAnalise', Koers 78(3), n.p. http://www.koersjournal.org.za/index.php/koers/issue/view/314 
Finland (Ministry of Education), 2008, PISA 2006: Analyses, reflections, explanations, Ministry of Education, Helsinki.

Finland (Ministry of Education), 2013, Finnish education in a nutshell, Ministry of Education, Helsinki.

Harris-van-Keurder, C., 2010, 'Influencing the status of teaching in Central Asia', in I. Silova (ed.), Globalization on the margins: Education and post-socialist transformations in Central Asia, pp. 121-139, Palgrave, London.

Hilden, R. \& Kantelinen, R., 2012, 'Language education - Foreign languages', in H. Niemi, A. Toom \& A. Kallioniemi (eds.), Miracle of education: The principles and practices of teaching and learning in Finnish schools, pp. 48-63, Sense Publishers, Dordrecht.

Ignatova, E., 2005, 'Ethnicity and educational policies in Bulgaria', in N. Genov (ed.), Ethnicity and educational policies in South Eastern Europe, pp. 32-46, Friedrich Ebert Stiftung, Berlin.

Kumpulainen, K. \& Lankinen, T., 2012, 'Striving for educational equity and excellence', in H. Niemi, A. Toom \& A. Kallioniemi (eds.), Miracle of education: The principles and practices of teaching and learning in Finnish schools, pp. 69-81, Sense Publishers, Dordrecht.

Kunter, M., Baumert, J., Blum, W., Klussman, U., Krauss, S. \& Neubrand, N., 2011, Professionelle Kompetenz der Lehrkräften: Ergebnisse des Forschungsprogramms COACTIV, Waxmann, Münster.

Kupari, P., Reinikainen, P. \& Törnroos, J., 2007, 'Finnish students' Mathematics and Science results in recent assessment studies: PISA and TIMSS', in E. Pehkonen, M. Ahtee \& J. Lavonen (eds.), How Finns learn Mathematics and Science, pp. 11-34, Sense Publishers, Rotterdam.

Lehtinen, E., 2004, Education system in the changing Finnish society, Sitra, Helsinki.

Lloyd, G., 1999, 'Two teachers' conceptions of a reform-orientated curriculum: Implications for Mathematics teacher development', Journal of Mathematics Teacher Education 2(3), 227-252. https://doi.org/10.1023/A:1009965804662

Lusenga, R.M., 2010, 'School leaders' moral understanding and moral reasoning', Unpublished dissertation, University of Pretoria.

MacDonald, C. \& Burroughs, E., 1990, Eager to talk and learn to think bilingual primary education in South Africa, Maskew Miller, Longman, Cape Town.

Mantila, H. \& Sulkala, H., 2010, Planning a new standard language: Finnish minority languages meet the new millennium, Finnish Literature Society, Helsinki.

Max Planck Institute, 2002, PISA 2000: Overview of the study: Design, methods and results, viewed 24 November 2013, from http://www.mpih_berlin.mpg. de/PISA_2000_Overview.pdf.

Meyer, H.-D. \& Benavot, A., 2013, PISA, power and policy: The emergence of global educational governance, Symposium, London. 
National Centre of Education Statistics (United States of America), 2002, 'Violence and discipline problems in U.S. public schools: 1996-1997', in EBSCOhost: Academic search Elite, viewed 23 April 2002, from http://www. sa.ebsco.com.

Nelsen, J., n.d., What is positive discipline?, viewed 25 December 2018, from https://www.positivediscipline.com/sites/default/files/what-is-positivediscipline.pdf.

Niemi, H., 2010, 'Teachers as high level professionals - What does it mean in teacher education? Perspectives from the Finnish teacher education', in K.G. Karras \& C.C. Wolhuter (eds.), International handbook of teacher education worldwide, pp. 255-268, Atrapos, Athens.

Niemi, H., 2012, 'The societal factors contributing to education and schooling in Finland', in H. Niemi, A. Toom \& A. Kallioniemi (eds.), Miracle of education: The principles and practices of teaching and learning in Finnish schools, pp. 21-39, Sense Publishers, Dordrecht.

Nolan, A., 2009, 'The spiritual life of the intellectual', in W. Gumede \& L. Dikeni (eds.), The poverty of ideas. South African democracy and the retreat of intellectuals, pp. 46-54, Jacana, Auckland Park.

Odendaal, N., 2017, 'South African policy uncertainty pushed further into negative territory', Creamer Media's Engineering News, viewed 21 December 2018, from http://www.engineeringnews.co.za/article/south-africas-policy-uncertaintypushed-further-into-negative-territory-2017-07-17.

OECD, 2004, 2003 Final results from PISA, viewed 25 November 2013, from http:// www.oecd.org.education/school/programmeforinternationalstudentassess mentpisa/34002454.pdf.

OECD, 2010, PISA 2009 results. Executive summary, viewed 26 November 2013, from http://www.oecd/PISA2009database.

OECD, 2013, PISA 2012 results in focus: What 15 year olds know and what they can do with what they know, viewed 11 December 2013, from http://www.oecd. org/pisa/keyfindings/pisa-2012-results.htm.

Oosthuizen, I.J., Wolhuter, C.C. \& Du Toit, P., 2003, 'Voorkomende of BestraffendeMaatreëls in Suid-AfrikaanseSkole: WatterBenadering Moet VoorkeurGeniet? [Preventative or Punitive Measures in South African Schools: Which Approach Should Be Preferred?]', Koers 68(4), 457-479. https://doi. org/10.4102/koers.v68i4.352

Pehkonen, E., 2007, 'Setting the landscape', in E. Pehkonen, M. Ahtee \& J. Lavonen (eds.), How Finns learn Mathematics and Science, pp. 3-7, Sense Publishers, Rotterdam.

Pehkonen, E., Ahtee, M. \& Lavonen, J., 2007, 'Introduction: Setting the landscape', in E. Pehkonen, M. Ahtee \& J. Lavonen (eds.), How Finns learn Mathematics and Science, pp. 1-10, Sense Publishers, Rotterdam.

Pehkonen, L. \& Krzywacki-Vainio, H., 2007, 'Mathematics teaching in primary schools', in E. Pehkonen, M. Ahtee \& J. Lavonen (eds.), How Finns learn Mathematics and Science, pp. 155-164, Sense Publishers, Rotterdam. 
Pellengrini, A.D., Bartini, M. \& Brooks, F., 1999, 'School bullies, victims, and aggressive victims: Factors relating to group affiliation and victimization in early adolescence', Journal of Educational Psychology 91(2), 216-224. https:// doi.org/10.1037/0022-0663.91.2.216

PISA, 2007, Naturwissenschaftliche Kompetenzenfür die Welt von Morgen: Kurzzusammenfassung, viewed 26 November 2013, from http://www. org/f1/education/scolaire/programmeinternationalpourlesuivideqcquis desdevespira/pisa3006verabs.htm.

Rademeyer, A., 2013, 'Stelsel Moet Onnies Inhok', Beeld, 14 February, p. 1.

Reinikainen, P., 2012, 'Amazing PISA results in Finnish comprehensive schools', in H. Niemi, A. Toom \& A. Kallioniemi (eds.), Miracle of education: The principles and practices of teaching and learning in Finnish schools, pp. 3-18, Sense Publishers, Dordrecht.

Sahlberg, P., 2010, Finnish lessons: What can the world learn from educational change in Finland? Teachers College Press, Amsterdam.

Silova, I. \& Kazimzade, E., 2010, 'The changing status of the teaching profession in post-soviet Azerbaijan: Implications for teacher education', in K.G. Karras \& C.C. Wolhuter (eds.), International handbook of teacher education worldwide, pp. 55-72, Atrapos, Athens.

Statistics Finland, 2011, Population structure, viewed 21 January 2014, from http:// www.stat.fi/til/vaerak/2010_2014-01-20_tie_001_en.html.

Thompson, M., 2018, Ethics for life, John Murray Learning, London.

UNESCO, 2014, UNESCO statistical yearbook 2014, UNESCO, Paris.

Van der Walt, J.L., Potgieter, F.J. \& Wolhuter, C.C., 2009, 'Addressing the discipline problem in South African schools by increasing the supply of social capital in society: A position paper', Journal of Educational Studies 8(1), 47-59.

Van der Walt, J.L., Potgieter, F.J. \& Wolhuter, C.C., 2010a, 'Positiewe Dissipline in die Hande van die Opvoeder [Positive Discipline in the Hands of the Educator]', Tydskrifvir Christelike Wetenskap 46(1), 145-168.

Van der Walt, J.L., Potgieter, F.J., Wolhuter, C.C., Higgs, P., Ntshoe, I. \& Higgs, L., 2010b, 'Teacher educators in South Africa: Something amiss with their performance?', Journal of Education 50, 197-222.

Van der Westhuizen, P.C., Oosthuizen, I.J. \& Wolhuter, C.C., 2008, 'The relationship between an effective organizational culture and student discipline in a boarding school', Education and Urban Society 40(2), 205-225. https://doi. org/10.1177/0013124507303992

Vitikka, E., Krokfors, L. \& Hurmerinta, E., 2012, 'The Finnish national core curriculum: Structure and development', in H. Niemi, A. Toom \& A. Kallioniemi (eds.), Miracle of education: The principles and practices of teaching and learning in Finnish schools, pp. 3-19, Sense Publishers, Dordrecht.

Wiseman, A.W., 2012, 'A framework for understanding international perspectives on education', in N. Popov, C.C. Wolhuter, B. Leutwyler, G. Hilton, J. Ogunleye \& 
P.A. Almeida (eds.), International perspectives on education, BCES conference books, vol. 10, pp. 1-21, Bulgarian Comparative Education Society, Sofia.

Wolhuter, C.C., 1997, 'Classification of national education systems: A multivariate approach', Comparative Education Review 41(2), 161-179. https://doi. org/10.1086/447428

Wolhuter, C.C., 2011, 'The education system of South Africa', in P.L. Schneller \& C.C. Wolhuter (eds.), Navigating the C's: Creativity, care, compassion, character, cosmopolitanism, contribution and critical awareness: An introduction to comparative education for the 21st century, pp. 69-88, Keurkopie, Noordbrug.

Wolhuter, C.C., Oosthuizen, I.J. \& Van Staden, J.G., 2010, 'Skoolfase/ Leerderouderdom as Faktor in Leerderdissipline in Suid-AfrikaanseSkole', Tydskrif vir Christelike Wetenskap 46(1), 169-186.

Wolhuter, C.C. \& Van der Walt, J.L., 2019, 'Indiscipline in schools: The parental/ community factor', Koers, Forthcoming.

Wolhuter, C.C., Van Jaarsveld, L. \& Challens, B., 2018, 'Die Oorkoming van Kontekstuele Beperkinge deur Leierskap aan Toppresterende Skole', Litnet Akademies, viewed n.d., from https://www.litnet.co.za/die-oorkoming-vankontekstuele-beperkinge-deur-leierskap-aan-toppresterende-skole.

Wolhuter, C.C. \& Van Staden, J.G., 2008, 'Bestaandaar ' $n$ dissiplinekrisis in Suid-Afrikaanseskole? Belewenis van opvoeders [Do you have a discipline crisis in South African schools? Experience of educators]', Tydskrif vir Geesteswetenskappe 48(3), 389-398.

World Bank, 2002, Constructing knowledge societies: New challenges for tertiary education, viewed 12 December 2013, from http://siteresources.worldbank.org/ INTAFRREGTOPTEIA/Resources/Constructing_Knowledge_Societies.pdf.

World Bank, 2013, World development indicators, viewed 12 December 2013, from http://data.worldbank.org/data-catalog/world-development-indicators.

\section{Chapter 10}

Andresen, E. \& Van der Walt, J.L., 2018, 'The impact of neoliberalism on TVET in England', in M. Carmo (ed.), Education applications and developments III, pp. 111-122, InSciencePress, Lisbon.

Balsvik, R.R., 1998, 'Student protest - University and State in Africa', Forum for Development Studies 1978(2): 301-325. https://doi.org/10.1080/08039410.19 98.9666087

Brenner, N., 2004, New state spaces: Urban governance and the rescaling of statehood, Oxford University Press, Oxford.

Buys, F., 2016, 'Die Nuwe Weste [The New West]', Beeld, 12 November, p. 22.

Carson, D.A., 2012, The intolerance of tolerance, Eerdmans, Grand Rapids, MI.

Cele, G. \& Koen, G., 2003, 'Student politics in South Africa. An overview of key developments', Cahiers de la Recherche sur l-éducation et les Savoirs 2, 201-223. 
Cunningham, J., 2013, 'Paris exiled: Herbert Marcuse and the One-Dimensional University', Journal of Philosophy of Education 47(4), 537-547. https://doi. org/10.1111/1467-9752.12037

Davidson, J.D. \& Rees-Mogg, W., 1992, The Great Reckoning: How the world will change in the depression of the 1990s, Sidgwick \& Jackson, London.

Duggan, S.P., 1916, A student's textbook of history of education, Appleton, New York, NY.

Du Plessis, T., 2016, 'Wit Mense, nie Zuma, is Malema se Teiken [Whites, not Zuma, is Malema's Target]', Rapport Weekliks, 13 November, p. 6.

European Union, 2016, Charter of fundamental rights of the European Union, viewed 31 October 2016, from http://www.europarl.europa.eu/charter/pdf/ text_en.pdf.

Excellencia in Education, 2014, Black + Brown: Institutions of higher education, viewed 11 November 2016, from http://files.eric.ed.gov/fulltext/ED562065. pdf.

Fredua-Kwarteng, E., 2016, 'Ethics and the developmental university', University World News, viewed 26 September 2019, from https://www. universityworldnews.com/post.php?story=20160923113239206.

Gaviria, P., 2012, 'Indigenous rights and advanced capitalism in community colleges: The case of Nunavut Arctic College', in A.W. Wiseman, A. Chase-Mayoral, T. Janis \& A. Sachdev (eds.), Community colleges worldwide: Investigating the global phenomenon (International Perspectives on Education and Society, Volume 17), pp. 99-128, Emerald Group Publishing Limited, London.

Guaghan, A.J., 2016, 'Five things that explain Donald Trump's stunning presidential election victory', Mail \& Guardian, viewed 18 November 2018, from https:// www.mg.co.za/article/2016-11-09-five-things-that-explain-donald-trumpsstunning-presidential-election-victory.

Habermas, J. \& Blazek, J.R., 1987, 'The idea of the university: Learning processes', New German Critique 41, 3-22. https://doi.org/10.2307/488273

Holzapfel, J., 2016, 'Revolusie van die Eensames [Revolt of the Lonely]', Rapport Weekliks, viewed 09 November 2016, from http://www.universityworldnews. com/article.php?story=20160923113239206.

Izevbaye, D., 2008, 'The idea of an African university', Social Dynamics 33(1), 217-222. https://doi.org/10.1080/02533950708628752

Jaspers, K., 1959, The idea of the university, Beacon Press, Boston, MA.

Kwiek, M., 2006, The classical German idea of the university revisited, or the nationalization of the modern institution, viewed 09 November 2016, from http://www.cpp.amu.edu.pl/publications.htm.

Maluleke, T., 2016, 'Macabre politics of university shutdowns', Mail \& Guardian 14-20 October 2016, p. 23.

Marcuse, H., 1964, One-dimensional man: Studies in the ideology of advanced industrial society, Beacon, New York, NY. 
Mojab, S. \& Hall, B., 2003, 'Education of a non-state nation: Reconstructing a university in a war zone of Iraqi Kurdistan', in W. Nelles (ed.), Comparative education, terrorism and human security: From critical pedagogy to peacebuilding? pp. 159-174, Palgrave Macmillan, New York, NY.

Neave, G., 2001, 'The European dimension in higher education: An excursion into the modern use of historical analogues', in J. Huisman, J., Maassen \& G. Neave (eds.), Higher education and the state. The international dimension of higher education, pp. 13-73, Pergamon Press, Amsterdam.

Newman, J.H., [1853] 2009, The idea of a university, Ashfield, Dublin.

Pienaar, H., 2016, 'Trump Sou Tuis Voel by Guptas [Trump would have felt at home with the Guptas]', Rapport Weekliks, 13 November, p. 5.

Potgieter, F.J., 2015, 'Beyond tolerance: Educating for religious respect and hospitality in pedagogic-multilogical sanctuaries', in N. Popov, C.C. Wolhuter, K.S. Ermenc, G. Hilton, G. Ogunleye \& J.E. Niemczyk (eds.), Quality, social justice and accountability in education worldwide, pp. 53-59, Bulgarian Comparative Education Society, Sofia.

Prinsloo, E.H., 2016, 'The role of the humanities in decolonising the academy', Arts and Humanities in Higher Education 15(1), 164-168. https://doi. org/10.1177/1474022215613608

Reddy, V., 2016, 'Varsities must meet labour needs', Weekly Mail \& Guardian, 04-10 November, p. 32.

Redwood, J., 1993, The global marketplace: Capitalism and its future, Harper Collins, London.

Republic of South Africa, 2016, Constitution of the Republic of South Africa, Act 108 of 1996, viewed 01 November 2016, from https://www.ru.ac.za/media/ rhodesuniversity/content/humanresources/documents/employmentequity/ Constitution\%20of\%20the\%20Republic\%20of\%20South\%20Africa\%201.pdf.

RSG (South African Radio Station), Monitor, 17 November.

Schreiber, L., 2016, 'Hierdie wraak kom al van ver [This Vengeance comes from long ago]', Rapport Weekliks, 13 November, pp. 8-9.

Schwartz, S., 2008, 'GLOBAL: What is a university?', University World News - The global window on higher education, viewed 18 September 2009, from http:// www.universityworldnews.com/article.php?story=20080522123642497.

Shenk, T., 2015, 'Booked \#3. What exactly is neoliberalism? (Interview with political scientist Wendy Brown)', Dissent, viewed 03 October 2016, from https:// www.dissent.magazine.org/blog/booked-3-what-exactly-is-neoliberalismwendy-brown-undoing-the-demos.

Tandwa, L., 2016, 'South Africa: \#FeesMustFall costs country R150Million Nzimande', News24 16 January, viewed 14 April 2016, from http://allafrica. com/stories/201601201489.html.

Thompson, M., 2018, Ethics for life, John Murray Learning, London. 
UNESCO, 2016, UNESCO convention on the rights of the child, viewed 31 October 2016, from http://www.unesco.org/education/pdf/CHILD_E.PDF.

United Nations, 2016, Universal declaration on human rights, viewed 31 October 2016, from http://www.un.org/en/universal-declaration-human-rights/.

Van der Walt, J.L., 2003, "n Beginselgrondslag vir Gesag, Vryheid en Orde en Dissipline in die Onderwysopset van die Vroeg Een-en-Twintigste Eeu [A Principal Basis for Authority, Freedom and Order and Discipline in the Education Setup of the Early Twenty-First Century]', Koers 68(4), 331-352. https://doi.org/10.4102/koers.v68i4.346

Van der Walt, J.L., Potgieter, F.J. \& Wolhuter, C.C., 2014, 'Can universities meet their mandate to be socially critical as well as constructive?', South African Journal of Higher Education 28(3), 832-848.

Viljoen, C., 2016, 'Die Trump Tsoenami: Hoe het dit Gebeur? [The Trump tsunami: How did it happen?]', Bee/d, 16 November, p. 21.

Wolhuter, C.C., 1997, 'Desiderata in South African higher education studies' window on the outside world', South African Journal of Higher Education 11(1), 35-40.

Wolhuter, C.C., 2012, "n Wêreldklasuniversiteit in Suid-Afrika: Ideaal, Wenslik, Haalbaar, Werklikheid, Hersenskim? [A world-class university in South Africa: Ideal, Desirable, Attainable, Reality, Brain Scene?]', Litnet Akademies 9(2), 284-308.

Wolhuter, C.C., 2014, 'Research on higher education in South Africa: Stocktaking and assessment from international comparative perspectives', South African Journal of Higher Education 28(1), 275-291. https://doi.org/10.20853/28-1-323

Wolhuter, C.C. \& Mushaandja, J., 2015, 'Contesting ideas of a university: The case of South Africa', Humanities 2015(4), 212-223.

Wolhuter, C.C. \& Van der Walt, J.L., 2019, 'Indiscipline in schools: The parental/ community factor', Koers, Forthcoming.

World Bank, 2009, Accelerating catch-up: Tertiary education for growth in subSaharan Africa, The World Bank, Washington, DC.

World Bank, 2016, World development indicators 2016, The World Bank, Washington, DC.

Yesufu, M.F., 1973, Creating the African university, Oxford University Press, Ibadan.

\section{Chapter 11}

Aboluwodi, A., 2015, 'A critical analysis of retributive punishment as a disciplinary measure in Nigeria's public secondary schools', Journal for Educational and Practice 6(10), 134-142.

Acar, I.H., Evans, M.Y.Q., Rudasill, K.M. \& Ykduz, S., 2018, 'The contributions of relationship with parents and teachers to Turkish children's anti-social behaviour', Educational Psychology: An International Journal of Experimental 
Educational Psychology 38(7), 877-897. https://doi.org/10.1080/01443410.2 018.1441377

Baldwin, T.R., 2005, 'Existentialism', in T. Honderich (ed.), The Oxford companion to philosophy, pp. 277-280, Oxford University Press, Oxford.

Boeree, C.G., 2006, Personality theories: Carl Rogers, Shippensburg University, Shippensburg, PA.

Bower, C., 2005, Open minds, closed minds and Christianity, Aardvark Press, Valyland.

Brand, G., 2011, 'Om hoog en laag by menseregte te sweer', Die Burger, 12 January, p. 8.

Camus, A., [1927] 2008, 'The myth of Sisyphus', in J. Cottingham (ed.), Western philosophy: An anthology, pp. 797-799, Blackwell Publishers, Oxford.

Comte-Sponville, A., 2005, The little book of philosophy, Vintage/Random House, London.

Cramer, K.E., 2002, 'The influence of parenting styles on children's classroom motivation', Unpublished master's dissertation, University of Louisiana.

Daniel, L., 2018, 'Schools in South Africa are becoming more violent', The South African, viewed 29 October 2018, from https://www.thesouthafrican.com/ south-africa-schools-violent-minister-speaks-out.

De Botton, A., 2012, Religion for atheists, Hamish Hamilton, London.

Eloff, C., Oosthuizen, I.J., Wolhuter, C.C. \& Van der Walt, J.L., 2013, 'Bydraende faktore tot leerderdissipline: 'n Multiveranderlike analise [Contributing factors to learner discipline: A multivariate analysis]', Koers 78(3), n.p. http://www. koersjournal.org.za/index.php/koers/issue/view/314.

Frankl, V.E., 1959, Man's search for meaning, Beacon, Boston, MA.

Frankl, V.E., 1965, The doctor and the soul: From psychotherapy to logotherapy, Knopf, New York, NY.

Frankl, V.E., 1978, The unheard cry of meaning, Simon and Schuster, New York, NY.

Gfroerer, K., Nelsen, J. \& Kern, R.M., 2013, 'Positive discipline', The Journal for Individual Psychology 69(4), 294-303.

Gray, J., 2003, Straw dogs. Thoughts on humans and other animals, Granta Books, London.

Harris, D., 2017, What are the causes of classroom discipline problems?, viewed 29 October 2018, from https://classroom.synonym.com/info-7964722causes-classroom-discipline-problems.html.

Heidegger, M., [1927] 2008, 'Being and time', in J. Cottingham (ed.), Western philosophy: An anthology, pp. 115-120, Blackwell Publishers, Oxford.

Kierkegaard, S., [1846] 2008, 'Concluding unscientific postscript', in J. Cottingham (ed.), Western philosophy: An anthology, pp. 376-382, Blackwell Publishers, Oxford. 
Lee, J. \& Kavanaugh, P.R., 2015, 'Discipline, shaming and antisocial attitude in Philadelphia Middle Schools', Sociological Spectrum 35(6), 504-517. https:// doi.org/10.1080/02732173.2015.1064801

Mabuza, E., 2018, A change in values is needed to fight sexual abuse in schools: FEDSAS, viewed 29 October 2018, from https://www.timeslive.co..za/southafrica/2018.03.14-a-change-in-values-is-needed-fedsas.

Maddi, S.R., 1978, 'Existentialism and individual psychology', Journal of Individual Psychology 34(2), 183-189.

Maslow, A., 1970, Motivation and personality, pp. 1-270, Harper, New York, NY.

McBride, W.L., 2005, 'Existentialism', in R. Audi (ed.), The Cambridge dictionary of philosophy, pp. 296-298, Cambridge University Press, Cambridge.

McGrath, A., 2005, The twilight of atheism. The rise and fall of disbelief in the modern world, Rider, London.

Meyer, W.F., 1990, 'Adler's individual psychology', in W.F. Meyer, C. Moore \& H.G. Viljoen (eds.), Personality theories Freud to Frankl, pp. 1-438, Lexicon, Johannesburg.

Mohler, A., 2008, Atheism remix, Crossway Books, Wheaton, IL.

Moore, C., 1990, 'Abraham Maslow's self-actualization theory', in W.F. Meyer, C. Moore \& H.G. Viljoen (eds.), Personality theories Freud to Frankl, pp. 357-372, Lexicon, Johannesburg.

Nation Master, 2019a, Crime statistics, viewed 27 May 2019, from https://www. nationmaster.com/country-info/profiles/south-africa/Crime.

Nation Master, 2019b, Crime statistics compared, viewed 27 May 2019, from https://www.nationmaster.com/compare/hungary/south-africa/Crime.

Nelsen, J., Lott, L. \& Glenn, H.S., 2019, Positive discipline in the school. Classroom teachers' guide activities for students, viewed 29 May 2019, from https:// www.positivediscipline.co/sites/default/files/pdc-teachers-guide-intro.pdf.

Ngwokabuenui, P.Y., 2015, 'Students' indiscipline: Types, causes and possible solutions. The case of secondary schools in Cameroon', Journal of Education and Practice 6(22), 64-72.

O'Grady, J., 2005, 'De Beauvoir, Simone', in T. Honderich (ed.), The Oxford companion to philosophy, pp. 191-192, Oxford University Press, Oxford.

Olthuis, J.H., 2012, 'A vision of and for love: Towards a Christian post-postmodern worldview', Koers 77(1), Art \#28. https://doi.org/10.4102/koersv77i.28.

Oosthuizen, I.J., Rossouw, J.P. \& De Wet, A., 2019, Introduction to Education Law, Van Schaik, Pretoria.

Oosthuizen, L.J., 2018, 'The role of motivation in absenteeism of students at a TVET College in the Western Cape' in M.A. Mokoena (ed.), A scholarly compendium of teaching and learning, pp. 1-390, Ivyline Publishers, Potchefstroom.

Rogers, C.R., 1966, On becoming a person, Constable, London.

Russo, C.J., Oosthuizen, I.J. \& Wolhuter, C.C. (eds.), 2015, International perspectives on student behavior: What we can learn, Lanham, New York, NY. 
Sackey, E., 2016, 'Analysis of the state of discipline in Kwanyarko Senior High School in the central region of Ghana', Journal of Education and Pratice 7(6), 124-139.

Republic of South Africa, 1996, South African Schools Act, 84 of 1996, Government Printers, Pretoria.

Republic of South Africa, 1998, Guidelines for a code of conduct for learners, Government Printers, Pretoria.

Strauss, D.F.M., 2009, Philosophy: Discipline of the disciplines, Paideia Press, Grand Rapids, MI.

Sun, R.C.F., 2015, 'Teacher's experiences of effective strategies for managing class room misbehaviour in Hong Kong', Teaching and Teacher Education 46(2015), 94-103. https://doi.org/10.1016/j.tate.2014.11.005

Taormina, R.J. \& Gao, J.H., 2013, 'Maslow and the hierarchy of needs: Measuring satisfaction needs', American Journal of Psychology 126(2), 155-177. https:// doi.org/10.5406/amerjpsyc.126.2.0155

UNESCO, 2006, Positive discipline in the inclusive, learning-friendly classroom: $A$ guide for teachers and teacher educators, UNESCO, Bangkok.

United State Department of Education (USDE), 2014, Guiding principles: A source for improving school climate and discipline, US Department of Education, Washington, DC.

Van der Walt, B.J., 2007, Transforming power, Institute for Contemporary Christianity in Africa, Potchefstroom.

Van der Walt, J.L., Potgieter, F.J. \& Wolhuter, C.C., 2009, 'Addressing the discipline problem in South African schools by increasing the supply of social capital in society: A position paper', Journal of Educational Studies 8(1), 47-59.

Van Heerden, G., 2018, 'Crime and security', in F. Cronje (ed.), Socio-economic survey of South Africa, n.p., Centre of Risk Analysis, Johannesburg.

Wolhuter, C.C., De Wet, N.C. \& Van der Walt, J.L., 2019, 'The congeniality to sound learner discipline of the Finnish education system: Relevance for approaching learner discipline in South African schools', in C.B. Zulu, I.J. Oosthuizen \& C.C. Wolhuter (eds.), A scholarly inquiry into disciplinary practices in educational institutions, A-B, AOSIS, Durbanville.

Wolhuter, C.C., Oosthuizen, I.J. \& Van Staden, J.G., 2010, 'Skoolfase/ Leerderouderdom as Faktor in Leerderdissipline in Suid-Afrikaanse Skole [School Phase / Learner Age as Factor in Learner Discipline in South African Schools]', Tydskrif vir Christelike Wetenskap 46(1), 169-186.

Wolhuter, C.C., Van Jaarsveld, L. \& Challens, B., 2018, 'Die Oorkoming van Kontekstuele Beperkinge in Leierskap aan Toppresterende Skole [Overcoming Contextual Constraints in Leadership at Top-Performing Schools]', Litnet Akademies 15(3), 866-892. 



\section{Index}

\#

\#DecoloniseOurUniversities, 244-245 \#FeesMustFall, 234, 238, 250, 253

\section{A}

abolishment, 51, 73-74

accept, 133, 151, 153, 271-272

acceptance, 22, 178-179, 281

accessibility, 129, 191, 195

acculturation through education, 16

adjourning, 120, 135, 139

Adler, 175-178, 262, 267-269, 272, 279, 281

administrative justice, 154

advanced education systems, 13 advice, 115, 118, 132, 134, 139, 163

Africa, 1, 3-4, 7, 10-13, 15, 20, 24-25, 27-28, 30, 32, 44-49, 51-52, 61-62, 67, 70, 73, 89-90, 93-95, 113-115, 118-121, 124-125, 127, 130-131, 133, 137, 140-141, 144-145, 154, 162-163, 169, 174, 185, 199-203, 205-206, 221-232, 234, 237-238, 243-245, 247, 249-253, 255-256, 259-260, 263

African, 2-4, 8, 11-12, 15, 21, 27-31, 47-50, 62, 81, 90, 104, 112, 114-115, 121, 139, 143, 145, 147-148, 154, 162, 172, 199-205, 221, 223-227, 229-234, 237-238, 240, 243-245, 248-253, 255-256, 260

age, 8-9, 14, 17, 21-22, 36, 56, 78, 166-167, 174, 192, 212, 235, 238, 244

agency, 9, 266-267

AIDS, 8

alternative disciplinary methods, 68 , 71, 81, 85 alternatives to corporal punishment, $45-50,52,54,56,58-62,64,66$ analogy, 160, 166 anomie and unruliness, 252 anxiety, 272 apartheid education, 4 appeal, 120, 136-137, 160, 177, 249, 256 application, 31, 60, 98, 113-116, 118, $120-122,124,126,128,130,132$, 134, 136-138, 140, 148, 169-170, 172-180, 182, 184-186, 188, 190, 192, 194, 196-198, 206, 252, 256, 264, 271

Aristotle, 262

assessment, 207, 213, 217, 222, 239

assets and resources, 249

at risk, 93, 98

attitude, 37, 51, 63, 104, 156, 270

authentic engagement, 19

authenticity, 275

awareness, 57, 171, 177, 179, 257, 275, 277

\section{B}

banning of corporal punishment, 46, 51-52, 56, 74

behaviour, 7, 9-10, 13, 18-19, 23-25, 28-34, 36-37, 40, 42-44, 50-52, 54-55, 59-61, 64-66, 69, 71-72, 74-77, 82-84, 86, 91-95, 101, 104-112, 115, 118-119, 126-127, $131,139,156,159,167,170-173$, 175-183, 185, 187, 193, 204-206, 219-222, 231, 236, 253, 261, 266-269, 271-272, 275, 277, 281 behaviour management, 52 behavioural consequences, 75-76, 81 Bible, 217, 278

Bill of Human Rights, 201, 235, 238 birth, 238 
black community, 3

Bologna Agreement, 212

Botswana, 67-70, 72-74, 77-80, 85-86

building a positive relationship, 265

Bulgaria, 218-219

bullying, 27-35, 39, 41-44, 70, 81-82, 92-94, 101, 107-109, 111, 115, 127, 191, 201, 221

bullying behaviour, 28-34, 42-44 business, 16-17, 102-103, 110, 175, 222, 248

\section{C}

call for social justice, 230, 232

calling in life, 9

campaigns, 234, 249-250

Camus, 275-276, 281

care, 10, 25-26, 28, 38, 41, 43, 110, $124-125,188,212,238,246$, 256, 266

catch them doing good, 264

causes and complexes of causes and conditions, 10

challenges, 31, 52-53, 57, 70, 90, 142, 180, 191

change, 64-65, 71-72, 83, 150, 204-205, 234, 261, 270

changing behaviour, 72, 75

changing demographics, 14

character, 18, 63, 241

characteristics, 23, 32, 36

charge sheet, 133, 142, 151, 153, 157-159, 161, 165

Charter of Fundamental Rights of the European Union, 237

child, 2, 11, 36, 38, 40, 47-48, 54, 66, 72-75, 118, 131, 133, 140, 151-152, 177, 203-204, 212, 237, 261, 267, 269-270, 278

child's best interest, 118

children, 10-11, 14, 17, 23, 30-31, 33, 37-40, 42-44, 48, 51, 54, 60, 64, 70, 72-77, 82-83, 144, 152, 175-178, 204-205, 213, 219-220, 250, 267

citizen, 246 class size, 203

class sizes, 213, 217

classroom management, 143, 214

climate, 30, 144, 203, 214, 218, 226

code of conduct for learners, 114, $117-118,121,126-127,136,139,154$, 172,263

codes of conduct, 117, 149, 155, 172, 263

coding and categorisation, 57-58

collaboration, 138, 214

colonialism, 244

colonisation, 240

communication, 7, 19-20, 66, 125, 129, 179-180, 188, 190-191, 193, 195, 198, 204-205

community, 3, 15, 17, 21, 23-25, 34, 48, $72,86,153,162,167,179,208$, 210, 215, 236, 240-245, 249, 252-253, 261, 267

Comparative Education, 209

comprehensive school, 211-213, 215-216

comprehensive schooling, 212

compulsory education, 211

compulsory schooling, 208, 212, 222

concept, 4, 9, 114, 122, 181, 241, 260, 265, 271

conceptualisation, 114-115, 117-118, 120, $122,138-140$

conflicting set of ideals, future plans, interests, values and norms, 253

consequences of, $65,71,83,86,126$, 159, 269

consequences of corporal punishment, $65,83,86$

conservative, 17, 246, 250

considering facts, 135-136, 139

constraints, 264, 278

constructive learning, 175, 213

consumerism, 248

content analysis, 68, 79

context, 7, 11, 13, 25, 28-33, 35, 38, 175, 200, 202, 206, 211, 220, 222-223, 226, 229-232, 234, 236, 238-240, 242, 244, 246, 248, 250-254, 256, 260, 279-281 
contextual, 24, 201, 209-210, 240, 246 conventional, 6, 275, 277

conveying a decision, 136, 139

corporal punishment, 13, 45-52, 54, $56-86,143,172-173$

corrective, 53, 118-119, 132, 139, 147, 153-154, 156, 165-167

corruption, 11-12

counselling, 68, 85, 87, 118-119, 139

court, $85,116,142,152,154,158,160$, 165-166

create, $5,7,17,103,132,176,188,205$, 226, 280

creating, 119, 179, 211, 244

Creed of Human Rights, 13, 21-22, 233-235, 238-240

crime, 11, 260, 266

cultural function, 233

culture, 11-12, 19, 22, 24, 30, 48, 59, 64, 83, 118, 132, 203, 213-214, 218, 233, 238-239, 248, 250, 263, 280

culture of human rights, 48 culture of teaching and learning, 11-12 curriculum, 2, 4, 18, 90, 100, 186, 214-216, 227, 230, 244

cyber society, 19

D

Dasein, 274-275, 277

death, 77, 276

deciding on action, 123

Declaration of Human Rights in France during the French Revolution in 1789, 235

defined, $6,8,10,26,29,43,47,72,79$, $162,171,224$

democracy, 201, 211, 223

democratic state, 236

democratic values, 119

democratisation since 1990, 245

design, 28, 34, 46, 55, 77, 96, 116, 145-146, 182

desirable behaviour, 71, 75

determination, 22, 166, 196

develop, 9, 33, 46, 75-76, 82, 204, 239, 243, 257, 265, 270-271, 277 developing, 43, 52, 54, 63, 121, 139 , 192, 201, 229, 233, 252, 255

development, 4, 12, 20-21, 32-33, 43-44, 48, 54, 63, 73, 75, 91, 139, 169, 177, 193, 201, 204, 207-208, 211, 225, 231, 235, 237, 241-242, 245, 257, 270-271, 273, 277, 281

developments in the modern world, 10

didactical interaction between teacher and learner, 9 dignity, 48, 52, 54, 119, 133, 140, 167, 192, 267, 281

disadvantaged areas, 14-15 disciplinary committee, 115, 123, 129-133, 135-136, 142, 146-147, 149-152, 156, 158-167

disciplinary hearing, 115, 122-123, 126, 128-132, 134-137, 142, 144, 147, 149-154, 157-158, 160-161, 163-165, 168

disciplinary measures, 46-49, 51-52, $56,59,61,65-66,69,76,143$, 172-173, 179, 193, 198, 221, 263 disciplinary methods, 55, 68, 71, 81, 85, 197

disciplinary practices, $1,27,45,56$, $67-68,70,89,113,141,169,199$, 229, 259

disciplinary procedure, 117, 151 disciplinary process, 114, 117-122, 131, 134, 140, 155, 158, 160, 163, 166 discipline, 1-3, 7-11, 13-14, 16-18, $23-26,28,30,32,44-55,57$, 60-65, 67-74, 76-78, 83-87, 114-121, 138, 140, 143-145, 152-153, 167-180, 182, 184-186, 188, 190, 192-196, 198-206, 208, 210, 212, 214, 216-222, 224-232, 251-252, 254-256, 259-264, 266, 268, 270, 272-274, 276-281

discipline in schools, 3, 7, 11, 13-14, 17, 24-25, 32, 46-47, 52, 114, 145, 200, 202-203, 205-206, 225, 228, 231, 262, 281 
discipline in the schools, 7

discipline levels, 49-50, 57, 217

discipline problems, $8,55,70,202$, 205, 220, 261

disciplined behaviour, 9-10, 13, 50, 59, 61,180

dual school system, 11

due process, 113-122, 124, 126, 128, 130, 132, 134, 136-140, 154, 165, 236

\section{E}

economic, 15-16, 21, 25, 103-104, 106-107, 201, 207-208, 211, 217-218, 222-223, 230, 232, 238-239, 246-247

economic Growth, 16 educate, 5, 37, 118

education, 1-9, 12-13, 15-18, 23, 26-28, $35,45,47-50,53,61,66-70$, 73-74, 77, 80-81, 83-84, 89-91, $96,100,104,106,112-113$, 115-116, 118-119, 123, 126, 131, 134-135, 137-138, 140-141, 143, $145-148,153,162,165-166$, 169-170, 172-175, 177-178, 185-186, 199-234, 237-248, 252-256, 259-262, 264, $266,268,270,272,274,276$, 278-280

education policy, 226

education system, 2, 73-74, 90, 115, $145,148,199-224,226,228,232$, 252, 261

education system-related factors, 202

educational research, 6

educators, 2-3, 5, 16, 18, 25-26, 46, $60,62,92-93,115,119-120$, 126, 138-140, 142-145, 149-152, 155-156, 159, 161, 168, 201, 216, $220,224,279-280$

effectiveness, 45-47, 53, 57-59, $62-64,66-68,70,72,74-80$, $82-86,189,197,222,248$

effectiveness of corporal punishment, 67-68, 70, 72, 74, 76-80, 82, 84-86 effects, 7, 50, 64-65, 68, 72, 75-76, $78-79,81-86,178,181$

Effects of, 50, 64-65, 68, 72, 75-76, $79,81-82,84,86,181$

effects of corporal punishment, 50, $68,72,75,79,81-82,84,86$

elementary schools, 201

empathy, 10, 204, 214, 257, 280

enemy, 5,38

enforcement, 147, 153, 177-178, 182, 251, 254

environment, $6,13,49-50,57,79,112$, $115,118-119,145,155,170-172$, 174-175, 177-179, 181-182, 186, 189, 194-195, 197-198, 203, 206, 215, 224-225, 238-239, 247, $256,263,269,271,273$

ethic, 225

ethical, 8-10, 25, 35, 58, 80, 98-99, $117,159,164,185,260-262$, 273-275, 277

ethical action, 25

ethical reciprocity, 10, 25

ethics, 26, 58, 80, 239, 262, 274, 276-277

ethnic-oriented developmental university, 243

Europe, 4, 13, 15, 210-211, 218, 223, $240,244,246$

European Union, 208, 212, 237

evidence, 20, 43, 120, 123-126, $133-134,136,143,148-150$, 155-156, 159-164, 222

evidence leader, 123 ex-model C schools (historically White schools), 11

exclusion, 28-29, 107

existentialism, 262, 266, 268-269, 275

expulsion, 115, 137, 153, 157, 166-168

\section{$\mathbf{F}$}

fairness, 47, 116-117, 120-121, 130, 141-142, 144, 153-155, 160, 163-165, 168

false news, 20

families, 176

family, 11, 167, 179, 207, 218 
father, 271

fear, 41-42, 50, 57, 65-66, 83, 179, 191

Finland, 200-201, 206-225, 227

flourishing, 221

focus group interview, 57

followership in the classroom, 9

forces that have an influence on education and secondarily on discipline, 8

formation, 2, 17, 206, 241

Frankl, 267, 269-270

Franz Fanon, Walter Rodney, Steve Biko, Cheik Anta Biop and Okot p'Bitek, 244

Further Education and Training, 170, 174,231

future, $1-8,10,12,14,16,18-20$, 22-24, 26, 31, 54, 63, 71-72, 177, 233, 248, 250, 253-255, 276

future and education, 6

future of the school, 2, 5

\section{G}

generation, 35, 268

Gini index, 210

global digital culture, 19

global societal context, 13

globalisation, 7, 20, 22, 210, 232, 250

globalising, 201

God, 235, 278

governance, 18, 91, 203

governing body, 16, 114-116, 121, 126-130, 135-137, 140, 143, 152,163

government, 4, 15-16, 21, 34, 60, 68-70, 73, 87, 128, 138, 172, 219, 226, 236, 239, 246-247, 249, 254

Greek, 172

growth, 7, 10, 13-16, 54, 208, 210, 213, 221, 223, 266-267, 272-273, 281

guiding, leading, equipping, forming and nurturing, 9
H

Hamburger Universities, 234

healthy society, 19

hearing of evidence, 123

hearing process, 131, 134

Heidegger, 274-276, 281

higher education, $3,91,113,174,185$,

212, 224, 230-232, 234, 237-239,

244-248, 252-256, 264

historical amnesia, 6

historical roots of the university, 240

historically black, 3, 11, 231, 243

historically Black schools, 3, 11

historically disadvantaged schools, 12,16

histories of our fields, 6

Holistic, 32

homo economicus, 17-18

homo educandus, 17

Hong Kong, 209

hope, 189

households, 11, 238

human, 1, 5-6, 9, 13, 16-18, 21-22, 24, $27,31,33,43,45,48,52-53$, 66-67, 72-73, 75, 77, 82, 89, 94-95, 113, 118-119, 133, 140-141, $143,169,171,173,176-177$, 199, 201, 204, 206, 221, 229, 233-240, 247-249, 253, 259, 262-263, 266-281

human being, 5, 9, 22, 235, 247, 253, 262, 267-271, 276-279

human capital, 16-17, 249

human resources, 16, 249

human rights, 1, 13, 21-22, 27, 45, 48, 53, 66-67, 72-73, 75, 77, 82, 89, 113, 118-119, 140-141, 143, 169, 199, 201, 204, 229, 233-240, 259, 263, 279-281

human rights environment, 13 Human Rights Watch, 75, 77, 82 humanity, 280

\section{I}

ICT revolution, 19

identity, 9, 35, 58, 242, 244-245, 250, 274, 277 
IEA, 207

ill-discipline, 3, 7-8, 10, 18, 227, 260-261

Illich, 5

Immanuel Kant, 235

implementation, 4, 46, 48-49, 51-53, 57-62, 66, 85, 114, 116, 178, 206

implementation of ATCP, 48, 51, 53, 57, 59-60, 66

implications of, 251, 255

importance, 9, 80, 113, 131, 147, 165, 168, 193-194, 216, 221, 225, 232, 266, 270, 274, 277

inclusion, 35, 85, 129

inclusive, 174

indiscipline, 12, 25, 60, 68-71, 74, 81, 85-86, 261, 266

inequality, 247, 256

influence, 4, 8, 33, 37, 41, 56, 102, 107, $110,114,174,177-178,186,188$, 192, 209, 217, 220, 242, 253, 266, 272, 278-280

information technologies, 6

infrastructure, 11-12, 33-34, 55, 91, 203, 221, 231, 249

infringement, 115, 127, 156, 166-167

initiation, 115

inside, 4

instruction, 12, 33

instructional, 6, 219

integrate, 227

integrity, 206, 265

Inter-American Convention of Human Rights, 237

interactive relational dynamics, 27-28, 30-32, 34, 36, 38, 40, 42-44

interests, 17, 148, 177, 213, 230, 250, 253, 256, 265, 268

International Association for the Evaluation of Educational Achievement, 207

International Convention on the Elimination of Discrimination against Women, 237

International Jurists in the discourse, 236

International Monetary Fund, 21 internationalisation, 7, 22

interpret, 97, 141, 148, 217

interpretation, 80, 147, 178

interview, 36-40, 57-58, 79-80, 99, 103, 105, 146, 194-195, 250

interviews, 34-35, 46, 56-58, 68, 79-80, 97, 102-103, 110, 116-117, 146-147, 150, 170, 182-183, 193, 219

intolerance of democratic majorities, 235

investigation, $53,56,68,71,123-128$, 131, 139, 147, 149-150, 153, 155, $162,167,217,224,233$

Ireland, 201

Israel, 50

J

Japan, 209

Jewish, 272

Johann Gottlieb Fichte, 235

John Locke, 235

judicial system, 121

justice, 95, 123, 131, 143, 148, 154, 163-164, 179, 181, 190-191, 198, 223, 230, 232, 261-262

K

Kierkegaard, 266, 273-274, 279, 281

kindness, 190-191, 198, 204, 221

kingdom, 21, 92-93, 106, 242, 246

knowledge economies, 232

$\mathbf{L}$

language, 79, 91, 146, 188, 209-210, 215-216, 218-220, 225,

227-228, 238

language diversity, 225, 227-228

languages, 33, 146, 215-216, 219, 225, 227, 239

lawful, 72, 114, 142, 260

laws, 73, 171, 206, 279

leadership, 166-167, 171, 203, 250

learner, 9, 26, 35-41, 45-47, 50-53, 55, 59-61, 63-65, 67-71, 74, 78-79, 81-87, 93, 113-140, 142-145, 
149-168, 199-204, 206, 208, 210, 212-218, 220-222, 224-228, $231,263,265,279-280$

learner behaviour, 50-52, 60, 64, 69, 82-84, 86, 118-119, 139 learner discipline, 45-46, 52-53, 55, 60-61, 65, 67-68, 70, 85, 87, $114-117,120,138,140,143-145$, 199-204, 206, 208, 210, 212, 214, 216-218, 220-222, 224-226, 228, 231

learner indiscipline, 60, 68-71, 74, 81, 85

learner misconduct, 68-70, 74, 93, 116, 142-144, 149, 263

learner-centred, 213-214

learner-related factors, 202 learners, 1-2, 6, 8-12, 14, 16, 18-19, 23-25, 27-30, 32-38, 40-71, 74-79, 81-86, 113-115, 117-119, 121-122, 124-129, 131, 136, 139-145, 149-155, 157, 160-162, $166-168,172,174-176,191$, 202-203, 205-207, 209-210, 212-214, 216-222, 224, 227, 261, 263-264, 280

learners or students, 8 legal environment, 13, 115, 203 legal System, 147-148 legislation, 47, 136, 148, 172, 211 liberal, 201, 241-242, 245, 250 liberal-humanistic education university, 242

liberation, 245

limits to behaviour, 231

listen, 10, 131, 133

love, 10, 25, 181-182, 272

Lutheran, 211, 217

Lutheranism, 211

\section{M}

maintaining discipline in classrooms, 13 managed as large business corporations, 248

management, 15, 45, 52, 67, 75-76, 90-91, 106, 117, 120, 140, 143-145, 170, 203, 214, 239 managerialism, 7, 248, 283

managing, 63, 86, 119, 139, 170, 193, 247

marginalisation, 227

Mark, 209, 216

Maslow, 267, 272-273

mass migration, 7

materialism, 247

Mathematics, 12, 194, 207, 209, 218

maximum equitable access to (higher) education, 238

media, 20-21, 29, 70, 103, 107, 115, 191, 193, 204, 207, 215, 222, 243

member checking, 58, 80, 98, 146, 185 metaphor, 148

methodology, 34, 55, 77-78, 96, 116, $145,147-148,182$

minutes, 117, 134-137, 139

misconduct, 46, 68-70, 74, 84, 89-94, 96-98, 100-112, 114-116, 124-129, 133-134, 136, 141-145, 149-152, 154-155, 159, 161-162, 165-168, 170-171, 173, 179-182, 187-189, 192-193, 196, 262-265, 268, 277

mission, 18, 200, 230-233, 241, 243

mission of the university, 230, 232

mixed methods, 55, 68, 77, 96, 182

model, 11, 31-32, 53-54, 71, 137, 140, 181, 201, 203, 211, 225, 241, 243, 245, 276

modern-day classrooms, 25

moral, 10, 25-26, 75, 206, 235, 253, 256-257, 260-261, 273, 277

moral absolutes, 235

moral awareness, 257

moral imagination, 10, 25-26

moral responsibility, 253

morality, 226, 253, 262, 274

motivation, 41, 50, 110, 196

multicultural diversity, 21

\section{$\mathbf{N}$}

nation state, 20-21, 211, 242, 246

National Student Financial Aid

Scheme (NSFAS), 106

nationalisation of universities, 242 
natural resources, 13

natural rights, 236

need, $6,9,13,16-17,30,42,46,61,64$, $66,105,112,118,132,158-160$, 170, 172-173, 175-176, 181, 189, 191-192, 194, 204, 206, 272-273 needs, 15, 17, 90, 95, 174-175, 204, 214, $218,223,243,268,270,272-274$

Négritude, 244

neoliberal economic revolution, 21 , 246-247

neoliberalism in education, 16

network, 19

networks, 103

new political dispensation in South Africa, 7

New Zealand, 21, 209

Nigeria, 245

non-punitive disciplinary measures, 49

norms, 23, 76, 95, 112, 118, 147, 172, 248, 251, 253-254

notice, $120,128-129,139,147$, 149, 151-152, 156-157, 159, $164,187,225$

nurture, $6,77,84$

nurturing, 9, 26, 44, 118

\section{O}

obedience, 36, 132

objective of education, 241

objectives, 148, 156, 176, 195, 222-223

operant conditioning, 53-54, 68, 71

order, 8-9, 14, 18, 20, 46, 50, 61, 83,

123, 145, 171-172, 208, 251-252,

254, 265, 267, 274

orderly and disciplined behaviour, 9

Organisation for Economic

Cooperation and

Development, 207

\section{P}

paradigm, 46, 116, 145, 147

parent, 2, 37, 41-42, 115, 126, 129-131,

134-137, 149-150, 152, 156, 159,

202, 206, 269

parental involvement, 203 parents, 2, 11, 16-17, 34-36, 39-40, $42-44,48,51,53,60,69,72-73$, 85-86, 93, 119, 128, 132, 136-137, 144, 149-152, 155-156, 161-162, 179, 190, 192, 198, 212, 217, 219, 254-255, 261, 267, 269, 272

participation, 57, 117, 170, 179, 190, 195, 197-198, 204

past, $6,200,231,233,246,261$

peace, 18, 223

peaceful coexistence, 24

pedagogical interaction, 9

penalties, 118-119, 139

people, 2, 4, 8-9, 11, 14-16, 19-22, 33, 91, 119, 126, 171-172, 177, 201, 204, 206, 210, 219-221, 243, 250, 253-254, 265, 267, 269, 275, 278-280

People's Education, 4 perceptions, 30, 45-48, 50, 52-56, 58-68, 78-79, 81-82, 84-86, 97, 147,149

performatism, 7

performativity, 247-248

perspectives of learners, 53

philosophy, 13, 66, 211, 235, 243-244, 255, 266-267, 278-279

pinnacle of the education system, 232

pitfalls surrounding attempts to predict the future in and of education, 5

policy, 4, 18, 51-52, 127, 130, 132, 136-137, 139, 149, 151, 157, 168, 174, 176, 178, 185, 190-191, 198, 205, 211, 213, 226, 251

political arena, 3, 208

political conditions in South Africa, 10 political landscape, 3

politics, 207, 211, 245, 250

poor, 12, 55, 65, 75-76, 90-91, 98, 104, $109,112,145,170,174,249-250$, 256, 261, 267

population explosion, 14

positive discipline, 52-54, 169-170, 172, 174-176, 178-180, 182, 184-186, 188, 190, 192, 194, 196, 198, 204, 259-260, 262-264, 
266, 268, 270, 272-274, 276, 278,280

post-truth, 20, 249

postmodernism, 279-281

poverty, 11, 15, 222

power, 16, 20-22, 28-29, 31-32, 36-37, 42-44, 72, 173, 175, 177-178, 208, 222-223, 226, 246, 250, 256

practical, 114-116, 120-122, 139-140, $163,175,186,224,241,274-275$

praxis, 245

pre-primary education, 212

preliminary investigation, 123-128, 131, 139

preparing (or actually training) students for the labour market, 248

preventative, 71, 119, 139, 179, 261, 263

preventative strategies, 179

prevention, 118, 152, 179

primary schools, 17, 203, 212

principals, 3, 34, 42, 58, 114-115, 121-122, 125-129, 132, 134-135, 138-144, 146, 156, 163, 168, 205, 215, 219

principles, 63, 66, 131, 141-142, 144-146, 148, 150, 152-158, 160, 162-164, 166, 168, 179, 182, 206, 211, 230-232, 247, 253, 255-256, 267, 269

privatisation, 247, 255

proactive, 53, 118-119, 139, 179, 263

procedural due process, 117,122 , 128, 139

procedural fairness, 164

process, 9, 18, 32-33, 50, 58, 113-122, 124-126, 128, 130-132, 134-140, $142,145,147,149,154-155,158$, $160,163,165-166,174,178,182$, $185,219,222,236,242,248$, $260,263,267,269,274-277$

Programme for International Student Assessment, 207

progressive authors, 5

prophesies, 5

proponents of, 178, 250 prosecution, 163-164

prosecutor, 123, 131, 133-135, 146, 149-152, 156-158, 161, 163-165

protection, 54, 73, 172, 204, 236

pseudonyms, 35, 58, 99

psychological, 30, 68, 75-76, 81-82, $86,92-93,143,153,260,262$, 266-269, 273, 276-277, 279, 281

public school, 5

public secondary schools, 67-70, 78-79

punishment, 13, 45-86, 119, 143, 152, $172-173,175,178,205,260-262$, 265-266, 278

punitive disciplinary measures, 49, 66 purpose, 7-8, 28, 46, 58, 79, 96, 98-99, 103, 115, 121, 123, 134, $136,142,151,156,158,183,185$, 197, 200, 202-203, 206, 222, 224, 233-234, 242, 248, 252, 267, 279

Q

qualifications of teachers, 12

qualitative, 28, 34, 46, 55, 57, 68, 78, $80,96-98,116,145-147,149,153$, 182-184

quantitative, 55, 77, 96-97, 182-184

\section{$\mathbf{R}$}

reactive strategies, 179

reasonable, 114, 124-125, 127, 131, 145, $150,159,166,237$

reasonable suspicion, 124

reciprocal, 10, 26, 28, 33, 40, 214

reciprocity, 10,25

recognition, $48,54,181,214,217,225$, $236,239,264,280$

Reimer, 5

reinforcement, 53-54, 63, 71-72, 85, 178-179, 204

relation, $60,171-172$

relational, 27-28, 30-34, 36, 38, 40, 42-44

relational perspective, 28,34 
relationship, 33, 41, 84, 119, 145, 190, $192,198,265-266,274,280$

religion, 21, 24, 211, 226-227, 235-236, 238, 278

religious and life-conceptual trends, 21

Religious Education, 226

remedial application, 264

representation, 137

research, 1-2, 6, 21, 24, 28-35, 44, $46,52,55,58,68,70-71,74$, 77, 80, 89-90, 93-94, 96-99, 102-107, 116, 141, 145-148, 169, 173, 182-183, 185, 200, 202-204, 206, 213, 216, 218, 220-221, 223-224, 227, 229-231, 233, 239-243, 245, 254, 259, 261

research design, $28,34,46,55,77,96$, 145,182

resources, 13-14, 16-17, 55, 90, 215, 217, 238, 249, 255-256

responsibilities, 1, 9, 154, 166, 247

responsibility, 72, 86, 118, 120-121, 167, 242, 246, 253, 267, 270, 275, 277, 279

restorative justice, 143, 179, 181, 190-191, 198

retributive justice, 261-262

revolutionary university, 244

right to (higher) education, 234

right to administrative action, 114

right to education, 112, 233-234, 237

right to freedom, 48, 167, 236

rights, $1,13,21-22,27,45,48,52-54$, $66-67,70,72-73,75,77,82$, 89, 93, 112-114, 118-119, 125-126, 133-134, 136, 140-141, 143, 154, $167,169,199,201,204,220,229$, 233-240, 259, 263, 279-281

risk, 13, 28, 69, 75, 77, 93, 98

Rogers, 267, 271-272

Roman, 147

Russia, 208, 272

\section{$\mathbf{S}$}

saleable commodities, 249

school, 1-3, 5-6, 8-9, 11, 14-19, 25, $27-32,34,36-38,40,42,44-47$,
51, 55-57, 59-60, 63-65, 67, 69, 73-74, 76, 78-79, 86, 90-91, 102, 114-120, 122-130, 132, 140-146, 148-157, 159-163, 165-168, 174, 176-177, 199, 202-203, 205-206, 209, 211-217, 219-222, 225-227, 230-231, 244, 255, 259, 263, 268, 280

school attendance, 14

school classroom, 8-9

school climate, 214

school management team, 120

school principals, 141-144, 146, 156, 163, 168, 205, 219

school-related factors, 202-203, 217

schooling, 5-7, 15-19, 23, 173, 208, 212-213, 215, 222

schools, 1-20, 23-25, 27-35, 41, 43-53, 55-59, 61-71, 73-74, 78-80, 85-87, 92-93, 104, 114-117, 119-121, 123-124, 127-130, 132, 134, 139-140, 142-146, 148-150, 153-154, 156, 159, 162, 168, 170, 172-175, 191, 199-206, 209-217, 219-221, 223, 225-228, 231, 260-263, 281

scribe, 134 search procedure, 124

secondary school, 28, 30-31, 44, 69, 130, 203, 209, 212, 231

secondary schools, 27-28, 32-33, 46, 55, 59, 66-70, 78-79, 85, 93, $104,223,231$

Section 26 of the United Nation's Universal Declaration of Human Rights, 237

section 29 of Chapter 2 of the Constitution, 237

secular humanism, 279-281

self-control, 118, 132

self-discipline, 77, 84, 118, 178, 204 , 214, 219, 221, 226-227, 263

self-Interest, 17 sending, 129, 149 sense of agency and identity, 9 separate, 95, 127, 175, 224, 226 serious learner misconduct, 142-144, 149 
serious misconduct, 46, 70, 105, 108, 111, 115-116, 124-127, 129, 134, 136, 141-143, 145, 149-152, 154-155, 159, 161-162, 168

serious misconduct., 46, 108, 125, 129, $141-142,150,152,155,161$

service function, 233

service providers, 138

service provision, 15

services, 132, 153, 246-247

Shanghai-China, 209

social and human capital, 16

social capital, 24, 201, 203, 206, 223, 226-227

social critique function, 233

social relations, 32

social space, 8-10, 25

social space and ethical function or action theory, 8,10

social trends, 7

societal and educational context in South Africa, 11

societal institution, 232, 240

societies, 5, 17, 22, 171, 200, 210, 217

society, 3-5, 10-11, 17, 19, 95, $119,171-172,176-178,200$, 202-203, 206, 211, 220, 223, 226, 231, 233, 235-236, 239, 244, 248, 256, 261-262, 267-268, 272

socio-economic, 25, 103-104, 106-107, 201, 217-218, 222-223, 238-239

South Africa, 1, 3-4, 7, 10-13, 15, 20, 24-25, 27-28, 30, 32, 44-49, 51-52, 61-62, 67, 70, 73, 89-90, 93-95, 113-115, 118-121, 124-125, 127, 130-131, 133, 137, 140-141, $144-145,154,162-163,169$, 174, 185, 199-203, 205-206, 221-232, 234, 237-238, 243-245, 249-253, 255-256, 259-260, 263

South African campuses, 231

South Korea, 209

Soviet Union, 208, 211

space, $8-10,25,41,43,217,221,275$, $277-278,280$

spaces, 8-9, 26, 28 stakeholders, $68,85-86,120,130,140$, $148,219,243,253-254$

status, 25, 37, 41-43, 73, 107, 216-218, $233-234,238,248,250$

stimulus, 55

stories, 280

story, $85,131,164$

student discipline, 170, 193, 195, 230-232, 251-252, 255

student misconduct, 89-94, 96-98, 100-104, 106-112, 170-171, 173, 179-182, 188-189, 192-193, 196, 262

students, 2, 8-9, 18-19, 30, 41, 81, 83, 90-94, 96, 100-107, 109-111, 170-172, 174-175, 179-181, 186-198, 204, 216, 219, 233-234, 238-240, 242, 244-245, 247-257, 263-265, 268, 281

substantive due process, 117,120 , 122, 139

substantive fairness, 142, 168

suffer, 77, 152

suffering, 205, 246, 260, 270

sufficient information, 128-129, 154

suspension, 47, 115, 127-129, 154, 157, 167-168

Sweden, 208-209, 211-212

\section{T}

teach, 75, 77, 84, 159, 167, 195, 227, 267

teacher, 2-3, 8-13, 16, 25, 28, 35-36, 39-42, 50-51, 59-64, 66, $69,78,81,83-84,87,139$, 169, 202-203, 206, 213-216, 218, 223-224, 226-227, 264-266, 269

teacher education, 2-3, 13, 16, 28, 216, 223-224, 226-227

teacher-related factors, 202

teachers, 2, 4, 6, 9, 12-13, 15-16, 25, 32, 36-37, 39-70, 73-74, 76, 78-79, 81-87, 172, 200, 203-206, 213-221, 223-224, 226-227, 240, 265, 267, 269, 272 
teaching-learning institution, 231

the Africanist university, 243-244

the conscience of society, 233, 248

the developmental university, 243

the moral principle of diligent care of and for the interests of all others involved, 256

theft, 12, 70, 92-94, 126, 143

theoretical, 8, 32, 53, 71, 94, 118, 139,173

time-out, 48, 179-180, 190, 198, 265

township secondary schools, 46,55 , 59, 66

traditional elitist and exclusive academic status, 233

training manuals, 138-139

training programmes, 138, 224

transcribe, 57

transcription, 79

Transformation, 173, 244, 246, 260

triangulation, 58

trust, 38, 42-43, 117, 166, 179, 181-182, 188, 190, 192, 198, 214-215, 265

trustworthiness, 35, 58, 80, 98, 116, 184-185

tyranny of kings, 235

U

understanding, 10, 28, 30-31, 34, $42,44,55,66,75,78,96,113$, 116-117, 171-172, 183, 203, 206, 222, 240, 274, 280

undesirable behaviour, 71

UNESCO, 224, 237, 278

UNESCO Convention on the Rights of the Child, 237

United Nations Convention on the rights of children, 70

universitas magistrorum et scholarium, 240

universities, 16, 90, 174, 224-225, 229-234, 239-245, 248-252, 254-257

university buildings and infrastructure, 231 unruly behaviour, 10, 69, 74, 261

unwanted behaviour, 76

urban, 33, 116

use of corporal punishment, 50-51, 54, 62, 69-70, 73-74, 76-77, 86

V

value, 18, 21-22, 24, 63, 179, 206, 211, $223,232,250,261-262$

values, 18, 21, 77, 84, 95, 118-119, 148, 168, 206, 211, 215, 223, 244 , 251, 253-254, 261, 269-270, 275-276, 280

victim, 29-30, 32, 34-35, 92

victimised, 85

vine, 172

violence, 11, 18, 29-31, 48, 51, 54-55, 64, 74, 76, 82, 92-94, 105, 115, 119, 143, 178, 204, 238, 261

violent behaviour, 75-76

virtue, 235, 262

virtues, 274

vocational education, 170, 173-174

void, 132

vulnerable, 30, 55

W

welcome, 132, 134, 136

welfare state, 246

well-being, 30, 32, 172, 201, 236, 238, 287

Western Europe, 15, 210-211, 218, 223 , 244, 246

wisdom, 217, 256

workplace, 91, 144

written, 2, 34-35, 47, 97, 109, 125-126, 136-137, 146, 149-150, 152, 155-156

Y

youth, 174-175, 177

$\mathbf{Z}$

Zeitgeistliche, 260, 278 
Student discipline has not received a great deal of research attention. In this collected work, Professor Connie Zulu and her co-authors contribute to addressing the dearth of scholarship in this field, asking timely and relevant questions whose answers should shape practice as well as develop competencies and knowledge amongst educators in schools and post-school institutions. The book is informed by different theoretical underpinnings and perspectives that are socio-political, legal, psychological and philosophical. This interdisciplinary approach is helpful in advancing knowledge and providing solutions to what is clearly a complex problem in the South African education system.

\section{Prof. Dr Pontso Moorosi, Centre for Education Studies, Faculty of Social Sciences, University of Warwick,} Coventry, United Kingdom

This book describes and explains factors impacting or accompanying discipline issues in various educational settings. The contribution of the book to the field of learner and student discipline matters is that it offers insights into disciplinary practices and issues in educational institutions hitherto not researched. Its value lies in the varied approaches to theory and practices, each well-argued and justified. It makes for fascinating reading.

Prof. Dr Petrusa du Toit, Department of Research and Postgraduate Studies, Faculty of Education, Cape Peninsula University of Technology, Cape Town, South Africa

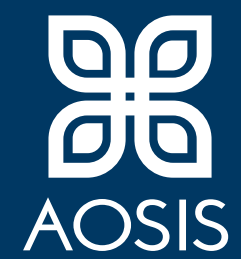

aosis.co.za

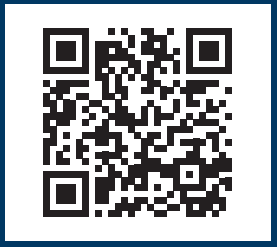

Open access at https://doi.org/10.4102/ aosis.2019.BK157

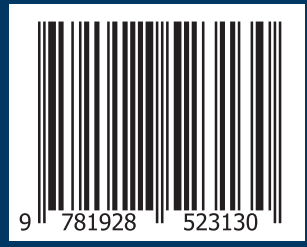

ISBN: 978-1-928523-13-0 